\title{
Thromboembolic reaction following vessel wall injury in arterioles and venules
}

Citation for published version (APA):

Oude Egbrink, M. (1989). Thromboembolic reaction following vessel wall injury in arterioles and venules.

[Doctoral Thesis, Maastricht University]. Rijksuniversiteit Limburg.

https://doi.org/10.26481/dis.19891019mo

Document status and date:

Published: 01/01/1989

DOI:

10.26481/dis.19891019mo

Document Version:

Publisher's PDF, also known as Version of record

\section{Please check the document version of this publication:}

- A submitted manuscript is the version of the article upon submission and before peer-review. There can be important differences between the submitted version and the official published version of record.

People interested in the research are advised to contact the author for the final version of the publication, or visit the DOI to the publisher's website.

- The final author version and the galley proof are versions of the publication after peer review.

- The final published version features the final layout of the paper including the volume, issue and page numbers.

Link to publication

\footnotetext{
General rights rights.

- You may freely distribute the URL identifying the publication in the public portal. please follow below link for the End User Agreement:

www.umlib.nl/taverne-license

Take down policy

If you believe that this document breaches copyright please contact us at:

repository@maastrichtuniversity.nl

providing details and we will investigate your claim.
}

Copyright and moral rights for the publications made accessible in the public portal are retained by the authors and/or other copyright owners and it is a condition of accessing publications that users recognise and abide by the legal requirements associated with these

- Users may download and print one copy of any publication from the public portal for the purpose of private study or research.

- You may not further distribute the material or use it for any profit-making activity or commercial gain

If the publication is distributed under the terms of Article $25 \mathrm{fa}$ of the Dutch Copyright Act, indicated by the "Taverne" license above, 


\section{Nos \\ (x) and}

incistos

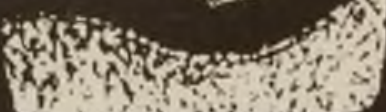

cols

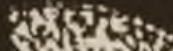

,

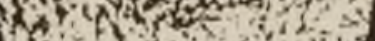

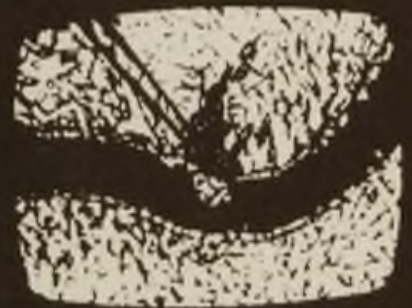

THROMBOEMBOLIC REACTION FOLLOWING

VESSEL WALL INJURY

IN ARTERIOLES AND VENULES
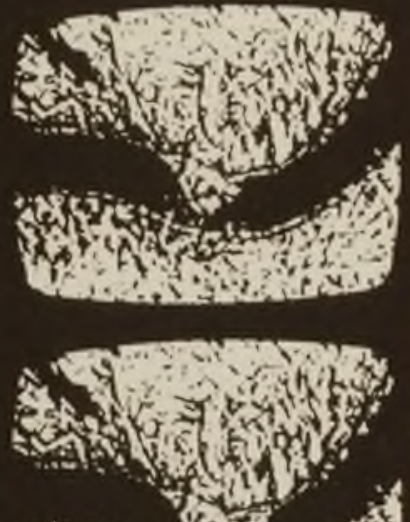

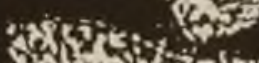

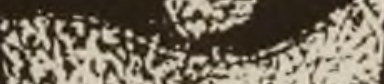

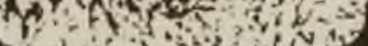

Non: enty ...

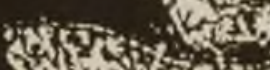

Mirjam oude Egbrink

3it

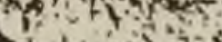

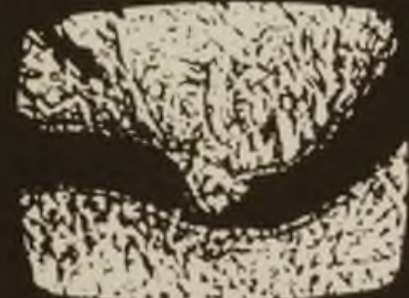




\section{STELLINGEN}

bij het proefschrift

Thromboembolic reaction following vessel wall injury in arterioles and venules

van Mirjam oude Egbrink

Maastricht, 20 oktober 1989 
1. Het is onjuist te spreken over het functioneren van de endotheelcel; zelfs binnen één weefsel bestaan er verschillen tussen het functioneren van endotheelcellen in verschillende typen bloedvaten (Gerritsen and Cheli, J Clin Invest 72: 1658-1671, 1983; Revtjak et al, Thromb Res 48: 671-683, 1987; dit proefschrift).

2. In arteriolen en venulen van het mesenterium van het konijn (diameter 20 tot 40 $\mu \mathrm{m}$ ) is de invloed van veranderingen in vloeistof dynamische condities op interacties tussen bloedplaatjes en de beschadigde vaatwand nihil (dit proefschrift).

3. Het "rollen" van witte bloedcellen langs de wand van venulen, zoals in vivo waar te nemen in het mesenterium van het konijn, is eerder een patho-fysiologisch dan een fysiologisch fenomeen.

4. De doelmatigheid van aspirine in de bestrijding van een thrombotische aandoening is niet alleen afhankelijk van de gebruikte dosis, maar ook van de situering van de aandoening.

5. Functioneel in vitro onderzoek aan geïsoleerde cellen levert veeleer informatie omtrent de cellulaire kwaliteiten dan omtrent het fysiologisch benutten van deze kwaliteiten in vivo.

6. De suggestie van Schmid-Schönbein en medewerkers, dat de toename in wall shear stress na het doorsnijden van een arteriole kleiner is dan na het aanprikken van een dergelijk vat, berust op een rekenfout; de toename in wall shear stress is in beide situaties vergelijkbaar (Schmid-Schōnbein et al, in: Blood vessels: problems ..., edited by Effert and Meyer-Erkelenz. Springer, Berlin, 1976́, pp 57-63).

7. Bij muizen bestaat tijdens de vroege zwangerschap een significante thrombocytopenie; dit zou erop kunnen duiden dat de platelet activating factor (PAF), die in dat stadium door de muize-embryo's wordt geproduceerd, indirect de groei van de embryo's zelf stimuleert, doordat de geactiveerde bloedplaatjes onder andere groeifactoren afgeven (O'Neill et al, J Reprod Fert, Suppl 37: 19-27, 1989).

Bij de mens daarentegen, waar embryo's ook PAF produceren, gaat deze hypothese niet op. 
8. Als bij het 'oogsten' van endotheelcellen intracellulaire processen op gang komen, die vergelijkbaar zijn met de processen die op gang komen bij het oogsten van fruit, dan levert onderzoek aan deze cellen vooral informatie op over verouderende cellen.

9. Ondanks de groeiende mogelijkheden op het gebied van de verwerking van bewegende beelden is het moeilijk een bewegend proces goed en duidelijk te illustreren in een proefschrift; een bladfilm kan hiervoor uitkomst bieden.

10. In de zorgzame samenleving volgens Lubbers c.s. worden groeperingen die extra zorg behoeven, zoals kinderen met leer- en opvoedingsmoeilijkheden, met onvoldoende zorg behandeld.

11. Opheffing van het reiskosten forfait is alleen zinvol als er een tegemoetkoming voor gemaakte openbaar vervoer-kosten voor in de plaats komt.

12. Bij een voortdurende verzuring van het milieu is het gezegde "hoge bomen vangen veel wind" binnenkort alleen nog figuurlijk toepasbaar.

13. Voor vrouwen is de kans op doorstroming naar hogere maatschappelijke posities nog steeds omgekeerd evenredig aan de kans op het krijgen/hebben van kinderen; voor mannen bestaat deze relatie niet.

14. Om de veelvuldig optredende verwarring met de RUL te voorkomen, moet de naam RL veranderd worden in RUM. 


\section{R.S. RENEMAN}

THROMBOEMBOLIC REACTION FOLLOWING VESSEL WALL INJURY IN ARTERIOLES AND VENULES 


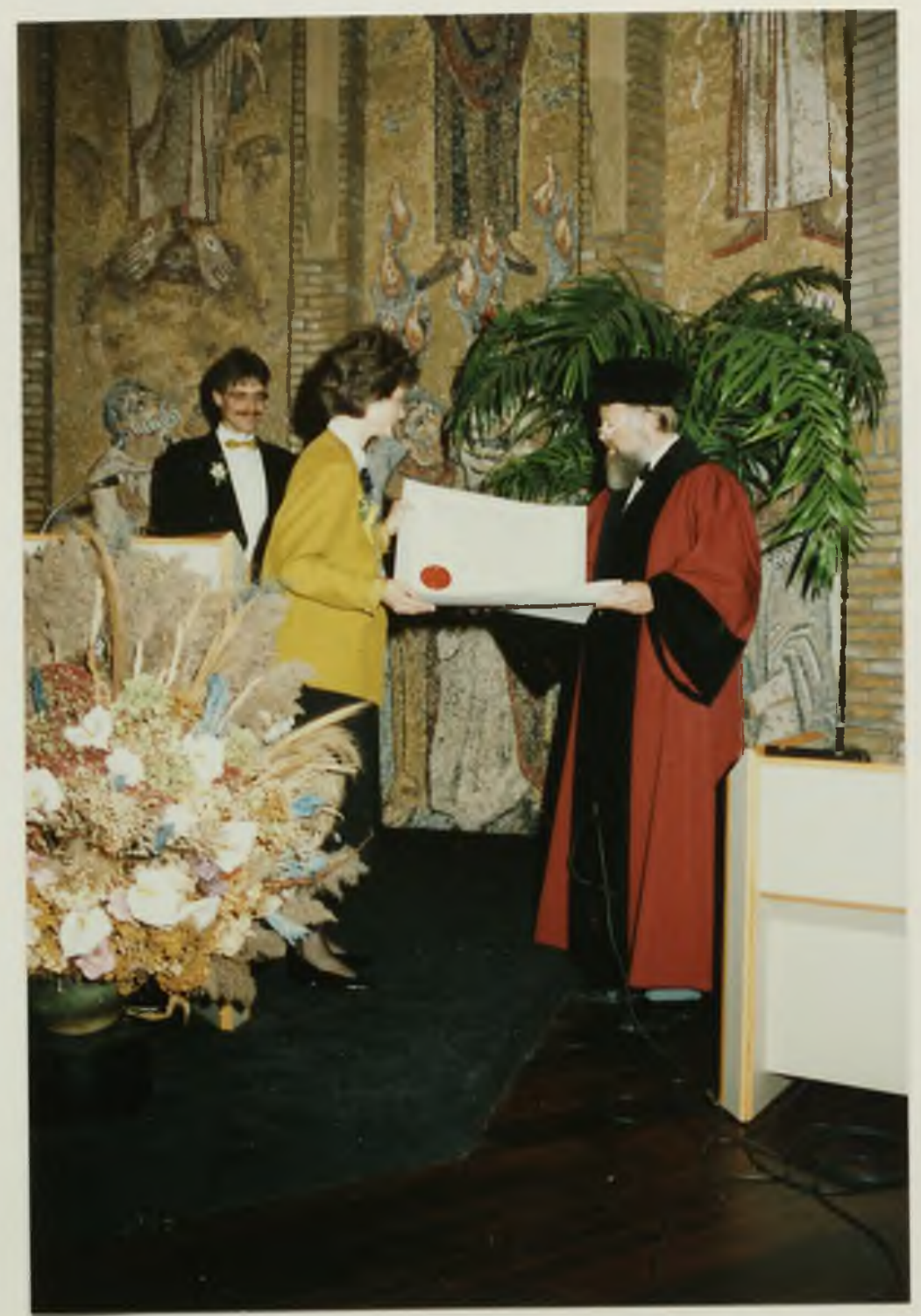




\title{
THROMBOEMBOLIC REACTION FOLLOWING VESSEL WALL INJURY IN ARTERIOLES AND VENULES
}

\author{
Proefschrift \\ ter verkrijging van de graad van doctor \\ aan de Rijksuniversiteit Limburg te Maastricht, \\ op gezag van de Rector Magnificus, Prof. dr. F.I.M. Bonke, \\ volgens het besluit van het College van Dekanen, \\ in het openbaar te verdedigen \\ op vrijdag, 20 oktober 1989 om 14.00 uur \\ door \\ Maria Geertruida Antonia oude Egbrink \\ geboren op 5 april 1960 te Oldenzaal
}


Promotor:

Co-promotores:

Beoordelingscommissie: Prof.Dr. H.A.J. Struyker Boudier, RL, voorzitter Prof.Dr. J.A. Flendrig, RL Prof.Dr. H.C. Hemker, RL Prof.Dr. F. ten Hoor, RL

Prof.Dr. J.J. Sixma, RUU

\section{CIP-DATA KONINKLIJKE BIBLIOTHEEK DEN HAAG}

oude Egbrink, Maria Geertruida Antonia

Thromboembolic reaction following vessel wall injury in arterioles and venules / Maria Geertruida Antonia oude Egbrink; [ill. by the author]. - Maastricht : Datawyse. - Ill.

Thesis Maastricht. - With ref. - With summary in Dutch

ISBN 90-5291-002-2

SISO 605.12 UDC 616.13/.14-005(043.3)

Subject headings: platelet-vessel wall interaction / vessel wall injury.

De uitgave van dit proefschrift en de promotie werden mede mogelijk gemaakt door financiële steun van de Nederlandse Hartstichting, het Interuniversitair Cardiologisch Instituut Nederland en de Wijnand M. Pon Stichting te Leusden, de Stichting Het Scholten-Cordes Fonds en de Stichting ter bevordering van de Research in de Cardiologie.

Lay-out: MIPS, Maastricht

Druk: Datawyse, Maastricht/Krips Repro, Meppel 
"The search for Truth is in one way hard and in another easy. For it is evident that no one can master it fully or miss it wholely. But each adds to our knowledge of Nature, and from all the facts assembled there arises a certain grandeur....."

Aristoteles

"Wie zich in wetenschappelijke problemen verdiept, heeft het niet gemakkelijk. Achter elk vraagstuk vindt hij een nieuwe complicatie; hij schilt een ui waarvan de rokken eindeloos zijn. Geen wonder dat zo iemand wel eens de tranen in de ogen springen."

naar Godfried Bomans 


\section{CONTENTS}

1. General introduction

2. Blood platelets and vessel wall injury

$2.1 \quad$ Blood platelets 5

$2.2 \quad$ Vessel wall 11

2.3 Factors influencing platelet-vessel wall interactions 15

$2.4 \quad$ Previous in vivo studies 18

2.4.1 Techniques other than mechanical stimulation $\quad 18$

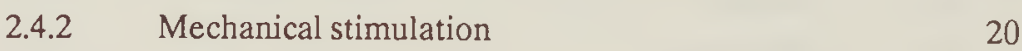

3. Survey of materials and methods 23

4. Thromboembolic reaction following wall puncture in arterioles and venules of the rabbit mesentery 27

$\begin{array}{lll}4.1 & \text { Introduction } & 27\end{array}$

4.2 Materials and methods 28

4.3 Results 31

4.4 Discussion 36

$\begin{array}{lll}4.5 & \text { Summary } & 39\end{array}$

5. The thrombus and its fluid dynamic consequences 41

5.1 Introduction 41

$5.2 \quad$ Materials and methods $\quad 42$

$\begin{array}{lll}5.3 & \text { Results } & 45\end{array}$

$\begin{array}{lll}5.4 & \text { Discussion } & 48\end{array}$

$\begin{array}{lll}5.5 & \text { Summary } & 52\end{array}$

5.6 Appendix $1 \quad 53$

$5.7 \quad$ Appendix 2

6. Effect of blood gases and $\mathrm{pH}$ on thromboembolic reactions in rabbit mesenteric microvessels $\quad 55$

$\begin{array}{lll}6.1 & \text { Introduction } & 55\end{array}$

6.2 Materials and methods 56

$\begin{array}{lll}6.3 & \text { Results } & 58\end{array}$

$\begin{array}{lll}6.4 & \text { Discussion } & 65\end{array}$

$\begin{array}{lll}6.5 & \text { Summary } & 67\end{array}$ 
7. Influence of hypercapnia and hypoxia on rabbit platelet aggregation

7.1 Introduction

7.2 Materials and methods

7.3 Results

$7.4 \quad$ Discussion

7.5 Summary

8. Interaction between leukocytes and platelets in venules

8.1 Introduction

8.2 Materials and methods

8.3 Results

8.4 Discussion

8.5 Summary

9. Effects of aspirin on the thromboembolic reaction following vessel wall injury differ in arterioles and venules

9.1 Introduction

9.2 Materials and methods

9.3 Results

9.4 Discussion

9.5 Summary

10. General discussion

References

Summary

Samenvatting

List of abbreviations

Curriculum vitae

Publications

Ter afsluiting ... 


\section{GENERAL INTRODUCTION}

In vertebrates, blood flows through the body in a practically closed vascular system. When a vessel is injured bleeding will occur. The processes involved in the control and prevention of bleeding are referred to as hemostasis and thrombosis. When a (small) vessel is transected bleeding is stopped by the formation of a hemostatic plug, that may protrude from the vessel. When the continuity of a vessel is not disturbed by the injury an intravascular thrombus will be formed to stop bleeding.

Microscopical observations of the formation of a thrombus following vessel wall injury were already made in the nineteenth century by Wharton-Jones in microvessels in the web of the frog's foot (1851) and by Zahn in the mesentery of the frog (1872). The cellular elements that formed the thrombus, described by both investigators as colorless corpuscles, were at that time not identified. The experiments of Zahn were repeated by Bizzozero in 1882, using the mesentery of mammals. His experiments confirmed that a thrombus was formed at the site of injury. He also observed embolization of parts of the thrombus. Moreover, Bizzozero demonstrated that both the thrombus and the emboli mainly consisted of "morphologische Elemente einer dritten Art, neben den rothen und weissen Blutkörperchen", which he called "Blutplättchen" or blood platelets. Before the turn of the century, this work was repeated and extended by a number of investigators, who established the important role of blood platelets. They also paid attention to the role of fibrin formation and polymorphonuclear leukocytes during hemostasis and thrombosis (for reviews see Tocantins, 1948; Poole and French, 1961).

Only during the last few decades, knowledge of the processes involved in thrombosis and hemostasis has been further extended. At present, in vitro studies rapidly accumulate knowledge of the biochemical aspects of the functioning of blood platelets. In addition, there has been an increasing awareness of the active involvement of components of the vessel wall, in particular the endothelial cells, mainly due to the development of techniques for culturing vascular cells (Gimbrone, 1981, 1986). However, in contrast to the experimental in vitro situations, where the reaction of one type of cell can be tested to changes in one variable, in vivo a great scale of variables simultaneously 
determines the outcome of a thrombotic reaction. The interaction between blood platelets and the vessel wall at a site of injury is a complex phenomenon, which may be influenced by the type of injury and the size and type of vessel, by fluid dynamic conditions, by the intravascular milieu and by the balance between activating and inhibiting agents originating from the platelets themselves, the injured vessel wall, other blood cells or the plasma. Studies performed in vitro may easily introduce artifacts, as is illustrated by the discrepancy between the effects of drugs and diets on platelet behavior in vitro and in vivo (Butler and White, 1977; Hornstra, 1980). Therefore, in addition to in vitro studies, the processes of thrombosis and hemostasis should be investigated in vivo to be able to assess under approximately physiological conditions the role of variables, that were found to be important in vitro.

The studies described in the present thesis were performed to obtain more insight into the role of some physiological variables in the thromboembolic reaction following vessel wall injury in vivo. The thromboembolic reaction, i.e. the formation of an intravascular thrombus and the subsequent embolization, was directly observed and investigated in microvessels of the rabbit mesentery by the use of intravital videomicroscopy.

Chapter 4 of this thesis describes the method that was developed to inflict a small, standardized mechanical trauma to microvessels by puncture with a micropipet. The subsequent intravascular reactions appeared to differ between arterioles and venules. Because the initial fluid dynamic conditions in both vessel types could be responsible for this difference, their role in the reaction was investigated.

In chapter 5 the role of fluid dynamic factors in the thromboembolic reaction in arterioles and venules is further evaluated, by investigating the fluid dynamic consequences of the presence of the thrombus.

Since the difference in thromboembolic reaction between arterioles and venules could not be explained by fluid dynamic factors, in chapter 6 the influence of changes in blood gas and $\mathrm{pH}$ values is described. In this study, in arterioles blood gas and $\mathrm{pH}$ values were created similar to those normally present in venules. Although changes in blood gas and $\mathrm{pH}$ values did influence the thromboembolic reaction, the differences in intravascular blood gas and $\mathrm{pH}$ values in arterioles and venules were not responsible for the difference in thromboembolic reaction between both vessel types.

To check whether the effect, as found in chapter 6 , was a consequence of an effect of hypercapnic and hypoxic gas tensions and $\mathrm{pH}$ values on the aggregation of rabbit blood platelets, an in vitro study was performed, which is described in chapter 7 .

Another difference between arterioles and venules that may be responsible for the difference in thromboembolic reaction is the presence of leukocytes, rolling along or sticking to the venular, but not the arteriolar vessel wall. In chapter 8 data are presented on the relation between the thromboembolic reaction and the degree of rolling or sticking of leukocytes.

In chapter 9 the different involvement of prostaglandins in the thromboembolic reaction in mesenteric arterioles and venules is described. 
As an introduction to the experimental chapters, in chapter 2 a brief survey is given of the present and most relevant knowledge on the role of blood platelets, the vessel wall and some additional factors in thrombotic processes, as derived from mainly in vitro studies. In addition, a short overview is presented of other in vivo studies, with emphasis on the studies using mechanical methods to create a vessel wall injury. Chapter 3 summarizes the methods used in the various studies. The thesis ends with a general discussion (chapter 10). 


\section{BLOOD PLATELETS AND VESSEL WALL INJURY}

In this chapter an overview is given of the present knowledge regarding the functioning of blood platelets and vascular cells in case of vessel wall injury and of the influence of some factors on this process. In addition, a brief survey is given of in vivo studies on platelet-vessel wall interactions, with the emphasis on those in which a mechanical method was used to induce vessel wall injury.

\subsection{BLOOD PLATELETS}

Blood platelets are the smallest cellular elements in the blood. In mammals they are cytoplasmic fragments, originating from megakaryocytes in bone marrow and lung (Penington, 1987). Consequently, they contain no nucleus and virtually lack protein synthesis, but are otherwise capable of many metabolic processes (Holmsen, 1985; Holmsen and Farstad, 1987). The platelets in the circulation are in dynamic equilibrium with those present in the spleen, which comprises about one-third of the total platelet pool (Penington, 1987). Under normal conditions platelets are cleared from the circulation by the spleen, liver and bone marrow after a life-span of 8-12 days in humans and 3 days in rabbits (Kotzé et al, 1985).

Blood platelets play a key role in the reaction of blood to vessel wall injury, i.e. in hemostasis and thrombosis. They also contribute to the normal healthy status of the endothelial lining (endothelial supporting function; Johnson et al, 1964; Gimbrone et $a l, 1969$ ), and participate in several other physiological and pathological processes (De Gaetano and Garattini, 1978).

\section{Platelet morphology}

The majority of the circulating platelets are disk-shaped (Figure 2.1), with an average diameter of $3 \mu \mathrm{m}$ and a mean thickness of about $1 \mu \mathrm{m}$ (Frojmovic and Milton, 
1982). A considerable heterogeneity exists within the population of circulating platelets, with respect to size, density and functional competence (Penington, 1987).

The ultrastructure of the platelet has recently been reviewed by Sixma (1986) and White (1987a). The platelet is surrounded by a plasma membrane, which invaginates into the cell interior to form the so-called open canalicular system. Therefore, the platelet surface area, that is exposed to surrounding blood plasma, is by far greater than might be expected from cell size and volume. The plasma membrane is covered by an exterior coat or glycocalix, which contains many different glycoproteins. These glycoproteins play an important role in several platelet functions and contribute to the net negative surface charge of platelets (George et al, 1985; Nurden, 1987). As in other cells, the plasma membrane of platelets is a lipid bilayer, containing transmembrane as well as peripheral proteins. The phospholipids are asymmetrically distributed with-

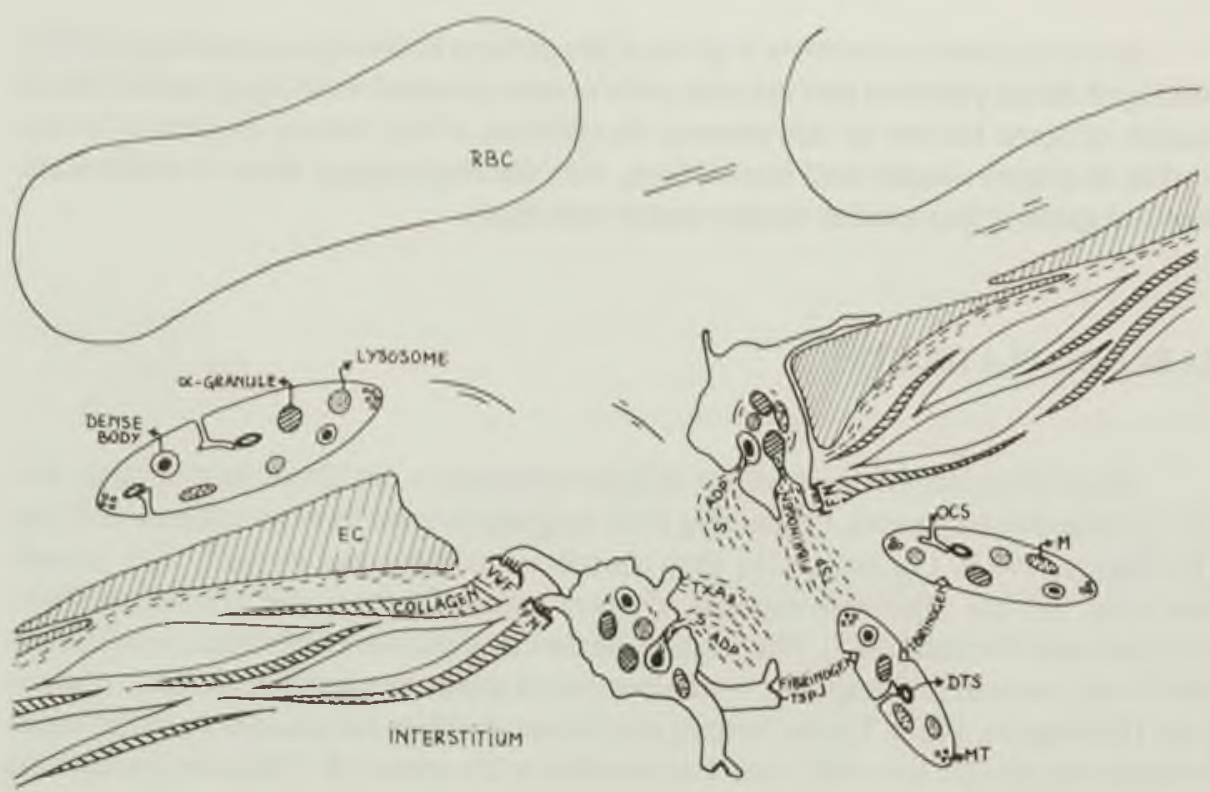

FIGURE 2.1 Schematic of platelet ultrastructure and of the initial phase of platelet-vessel wall interactions following vessel wall injury. The disk-shape of circulating platelets is maintained by $a$ circumferential band of microtubules (MT). Platelets contain as secretory vesicles a-granules, dense bodies and lysosomes; they also contain mitochondria $(M)$ and two membrane systems (open canalicular system (OCS) and dense tubular system (DTS)). Upon activation at a site of vessel wall injury, platelets adhere to the exposed collagen via the adhesive proteins von Willebrand factor (VWF) and fibronectin (FN). Fibrinogen and thrombospondin (TSP) serve as bridging molecules during aggregation, when the platelets may or may not have changed their shape. Activated platelets can secrete the contents of their $\alpha$-granules (e.g. several adhesive proteins) and dense bodies (e.g. $A D P$ and serotonin $(S)$ ) through the OCS. They also release metabolic products like $T X A_{2}$. $E C=$ endothelial cell; $R B C=$ red blood cell. 
in the membrane. In the unstimulated platelet practically all the negatively charged phospholipids, i.e. phosphatidylinositol and phosphatidylserine, are confined to the inner leaflet of the bilayer. The major part of the esterified arachidonic acid is incorporated in phospholipids, which are present in the cytosolic part of the plasma membrane and in other intracellular membranes (Perret et al, 1979; Chap et al, 1987).

In the periphery of the platelet, a circumferential band of microtubules is present in the equatorial plane of the disk (Figure 2.1). It consists of one single coiled microtubule, which maintains the discoid shape of resting platelets. Between the plasma membrane and the microtubular band, a system of microfilaments is found, which extends into the rest of the cytoplasm. These microfilaments represent mainly actin filaments, which are in close contact with the plasma membrane.

The organelles, which are randomly distributed in resting platelets, consist of secretory vesicles, the dense tubular system, which is derived from the smooth endoplasmatic reticulum of the parent megakaryocyte, and a small number of mitochondria (Figure 2.1). The mitochondria are responsible for more than half of the energy metabolism in resting platelets (Akkerman, 1978). In addition, platelets contain large stores of glycogen, which is utilized on energy demand (Holmsen and Farstad, 1987).

Of the secretory vesicles, the electron-dense bodies contain serotonin, calcium and magnesium, inorganic phosphate and a non-metabolic pool of adenosine diphosphate (ADP) and adenosine triphosphate (ATP). The ratio of the amount of ATP and ADP in the dense bodies varies greatly between platelets from different species $(0.8$ in humans and 5 in rabbits), primarily due to differences in ADP concentrations (Mills and Thomas, 1969; Holmsen, 1985). The other secretory vesicles or granules can be divided into $\alpha$-granules, lysosomes and peroxisomes. $\alpha$-Granules are the storage site for several non-enzymatic proteins, like adhesive proteins (fibrinogen, thrombospondin, fibronectin, von Willebrand factor), proteins that participate in coagulation (for instance: factor $V$ and the heparin-binding platelet factor 4), several platelet-derived growth factors, $\beta$-thromboglobulin-like proteins and albumin (Niewiarowski, 1987). The lysosomes contain several acid hydrolases, while the enzyme catalase and other oxidases are found in the peroxisomes.

The dense tubular system is a membrane system, which is not continuous with the plasma membrane. It serves as a calcium storage organelle and contains the full enzymatic potential for the conversion of arachidonic acid to thromboxane $\mathrm{A}_{2}\left(\mathrm{TXA}_{2}\right)$.

\section{Platelet responses to vessel wall injury}

Under normal conditions, circulating blood platelets come frequently close to and in apparent contact with the vessel wall (Tangelder et al, 1985, 1986), but do not stick to the endothelium. When a vessel is damaged, however, platelets are rapidly activated. They immediately adhere to the injured vessel wall and surrounding tissue (adhesion) and to each other (aggregation), forming a plug or thrombus, which stops the bleeding. The activated platelets loose their discoid shape and form pseudopods (shape change), secrete to a varying degree the contents of their secretory vesicles (release) and promote blood coagulation at their surface (procoagulant activity). This sequence 
of events is illustrated in Figure 2.1 and has been reviewed by several authors (for example: Sixma and Wester, 1977; Chesterman and Berndt, 1986; Stormorken, 1986; White, 1987b; Tangelder et al, 1989).

Adhesion. The initial reaction following vessel wall injury is a rapid adherence of blood platelets to collagen fibers and microfibrils present in the subendothelium and in the deeper layers of the vessel wall (Figure 2.1). At least two adhesive proteins are important in this process: von Willebrand factor (VWF) and fibronectin, both of which are present in blood plasma, the subendothelium and in the $\alpha$-granules of blood platelets. The role of $v W F$ in platelet adhesion is important at high velocity gradients or shear rates, which occur in small blood vessels. In situations of low shear rates, however, beside fibronectin vWF may also be involved (Sixma, 1987; Nievelstein and de Groot, 1988). Glycoprotein Ib is the major binding site for collagen-bound $v W F$ on the platelet surface, while the glycoprotein complex IIb-IIIa acts as a second receptor (Coller, 1985; Nurden, 1987; Sixma, 1987; Nievelstein and de Groot, 1988). Fibronectin also binds to platelets via glycoprotein IIb-IIIa and possibly via a second binding site on the platelet membrane (Sixma, 1987). Another platelet membrane glycoprotein that might be involved in platelet adhesion is glycoprotein Ia. This glycoprotein reacts directly with collagen (Nieuwenhuis et al, 1985, 1986).

Immediately following adhesion, the platelets spread out over the exposed surface. During this process they probably loose their discoid shape, become spherical and form pseudopods due to reorganization of microtubules and microfilaments. In each pseudopod, bundles of parallel microfilaments can be found. Simultaneously, the cytoplasmic organelles are displaced to the central region of the platelet, where they are packed within a web of microfilaments and microtubules (White, 1987a).

Release. Following centralization of the organelles, the platelets start to secrete the contents of their secretory vesicles into channels of the open canalicular system. In addition, they release arachidonic acid metabolites, like TXA 2 (Figure 2.1). While the secretion of contents of dense bodies and $\alpha$-granules is induced by the same platelet agonists and follows similar time courses, lysosomal secretion is slower and requires a greater stimulus strength.

As a consequence of the release reaction two important positive feedback loops are initiated. The released TXA 2 as well as the ADP, secreted from the dense bodies, will amplify the thrombotic reaction by activating other platelets, that are not yet in contact with collagen. Moreover, TXA2 and ADP may synergize each other and other agomists, even if they are present at subtreshold concentrations.

Aggregation. Upon activation, platelets will bind to each other. The glycoprotein IIb-IIIa complexes, present on the cell surface, are transformed to binding sites for fibrinogen, probably through a conformational change (Phillips et al, 1988). Fibrinogen, derived from plasma or from the $\alpha$-granules, appears to be essential for platelet aggregation. It is an elongated molecule with a length of about $0.45 \mu \mathrm{m}$ that possesses binding sites for platelet receptors on both ends, and is therefore well suited to cross-link two platelets (Bennett, 1985). This cell-cell binding appears to be stabilized by thrombospondin, which is another adhesive protein released from the $\alpha$-granules. This pro- 
tein can bind both to platelet glycoprotein IV and to the cross-linking fibrinogen molecules (Leung, 1984; Nachman et al, 1987).

Procoagulant activity. Another important functional response of blood platelets to activation is exposure of procoagulant activity, resulting in a dramatic acceleration of two sequential reactions in the coagulation pathway: the activation of factor $\mathrm{X}$ and prothrombin. Changes in the phospholipid composition of the outer leaflet of the plasma membrane result in the formation of a catalytic surface on which various coagulation factors can interact. An increased exposure of negatively charged phosphatidylserine at the platelet outer surface, presumably by enhanced transbilayer movement (flip-flop) of phospholipids, appears to be responsible for the increase in procoagulant activity (Zwaal et al, 1986; Chap et al, 1987).

\section{Mechanisms of platelet activation and inactivation}

Blood platelets can be activated by a variety of physiological and non-physiological agonists. The most important substances thought to initiate platelet responses in vivo following vessel wall injury are: collagen, present in subendothelium and in deeper vessel wall layers; thrombin, rapidly formed at the site of damage from circulating prothrombin; and ADP, released from damaged cells. Release of ADP, serotonin and $\mathrm{TXA}_{2}$ from the activated platelets themselves will activate more platelets (Rink and Hallam, 1984; Holmsen, 1987a). Examples of platelet inhibiting substances, or antagonists, that may be important in vivo, are prostacyclin and adenosine, both produced in the vessel wall.

All agonists and antagonists exert their effects through interaction with specific receptors on the platelet surface (Phillips, 1985; Holmsen, 1987a; Holmsen, 1987b; Siess, 1989). Binding of a substance to its specific receptor initiates a sequence of re-

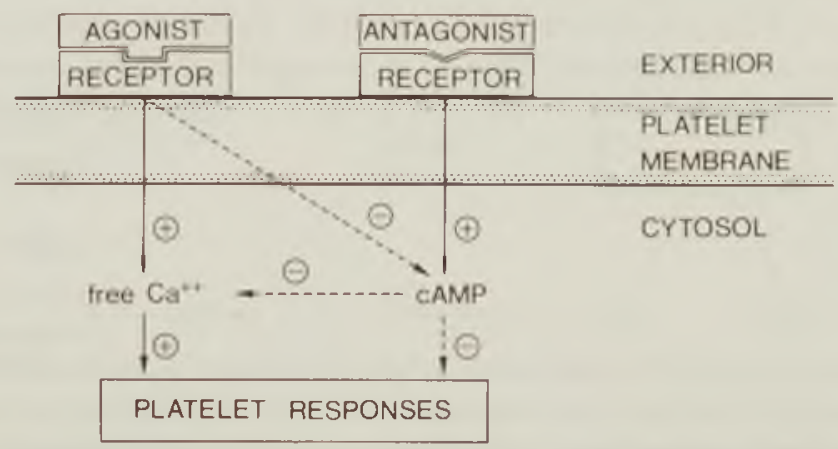

FIGURE 2.2 Schematic representation of the main mechanisms involved in signal transduction as initiated by binding of an agonist or an antagonist to its specific receptor on the platelet membrane. Activation and inhibition are indicated by + and, respectively. $C A M P=$ cyclic adenosine monophosphate. 
actions to transduce the stimulus across the plasma membrane into the cytosol, where the platelet response will be evoked (reviews: Rink and Hallam, 1984; Chap et al, 1986; Crawford and Scrutton, 1987; Haslam, 1987; Holmsen, 1987b; Siess, 1989). As is illustrated in Figure 2.2, an increase in the intracellular concentration of free calcium is considered to be crucial in platelet activation. Inhibition of platelet functions by antagonists is mediated by the production of cyclic adenosine monophosphate (cAMP), which can in turn be blocked by platelet stimulating agonists.

The most important events following binding of a stimulating agonist to its receptor are illustrated in Figure 2.3. The enzyme phospholipase $\mathrm{C}(\mathrm{pC})$ is activated through mediation by one of the guanine nucleotide-binding proteins ( $\mathrm{G}$-proteins). Activated phospholipase $\mathrm{C}$ hydrolyzes specifically inositol-containing phospholipids, mainly phosphatidylinositol biphosphate $\left(\mathrm{PIP}_{2}\right)$. The products of the degradation of $\mathrm{PIP}_{2}$ are inositol triphosphate $\left(\mathrm{IP}_{3}\right)$ and diacylglycerol $(\mathrm{DAG})$, which are considered to function as second messengers in signal transduction. Another direct effect of the binding between agonist and receptor is an influx of extracellular calcium through receptor-operated calcium channels in the platelet membrane.

Inositol triphosphate $\left(\mathrm{IP}_{3}\right)$ promotes mobilization of calcium from the dense tubular system (DTS). This mobilization of intracellular calcium, in combination with the afore mentioned calcium influx causes an increase in the cytosolic calcium concentration from about $0.1 \mu \mathrm{M}$ up to more than $3.0 \mu \mathrm{M}$. This increase in free calcium allows

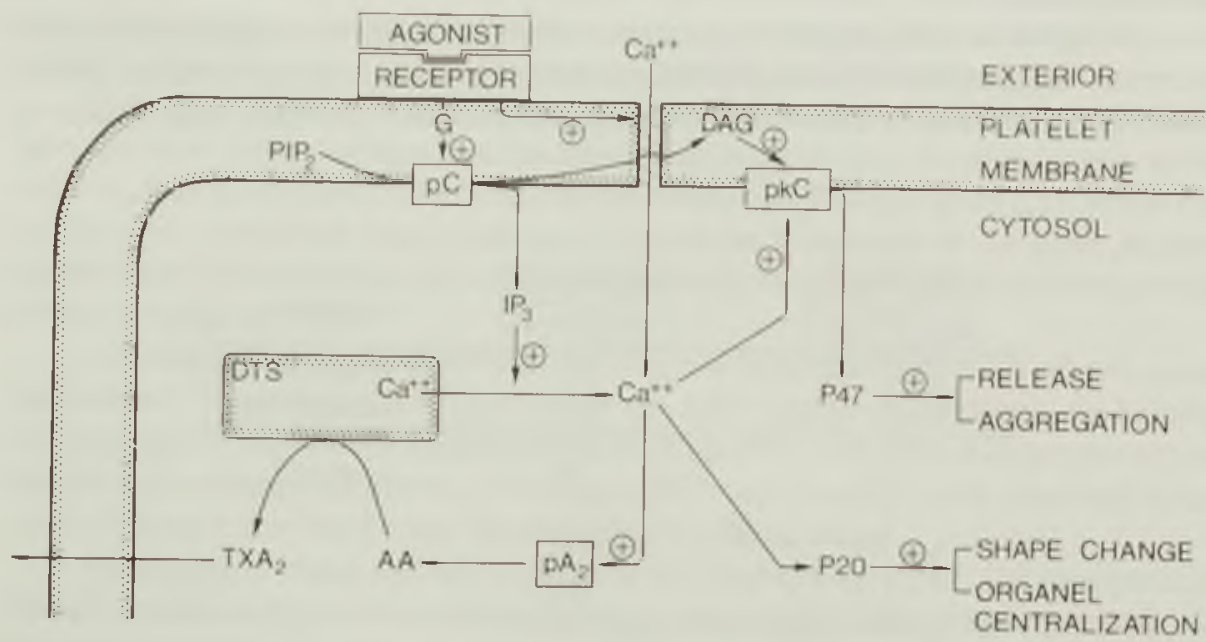

FIGURE 2.3 Schematic representation of the signal transduction systems initiated by platelet activating agonists. The different reactions are described in the tex. Activation is indicated by.$+ G$ $=G$-protein; $p C=$ phospholipase $C ; P I P_{2}=$ phosphatidyl inositol biphosphate; $D A G=$ diacylglycerol; $p k C=$ protein kinase $C ; P 47=47 \mathrm{kDa}$ protein; $I P_{3}=$ inositol triphosphate; $P 20=20 \mathrm{kDa}$ protein; $p A_{2}=$ phospholipase $A_{2} ; A A=$ arachidonic acid; $T X A_{2}=$ thromboxane $A_{2} \cdot D T S=$
dense tubular system. 
the activation of several enzymes. One of the consequences is an enzymatic phosphorylation of the $20 \mathrm{kDa}$ myosin light chain (P20). Phosphorylation of P20 and the resulting activation of myosin induces contractile processes, which may lead to platelet shape change, spreading and centralization of the organelles.

In addition, an increase in free cytosolic calcium activates platelet phospholipase $\mathrm{A}_{2}\left(\mathrm{pA}_{2}\right)$. Activated phospholipase $\mathrm{A}_{2}$ liberates from membrane phospholipids arachidonic acid (AA), which is converted into breakdown products by cyclooxygenase or by lipoxygenase at the membranes of the dense tubular system. The main products of this conversion are TXA 2 and 12-HPETE (12-hydroperoxyeicosatetraenoic acid), respectively. The biological function of 12-HPETE is not clear (Brash, 1985). TXA2 is a platelet agonist; it is released and will bind to a receptor on the platelet surface to potentiate and extend the activation process.

Moreover, the increase in free cytosolic calcium stimulates protein kinase $\mathrm{C}$ ( $\mathrm{pkC}$ ), an enzyme that is activated by diacylglycerol (DAG), the second product of PIP2 hydrolysis. Activated protein kinase $\mathrm{C}$ catalyzes the phosphorylation of a cytosolic protein with a molecular weight of $47 \mathrm{kDa}(\mathrm{P} 47)$. The identity of $\mathrm{P} 47$ is unknown yet. Phosphorylation of $\mathrm{P} 47$ is clearly related to the platelet release reaction and may also be involved in aggregation.

Platelet activation by thrombin, collagen and TXA $\mathrm{TX}_{2}$ involves hydrolysis of $\mathrm{PIP}_{2}$, as well as influx of extracellular calcium. ADP exerts its activating effect mainly through stimulation of calcium influx, which may result in the production and release of enough $\mathrm{TXA}_{2}$ to evoke $\mathrm{PIP}_{2}$ hydrolysis.

Binding of an antagonist, like prostacyclin and adenosine, to its receptor, leads to activation of the membrane-bound enzyme adenylate cyclase. This enzyme catalyzes the formation of CAMP from ATP. Elevation of the cAMP concentration is attended with a decrease in the level of free calcium, by inhibition of several steps in $\mathrm{PIP}_{2}$ hydrolysis, by a decrease in the phosphorylation of $\mathrm{P} 20$ and $\mathrm{P} 47$ and by phosphorylation of other proteins, the identity and function of which are not clear. Platelet activating agonists, like collagen, thrombin, $\mathrm{ADP}$ and $\mathrm{TXA}_{2}$, are able to inhibit the enzyme adenylate cyclase and, hence, the formation of cAMP (Crawford and Scrutton, 1987; Haslam, 1987; Holmsen, 1987b).

\subsection{VESSEL WALL}

Walls of blood vessels are composed of three layers: the tunica intima, the tunica media and the tunica adventitia. The innermost layer, the tunica intima, consists of the endothelium, which lines the vessel lumen, and a subendothelial layer with connective tissue, forming the basement membrane and the extracellular matrix. The tunica media mainly consists of smooth muscle cells, while the tunica adventitia consists of a network of collagenous and elastic fibers (Junqueira et al, 1986). In microvessels these layers are very thin. The wall of arterioles with a diameter up to $50 \mu \mathrm{m}$ consists of en- 
dothelium with a non-continuous basement membrane, a tunica media of one layer of smooth muscle cells, and a tunica adventitia of collagen fibers with occasionally a fibroblast (Rhodin, 1967). The wall of venules with similar diameter consists of endothelium, surrounded by one layer of pericytes or primitive smooth muscle cells and by collagen fibers with also occasionally a fibroblast (Rhodin, 1968).

Until 10 to 15 years ago the vessel wall, and especially the endothelium, was generally considered as a passive barrier between blood and surrounding tissue. At present, however, it is generally accepted that all layers of the wall are biologically active tissues with functional specializations that vary from one anatomical site to another. Vessel wall components actively participate in processes of thrombosis and hemostasis. Under normal conditions, the vessel wall is thromboresistant through some active antithrombotic mechanisms. Injury of the wall, however, induces an increased expression of prothrombotic properties, while the antithrombotic properties may decrease. Present knowledge of the anti and prothrombotic properties of vascular cells, as summarized in Table 2.1, will be discussed below (for recent reviews see: Shepro and d'Amore, 1984; Gimbrone, 1986; Gordon and Pearson, 1987 and Rodgers, 1988). Most of this knowledge is derived from studies on vascular cells from larger vessels; in case data were obtained with vascular cells from microvessels this will be explicitely mentioned.

\section{Antithrombotic properties}

The thromboresistance of vessel walls can be partly explained by antiplatelet mechanisms. One of these mechanisms is the production and release of prostacyclin ( $\mathrm{PGI}_{2}$ ) especially by endothelial cells, but also by other vascular cells, albeit in lower amounts (Moncada et al, 1977a). PGI 2 is a potent inhibitor of platelet activation (Moncada et al, 1976). Circulating plasma levels of $\mathrm{PGI}_{2}$ are generally too low to exert an

TABLE 2.1 The anti and prothrombotic properties of vascular cells.

Antithrombotic properties

*antiplatelet properties: -prostacyclin

-EDRF (nitric oxide)

-13-HODE

-ecto-nucleotidases

*anticoagulant properties: -heparin-like molecules -thrombomodulin -protein C/protein S

-profibrinolytic properties: -tissue plasminogen activator
Prothrombotic properties

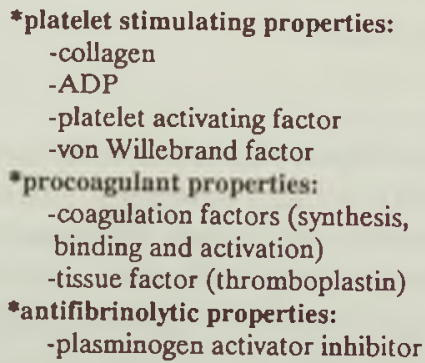


inhibiting effect on platelet function (Blair et al, 1982). Potentiation of the effects of subthreshold PGI2 concentrations may occur by endothelium-derived relaxing factor (EDRF; Moncada et al, 1987). EDRF, part of which appears to be identical to nitric oxide (Palmer et al, 1987; Myers et al, 1989), is also an inhibitor of platelet activation (Radomski et al, 1987). The production of $\mathrm{PGI}_{2}$ and EDRF can be stimulated by platelet agonists like thrombin and ADP. Therefore, the production of $\mathrm{PGI}_{2}$ and EDRF may increase at a site of vessel wall injury and limit the extent of thrombus formation.

Adhesion of platelets to the endothelium and especially to the underlying basement membrane is inhibited by 13-hydroxyoctadecadienoic acid (13-HODE; Buchanan and Bastida, 1987). 13-HODE is produced by endothelial cells and is released on the basement membrane. Consequently, platelets will not initially adhere to the basement membrane following endothelial cell denudation (Buchanan et al, 1987). When the production of 13-HODE is inhibited or when deeper layers in the vessel wall are exposed, platelets will not only adhere but also aggregate (Buchanan, 1988).

On the luminal surface of endothelial cells enzymes are present capable of degradating the platelet stimulator ADP (Pearson et al, 1980; Gerlach et al, 1987). These so-called ecto-nucleotidases convert ADP, which may be released from red blood cells and from cells in the vessel wall, into the platelet inhibitors AMP and adenosine.

Vascular thromboresistance is maintained not only by antiplatelet mechanisms, but also by anticoagulant properties. Endothelial cells synthetize and express on their luminal surface heparin-like molecules, such as heparan sulfate. These substances are able to bind antithrombin and to catalyze the neutralization by antithrombin of coagulation factors such as thrombin (Marcum et al, 1986). Substances released from activated platelets, like platelet factor 4 , will interfere with binding of antithrombin to the heparin-like molecules, thereby inhibiting antithrombin activity (Marcum et al, 1986).

Another mechanism by which thrombin activity is controlled is the protein C pathway (Esmon, 1986). Endothelial cells synthetize and express at their luminal surface a specific receptor for thrombin, which is called thrombomodulin. Binding of thrombin to thrombomodulin diminishes the procoagulant and platelet stimulating activities of thrombin, but dramatically increases the thrombin dependent activation of the anticoagulant protein C. Activated protein C binds to protein S, another receptor synthetized by and expressed on the endothelium. Bound to protein S, activated protein Cexerts its anticoagulant effect through the inactivation of two activated coagulant factors, $\mathrm{V}_{\mathrm{a}}$ and $\mathrm{VIII}_{\mathrm{a}}$, thereby inhibiting thrombin and fibrin formation. In addition, activated protein $\mathrm{C}$ stimulates fibrinolysis.

Fibrinolytic activity is also enhanced by tissue plasminogen activator, a substance synthetized and secreted by endothelial cells in response to various stimuli (Astrup, 1966; Erickson et al, 1985; Loskutoff, 1986). Tissue plasminogen activator cleaves circulating plasminogen, which results in the formation of the enzyme plasmin; plasmin dissolves fibrin.

\section{Prothrombotic properties}

Vessel wall injury results in exposure of different types of collagen present in the

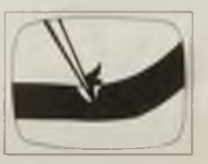


subendothelial layers of all vessel walls. Most of these collagen types are able to induce platelet activation (Barnes, 1986).

Vascular cells are a potential source of the platelet agonist ADP and its precursor ATP. Following vessel wall injury these substances are released from damaged vascular cells into the blood. The amount of ADP, present at the site of injury, both released and generated enzymatically from ATP, is probably high enough to induce platelet activation (Born and Kratzer, 1984; Born, 1985). In addition, activation of blood platelets may be caused by the release of platelet-activating factor (PAF) from vascular cells at the site of injury. PAF is produced by and secreted from endothelial cells in response to stimuli like thrombin, and is a potent activator of platelets (Zimmerman et al, 1985). Another prothrombotic activity inducing platelet activation is the synthesis of $\mathrm{VWF}$ and its secretion into the blood and the subendothelial matrix, where it acts as a cofactor for platelet adhesion following vessel wall injury (section 2.1). Secretion of endothelial vWF can be stimulated by thrombin.

Like platelets, endothelial cells allow coagulation factors to adhere to their luminal surface after a perturbing stimulus, thus facilitating the coagulation cascade (Nawroth and Stern, 1986). Binding sites have been shown for blood born coagulation factors $\mathrm{IX}, \mathrm{IX}_{\mathrm{a}}, \mathrm{X}$ and $\mathrm{X}_{\mathrm{a}}$, while factor $\mathrm{V}$ is synthetized by endothelial cells. Perturbance of vascular cells also induces the expression of tissue factor (thromboplastin), which binds with factor VII/VII ${ }_{a}$. In general, stimuli that enhance the expression of tissue factor decrease the ability of endothelial cells to express anticoagulant activity via the protein $\mathrm{C}$ pathway (Rodgers, 1988).

Another prothrombotic property of injured endothelial cells is an increased secretion of plasminogen activator inhibitor (Erickson $e t$ al, 1985). This substance inhibits tissue plasminogen activator and, hence, diminishes the fibrinolytic activity of the vessel wall, resulting in enhanced thrombotic potential. Secretion of plasminogen activator inhibitor is stimulated by thrombin.

\section{Differences in vessel wall functions}

There is increasing evidence that functional differences exist between the walls of different vessel types. As far as anti and prothrombotic properties are concerned, Coccheri and Astrup (1961) already showed that fibrinolytic and thromboplastic activities are not the same in vessel walls of arteries and veins. Other studies have shown that arachidonic acid metabolism is not equal in arterial and venous vessel walls (Moncada et al, 1977b; Villa and de Gaetano, 1977; Johnson, 1980; Mehta and Roberts, 1983). In addition to these differences between arteries and veins, functional differences also exist between cells from macro and microvascular origin. For example, the production of $\mathrm{PGI}_{2}$ (Gerritsen and Cheli, 1983; Revtyak et al, 1987) as well as the uptake and metabolism of adenosine (Gerlach, 1987) differ between macro and microvascular endothelial cells. Although care must be taken in extrapolating in vitro findings to in vivo situations, these data indicate that functional properties of vessel walls may vary depending on vessel type and size and on anatomical location. 


\subsection{FACTORS INFLUENCING PLATELET-VESSEL WALL INTERACTIONS}

The interactions between blood platelets and the injured vessel wall in vivo can be influenced by a variety of factors. The most important agonists, antagonists and adhesive proteins involved have been discussed in the previous sections (2.1 and 2.2). In vivo, these factors will act at the same time (synergism), amplifying or weakening each others influence. Other factors that may influence platelet-vessel wall interactions in vivo are the number and integrity of circulating platelets, the fluid dynamic conditions, the other blood cells and the intravascular milieu, in particular the blood gas and $\mathrm{pH}$ values. The possible influence of these factors will be discussed below.

\section{Synergism}

In vivo platelets will be simultaneously activated by several agonists, acting synergistically and amplifying the platelet responses (Kinlough-Rathbone et al, 1977a; De Clerck and Herman, 1983). At the same time, inhibitory agents released by the vessel wall will also influence the reactions. The release of such antagonists depends not only on the type of vessel that is injured (section 2.2), but also on the degree of injury, since different layers of the vessel wall produce different amounts of, for example, $\mathrm{PGI}_{2}$ (Moncada et al, 1977a).

\section{Platelet number and integrity}

The number of circulating platelets may also affect the processes of thrombosis and hemostasis. However, the critical number of platelets required for normal hemostasis is much lower than the physiological number of circulating platelets. Bergqvist and Arfors (1973a) showed that the platelet count in rabbits had to decrease from the normal number of about $500 \times 10^{9}$ per liter to $30-50 \times 10^{9}$ per liter before bleeding from transected mesenteric microvessels dramatically increased. The integrity of the platelets is another important factor. Defects in contents of platelet secretory vesicles, surface receptors or activation mechanisms, as occurs in certain platelet diseases, will hamper their responses (reviewed by Mustard and Packham, 1977; Hardisty and Caen, 1987).

\section{Fluid dynamics}

In vivo, platelets are subject to external fluid dynamic forces. They are suspended in constantly flowing plasma, in which red blood cells are present in excess. Blood flow through a vessel is in most instances laminar. Moving from the wall, where a thin layer of plasma remains stationary (no-slip condition), towards the center of the vessel, where the velocity is maximal, successive layers of blood slide along each other. The velocity gradient, or shear rate, is maximal at the vessel wall and decreases to zero in the center of the vessel. The force that maintains the flow is defined as shear stress. The ratio of the shear stress and the resulting shear rate is a measure for the internal friction of the blood and is defined as viscosity (Goldsmith and Turitto, 1986). 
If the viscosity of a fluid is independent of the actual shear rate, such a fluid is called Newtonian and the velocity profile in a straight tube is parabolic. In contrast to plasma, blood is not a homogeneous Newtonian fluid, due to the presence of red blood cells. In microvessels, where flow is dominated by non-Newtonian viscous forces and to a far lesser degree by pulsatility, the velocity profile is not parabolic but blunted in the center, as has been shown experimentally in mesenteric arterioles in vivo (Tangelder et al, 1986). As a consequence of the blunted velocity profile, in arterioles the wall shear rate is at least two times higher than expected on the basis of a parabolic velocity profile (Tangelder $e t$ al, 1988). The concentration of the platelets in mesenteric arterioles is about two times higher near the vessel wall than in the center of the vessel (Tangelder $e t a l, 1985$ ). Therefore, about $70 \%$ of the platelets flowing through an arteriole are within the high shear domain near the wall.

Thus, in case of a wall injury in microvessels, a relatively high percentage of platelets with a relatively low velocity will come into contact with activating agents released from the damaged vessel wall or from the activated platelets themselves. Moreover, platelets are subjected to high wall shear rates, which will even be higher in case of bleeding or an intravascular stenosis due to a thrombus (Schmid-Schönbein et al, 1976). In vitro studies have shown that the release reaction and the aggregation of platelets can be stimulated by increasing shear rates (Goldsmith et al, 1975; Turitto and Baumgartner, 1979; Badimon et al, 1987). Platelet adhesion, which initially increases with increasing shear rates, becomes reduced at shear rates higher than about $3000 \mathrm{~s}^{-1}$ (Turitto and Baumgartner, 1979; Badimon et al, 1987).

High levels of shear rate in a blood vessel do not only influence platelet behavior, but also stimulate the production and release by endothelial cells of two platelet inhibiting agents, PGI2 (Rubanyi et al, 1986; McIntyre et al, 1987) and EDRF (Rubanyi et $a l, 1986$; Griffith et al, 1989). Therefore, enhanced shear rates at a site of injury may not only stimulate, but also inhibit platelet reactions through the release of $\mathrm{PGI}_{2}$ and/or EDRF from endothelial cells. In addition, high shear forces may cause disruption of parts of the thrombus. The net effect of high shear rates on platelet-vessel wall interactions in vivo is not clear.

\section{Red blood cells}

Red blood cells are the most abundant cellular components of the blood. In vitro, a positive relation was found between hematocrit on the one hand and platelet adhesion and aggregation on the other (Turitto and Weiss, 1980; Saniabadi et al, 1985). ADP, released from damaged red blood cells, may contribute to this relation (Born et al, 1976). In case of lysis of red blood cells, platelets may be activated as a result of exposure of the procoagulant inner leaflet of the red blood cell membrane (Chapet al, 1987). In addition, the enhanced platelet activity with higher hematocrits may be the result of an increase in collision rate of platelets with the vessel wall and with other platelets, due to the presence of a high concentration of red blood cells (Yu and Goldsmith, 1975; Turitto and Baumgartner, 1975; Turitto and Weiss, 1980). 
White blood cells

White blood cells, or leukocytes, are present in blood in a concentration lower than that of platelets or red blood cells (ratio in rabbits 1:50:700; Kozma et al, 1974). In venules, leukocytes can roll along or adhere to the vessel wall (Atherton and Born, 1972; Schmid-Schönbein et al, 1980; House and Lipowsky, 1987). This phenomenon is not observed in arterioles, where they usually flow in the more central portion of the vessel (Gaethgens, 1987). Therefore, in venules leukocytes are present in relatively high concentrations near the vessel wall and may interfere with the interactions between platelets and the wall in case of an injury. Such interference may, for example, consist of the release of substances from the leukocytes which can influence platelet behavior, the transfer of prostaglandin endoperoxides from leukocytes to the vascular endothelium resulting in enhanced vascular $\mathrm{PGI}_{2}$ production, or a physical hindrance of the platelets in their reaction to vessel wall injury. So far, it is not known whether leukocytes actually influence platelet-vessel wall interactions in vivo.

\section{Blood gas and $\mathrm{pH}$ values}

Intravascular blood gas and $\mathrm{pH}$ values differ between arterioles, which are feeding vessels, and venules, which are draining vessels. In vitro studies have shown that changes in $\mathrm{pH}$ and $\mathrm{pCO}_{2}$ can influence the response of blood platelets to various agents (Rogers, 1972; Tang and Frojmovic, 1977), while the effect of changes in $\mathrm{pO}_{2}$ is not clear. Therefore, in vivo the differences in blood gas and $\mathrm{pH}$ values between arterioles and venules may influence the reaction of platelets to a vessel wall injury in these vessel types. Until now, information about the influence of changes in blood gas and $\mathrm{pH}$ values on platelet-vessel wall interactions in vivo is scarce.

\section{INTERMEZZO}

Most of the data on platelet-vessel wall interactions, as described in the previous sections (2.1 to 2.3), have been obtained in in vitro experiments. One should realize, however, that it is not at all certain that the results obtained in these studies are representative of the in vivo situation. The isolation of cells from their in vivo environment is such a drastic event, that it is not unlikely that the functional behavior of such cells changes. Moreover, the in vitro data on the various characteristics of the different cell types do not give any information about their importance in vivo. Therefore, plateletvessel wall interactions following vessel wall injury have to be studied in vivo, where the cells are in their natural environment and environmental factors, if any, can influence the interactions. In such in vivo studies, the method used to induce vessel wall injury becomes very important. For a realistic approach of naturally occurring vessel wall injuries, the method should involve damage to the wall only. In the present study, a mechanical method has been used which induces platelet-vessel wall interactions as a result of real vessel wall damage. 


\subsection{PREVIOUS IN VIVO STUDIES}

Different methods have been developed to study platelet-vessel wall interactions following vessel wall injury in vivo. For a review of the numerous techniques, that have been used in large and small vessels, the reader is referred to Didisheim (1972). In this section only the experimental models used to study hemostatic and thrombotic processes in the microcirculation by intravital microscopy will be discussed. The techniques most frequently employed in microvessels are summarized in Table 2.2. In the first subsection non-mechanical techniques are discussed, while in the second subsection previous studies using a mechanical method will be described in more detail.

\subsubsection{Techniques other than mechanical stimulation}

\section{Laser}

Induction of platelet-vessel wall interactions with the thermal energy of a laser has been claimed as the most accurate and standardized method. The laser beam, which can traverse the optical system of an intravital microscope, is focused inside the vessel near the wall to induce a thromboembolic reaction. However, proper positioning is critical and ultrastructural and functional studies demonstrated, that intravascular reactions as evoked by a Ruby laser are not induced by vessel wall injury, but by ADP released from damaged red blood cells (Hovig et al, 1974; McKenzie et al, 1974; Wiedeman, 1974). Heat-coagulated red blood cells appeared to form the core of the platelet aggregates. Some authors have suggested that the use of an Argon laser, either with (Kovacs et al, 1975) or without (Weichert et al, 1983) the previous injection of an energy absorbing dye, could produce some sort of vascular injury. Nevertheless, even with this type of laser red blood cell damage (Kovacs et al, 1975; Boergen et al, 1981) and ADP (Seiffge and Kremer, 1986) are important determinants of the intravascular platelet reaction. Therefore, it is questionable whether and to what degree vessel wall damage is involved in laser induced platelet activity. The laser technique may be well suited to investigate pure ADP induced platelet activation in vivo, but is probably not the most appropriate method to study platelet-vessel wall interactions following vessel wall damage.

\section{Photochemical stimulation}

Another method to induce intravascular platelet activity without touching the vessel wall, is photochemical stimulation. Microvessels are irradiated with filtered UV light after intravenous injection of a fluorescent dye, which acts as a target for the radiant energy. It has been proposed that the excitation of the fluorescent dye induces the local production of free radicals such as superoxide, which may cause intravascular vessel wall damage (Herrmann, 1983). Ultrastructural studies showed that subendothelial layers were not exposed; the exact nature of the platelet activating stimulus could 
TABLE 2.2 Most frequently used techniques to induce platelet-vessel wall interactions in microvessels.

Techniques

Laser irradiation

Photochemical stimulation

Electrical stimulation

Biochemical stimulation

Mechanical stimulation

\section{References}

Grant and Becker (1965)

Kochen and Baez (1965)

Arfors et al (1968)

Kovacset al (1975)

Chernukhet al (1976)

Weichert et al (1983)

Seiffge and Kremer (1986)

Rosenblum and El-Sabban (1977)

Herrmann (1983)

Sato and Oshima (1984)

Reber (1965)

Duval et al (1970)

Gordon et al (1973)

Takano and Suzuki (1982)

Begent and Born (1970)

Shishido and Katori (1981)

Bourgain et al (1984)

Hatanaka et al (1985)

Apitz (1942)

Zucker (1947)

Chen and Tsai (1948)

Hugues (1953)

Honour and Ross (1962)

Bergqvist (1974)

not be elucidated (Herrmann and Voigt, 1984). In addition, thrombus formation appears to stop immediately following inactivation of light irradiation (Sato and Oshima, 1984). This is not in agreement with the expected ongoing response following real vessel wall damage.

\section{Electrical stimulation}

To evoke a vessel wall injury in microvessels by electrical stimulation a current of at least $160 \mu$ A seems to be necessary (Takano and Suzuki, 1982). The tip of the electrode has to be positioned accurately on or at a standardized distance from the vessel wall to obtain reproducible vascular and intravascular reactions (Gordon et al, 1973). A drawback of electrical stimulation is that it induces the electrolytic formation of gas bubbles in the superfusing fluid, which may result in considerable changes in the $\mathrm{pH}$ of the fluid; this phenomenon can seriously influence the observed reactions (Gordon 
et al, 1973).

\section{Biochemical stimulation}

Biochemical induction of platelet-vessel wall interactions can be performed by topical application of ADP (Begent and Born, 1970; Hatanaka et al, 1985) or thrombin (Hatanaka et al, 1985), without involvement of vessel wall damage. Smaller amounts of substances like ADP, which by themselves are not enough to evoke platelet activity, can also be used following pretreatment with subtreshold electrical stimulation which renders the vessel wall more permeable (Shishido and Katori, 1981; Bourgain et al, 1984). This method may induce some endothelial damage, although not enough to induce platelet-vessel wall interactions per se.

In conclusion, it is often questionable whether vessel wall injury is the initiating stimulus to induce platelet-vessel wall interactions, when the above mentioned methods are applied. It is evident that no or only very limited vessel wall damage is evoked by the biochemical method. This may also hold for laser irradiation and photochemical stimulation. The technique of electrical stimulation is associated with some severe methodological problems. Therefore, these techniques have been mainly used to yield information with regard to pharmacological manipulation of platelet aggregation in vivo. The use of a mechanical method to evoke platelet-vessel wall interactions, where vessel wall damage is the only initiating stimulus without interference of additional substances, may be a more realistic approach to obtain insight into the way in which platelet-vessel wall interactions generally occur in humans and animals.

\subsubsection{Mechanical stimulation}

The use of mechanical means to induce platelet-vessel wall interactions clearly involves as an initiating stimulus damage to the wall, either to part of it or to all layers. Before 1950 the reactions, as induced by either puncture or transection of microvessels, were described primarily in a qualitative way (Apitz, 1942; Zucker, 1947; Chen and Tsai, 1948). In these studies and also in most of the later studies microvessels of rabbit or rat mesentery were traumatized, because the mesentery is an easily accessible, transparent tissue. Vessel transection has been used in most of the later s'udies, while one group used the technique of pinching.

\section{Vessel transection}

The first thorough study, providing quantitative as well as qualitative data, was performed by Hugues (1953). He transected rabbit mesenteric arterioles and venules, a method which was later also employed by Bergqvist and Arfors (Arfors et al, 1972; Bergqvist, 1974). The duration of the bleeding period, which was stopped by the formation of a hemostatic plug, was measured to quantify the platelet reaction. Bergqvist (1974) also recorded the frequency and duration of the rebleedings as a measure of 
plug stability. The hemostatic plug, as formed after transection of a mesenteric microvessel, primarily consists of blood platelets with small quantities of fibrin near the surface of the plug (Kjaerheim and Hovig, 1962). Fibrin formation, which seems to start at a very early stage of the hemostatic process, is probably essential for the stability of the plug. Both induction of fibrinolysis and anticoagulation treatment resulted in a diminished stability of the hemostatic plug, while the plug formation time, which seems to reflect mainly the platelet response, was not influenced (Bergqvist and Arfors, 1974). Heparin treatment, which may influence platelet responses as well as coagulation reactions, prolonged the hemostatic plug formation time in arterioles and venules, while administration of thrombin had no effect (Hugues, 1953; Bergqvist and Arfors, 1976). Removal of fibrinogen led to a prolongation of the hemostatic plug formation time and a decrease in plug stability (Bergqvist and Arfors, 1974), which is in agreement with the important role of fibrinogen during platelet aggregation (section 2.1).

A significant relation was found between arteriolar vessel diameter and bleeding time following transection (Hugues, 1953; Bergqvist, 1974), indicating that the size of the vessels under investigation is an important parameter when reactions have to be compared. Vasoconstriction, however, was shown to be of no importance for the subsequent reaction in mesenteric microvessels (Hugues, 1953; Affors and Bergqvist, 1975). In addition, the hemostatic process in both arterioles and venules was not influenced by blood flow velocity (Arfors and Bergqvist, 1974), indicating that in vessels of similar size differences in transmural shear forces are relatively unimportant for the process of hemostatic plug formation under the prevailing flow conditions.

Differences in hemostatic pattern between arterioles and venules were found by Hugues (1953) and also by Bergqvist (1974), but the data were contradictory. While Hugues found longer bleeding times in arterioles, Bergqvist found the opposite: a shorter hemostatic plug formation time, associated with a higher plug stability and a higher plug growth rate in arterioles than in venules (Bergqvist, 1974; Bergqvist and Arfors, 1973b). The reason for this discrepancy in results is unknown. Arfors and colleaques (1976a) showed that the differences between arteriolar and venular reactions could be totally abolished by the cyclooxygenase inhibitor indomethacin. They postulated that prostaglandins, produced by the mesenteric tissue due to the transectioning trauma, preferentially enter the venules and inhibit the venular hemostatic process. Therefore, tissue trauma should be avoided as far as possible in studies, in which platelet-vessel wall interactions following vessel wall injury are compared between arterioles and venules.

\section{Pinching}

The so-called "pinching" technique was introduced by Honour and Ross; they pinched cortical and mesenteric arteries with a diameter of 100 to $200 \mu \mathrm{m}$ with a forceps (Honour and Ross, 1962). Forceful pinching induced major injury, resulting in vasoconstriction, bleeding and a thromboembolic reaction, which could continue for 2 or 3 hours. Gently pinching induced a minor injury, without bleeding and thrombus formation, but with a small constriction. Thrombus formation and embolization could be 
induced at a minor injury spot by extravascular application of platelet activating agents such as ADP. Poisening of the cells in the vessel wall with enzyme inhibiting substances, like azide, inhibited the thromboembolic reaction as induced by a major injury, but could not prevent the effect of ADP at a spot of minor injury (Honour and Mitchell, 1964). Thereupon, Honour and Mitchell (1964) proposed that ADP-related substances originating from the damaged vessel wall are important for the initiation of the thromboembolic reaction, an idea that remains to be substantiated. With the use of antagonists, serotonin was found to be of minor importance in this thrombotic process (Honour and Mitchell, 1964). In the process of hemostatic plug formation after vessel transection serotonin was also found not to be important (Bergqvist et al, 1983).

In summary, previous studies using mechanical methods have provided knowledge of the behavior of platelets and the role of fluid dynamics and coagulation in hemostatic plug formation in vivo. Information about the role of agonists and antagonists involved in the reactions is still scarce. Knowledge of thrombotic processes following mechanically induced vessel wall injury in vivo is even more limited. The intravascular reactions following puncture of a microvessel have not yet been quantified. Therefore, in the studies described in the present thesis a model was developed, which offers the possibility to investigate in vivo the platelet-vessel wall interactions following puncture of the wall of microvessels. This model can be combined with study of the flow behavior of individual platelets after selective labeling in vivo with a fluorescent dye (Tangelder, 1982; Tangelder $e t$ al, 1982a). In addition, the model was found to be suitable to study the role of agonists and antagonists and the influence of additional factors, like fluid dynamic parameters, in thrombotic processes. An advantage of the method of puncturing is that it will induce less tissue trauma than transectioning or pinching of a vessel. Therefore, the processes of thrombus formation and embolization can be studied with less interference of tissue substances, which might influence primarily the venular reaction. 


\section{SURVEY OF MATERIALS AND METHODS}

In this chapter a brief survey is presented of the materials and methods used in the studies that are described in this thesis. For detailed information the reader is referred to the different chapters.

\section{Rabbits}

In all experiments rabbits were used of various breeds and either sex, ranging in weight from 2.3 to $3.5 \mathrm{~kg}$. In Figure 3.1 the situation of the anesthetized rabbit during an experiment is shown. Anesthesia was induced by intramuscular injections and maintained by intravenous infusion of ketamine and xylazine. Throughout the experiments body temperature was kept at 37 to $38^{\circ} \mathrm{C}$, using an infra-red heating lamp controlled by a thermo-analyzer system, that was connected to a rectal probe. Prior to surgery electronic platelet counts and hematocrits were determined in blood collected from a central ear artery.

The femoral artery and the femoral vein were cannulated in all experiments. Through the arterial catheter arterial blood pressure was recorded continuously. To keep this catheter patent it was continuously, but slowly, perfused with physiological saline. The venous catheter was used for infusion of the anesthetics. A marginal ear vein was cannulated for administration of aspirin (chapter 9).

The trachea was cannulated and connected to an infant ventilator. Throughout the experiments the rabbits were ventilated with a mixture of gases to maintain systemic $\mathrm{pH}, \mathrm{pCO}_{2}$ and $\mathrm{pO}_{2}$ at normal values, or to induce disturbances in these parameters (chapter 6). At regular time intervals blood gas and $\mathrm{pH}$ values were assessed in blood collected from a central ear artery.

\section{Mesentery preparation}

A short segment of the distal ileum was externalized through a small midline incision in the abdomen (Figure 3.1). The mesentery was carefully spread over a siliconized glass plate mounted in an electrically heated stage of an intravital microscope. 


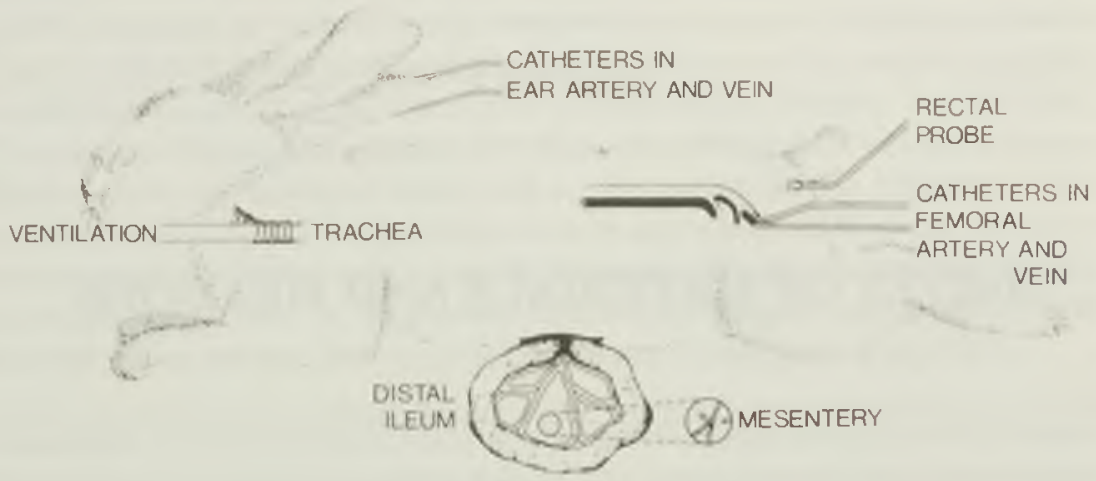

FIGURE 3.1 Schematic representation of the anesthetized rabbit with exposed mesentery.

From the first moment of exposure on, the tissue was superfused with a buffered Ty-

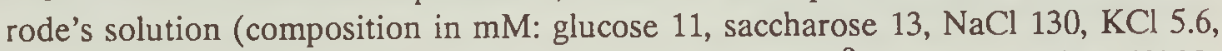
$\mathrm{CaCl}_{2} 2.9, \mathrm{MgCl}_{2} 1.2, \mathrm{NaHCO}_{3} 25$ and $\mathrm{NaH}_{2} \mathrm{PO}_{4} 1.4$ ) at $37^{\circ} \mathrm{C}$, saturated with $95 \% \mathrm{~N}_{2}$ and $5 \% \mathrm{CO}_{2}$. The bowels were kept moist with overlying wet gauze.

The mesentery has been widely used for intravital microscopic studies of the microcirculation. The structure of the mesenteric vascular bed in rats has been described by Chambers and Zweifach (1944). In rabbits, as in rats, the number of vessels per unit of area is low, especially the number of capillaries, while many arteriolo-venular shunts can be found.

\section{Microscopic system}

A schematic representation of the experimental setup is given in Figure 3.2. Observations of the mesenteric microcirculation were made with a Leitz Intravital microscope, adapted to telescopic imaging (Slaaf et al, 1982), and a Leitz long working distance objective. The mesentery was transilluminated with a tungsten lamp. Images were displayed on a monitor through a TV camera and recorded on videotape for offline analysis.

Red blood cell velocity measurements were performed on-line with a prism grating system (Slaaf $e t$ al, 1981). Vessel diameters were measured off-line, using a video image shearing device (Intaglietta and Tompkins, 1973).

\section{Vessel wall injury}

Vessel wall injury was induced mechanically by micropuncture with glass micropipets. A micropipet was positioned against a vessel wall, which was subsequently sucked to the tip of the micropipet to prevent sliding of the micropipet along the wall during puncture. A glass rod was placed near the site of puncture to prevent moving of the 


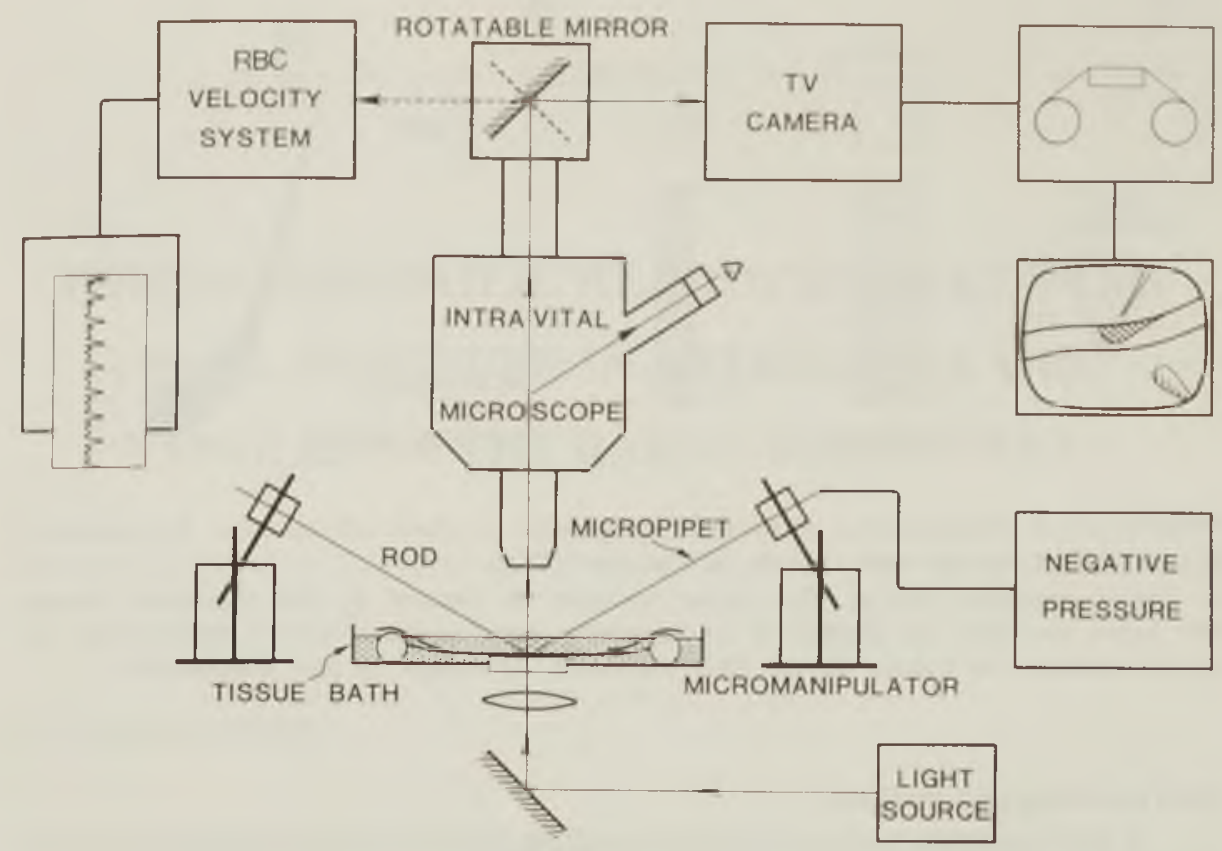

FIGURE 3.2 Schematic representation of the experimental setup.

mesenteric tissue (Figure 3.2). Puncture was considered to be successful only if red blood cells left the vessel to be sure that all layers of the vessel wall were damaged.

Immediately following puncture the thromboembolic reaction started in all vessels; a thrombus was formed and in most vessels embolization occurred. Off-line, several aspects of these processes of thrombus formation and embolization were analyzed.

\section{Platelet aggregation in vitro}

Aggregation of rabbit blood platelets in vitro was studied (chapters 7 and 9), using a photometric aggregometer (Born, 1962). The principle of this aggregometer is illustrated in Figure 3.3A. The amount of light, transmitted through a cuvette filled with stirred platelet rich plasma, was recorded before and following the addition of an aggregating agent (Figure 3.3B). The tracing illustrates different stages of the aggregation process, that can be quantified. The first reaction to many agents is that platelets swell (shape change), which is represented by a decrease of the amount of transmitted light as compared to the level of light transmission through unstimulated platelet rich plasma. The subsequent clumping of platelets during the aggregation phase results in an increase in light transmission. 
(A)

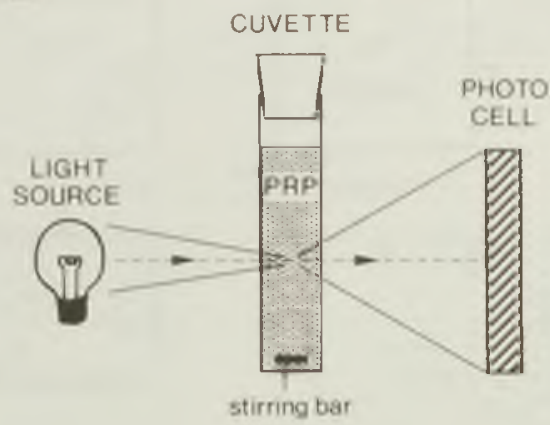

(B)

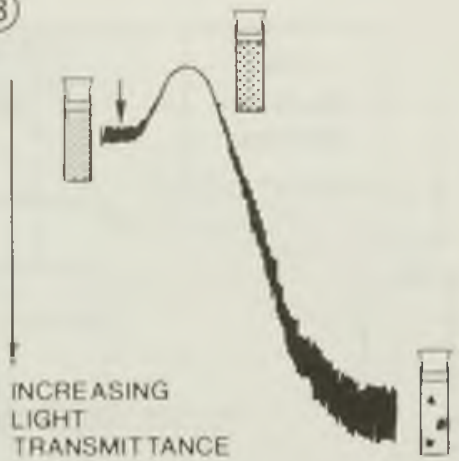

FIGURE 3.3 A. Principle of a photometric aggregometer. A photo cell measures the amount of light transmitted through stirred platelet rich plasma (PRP).

B. Typical aggregation tracing. The tracing represents the amount of light transmitted through PRP before and after the addition of an aggregating agent (indicated by the small arrow); the cuvettes illustrate the changes in the PRP, that result in changes in light transmittance.

\section{Data handling and statistics}

A VAX computer was used for data handling. Statistics were performed using the BMDP package (Dixon, 1983). Because of their non-symmetrical distribution, most data were presented as medians, unless indicated otherwise. For the same reason nonparametric tests (Siegel, 1956) were used in most cases. 


\section{THROMBOEMBOLIC REACTION FOLLOWING \\ WALL PUNCTURE IN ARTERIOLES AND \\ VENULES OF THE RABBIT MESENTERY}

\subsection{INTRODUCTION}

Injury to the wall of blood vessels usually results in thrombus or hemostatic plug formation through the activation of blood platelets. Most studies on the activation or inactivation of platelets have been performed in vitro. Investigation of thrombus or hemostatic plug formation in microvessels in vivo with the use of intravital video-microscopy allows the direct observation of these processes. Several methods have been developed to evoke a platelet reaction in microvessels in vivo. Focusing a laser beam just inside the vessel wall induces platelet activation (Arfors et al, 1968), probably as a consequence of the release of ADP from burned red blood cells (McKenzie et al, 1974; Wiedeman, 1974). With this method only a slight damage of the vessel wall is produced (Hovig et al, 1974). Irradiation with light of vessels containing an appropriate dye also leads to platelet aggregation (Herrmann, 1983; Sato and Oshima, 1984) and minimal vessel wall damage (Herrmann and Voigt, 1984). In this method, however, the platelet activating stimulus is not known. On the other hand, in studies using a mechanical method, like transection (Apitz, 1942; Zucker, 1947; Hugues, 1953; Bergqvist, 1974) or puncture (Apitz, 1942; Chen and Tsai, 1948; Herrmann et al, 1968) of the vessel wall, the injury involves all layers of the wall. However, the transection method also leads to considerable tissue trauma. In studies using puncture, tissue damage, and, hence, the effect of tissue factors on platelet reaction, will be smaller. So far the thromboembolic reaction to vessel wall injury, as induced by puncture, has only been described in a qualitative way.

The aim of the present study was to develop a method to inflict a standardized small mechanical trauma to arterioles and venules (diameter 20 to $40 \mu \mathrm{m}$ ) by puncture 
with a micropipet, and to investigate in a quantitative way whether the in vivo thromboembolic reaction in these two vessel types differs and whether fluid dynamic conditions play a part in this reaction. Vessels of this small caliber were chosen, because individual blood platelets, flowing in these vessels, can be visualized with fluorescence techniques (Tangelder et al, 1982a) allowing detailed investigation of the rheological behavior of blood platelets (Tangelder et al, 1982b, 1985, 1986) during thrombus formation in subsequent studies. In addition, the use of micropipets yields the possibility of local intra and extravascular application of chemical tools to study in vivo the cellular and biochemical reactions involved.

\subsection{MATERIALS AND METHODS}

\section{Experimental setup}

The experiments were performed on 13 rabbits of various breeds and either sex, ranging in weight from 3.0 to $3.6 \mathrm{~kg}$. Anesthesia was induced with $40 \mathrm{mg} / \mathrm{kg}$ body weight ketamine hydrochloride (Vetalar, Parke-Davis) and $4 \mathrm{mg} / \mathrm{kg}$ body weight 5.6-dihydro2-(2.6-xylidino)4H-1.3-thiazine hydrochloride (Rompun, $2 \%$ solution, Bayer) by intramuscular injections and was maintained with a continuous intravenous infusion of Vetalar ( $40 \mathrm{mg} / \mathrm{kg} /$ hour) and Rompun ( $5 \mathrm{mg} / \mathrm{kg} /$ hour $)$, dissolved in a lactetrol solution (15 ml/hour; Aesculaap). The infusion of these anesthetics started about 60 minutes after induction, through a polyethylene catheter (PE-60) in the femoral vein. After induction of anesthesia blood was collected from a central ear artery in disodium ethylenediaminetetraacetic acid (EDTA, $0.1 \mathrm{vol}, 0.027 \mathrm{M}$ ). Electronic platelet counts and hematocrit measurements were performed in duplicate with a Coulter Counter (model $\mathrm{ZF}$ ) and an Autocrit II centrifuge (Clay Adams), respectively. The $\mathrm{pH}, \mathrm{pO}_{2}$ and $\mathrm{pCO}_{2}$ were measured with an acid-base analyzer (ABL 3, Radiometer).

A second polyethylene catheter (PE-60) was placed in the femoral artery for measuring arterial blood pressure, using an external pressure transducer (CTC, CP01 ), and heart rate from the instantaneous pressure signal. Both variables were registered continuously on a physiological recorder (Schwarzer, US 266). To keep the cannula patent, it was continuously perfused with physiological saline ( $5 \mathrm{ml} /$ hour); no heparin was used. The trachea was cannulated and the cannula was connected to an infant ventilator (LOOSCO, mk 2) to maintain systemic $\mathrm{pH}, \mathrm{pCO}_{2}$ and $\mathrm{pO}_{2}$ at normal values. Throughout the experiment the rabbits were ventilated with a mixture of air and oxygen (total volume $3 \mathrm{~V} / \mathrm{min} ; 0.2$ to $0.3 \mathrm{~V} / \mathrm{min} \mathrm{O}_{2}$ ). The tidal volume was adjusted to approximately $20 \mathrm{ml}$, depending on the individual $\mathrm{pH}, \mathrm{pCO}_{2}$ and $\mathrm{pO}_{2}$ values. The blood gas values were assessed every 30 minutes in blood collected from a central ear artery.

As soon as the blood gas values were within normal ranges, the distal part of the ileum was brought outside through a small midline incision in the abdomen. The mesentery was spread over a siliconized glass plate in an electrically heated microscope 
table $\left(37^{\circ} \mathrm{C}\right)$. During the experiment the preparation was continuously superfused with a buffered Tyrode solution $\left(37^{\circ} \mathrm{C} ; \mathrm{pH} 7.37 \pm 0.04 ; \mathrm{pCO}_{2} 39 \pm 4 \mathrm{mmHg}\right.$; pO2 $40 \pm 11$ $\mathrm{mmHg}$ ). The bowels were kept moist with overlying wet gauze. Care was taken not to touch or stretch the mesentery itself. Only preparations with minimal adherence of leukocytes to the wall of venules (see chapter 8) were used.

Observations of the mesenteric microcirculation were made with a Leitz intravital microscope adapted to telescopic imaging (Slaaf et al, 1982). Microscopy was performed with a Leitz LL25 objective (long working distance; numerical aperture 0.35) under transillumination with a tungsten lamp. Images were recorded through a TV camera (Bosch, Ultricon 4532, 1 inch) and stored on videotape (Sony, U-matic VO5800 PS). The final magnification at the front plane of the TV camera was $\times 52$.

\section{Vessel wall puncture}

Twenty arterioles and 15 venules were selected, ranging in diameter from 20 to $40 \mu \mathrm{m}$. No distinction was made between straight and winding vessels, since most vessels in the unstretched mesentery meander with curves in opposite directions shortly following each other. The sites of puncturing were selected so that no upstream branch points could be observed within at least 6 vessel diameters.

Glass micropipets were used to inflict the vessel wall traumas. The micropipets were pulled from glass capillaries (OD $0.98 \mathrm{~mm}$, ID $0.53 \mathrm{~mm}$ ) with a microelectrode puller (Siegenbeek van Heukelom et al, 1976). A tip diameter of 6 to $8 \mu \mathrm{m}$ was achieved by breaking it off at the right site under microscopic control. The tip of the micropipet was placed against a vessel wall (Figure 4.1A) with the use of a micromanipulator. Sliding of the micropipet along the vessel wall during puncturing was prevented by sucking the vessel wall against the tip of the micropipet by means of a servo nulling system (IPM, model 4A), normally used to measure micropressures. A glass rod was placed near the site selected for puncturing to prevent moving of the mesentery. Puncturing of the vessel wall was performed by a tap on the micromanipulator, which caused the micropipet to penetrate the wall, whereupon it spontaneously returned to its original position. The micropipet was immediately removed from the field of view thereafter. A puncture was considered to be successful, if red blood cells (RBCs) left the vessel (Figure 4.1B). An estimation was made of the number of RBCs leaving the vessel during the first second after puncture to obtain an idea about the extent of the injury. For this estimation a 4 point scale, regarding the number of RBCs leaving the vessel, was used: one or $2 \mathrm{RBCs}$ (score: 1), more but still individually visible RBCs (score: 2 ), a small cloud of RBCs, which could not be distinguished from each other anymore (score: 3 ) and a definitely larger mass of RBCs (score: 4). The moment of puncturing and the following platelet reaction were recorded. The platelet reaction was observed for 600 seconds. In about $30 \%$ of the cases platelet reaction started before the micropipet actually punctured the wall; the results of these experiments were excluded. Off-line bleeding times, the moment at which thrombus formation started, the maximal distance over which thrombi grew into the vessel lumen relative to the local vessel diameter (maximal relative thrombus size), the number of emboli produced and the moments at 

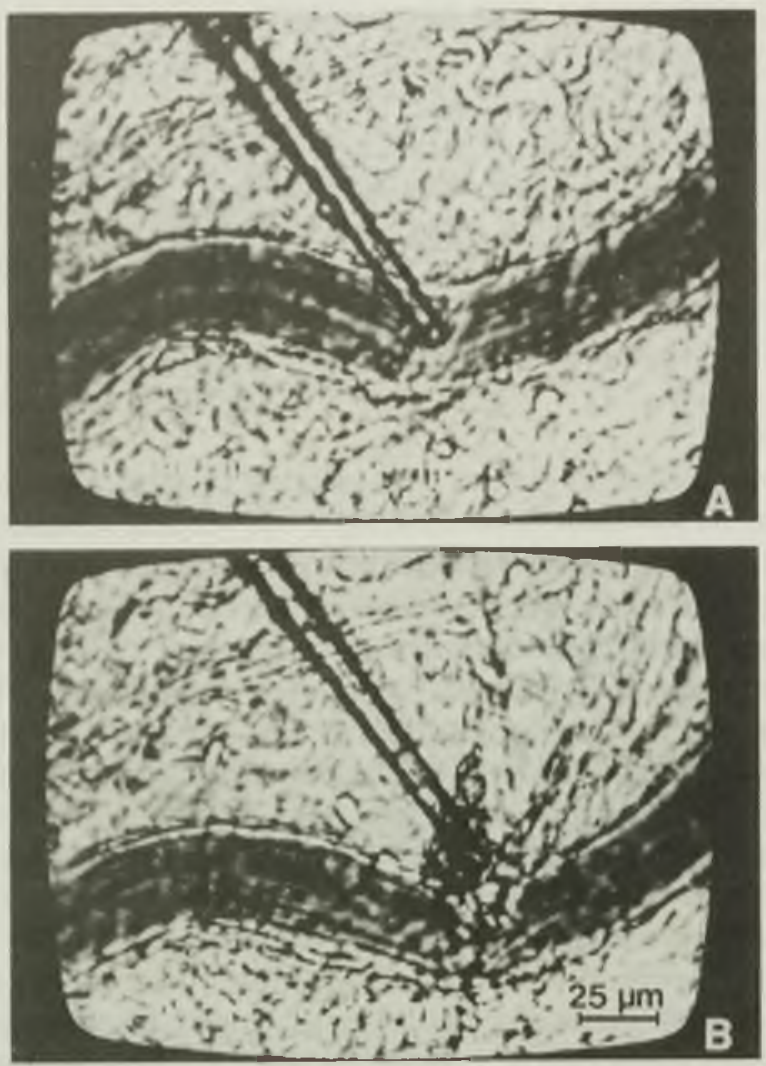

FIGURE 4.1 Puncture of the wall of an arteriole (diameter $35 \mu \mathrm{m}$ ). The tip of a glass micropipet is placed against the vessel wall (A). Puncturing is performed by a tap on the micromanipulator; red blood cells leaving the vessel $(B)$ show that the puncture was successful.

which emboli were breaking loose and, hence, the duration of embolization were determined. Emboli were only counted when the short axis, perpendicular to the vessel wall, was greater than $25 \%$ of the local vessel diameter. These measurements could be made off-line on still frames. In vessels, where rebleeding occurred, the number and duration of these rebleedings were measured. To obtain information about the growth rate of the thrombi, in a few vessels (4 arterioles and 1 venule) the length of the base and the height of the thrombus were measured every $100 \mathrm{~ms}$ during the first $2 \mathrm{~s}$ following puncture. 


\section{Fluid dynamic conditions}

To obtain insight into the fluid dynamic conditions at the moment of puncture, vessel diameter and mean $\mathrm{RBC}$ velocity were determined at the selected vessel sites. Local vessel diameters were measured from video images using a shearing monitor device (Intaglietta and Tompkins, 1973), built in our workshop. Mean RBC velocities were measured at each selected vessel site with the bidirectional optical three-stage prism grating system (BDO; Slaaf et al, 1981) with the slit covering the whole vessel width. The values, as measured in this way, were then divided by a conversion factor of 1.1 to obtain actual mean RBC velocities (Slaaf et al, 1986). These measurements were done prior to wall puncture and following the observation period. In both arterioles and venules the means of these two values were used in the analysis. To obtain information about the mean local shear rate at the moment of puncture the reduced velocity $U$ ( $U=$ mean $R B C$ velocity divided by vessel diameter) was calculated in the arterioles as well as the venules.

\section{Statistical analysis}

Because of their non-symmetrical distribution, most data are presented as medians. To test differences between two groups, if any, on statistical significance $(p \leq 0.05)$, the non-parametric Mann-Whitney U test was used. Correlations between two sets of data were tested with the Spearman rank correlation test. In case of hematocrits and electronic platelet counts, blood gas values, arterial pressures and heart rates, data are presented as means with standard deviations.

\subsection{RESULTS}

In the 13 rabbits the hematocrits ranged from 34 to $41 \%$ (mean $38 \%$ ) and the electronic platelet counts from 404 to $632 \times 10^{9} / \mathrm{l}$ (mean $497 \times 10^{9} / \mathrm{l}$ ). These values are within the normal range for rabbits (Burns and de Lannoy, 1966; Kozma et al, 1974).

During artificial ventilation the mean blood gas values were: $\mathrm{pH} 7.40 \pm 0.03$, $\mathrm{pCO}_{2} 32.9 \pm 5.5 \mathrm{mmHg}$ and $\mathrm{pO}_{2} 104.7 \pm 13.3 \mathrm{mmHg}$ (values at the moments of puncture).

Mean arterial pressure and mean heart rate, at the moments of puncture, were $65 \pm 8 \mathrm{mmHg}$ and $119 \pm 18$ beats per minute, respectively.

\section{Reactions following wall puncture}

In both arterioles and venules changes in diameter following wall puncture were minimal (on the average 3 and $4 \%$ diameter reduction, respectively). In all vessels the injury, resulting from puncture, involved all layers of the vessel wall, as demonstrated by the RBCs leaving the vessel. Intrusion of tissue into the vessel lumen near the site of puncture was not seen. Although a small dent in the vessel wall could be occasionally observed, there were no signs of extensive permanent dents. Bleeding as well as 

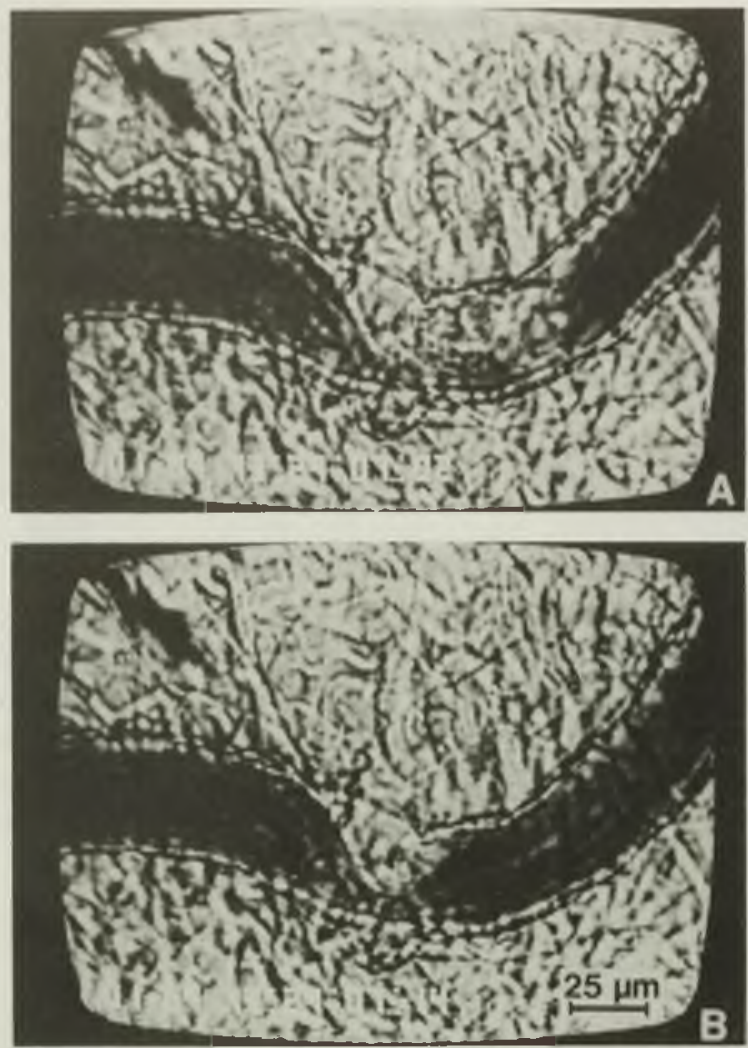

FIGURE 4.2 The thromboembolic reaction following wall puncture in an anteriole (diameter 38 $\mu \mathrm{m})$. By adhesion of circulating platelets the thrombus grows (A), till the newly formed downstream pan embolizes (B). This process repeats itself during the embolization period.

the thromboembolic reaction (Figure 4.2) started immediately after infliction of the injury. Bleeding times were short, ranging in arterioles from 0.1 to $5.5 \mathrm{~s}$ (median $1.7 \mathrm{~s}$ ) and in venules from 0.1 to $8.2 \mathrm{~s}$ (median $2.3 \mathrm{~s}$ ), a non-significant difference. The number of RBCs leaving the vessel during the first second following puncture, as estimated on a 4 point scale, was not different in both types of vessels (estimated median value in arterioles 2.0, in venules 3.0 ) and did not correlate with the following thromboembolic reaction (i.e. the number of emboli produced; arterioles: $\mathrm{r}_{\mathrm{s}}=0.11$, venules: $\mathrm{r}_{\mathrm{s}}$ $=-0.16$ ). A thrombus, mainly consisting of platelets, started to grow within $0.1 \mathrm{~s}$ after wall puncture and in most vessels reached its maximal size within 1 to $2 \mathrm{~s}$. This maximal thrombus size, as related to the local vessel diameter, was $65 \%$ in arterioles and $63 \%$ in venules. In 4 arterioles and one venule the growth rate of the thrombus could 


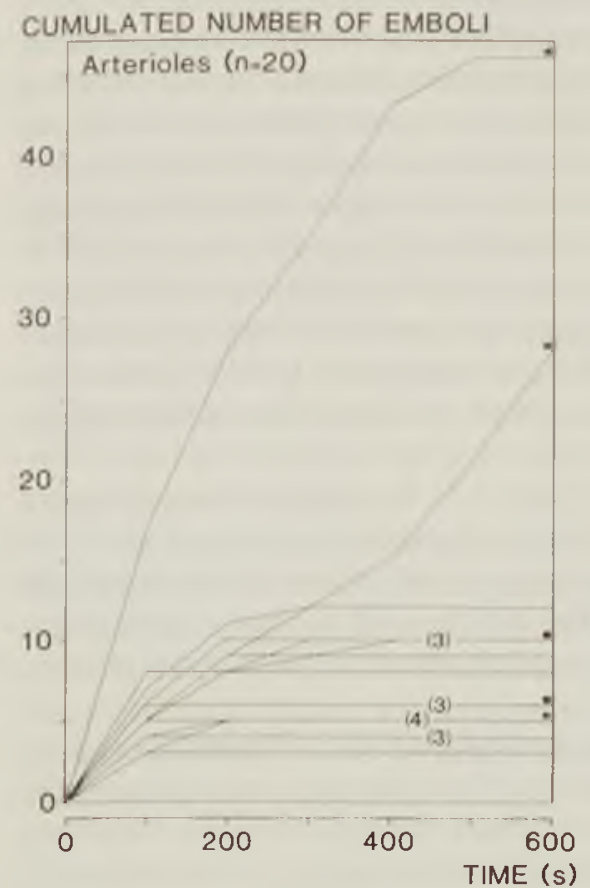

FIGURE 4.3 The cumulated number of emboli produced per unit of time in individual arterioles, as measured following each $100 \mathrm{~s}$. The horizontal part of the curves represents the total number of emboli produced. The numbers in parentheses represent the number of vessels shown in one line. $\star=$ vessel with hampered bloodstream; = vessel with rebleeding(s).

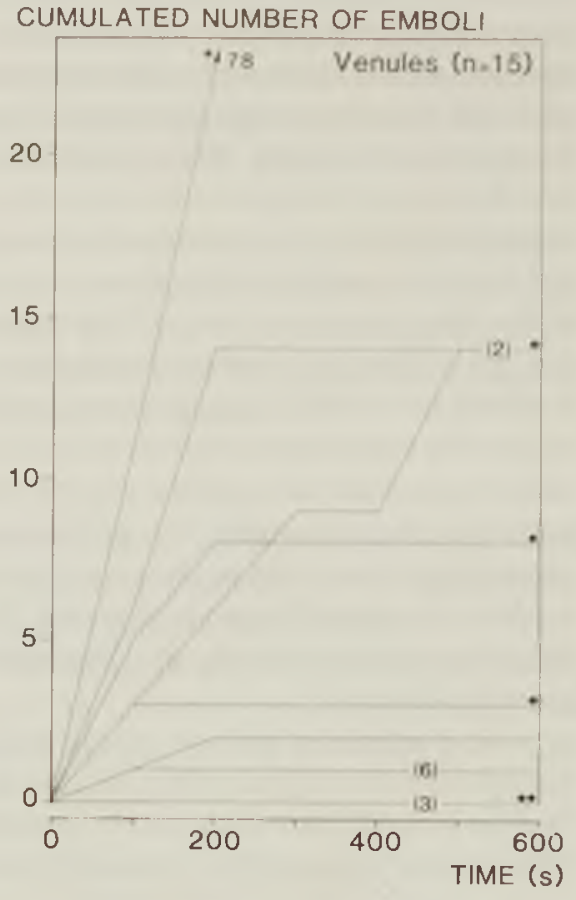

FIGURE 4.4 The cumulated number of emboli produced per unit of time in individual venules, as measured following each $100 \mathrm{~s}$. The horizontal part of the curves represents the total number of emboli produced. The numbers in parentheses represent the number of vessels shown in one line. In one venule 78 emboli were produced in the $600 \mathrm{~s}$ period, during which embolization did not stop. $\star=$ vessel with hampered blodstream; $=$ vessel with rebleeding(s).

be measured almost each $100 \mathrm{~ms}$ during the first $2 \mathrm{~s}$ following puncture. In these vessels the length of the base of the thrombus was found to be maximal at the first measurement. During the first $0.2 \mathrm{~s}$ the thrombus grew to $75 \%$ or more of its ultimate height, which was reached within 0.5 to $1.6 \mathrm{~s}$ following puncture. From that moment on the thrombus height was relatively constant.

Adhesion of circulating platelets to the thrombi, preferentially on their downstream side, continued in most vessels. Parts of these thrombi embolized, starting $15 \mathrm{~s}$ after wall puncture in arterioles and after $16 \mathrm{~s}$ in venules, a non-significant difference. Embolization mainly occurred from the downstream side of the thrombus, leaving the height of the thrombus virtually unaffected. The duration of the total embolization pro- 
cess and the number of emboli produced per individual vessel are shown in the Figures 4.3 and 4.4. In these figures the total number of emboli produced during the observation period of $600 \mathrm{~s}$ as well as the cumulated number of emboli as measured following each $100 \mathrm{~s}$ are presented. A constant slope means a constant number of emboli produced per unit of time. When the curve takes a horizontal course no emboli are produced anymore; this part of the curve represents the total number of emboli produced. In most arterioles the embolization stopped within $200 \mathrm{~s}$ (Figure 4.3). In one of the arterioles there was no embolization at all and in another the embolization did not stop within the observation period. The median duration of embolization in the arterioles was $101 \mathrm{~s}$. The total number of emboli produced per vessel varied (median production: 6 emboli per vessel). In some cases arteriolar emboli could be followed downstream, where they sometimes completely blocked capillaries or pre-capillary arterioles. In venules the process was significantly different (Figure 4.4). In 7 of the 15 vessels the embolization stopped within $27 \mathrm{~s}$, in 3 vessels there was no embolization at all and in the remaining 5 vessels the process went on for a longer period of time. In the venules the median duration of embolization was $17 \mathrm{~s}$. The median total number of emboli produced per venule was only one. The median reaction pattern for both vessel groups is shown in Figure 4.5.

In 3 arterioles and one venule (data marked by asterisks in Figures 4.3 and 4.4) the growth of the thrombus by adhesion of activated blood platelets was so pronounced, that the bloodstream was severely hampered until part of the platelet mass embolized. This process repeated itself several times. After the embolization process stopped, in

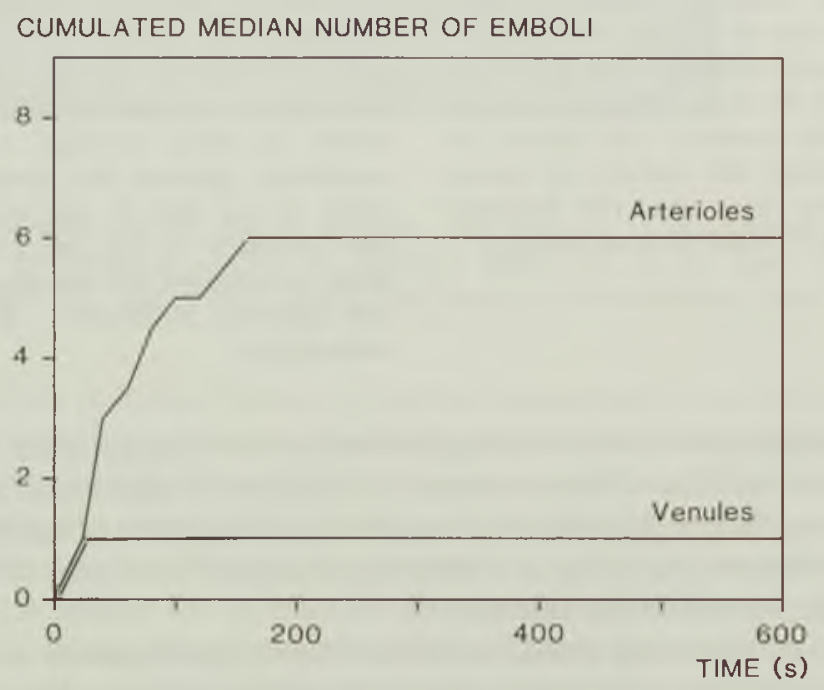

FIGURE 4.5 The cumulated median number of emboli produced per unit of time in arerioles $(n=20)$ and venules $(n=15)$, as measured following each 20 s. The horizontal part of the curves represents the median total number of emboli produced. 
some vessels small platelet aggregates, with a short axis smaller than $25 \%$ of the local vessel diameter, were shooting off the thrombus for some time. Those aggregates could hardly be distinguished from the blood. In most venules and arterioles leukocytes could be seen rolling slowly along the thrombus, or briefly sticking to it, during and after embolization. The thrombus itself stayed at the site of injury, at least for the duration of the observation period.

Rebleeding through the initially efficient thrombus occurred in 2 of the 20 arterioles ( 1 and 3 times) and in 5 of the 15 venules ( 1 to 12 times). The duration of a single rebleeding period in the arterioles ranged from 1.4 to $12.1 \mathrm{~s}$ (median duration $4.1 \mathrm{~s}$ ) and from 0.1 to $51.4 \mathrm{~s}$ (median duration $8.6 \mathrm{~s}$ ) in the venules. The vessels with rebleeding periods are also marked in the Figures 4.3 and 4.4 (circles).

\section{Fluid dynamic conditions}

The fluid dynamic parameters are shown in Figure 4.6. Vessel diameters, which had been selected within the range of 20 to $40 \mu \mathrm{m}$, were similar in both vessel types: median values $29.5 \mu \mathrm{m}$ in arterioles and $31.0 \mu \mathrm{m}$ in venules, respectively.

Mean $\mathrm{RBC}$ velocity, which remained stationary during the observation period, was significantly higher in arterioles (range: 1.0 to $7.5 \mathrm{~mm} / \mathrm{s}$; median: $2.4 \mathrm{~mm} / \mathrm{s}$ ) than in venules (range: 1.1 to $4.7 \mathrm{~mm} / \mathrm{s}$; median: $1.5 \mathrm{~mm} / \mathrm{s}$ ). In both arterioles $\left(\mathrm{r}_{\mathrm{s}}=-0.10\right.$ )

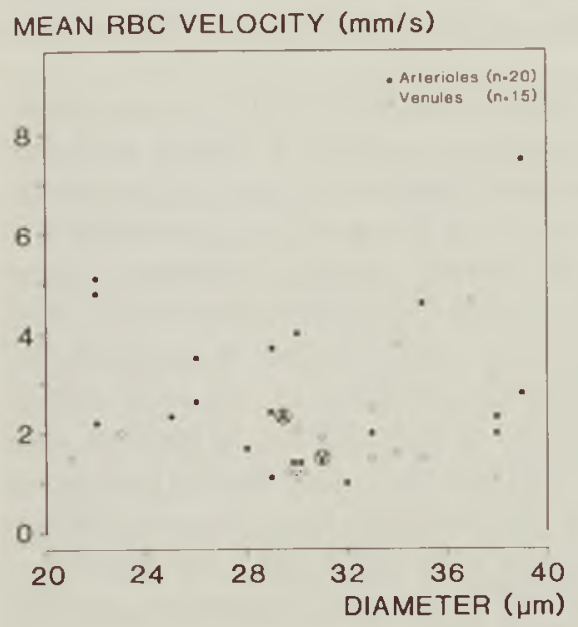

FIGURE 4.6 The relation between diameter and mean red blood cell velocity, as measured in arterioles and venules (diameter 20 to $40 \mu \mathrm{m}$ ).

(A) and (D) represent the median values of mean red blood cell velocity and diameter of the arterioles and venules, respectively.
TOTAL NUMBER OF EMBOLI

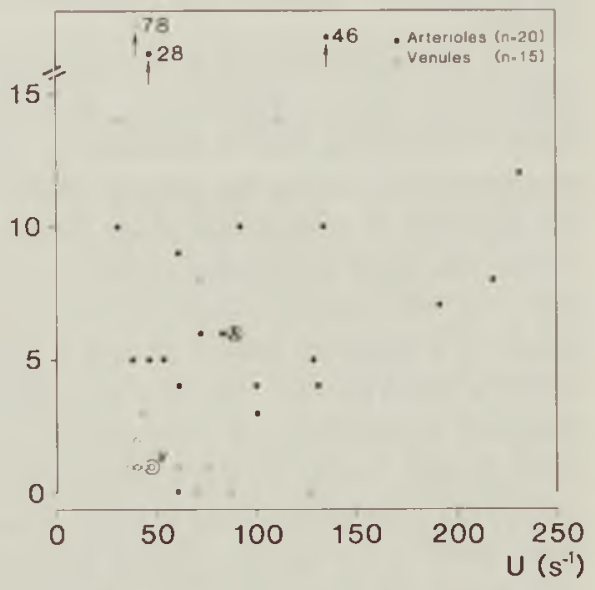

FIGURE 4.7 The relation between the reduced velocity $U$ and the total number of emboli produced per vessel in arterioles and venules. (A) and $(1)$ represent the median values of $U$ and the total number of emboli in the arterioles and venules, respectively. In 3 vessels more than 15 emboli were produced. 
and venules $\left(r_{s}=0.20\right)$ there was no significant relation between mean $R B C$ velocity and vessel diameter.

The reduced velocity, $\mathrm{U}$, was also significantly higher in arterioles (range: 31 to $232 \mathrm{~s}^{-1}$; median: $88 \mathrm{~s}^{-1}$ ) than in venules (range: 29 to $127 \mathrm{~s}^{-1}$; median: $47 \mathrm{~s}^{-1}$ ). In Figure 4.7 the relation between $U$ and the number of emboli produced per vessel is shown; this relation was not significant in the arterioles $\left(r_{s}=0.18\right)$ as well as the venules $\left(r_{s}\right.$ $=-0.40$ ).

\subsection{DISCUSSION}

In the present study the reaction of blood platelets to mechanical injury of the vessel wall, as induced by micropuncture, was investigated in vivo in a quantitative way in arterioles and venules of the rabbit mesentery. An advantage of the method used in this study over transection, which also causes mechanical injury to all vessel wall layers, is a smaller amount of tissue trauma. Arfors and coworkers (1976a) showed that an increasing amount of tissue trauma, as caused by transectioning, leads to an increased prostaglandin production in the tissue. They proposed that the prostaglandins enter the venules and by this preferentially influence the venular hemostatic plug formation. This means that in studies, in which the platelet reaction following vessel wall injury is compared between arterioles and venules, tissue trauma should be avoided as far as possible.

A second advantage of puncturing over transection, with regard to in vivo investigations on the involvement in the thromboembolic reaction of platelet activating and/or inactivating factors released by the damaged vessel walls, might be the shorter bleeding time. During the outflow of blood total shear forces will be increased due to the addition of transmural shear forces to the already existing intravascular shear forces; this might add an extra platelet activating factor (Schmid-Schōnbein et al, 1976) obscuring the factors induced by the damaged vessel wall. Puncture of the vessel wall results in a bleeding period of only a few seconds in arterioles as well as in venules, which is much shorter than the subsequent period of embolization. In contrast, after complete transection of a microvessel in the rabbit mesentery the bleeding periods are much longer, lasting for the whole duration of the hemostatic plug formation (Bergqvist, 1974). One should bear in mind, however, that a thrombus with a maximal size of about $65 \%$ of the vessel diameter stays at the wall for the total observation period in both arterioles and venules (see Figure 4.2). High shear forces present within the so formed stenosis might be an additional platelet activating stimulus. However, the finding that in our experiments embolization stops while the thrombus remains, suggests that either these high shear forces are not capable of activating the blood platelets enough to adhere and aggregate, or the vessel wall produces a factor preventing such a platelet reaction after embolization has stopped. 
Infliction of the injury to a vessel wall almost immediately leads to thrombus formation, mainly by aggregation of blood platelets, in both arterioles and venules. This process takes place within $0.1 \mathrm{~s}$ after puncture, a time interval in which the largest part of the ultimate thrombus is likely to be formed. More exact determination of the interval between puncture and the start of thrombus formation is impossible because the first few video frames following puncture are often vague due to small movements of the tissue at the moment of puncture and immediately thereafter. In addition, the temporal resolution of the video system used is limited ( 50 frames/s). The fast thrombotic reaction means that the first blood platelets must have been activated within tens of milliseconds, which is some orders of magnitude faster than expected on the basis of in vitro experiments with the use of an aggregometer (Born, 1970). The maximum relative thrombus size, which is about $65 \%$ in both arterioles and venules, is reached within 1 to $2 \mathrm{~s}$ after puncture. The relatively high concentration of platelets near the vessel wall, as found in arterioles (Tangelder et al, 1985), may contribute to this fast thrombus growth.

Embolization of thrombus fragments appears to be different in arterioles and venules. The number of emboli, used as a parameter in the present study, can be considered to be an indirect measure of the growth rate of microthrombi formed at a vessel wall injury site (Arfors et al, 1976b) and thus of the number of blood platelets activated. The first embolus is produced in the same time interval in arterioles and venules, whereafter the thromboembolic process stops in the venules, while it continues uninhibited in the arterioles for over $100 \mathrm{~s}$. A second distinction between arterioles and venules is that thrombi formed by activated platelets are less effective in plugging the holes caused by puncturing in venules than in arterioles. The extra transmural shear stress resulting from the outflow of blood during the rebleeding periods is apparently not high enough to influence embolization in the rebleeding vessels as compared to the non-rebleeding ones (see Figures 4.3 and 4.4).

In the vessels with the largest production of emboli (more than 15) the growth of the thrombus was so pronounced that the bloodstream was temporarily hampered (see Figures 4.3 and 4.4). This resulted in a significant reduction in flow and thus in a considerable increase in the pressure gradient over the thrombus, until the pressure difference was high enough to detach an embolus. This process repeated itself several times, contributing to the large production of emboli. The high thrombus growth rate in these vessels is uncompletely understood and cannot be explained by higher shear rates at the moment of puncture, because the U-values were not significantly different from those in vessels with a less pronounced thrombus growth. Methodological differences do probably not cause the rather large variation in the production of emboli in the arterioles and venules, which produce less than 15 emboli. The degree of injury of the vessel wall, as estimated by the number of RBCs leaving the vessel during the first second following puncture, is not related to the extent of embolization. In addition, during the first $20 \mathrm{~s}$ following puncture there are no significant differences in bleeding time, the initial rate of thrombus growth, and the start and initial rate of embolization between arterioles and venules. 
Fluid dynamic differences can probably not explain the differences in thromboembolic reaction following wall puncture between arterioles and venules, as found in the present study. Vessel diameters do not differ between arterioles and venules, but mean $\mathrm{RBC}$ velocities as well as $\mathrm{U}$-values do. However, when only vessels with a mean $\mathrm{RBC}$ velocity of $3.0 \mathrm{~mm} / \mathrm{s}$ or less are considered, a group of vessels in which diameters (medians: arterioles $30 \mu \mathrm{m}$, venules $30 \mu \mathrm{m}$ ), mean RBC velocities (medians: arterioles $2.0 \mathrm{~mm} / \mathrm{s}$, venules $1.5 \mathrm{~mm} / \mathrm{s}$ ) and U-values (medians: arterioles $61 \mathrm{~s}^{-1}$, venules $45 \mathrm{~s}^{-1}$ ) are not different in arterioles and venules, the median production of emboli is still significantly higher in arterioles ( 5 emboli) than in venules ( 1 embolus). Thus, in vessels with comparable vessel diameters, mean $\mathrm{RBC}$ velocities and $\mathrm{U}$-values the thromboembolic reaction differs in arterioles and venules. However, the possibility that similar Uvalues lead to different mean shear rate values in arterioles and venules cannot be excluded, because it is not known whether the shape of the velocity profiles is the same in these microvessels. The velocity profiles in arterioles, within the diameter range of the present study, are flattened as compared to a parabola, while their shape is rather consistent and only marginally dependent on vessel diameter (Tangelder $e t a l, 1986$ ). To our knowledge no information is available about the shape and consistency of velocity profiles in venules. This means that shear rate values derived from $U$-values cannot be compared in arterioles and venules. However, the finding that there is no significant relation between U-values and embolus production in arterioles indicates that mean local shear rate is not a decisive factor for the degree of embolization in these microvessels. This may also hold for venules, in which also no significant correlation was found between U-values and the number of emboli produced, assuming that the shape of the velocity profiles is not dependent on the actual mean velocity. Nevertheless one has to keep in mind that it is not clear whether the number of platelets passing the site of injury per unit of area and time is the same in arterioles and venules, because it is not yet known whether the distribution of platelets is identical in both types of microvessels.

Another possible explanation for the differences in thromboembolic reaction, as found between arterioles and venules, is that the intravascular milieu is not the same in both vessel types. Differences in intravascular blood gas and $\mathrm{pH}$ values between arterioles and venules, for example, might influence platelet behavior, since in vitro studies have shown that changes in $\mathrm{pH}$ and $\mathrm{pCO}_{2}$ can influence the aggregation of blood platelets to various agents (Rogers, 1972; Tang and Frojmovic, 1977).

Beside intravascular factors, differences in thrombogenic or antithrombogenic activity of the vessel walls following wall puncture may be a cause of the differences between arteriolar and venular platelet behavior. Fibrinolytic activity, for example, is shown to be higher in venous than in arterial vessel walls (Coccheri and Astrup, 1961). Noordhoek Hegt (1977) attributed this to a higher plasminogen activator activity in the endothelial cells and a lower fibrinolysis inhibitory activity in the smooth muscle cells in venous walls, as compared to arterial walls. The number of smooth muscle cells present in the subintimal layers seems to be an important factor for the degree of fibrinolysis inhibition. A high net fibrinolytic activity could play a role in the less effective 
plugging of holes in the mesenteric venules, as compared to the arterioles. However, one has to keep in mind that the studies mentioned have been performed on large vessels and not at the microcirculatory level. The same holds for a study of Mehta and Roberts (1983) on the production of prostaglandin $\mathrm{I}_{2}\left(\mathrm{PGI}_{2}\right)$ and thromboxane $\mathrm{A}_{2}\left(\mathrm{TXA}_{2}\right)$ in arterial and venous vessel walls. A higher proportion of $\mathrm{TXA}_{2}$, as compared with $\mathrm{PGI}_{2}$, was found in arteries than in veins, which could contribute to a greater inhibition of platelet function in veins than in arteries.

In conclusion, a method has been developed to inflict by micropuncture a standardized, small mechanical trauma to the vessel wall of small arterioles and venules in the rabbit mesentery. The resulting thromboembolic reaction has been investigated in a quantitative way. The response is different in arterioles and venules. In arterioles embolization continues for a longer period of time than in venules. This difference can probably not be explained by fluid dynamic factors.

\subsection{SUMMARY}

The walls of rabbit mesenteric arterioles and venules (diameter 20 to $40 \mu \mathrm{m}$ ) were punctured with glass micropipets (tip diameter 6 to $8 \mu \mathrm{m}$ ). Thromboembolic reactions resulting from this standardized, small mechanical vessel wall injury could be quantified in vivo with the use of intravital videomicroscopy. Following induction of the injury thrombus growth started immediately $(<0.1 \mathrm{~s})$. Bleeding times were short, on the average less than $2 \mathrm{~s}$, and did not differ between arterioles and venules. The duration of the embolization process was significantly longer in arterioles than in venules (median 101 and $17 \mathrm{~s}$, respectively), and more emboli were produced in arterioles than in venules (median 6 and 1, respectively). Arteriolar thrombi were more effective in plugging the punctured holes than venular thrombi. The differences in thromboembolic reaction between arterioles and venules, as found in the present study, can probably not be explained by fluid dynamic factors. 


\section{THE THROMBUS AND ITS FLUID DYNAMIC CONSEQUENCES}

\subsection{INTRODUCTION}

Puncture of the wall of arterioles and venules of the rabbit mesentery induces in these microvessels the formation of a thrombus similar in height, but with a number of emboli produced which is 6 times higher in arterioles than in venules (oude Egbrink et $a l, 1988$; chapter 4). This difference cannot be explained by differences in fluid dynamic conditions prior to puncture, as far as velocity and reduced velocity, a measure of wall shear rate, are concerned.

Despite the similar thrombus height in arterioles and venules, it cannot be excluded that the shape and, hence, the effective cross-sectional area of the thrombus differs in these microvessels. Moreover, even if size and shape of the thrombus are similar and fluid dynamic conditions prior to puncture are the same, thrombus formation can still induce different changes in flow, if the concomitant relative changes in resistance differ. This is the case when the lengths of the punctured vessels between up and downstream bifurcations are different. Consequently, differences in pressure drop over the thrombus in arterioles and venules may occur, if the shape of the thrombus and/or the flow changes are different.

Therefore, the first aim of the present study was to estimate the effective size of the cross-sectional area of the thrombus, as formed following vessel wall puncture, in order to find out whether a difference in the degree of stenosis contributes to the difference in the degree of embolization between arterioles and venules. The second aim was to investigate in both vessel types the influence of a thrombus on blood flow and reduced velocity, because in vitro studies suggest that increases in wall shear rate induce extra platelet activation (Brown et al, 1975; Turitto and Baumgartner, 1979) and, hence, embolization activity. To this purpose red blood cell (RBC) velocity and vessel diameter were measured upstream of the site of puncture prior to infliction of the in-

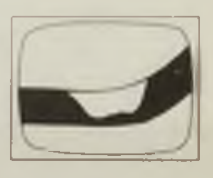


jury; following vessel wall puncture velocity and diameter were measured upstream of and in the stenosed vessel segment. The experiments were performed in the rabbit mesentery.

\subsection{MATERIALS AND METHODS}

\section{Animal preparation}

4 New Zealand white rabbits of either sex were used, ranging in weight from 2.5 to $2.8 \mathrm{~kg}$. Surgery, mesentery preparation and intravital videomicroscopy were performed, as previously described (oude Egbrink et al, 1988; chapter 4). In short, the rabbits were anesthetized by intramuscular injections of $40 \mathrm{mg} / \mathrm{kg}$ body weight ketamine hydrochloride (Nimatek, A.U.V.) and $4 \mathrm{mg} / \mathrm{kg}$ body weight xylazine hydrochloride (Sedamun, A.U.V.). Anesthesia was maintained by continuous infusion of ketamine (40 $\mathrm{mg} / \mathrm{kg} / \mathrm{hr})$ and xylazine $(5 \mathrm{mg} / \mathrm{kg} / \mathrm{hr})$, dissolved in a lactetrol solution $(15 \mathrm{ml} / \mathrm{hr}$; Aesculaap). Electronic platelet counts, hematocrit values, arterial blood pressure and heart rate were assessed (oude Egbrink et al, 1988; chapter 4). Electronic platelet counts (range: $235-400 \times 10^{\circ} \mathrm{n}$ ) and hematocrit values (range: $33.3-41.9 \%$ ) were within normal ranges in all 4 rabbits (Kozma et al, 1974). Mean arterial blood pressure varied between 67 and $83 \mathrm{mmHg}$ throughout the experiments (mean: $74 \mathrm{mmHg}$ ), while heart rates ranged from 72 to 114 beats per minute (mean: 92 beats per minute).

The rabbits were ventilated with a mixture of nitrogen, oxygen and carbon dioxide to maintain systemic arterial $\mathrm{pH}, \mathrm{pCO}_{2}$ and $\mathrm{pO}_{2}$ values at normal levels (oude Egbrink et al, 1988; chapter 4).

The mesenteric preparation was visualized microscopically, using a long working distance objective (LL 25, numerical aperture 0.35 ). Images were recorded on videotape for off-line analysis.

\section{Induction of thrombus formation}

The walls of arterioles and venules, ranging in diameter from 20 to $40 \mu \mathrm{m}$, were punctured using glass micropipets with tip diameters of 6 to $8 \mu \mathrm{m}$, as previously described in detail (oude Egbrink et al, 1988; chapter 4). Puncture was considered to be successful only if RBCs left the vessel. Immediately following puncture thrombus formation as well as bleeding started in all vessels. The thrombus itself stayed at the site of injury with a relatively constant shape, at least for the duration of the observation period (10 minutes). In most vessels adhesion of circulating platelets to this stationary thrombus continued on its downstream side. These newly formed parts of the thrombus embolized during a certain period of time.

\section{Measurements of RBC velocity, vessel diameter and thrombus height}

Following selection of the site of puncture, RBC velocity was measured (see below) within a distance of one diameter upstream of the selected puncture site for 1 


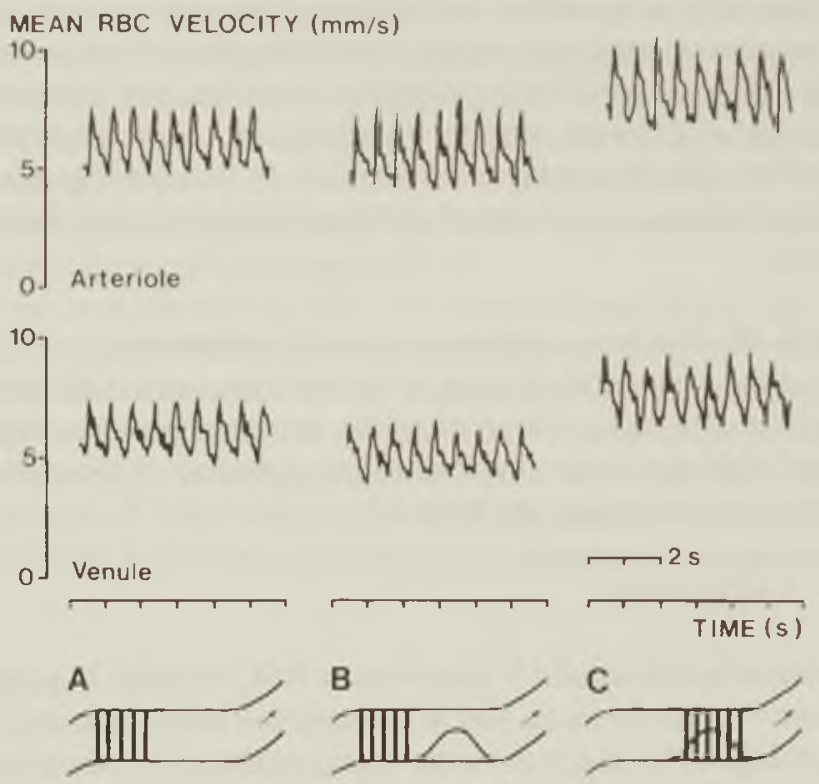

FIGURE 5.1 Velocity tracings, as recorded in an arteriole (diameter: $30 \mu \mathrm{m}$; lop panel) and a venule (33 $\mu \mathrm{m}$; lower panel), with similar mean $R B C$ velocities before puncture (5.9 and 6.4 $\mathrm{mm} / \mathrm{s}$; tracing $A)$. In both vessels velocity in the vessel segment upstream of the thrombus decreased slightly following puncture (B). At the site of the thrombus RBC velocity was clearly higher $(C)$ than in the upstream segment (B). Arrows indicate direction of flow.

minute prior to puncture (Figure 5.1A) and for a period of 1 to 5 minutes (average: 2 minutes) after puncture (Figure 5.1B). At the end of this period RBC velocity was measured at the site of the thrombus itself (Figure 5.1C) and, subsequently, again in the vessel segment upstream of this thrombus. At each of the velocity measurement sites local vessel diameter was measured off-line. With the setup used it was not possible to measure velocity in a segment upstream of the thrombus and to record the embolization reaction at the same time.

Vessel diameters and the height of the thrombi were measured off-line using a home-built video image-shearing device (Intaglietta and Tompkins, 1973). RBC velocities were measured on-line, using a prism grating system (Slaaf et al, 1981) coupled to an IPM correlator. Measurements were always performed with the sample volume covering the whole vessel width. The length of the sample volume was variable, but at the site of the thrombus adjusted to the length of the thrombus (see Figure 5.1C). The instantaneous and a mean velocity signal were registered on a physiological recorder (Schwarzer, US 266). Mean velocity was obtained by filtering the instantaneous signal at $1 \mathrm{~Hz}$. The mean velocity values, as measured in this way, were divided by a conversion factor of 1.1 to obtain actual mean RBC velocities (Slaaf et al, 1986). 
In some vessels the height of the thrombus could not be measured. In some other vessels velocity measurements in the segment containing the thrombus were impossible due to overlying RBCs as a result of the bleeding. Therefore, the data presented in the Results-section refer to different numbers of experiments. Because of their non-symmetrical distribution, data are expressed as medians. Differences between two groups of data were tested with the non-parametric Mann-Whitney U test, the level of significance being 0.05 .

\section{Assessment of the effective cross-sectional area of the thrombus}

The ratio of the cross-sectional area of the thrombus and that of the vessel segment containing the thrombus, representing the degree of stenosis, was determined from velocity and diameter measurements, in and upstream of the stenosis, with the use of the following equation (see appendix 1):

$$
\mathrm{A}_{\mathrm{th}} / \mathbf{A}_{\mathrm{sv}}=1-\mathrm{k}\left(\mathrm{V}_{\mathrm{up}} / \mathrm{V}_{\mathrm{sv}}\right)
$$

where $A$ is cross-sectional area and $V$ actual mean $R B C$ velocity. $V_{\text {up }}$ and $V_{\text {sv }}$ are the velocities measured in the upstream and in the stenosed vessel segment, respectively, as is illustrated in Figure 5.2. $A_{t h}$ is the cross-sectional area of the thrombus. $A_{s v}$ is the cross-sectional area of the vessel segment, containing the thrombus, as calculated from: $A=\pi \cdot(D / 2)^{2}$, where $D$ is the vessel diameter. The factor $k$ quantitates the tapering of the vessel and is always close to $1 ; \mathrm{k}$ equals $\mathrm{A}_{\mathrm{up}} / \mathrm{A}_{\mathrm{sv}}$, where $\mathrm{A}_{\mathrm{up}}$ is the cross-sectional area of the upstream vessel segment.

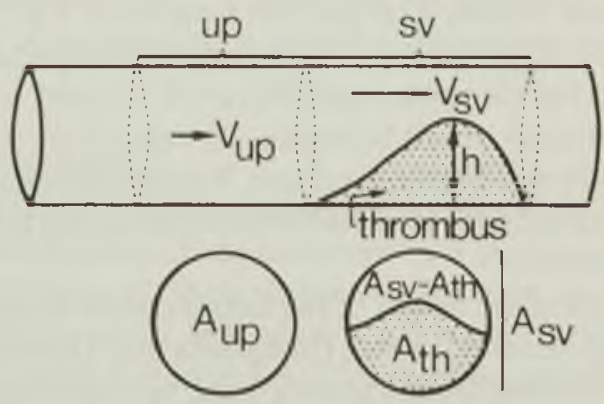

FIGURE 5.2 Schematic representation of a vessel containing a thrombus; longitudinal and crosssections of the upstream (up) and the stenosed vessel segment (sv) are shown. $V_{\mathrm{up}}$ and $V_{\mathrm{sv}}$ are mean $R B C$ velocities measured in the upstream and stenosed vessel segment; $h$ is the thrombus height; $A_{\mathrm{up}} A_{\mathrm{sv}}$ and $\mathcal{A}_{\mathrm{th}}$ are cross-sectional areas of the upstream and stenosed vessel segment and of the thrombus, respectively. 
Assessment of the fluid dynamic consequences of thrombus formation

The formation of a thrombus results in a change of the volume flow $Q$ in the vessel, as calculated from the velocity and diameter data, measured in the upstream vessel segment $\left(Q=V \cdot A=V \cdot \pi \cdot(D / 2)^{2}\right)$. The ratio of the volume flow in the presence of the thrombus to the flow prior to puncture is calculated from: $Q^{d} / Q^{p}$, where $Q^{d}$ is the volume flow during the presence of the stenosing thrombus, while $\mathrm{Q}^{\mathrm{P}}$ is the flow prior to thrombus formation (see appendix 2).

Due to the reduction of the effective cross-sectional area of the vessel both the velocity and the reduced velocity $U$ in the stenosed vessel segment increase, superimposed on the observed change in flow. $U$ is defined as $V / D$. Assuming a circular lumen in the stenosed vessel segment, the ratio of the reduced velocity in the presence of a thrombus to the reduced velocity prior to thrombus formation can be calculated from: $U_{s v}{ }^{d} / U_{s v}{ }^{p}$, where $U_{s v}{ }^{d}$ is the reduced velocity in the stenosed vessel segment and $U_{s v}{ }^{p}$ the reduced velocity in the same segment prior to puncture (see appendix 2).

\subsection{RESULTS}

Data were obtained from 16 arterioles and 10 venules. Before puncture, vessel diameters ranged from 21 to $40 \mu \mathrm{m}$ (median: $32 \mu \mathrm{m}$ ) in the arterioles and from 24 to $40 \mu \mathrm{m}$ (median: $31 \mu \mathrm{m}$ ) in the venules. A considerable overlap existed in mean RBC velocities in arterioles (range: $1.0-7.6 \mathrm{~mm} / \mathrm{s}$; median: $3.6 \mathrm{~mm} / \mathrm{s}$ ) and in venules (range: 0.8-6.4 mm/s; median: $2.3 \mathrm{~mm} / \mathrm{s}$ ), but the difference between both groups was significant $(p \leq 0.05)$. Blood flow and reduced velocity $U$ were not different between arterioles and venules; blood flow ranged from 0.5 to $9.6 \mathrm{nl} / \mathrm{s}$ (median: $3.3 \mathrm{nl} / \mathrm{s}$ ) in the arterioles and from 0.6 to $5.1 \mathrm{nl} / \mathrm{s}$ (median: $1.3 \mathrm{nl} / \mathrm{s}$ ) in the venules, while $U$ ranged from 38 to $197 \mathrm{~s}^{-1}$ (median: $109 \mathrm{~s}^{-1}$ ) in the arterioles and from 26 to $200 \mathrm{~s}^{-1}$ (median: $57 \mathrm{~s}^{-1}$ ) in the venules.

\section{Estimation of the degree of stenosis}

Mean $\mathrm{RBC}$ velocity was always higher in the stenosed segment than in the segment upstream of the thrombus. An example is shown in Figure 5.1B and C. In Figure 5.3 the ratio of the velocity in the stenosed vessel segment and the velocity in the upstream vessel segment, after correction for tapering of the vessel with factor $\mathrm{k}$, is plotted as a function of the relative thrombus height (h/D). Arteriolar and venular thrombi of comparable height appeared to induce similar increases in mean $\mathrm{RBC}$ velocity.

The degree of stenosis as caused by the thrombus was estimated from the term 1-k. $\left(V_{u p} / V_{s v}\right)$, according to equation (1); it ranged from 6 to $76 \%$ of the vessel lumen in arterioles and from 4 to $51 \%$ in venules. The relation between the degree of stenosis and the relative thrombus height is very similar to the relation shown in Figure 5.3. In Figure 5.4 the degree of stenosis is plotted as a function of the square of the relative thrombus height. Thrombi of comparable height induce a similar degree of stenosis in 


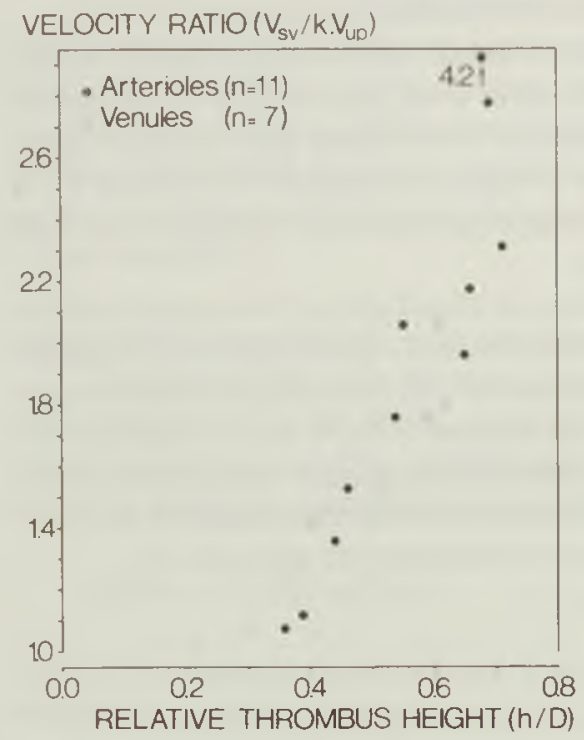

FIGURE 5.3 Scatter plot of the increase in velocity within the stenosis as a function of relative thrombus height, $h / D$. The increase in velocity is calculated from the ratio of mean $R B C$ velocity in the stenosis and the velocity upstream of the thrombus, corrected by factor $k$ for tapering of the vessel $\left(V_{s v} / k . V_{u p}\right)$. In one anteriole, indicated by the arrow, the ratio was 4.2 .

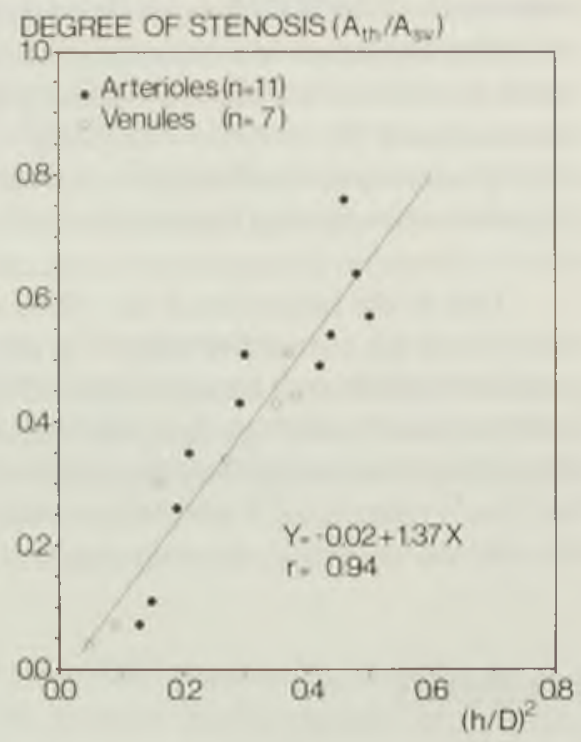

FIGURE 5.4 Scatter plot of the degree of stenosis, $A_{\mathrm{th}} / A_{\mathrm{sv}}$ (as estimated from the relation: $\left.A_{\mathrm{ih}} / A_{\mathrm{sv}}=1-k \cdot\left(V_{\mathrm{up}} / V_{\mathrm{sv}}\right)\right)$, as a function of the square of the relative thrombus height, $(h / D)^{2}$. The linear best fit of the data and its correlation coefficient $(r)$ are also shown.

arterioles and venules, as indicated by the fact that the regression lines through the arteriolar and through the venular data points (not shown in Figure 5.4) are not different from the regression line through all data points.

\section{Consequences for flow and reduced velocity}

The formation of the thrombus resulted in a reduction of blood flow in the vessel. An example is shown in Figure 5.1A and B. The change in blood flow in all vessels is plotted as a function of the degree of stenosis in Figure 5.5. In both arterioles and venules blood flow fell on the average less than $10 \%$ up to and including a degree of stenosis of $51 \%$ of the vessel lumen. In 4 of the 5 arterioles with a higher degree of stenosis a clear decrease in blood flow was observed.

In arterioles and venules, a similar degree of stenosis induced a similar increase in velocity as compared to the velocity before puncture. The increase in reduced velocity $\mathrm{U}$ in the stenosed vessel segment can only be approximated. The cross-sectional area of the remaining lumen in the stenosed vessel segment is definitely not circular, 


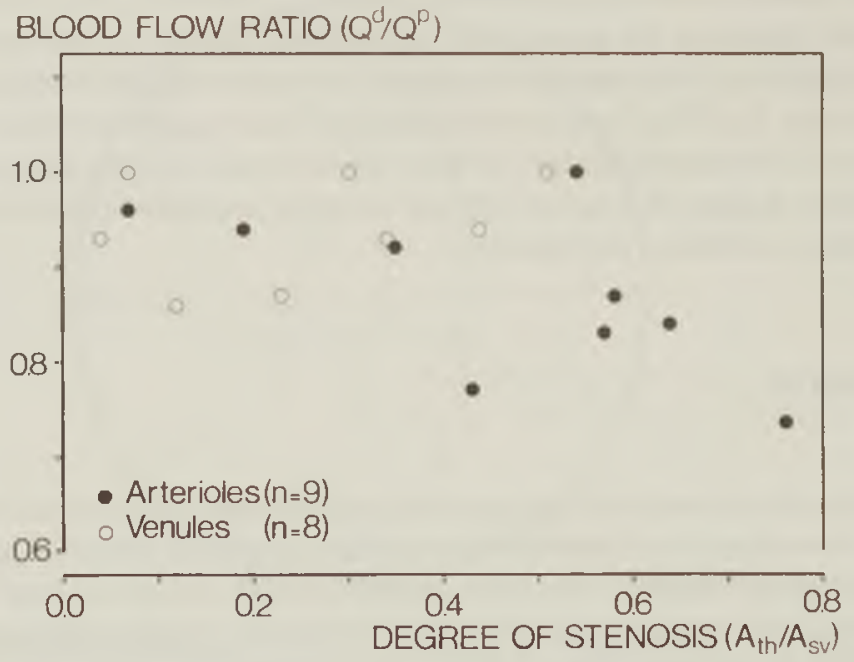

FIGURE S.5 Scatter plot of blood flow in the upstream vessel segment after thrombus formation, relative to the flow before puncture, $Q^{\mathrm{d}} / Q^{\mathrm{p}}$, as a function of the degree of stenosis, $A_{\mathrm{th}} / A_{\mathrm{sv}}$ (as estimated from the relation: $\left.A_{\mathrm{th}} / A_{\mathrm{sv}}=t-k_{.}\left(V_{\mathrm{up}} / V_{\mathrm{sv}}\right)\right)$.

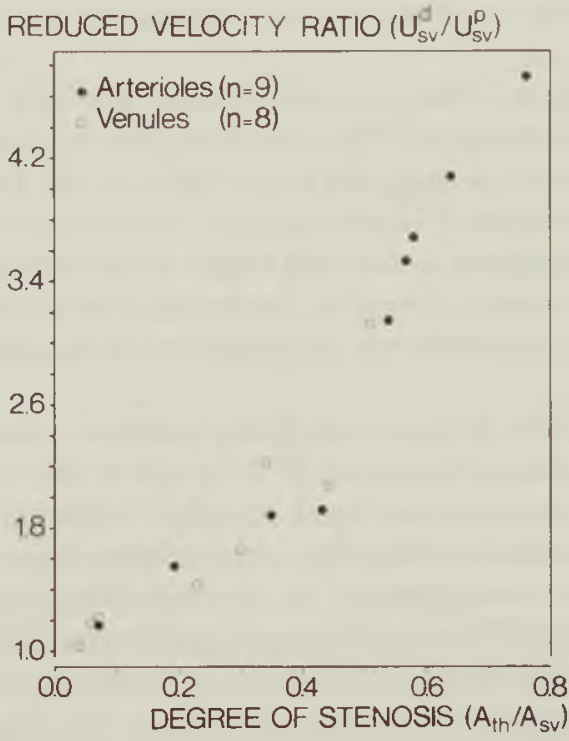

FIGURE 5.6 Scatter plot of the ratio of reduced velocity $U$ in the stenosed vessel segment and the reduced velocity in the same segment before puncture, $U_{\mathrm{sv}}{ }^{d} / U_{s v}$, as a function of the degree of stenosis, $A_{\mathrm{th}} / A_{\mathrm{sv}}$ (as estimated from the relation: $A_{\mathrm{th}} / A_{\mathrm{sv}}=1-\mathrm{k}_{\mathrm{v}}\left(V_{\mathrm{up}} / V_{\mathrm{sv}}\right)$ ). 
and the flow profile in this segment is not parabolic. However, for a least estimate of $\mathrm{U}_{\mathrm{sv}}{ }^{\mathrm{d}}$ along the thrombus the assumption can be made that the cross-sectional area of the remaining lumen in the stenosed segment is circular and the flow profile is parabolic. In this way, $\mathrm{U}_{\mathrm{sv}}{ }^{\mathrm{d}} / \mathrm{U}_{\mathrm{sv}}{ }^{\mathrm{p}}$ can be calculated as a least estimate of the change in reduced velocity. The data are plotted in Figure 5.6 as a function of the degree of stenosis. Again, a similar degree of stenosis induced a similar increase in reduced velocity or wall shear rate in arterioles and venules.

\subsection{DISCUSSION}

Puncture of the vessel wall of arterioles and venules of the rabbit mesentery results in the formation of a thrombus with similar height and effective cross-sectional area. The formation of such a thrombus induces similar changes in flow and reduced velocity. These data strongly suggest that the difference in embolus production between arterioles and venules cannot be explained by different changes in flow and reduced velocity, if any, as a result of thrombus formation.

The thrombus heights, as found in the present study, and the initial perfusion conditions do not differ from those obtained in an earlier study (oude Egbrink et al, 1988; chapter 4). This implies that, although the number of emboli could not be counted in the present study, the present findings can be applied to the findings of the previous study.

For a given height the effective cross-sectional area of a thrombus does not differ between arterioles and venules. The mean $\mathrm{RBC}$ velocity played a key role in the assessment of the effective cross-sectional area of the thrombi. During the $\mathrm{RBC}$ velocity measurements in the stenosed vessel segment, the sample volume of the velocity measuring system was adjusted to the total length of the thrombus (Figure 5.1C). The calculated degree of stenosis, therefore, represents the average effect of the total thrombus and can be considered as a least estimate of the actual maximal degree of stenosis.

Using the data of the present study, it is possible to make an approximation of the shape of the thrombus cross-section. If the shape of the thrombus is constant, its cross-sectional area is proportional to the square of its height $\mathrm{h}$. Based on line-symmetry considerations and a smooth surface, the thrombus cross-section can be approximated by an ellipse with excentricity $\epsilon$, i.e. the ratio of the long and short axis of the ellipse (see appendix 1). The average value of $\varepsilon$ for the total vessel population is found by plotting the degree of stenosis as a function of the square of the relative thrombus height, according to equation (c) in appendix 1 (Figure 5.4). The slope of the regression line, which is equal to the average excentricity, is 1.37 . The arteriolar and venular data points fit equally well with this regression line. In Figure 5.7 the result of this approximation is shown for 3 different relative thrombus heigths and $E=1.37$. A small part of the area of the elliptic thrombus is located outside the circular vessel. Planimetric as- 


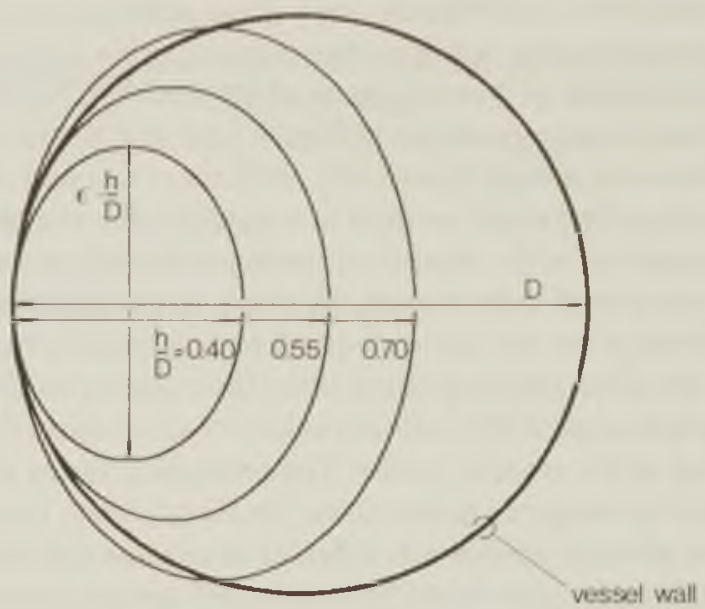

FIGURE 5.7 Schematic representation of the cross-section of a vessel (circle with diameter D) and 3 different thrombi, the form of which is approximated by an ellipse with height h/D and an exceniricity $\epsilon$ of 1.37. Note that the area of the ellipse, that falls outside of the vessel, is largest for the ellipse with the greatest $h$.

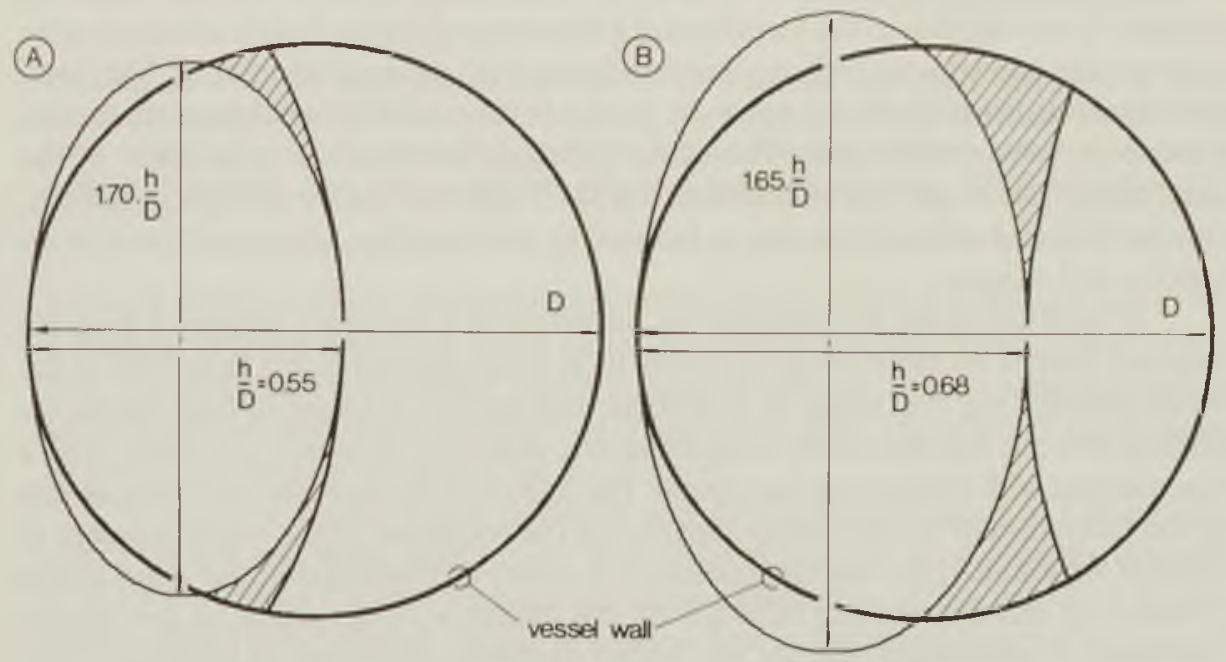

FIGURE 5.8 Schematic representation of the cross-section of the 2 arterioles with the largest extravascular areas of the ellipses. (A) Ellipse with $h / D=0.55$ and $E=1.70$, with an extravascular area of $7 \%$ of its total area. (B) Ellipse with $h / D=0.68$ and $\epsilon=1.65$, with an extravascular area of $13 \%$ of its total area. The hatched areas represent the extravascuiar areas after projection in the vessel. 
sessment of the ratio of the extravascular area of the ellipse to its total area for all individual vessels showed that the ratio was often unmeasurable and smaller than or equal to 0.03 , with the exception of 2 arterioles in which the ratio was 0.07 and 0.13 , respectively. These 2 arterioles are shown in Figure 5.8A and B. Only in the vessel with the greatest extravascular area (Figure 5.8B), addition of this part of the ellipse to the intravascular area (hatched area) resulted in a considerable change of the estimated shape of the cross-section of the thrombus; the upper thrombus surface became concave instead of convex. In all other vessels the shape, as estimated by the ellipse, hardly changed by correction for the relatively small extravascular area, indicating that an approximation of the cross-sectional shape of the thrombus by an ellipse is reasonable.

Conversion of measured $\mathrm{RBC}$ velocity values to actual mean $\mathrm{RBC}$ velocity values requires knowledge of the velocity profile. The conversion factor used in this study is based on the profile as measured in arterioles (Slaaf et al, 1986; Tangelder et al, 1986). It is likely that the velocity profiles are different in venules and arterioles. However, the value of a correct conversion factor for venules will deviate less than $20 \%$ from that of arterioles (1.1), being the maximal difference with a parabolic profile (1.33) and a flat profile (1.0). In the determinations of the degree of stenosis and the changes in fluid dynamic parameters due to thrombus formation, the conversion factor used is of no importance because it is divided out. Only if the change in profile from a straight vessel segment to the stenosed segment is dramatically different in arterioles and venules, an error might have been made in the calculations and, hence, in the comparisons between the data obtained in arterioles and venules. However, the observed changes in velocity due to the formation of a thrombus of similar height are much alike in arterioles and venules with comparable initial fluid dynamic conditions. This indicates that the disturbance of the velocity profile in the stenosed vessel segment is comparable in both vessel types. Therefore, although the absolute magnitude of the determined values may not be accurate, it is likely that the relative changes in velocity, volume flow and reduced velocity, as induced by the thrombus, are not different in arterioles and venules.

In both arterioles and venules, the formation of a thrombus induces a decrease in blood flow of on the average less than $10 \%$, if the stenosis is less than $50 \%$ of the vessel lumen. One may argue as to whether this limited decrease in flow can be explained without autoregulatory compensations, since the mesentery is known to be a vascular bed with limited autoregulation. The impact of the increase in resistance due to the formation of the thrombus depends on the resistance of the vessel segment in which it is formed. If the vascular resistance is evenly distributed over the vessel length between up and downstream bifurcations, the influence of the length on flow can be calculated to investigate whether the limited decrease in flow can be explained without autoregulatory compensation. In Figure 5.9 the decrease in flow as a function of the degree of stenosis is shown for different values of $\alpha$, being the ratio of vessel length and thrombus length. The data in this figure indicate that, with a stenosis of $50 \%$ of the vessel lumen, $\alpha$ has to be between 20 and 30 to explain a decrease in blood flow of about $10 \%$. Assuming an average thrombus length of $20 \mu \mathrm{m}$, the length of the punctured vessel 


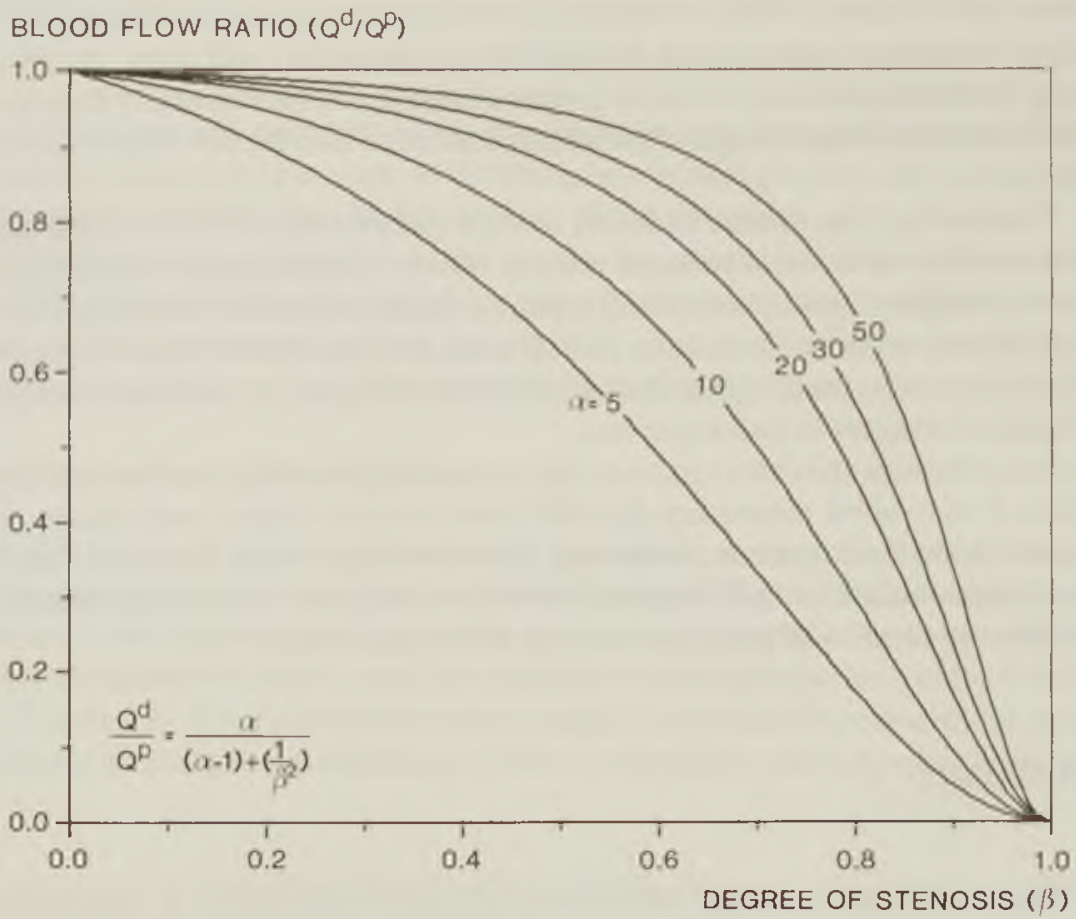

FIGURE 5.9 Ratio of blood flow in the presence of a stenosis and blood flow prior to the formation of the stenosis, $\left(Q^{\mathrm{d}} / Q^{p}\right)$, as a function of the degree of stenosis (expressed as $\beta$ ) for different values of $\alpha$ ( $\alpha=$ vessel length/thrombus length), assuming constant perfusion pressure and applying Poiseuille's Law. The curves are calculated using the equation: $Q^{d} / Q^{\rho}=\alpha /\left((\alpha-1)+\left(1 / \beta^{2}\right)\right)$.

between the bifurcations should be about $400-600 \mu \mathrm{m}$, which is a realistic value. With a stenosis of more than $50 \%$ of the lumen flow has to decrease considerably (Figure 5.9). This predicted reduction of flow is in good agreement with our experimental data in the arterioles with degrees of stenosis of more than $50 \%$. The effect of these degrees of stenosis in venules remains to be investigated.

It could be argued that in arterioles and venules the formation of a thrombus of similar height and shape might result in a different pressure drop over the thrombus. If this were indeed the case for a given cross-sectional area of the thrombus, it should have resulted in a different change in volume flow in the vessel segment and in a different velocity at the site of the thrombus. Our present data, however, show that changes in volume flow and velocity are similar in arterioles and venules with a degree of stenosis of $50 \%$ or less. This also indicates that the initial pressure drops over the punctured vessel segments are similar in both vessel types. This phenomenon can be explained by the structure of the mesenteric vascular network, which is arcading 
(Frasher and Wayland, 1972). In rabbits, as in rats (Chambers and Zweifach, 1944), the capillary density per unit of tissue is rather low in mesentery and many shunting vessels can be found. Moreover, venular pressure is higher in the mesentery than in other tissues, because of the drainage of the mesenteric blood into the portal vein (Zweifach, 1974).

The finding, that in arterioles and venules thrombi with similar heights seem to induce a similar increase in reduced velocity relative to the reduced velocity prior to puncture, indicates that in both vessel types a similar increase in wall shear rate is induced. Therefore, the difference in embolizaton activity normally found between arterioles and venules (oude Egbrink et al, 1988; chapter 4) can probably not be explained by different increases in wall shear rate.

In conclusion, the observations in the present study indicate that in arterioles and venules of the rabbit mesentery thrombi have a similar shape and induce similar changes in local fluid dynamic conditions, if the thrombus height is similar. Therefore, these changes cannot be held responsible for the difference in thromboembolic reaction following vessel wall puncture between both vessel types.

\subsection{SUMMARY}

The height and functional cross-sectional area of a thrombus, as formed following puncture of the wall of arterioles and venules of the rabbit mesentery, were estimated to determine whether a difference in the degree of stenosis could contribute to the difference in the degree of embolization, as normally found between both vessel types. To this purpose, RBC velocity and vessel diameter were measured upstream of and in the stenosed vessel segment. Thrombi with similar height appeared to induce similar degrees of stenosis in arterioles and venules. The generalized shape of the thrombus cross-section could be approximated by an ellipse with an average excentricity of 1.37 . This approximation fitted equally well for arteriolar and venular thrombi. The fluid dynamic consequences of the formation of a thrombus were determined from velocity and diameter measurements performed prior to and following thrombus formation. In both arterioles and venules the formation of a thrombus, that caused a stenosis of less than approximately $50 \%$ of the vessel lumen, induced only a small decrease in blood flow ( $<10 \%)$. Reduced velocity, which is a measure of wall shear rate, increased similarly in both vessel types for thrombi with comparable height. Therefore, the findings of the present study indicate that the differences in embolization activity between arterioles and venules cannot be explained by differences in effective size of the thrombus or by different changes in blood flow and reduced velocity, as induced by the thrombus. 


\subsection{APPENDIX 1}

In this appendix calculations are presented for the assessment of the effective cross-sectional area and the shape of the thrombus. All data used in the calculations of this appendix were measured in the presence of the thrombus.

The cross-sectional area ( $A$ ) of the vessel is assumed to be circular: $A=\pi \cdot(D / 2)^{2}$, where $\mathrm{D}$ is the vessel diameter. Applying the principle of continuity of flow to the upstream and stenosed vessel segment, the effective cross-sectional area occupied by the thrombus can be assessed with the use of the following equation:

$$
Q=A_{u p} \cdot V_{u p}=\left(A_{s v}-A_{t h}\right) \cdot V_{s v}
$$

where $\mathrm{Q}$ is flow and $\mathrm{V}$ mean $\mathrm{RBC}$ velocity. $\mathrm{A}_{\text {up }}$ and $\mathrm{V}_{\text {up }}$ are cross-sectional area and velocity, as measured in the upstream vessel segment (Figure 5.2). $A_{\text {sv }}$ and $V_{\text {sv }}$ are measured in the stenosed vessel segment, $A_{s v}$ representing the cross-sectional area of this vessel segment as a whole. Ath is the effective cross-sectional area of the thrombus itself (Figure 5.2). The ratio of the cross-sectional area of the thrombus and that of the thrombus containing vessel segment as a whole is found by rearrangement of equation (a):

$$
\mathrm{A}_{\mathrm{th}} / \mathrm{A}_{\mathrm{sv}}=1-\left(\left(\mathrm{A}_{\mathrm{up}} / \mathrm{A}_{\mathrm{sv}}\right) \cdot\left(\mathrm{V}_{\mathrm{up}} / \mathrm{V}_{\mathrm{sv}}\right)\right)=1-\mathrm{k} \cdot\left(\mathrm{V}_{\mathrm{up}} / \mathrm{V}_{\mathrm{sv}}\right),
$$

where $\mathrm{k}$ can be regarded as a correction factor for the tapering of the vessel; $\mathrm{k}$ is defined as $A_{u p} / A_{\text {sv }}$ and is always close to 1.

If the shape of the thrombus is constant, its cross-sectional area is proportional to the square of its height h. Based on line-symmetry considerations and a smooth surface, a first approximation of the thrombus cross-section can be an ellipse with excentricity $\epsilon$, i.e. the ratio of the long and short axis (see Figure 5.7).

In that case $A_{t h}=E \cdot \pi \cdot(h / 2)^{2}$. Rewriting equation (b) yields:

$$
\text { E. }\left(h / D_{s v}\right)^{2}=1-k .\left(V_{u p} / V_{s v}\right),
$$

where $\mathrm{D}_{\mathrm{sv}}$ is the diameter of the vessel segment, containing the thrombus.

\subsection{APPENDIX 2}

In this appendix, the calculations used to assess the changes in blood flow and reduced velocity $U$ as a consequence of the formation of a thrombus are presented. The data used are measured either prior to thrombus formation, as indicated by superscript 
'p', or during the presence of the stenosing thrombus, as indicated by superscript 'd'. The site of measurement is indicated by subscripts (see appendix 1 and Figure 5.2).

The volume flow in the vessel prior to thrombus formation $\left(\mathrm{Q}^{\mathrm{P}}\right)$ as well as the flow in the presence of the thrombus $\left(Q^{\mathrm{d}}\right)$ are calculated from data measured in the upstream vessel segment according to: $Q=V_{\text {up. }} A_{u p}$. The ratio of the volume flow in the presence of the thrombus to the flow prior to puncture is calculated from: $Q^{d} / Q^{P}$.

In case of a circular cross-sectional area of the vessel and a parabolic flow profile, the reduced velocity $U$ can be defined as $U=V / D$. Prior to thrombus formation, reduced velocity $U$ in the vessel segment in which the thrombus will be formed is given by:

$$
U_{s v}^{p}=V_{s v}^{p} / D_{s v}^{p}
$$

where $\mathrm{V}_{\mathrm{sv}}{ }^{\mathrm{p}}$ and $\mathrm{D}_{\mathrm{sv}} \mathrm{p}^{\mathrm{p}}$ are velocity in and diameter of the vessel segment, in which the thrombus will be formed, prior to puncture. Since $V_{s v}{ }^{p}$ was not directly measured in this vessel segment, it is calculated using the principle of continuity of flow: $V_{\mathrm{sv}}{ }^{p}=$ $\mathrm{Q}^{\mathrm{p}} / \mathrm{A}_{s v}{ }^{\mathrm{p}}$. $\mathrm{A}_{s v}{ }^{\mathrm{p}}$ can be calculated from the vessel diameter $\left(\mathrm{A}_{s v}{ }^{\mathrm{p}}=\pi \cdot\left(\mathrm{D}_{s v}{ }^{\mathrm{p}} / 2\right)^{2}\right)$ and $\mathrm{Q}^{\mathrm{P}}$ is known (see paragraph above). Hence:

$$
U_{s v}{ }^{p}=Q^{p} /\left(D_{s v}{ }^{p} \cdot A_{s v}{ }^{p}\right)
$$

Following puncture, the reduced velocity $U$ in the stenosed segment, which then contains the thrombus, is found from:

$$
\mathrm{U}_{\text {sv }}{ }^{\mathrm{d}}=\mathrm{V}_{\mathrm{sv}}{ }^{\mathrm{d}} / \mathrm{D}_{\mathrm{sv}-\mathrm{th}}{ }^{\mathrm{d}}
$$

where $V_{s v}{ }^{d}$ is the velocity measured in the stenosed vessel segment and $D_{s v-t h}{ }^{d}$ the diameter of the remaining lumen in the stenosed vessel segment. However, the crosssectional area of this lumen is definitely not circular. Nevertheless, a least estimate of $\mathrm{U}_{\mathrm{sv}}{ }^{\mathrm{d}}$ can be found by assuming this area to be circular and the flow profile to be parabolic. Under these assumptions $D_{\text {sv-th }}{ }^{d}$ can be calculated from the relation:

$$
\pi \cdot\left(D_{\text {sv-th }}{ }^{d} / 2\right)^{2}=A_{s v}-A_{t h}
$$

where $A_{s v}$ is the cross-sectional area of the thrombus containing vessel segment as a whole and $A_{t h}$ the effective cross-sectional area of the thrombus (see appendix 1). The ratio of the reduced velocity $U$ following thrombus formation and prior to puncture $\left(U_{s v}{ }^{d} / U_{s v}{ }^{d}\right)$ can be calculated from the equations (e) through (g). Since $U_{s v}{ }^{d}$ is a least estimate of the reduced velocity in the presence of a thrombus, the ratio $U_{s v}{ }^{d} / U_{s v}{ }^{p}$ is also a least estimate of the change in reduced velocity. 


\section{EFFECT OF BLOOD GASES AND $\mathrm{pH}$ ON THROMBOEMBOLIC REACTIONS IN RABBIT MESENTERIC MICROVESSELS}

\subsection{INTRODUCTION}

The thromboembolic reaction following vessel wall puncture is different in arterioles and venules. The number of emboli produced is on the average 6 times higher in arterioles than in venules. This difference cannot be explained by fluid dynamic factors (oude Egbrink et al, 1988; chapters 4 and 5).

An alternative explanation for the observed difference in thromboembolic reaction may be the different intravascular blood gas and $\mathrm{pH}$ values in both vessel types, because in vitro studies have shown that changes in $\mathrm{pH}, \mathrm{pCO}_{2}$ and $\mathrm{pO}_{2}$ can influence the aggregation of blood platelets in response to various agents (Flatow and Freireich, 1966; Kikugawa et al, 1972; Rogers, 1972; Goldschmidt, 1973; Han and Ardlie, 1974; Tang and Frojmovic, 1977; Kennedy et al, 1981; Vermijlen et al, 1986).

So far, the influence of systemic blood gases and acidity on thromboembolic reactions has not been investigated in vivo. In the present study systemic hypercapnia and/or hypoxia were used to induce in rabbit mesenteric arterioles and venules changes in blood gas and $\mathrm{pH}$ values, and to investigate the influence of these changes on the thromboembolic reaction following wall puncture in these microvessels. The systemic changes induced were of sufficient magnitude to create in the arterioles blood gas and $\mathrm{pH}$ values normally present in venules. Comparison of the thromboembolic reaction in the different situations will reveal whether differences in $\mathrm{pH} / \mathrm{pCO}_{2}, \mathrm{pO}_{2}$, or both between arterioles and venules are responsible for the difference in reaction normally found between these microvessels. Changes in systemic arterial $\mathrm{pO}_{2}$ and $\mathrm{pCO}_{2}$, and hence $\mathrm{pH}$, were induced by different ventilation regimens. 


\subsection{MATERIALS AND METHODS}

\section{Experimental setup}

The experiments were performed on 4 groups of rabbits of various breeds and either sex, which were comparable in weight (range $2.9-3.6 \mathrm{~kg}$, mean $3.3 \mathrm{~kg}$ ). All animals were anaesthetised with ketamine hydrochloride (Vetalar, Parke-Davis) and 5.6dihydro-2-(2.6-xylidino)4H-1.3-thiazine hydrochloride (Rompun, 2\% solution, Bayer). Anesthesia was induced by intramuscular injections of $40 \mathrm{mg} / \mathrm{kg}$ body weight Vetalar and $4 \mathrm{mg} / \mathrm{kg}$ body weight Rompun and maintained by continuous intravenous infusion of $40 \mathrm{mg} / \mathrm{kg} /$ hour Vetalar and $5 \mathrm{mg} / \mathrm{kg} /$ hour Rompun, dissolved in a lactetrol solution ( $15 \mathrm{ml} /$ hour; Aesculaap). Electronic platelet counts, hematocrit values, arterial blood pressures and heart rates were measured as described previously (oude Egbrink et al, 1988; chapter 4).

The trachea was cannulated and the cannula (4.5 mm I.D.; Mallinckrodt) was connected to an infant ventilator (LOOSCO, mk2). Ventilation was performed with $2 \mathrm{~cm}$ $\mathrm{H}_{2} \mathrm{O}$ positive end-expiratory pressure. The respiratory rate was $60 / \mathrm{min}$. Total gas flow through the ventilator was set at $31 / \mathrm{min}$, and the inspiration:expiration ratio at 1:1.5. This resulted in a respiratory minute volume of $1.2 \mathrm{l} / \mathrm{min}$ and, hence, a tidal volume of $20 \mathrm{ml}$, which is normal for these rabbits (Kozma et al, 1970). By adjusting the composition of the gas mixture in the ventilator, 4 experimental groups were created: a control group with normal blood gas values (referred to as CONT), a normoxic hypercapnic group (HC), a normocapnic hypoxic group (HO) and a group that was both hypercapnic and hypoxic $(\mathrm{HCHO})$. The average composition of the gas mixtures used are presented in Table 6.1. The blood gas values were assessed about every 30 minutes with an acidbase analyzer (ABL 3, Radiometer) in blood samples collected in heparinized tubes from a central ear artery. If necessary, these values were adjusted by changing the composition of the gas mixture. Blood gas and $\mathrm{pH}$ values at the moments of vessel wall

TABLE 6.1 Average composition of gas mixtures used to ventilate the rabbits of the different groups

\begin{tabular}{lccc}
\hline \multirow{2}{*}{ Group } & \multicolumn{3}{c}{ Mean composition of ventilation gas (\%) } \\
\cline { 2 - 4 } & $\mathrm{O} 2$ & $\mathrm{~N}_{2}$ & $\mathrm{CO}_{2}$ \\
\hline $\mathrm{CONT}$ & 25 & 75 & - \\
$\mathrm{HC}$ & 24 & 72 & 4 \\
$\mathrm{HO}$ & 17 & 83 & - \\
$\mathrm{HCHO}$ & 14 & 83 & 3 \\
\hline
\end{tabular}

CONT = control; $H C=$ hypercapnia; $H O=$ hypoxia;

$\mathrm{HCHO}=$ hypercapnia and hyparia 
puncture were estimated by linear interpolation from the two nearest measurements.

Mesentery preparation and intravital microscopy were performed as described in detail before (oude Egbrink et al, 1988; chapter 4). Vessel diameter and mean red blood cell $(\mathrm{RBC})$ velocity were measured in all selected vessels at the site of puncture, using the methods described by Intaglietta and Tompkins (1973) and by Slaaf and colleagues $(1981 ; 1986)$, respectively. To obtain information about mean local shear rate the reduced velocity $\mathrm{U}(\mathrm{U}=$ mean $\mathrm{RBC}$ velocity/vessel diameter) was calculated.

To estimate whether the systemically induced blood gas and $\mathrm{pH}$ changes were of sufficient magnitude to create in the mesenteric arterioles values normally present in venules, blood samples were collected in 6 rabbits from an artery and a vein, traversing the mesentery, and supplying blood to and carrying blood from the intestinal wall and the mesentery itself, respectively. The diameters of these vessels were 150 to 300 $\mu \mathrm{m}$ and blood could be collected using a $1 \mathrm{ml}$ syringe and a $25 \mathrm{G}$ needle. In these blood samples blood gas and $\mathrm{pH}$ values were measured. In 3 of the rabbits systemic blood gas and $\mathrm{pH}$ values were equal to the values of the rabbits in the CONT-group. In the 3 other rabbits systemic $\mathrm{pO}_{2}$ was lowered, to check the local effects of such a change on the arterial as well as the venous side.

In the feeding arteries the $\mathrm{pO}_{2}$ was equal to or less than the systemic arterial values in all rabbits (mean difference $3.4 \mathrm{mmHg}$, greatest difference $22 \mathrm{mmHg}$ ). In the draining veins of the 3 rabbits with a mean systemic arterial $\mathrm{pO}_{2}$ of $106 \mathrm{mmHg}$ (same $\mathrm{pO}_{2}$ as in control-rabbits, see Table 6.3) the $\mathrm{pO}_{2}$ was found to be $50 \mathrm{mmHg}$. This local venous $\mathrm{pO}_{2}$ is equal to the systemic arterial $\mathrm{pO}_{2}$ of the rabbits in the $\mathrm{HO}$ and $\mathrm{HCHO}$ groups (see Table 6.3). In the 3 rabbits with a lowered systemic arterial $\mathrm{pO}_{2}(81 \mathrm{mmHg})$, local venous $\mathrm{pO}_{2}$ was $28 \mathrm{mmHg}$. This finding, that the difference in $\mathrm{pO}_{2}$ between systemic arteries and draining veins is the same in both situations, indicates that systemically induced changes in $\mathrm{pO}_{2}$ are followed by changes along the whole vascular tree till at least the level of the draining veins. The same trend holds for $\mathrm{pH}$ and $\mathrm{pCO}_{2}$. In the feeding arteries $\mathrm{pH}$ and $\mathrm{pCO}_{2}$ were only slightly different from systemic arterial values (mean differences 0.002 and $0.2 \mathrm{mmHg}$, respectively). In the draining veins $\mathrm{pH}$ and $\mathrm{pCO}_{2}$ differed on the average 0.006 and $2.0 \mathrm{mmHg}$, respectively, from systemic arterial values. These differences were smaller than the systemically induced differences between the CONT and the $\mathrm{HC}$ and HCHO-groups (see Table 6.3). Since only $1 \%$ or less of the intestinal blood flow passes through arteriovenous shunts (Lundgren, 1984), local venous blood gas and $\mathrm{pH}$ values will reflect venular values. Therefore, the systemically induced changes in blood gas and $\mathrm{pH}$ values in the $\mathrm{HC}, \mathrm{HO}$ and $\mathrm{HCHO}$ groups were great enough to induce blood gas and $\mathrm{pH}$ values in the arterioles which were at least equal to the values normally present in venules; in the venules themselves blood gas and $\mathrm{pH}$ values were also changed.

\section{Vessel wall puncture}

In every rabbit, mesenteric arterioles and venules were selected within the diameter range of 20 to $40 \mu \mathrm{m}$. Per animal one to 6 vessels ( 3 arterioles and 3 venules) were punctured within a period of 180 minutes following preparation of the mesentery. 
Puncture was performed with glass micropipets having tip diameters of 6 to $8 \mu \mathrm{m}$, as previously described (oude Egbrink et al, 1988; chapter 4). A puncture was considered to be successful, only if RBCs left the vessel. The moment of puncture and the subsequent intravascular reactions were recorded on videotape up to 600 seconds.

\section{Analysis of thromboembolic reaction}

Bleeding time, the moment at which thrombus formation started, the maximal thrombus height relative to the local vessel diameter, the number of emboli produced and the moments at which emboli were breaking loose were determined off-line. Emboli were only counted if their short axis, perpendicular to the vessel wall, was greater than $25 \%$ of the local vessel diameter. Aggregates of smaller dimensions could not always be distinguished from the background with sufficient accuracy. The extent of vessel wall injury was estimated by assessing the number of RBCs leaving the punctured vessel, as described in detail before (oude Egbrink et al, 1988; chapter 4).

In 5 arterioles and 6 venules of the CONT-group and in 4 arterioles and 4 venules of the $\mathrm{HCHO}$-group one or more growth patterns of the thrombus between two embolizations were analyzed in detail. Vessels, which had an intravascular contrast high enough to allow reliable estimation of the surface of the thrombus during its growth, were selected at random. A transparancy was placed over the monitor screen. From a still frame the circumference of a thrombus was drawn every second until embolization occurred. The surface area of every drawing was measured, using the SigmaScan program (Jandel Scientific) on a personal computer (IBM-AT). When the growth pattern of a thrombus was analyzed in a vessel, in which only one embolus was produced, the analysis was started from the moment that the thrombus was in focus.

\section{Statistics}

Most data are presented as medians, because of their nonsymmetrical distribution. Differences between groups and vessels were tested with the non-parametric Kruskal-Wallis one way analysis of variance (significance level $\mathrm{p} \leq 0.05$ ). Correlations between two sets of data were tested with the Spearman rank correlation test. Blood gas and $\mathrm{pH}$ values are presented as means with standard deviations; differences between groups were tested with the student's t test.

\subsection{RESULTS}

Data concerning the rabbits used in the 4 experimental groups are shown in Table 6.2. Hematocrits and electronic platelet counts were within normal ranges for rabbits (Kozma et al, 1974). Electronic platelet counts were lower in the HCHO-rabbits than in the rabbits of the CONT-group. Mean arterial blood pressure was also lower in the rabbits of the HCHO-group than of the CONT-group. However, no significant correlations were found between platelet counts, mean arterial blood pressure, hematocrits 
TABLE 6.2 Data, concerning the rabbits used in the 4 groups. Median values and ranges are presented.

\begin{tabular}{lcccccc}
\hline Group & $\mathrm{n}$ & $\begin{array}{c}\text { Weight } \\
(\mathrm{kg})\end{array}$ & $\begin{array}{c}\text { Hematocrit } \\
(\%)\end{array}$ & $\begin{array}{c}\text { Platelet count } \\
\left(\times 10^{\%} / 1\right)\end{array}$ & $\begin{array}{c}\text { MAP } \\
(\mathrm{mml})\end{array}$ & $\begin{array}{c}\text { IIR } \\
(\mathrm{bpm})\end{array}$ \\
\hline & & & & & & \\
CONT & 13 & 3.3 & 38 & 476 & 67 & 120 \\
& & $(3.0-3.6)$ & $(34-41)$ & $(404-632)$ & $(53-80)$ & $(108-168)$ \\
HC & 13 & 3.3 & 38 & 468 & 71 & 145 \\
& & $(3.1-3.4)$ & $(37-41)$ & $(369-690)$ & $(49-93)$ & $(100-210)$ \\
HO & 7 & 3.3 & 37 & 358 & 61 & 159 \\
& & $(2.9-3.3)$ & $(34-43)$ & $(282-655)$ & $(48-68)$ & $(112-180)$ \\
HCHO & 7 & 3.3 & 37 & $417 *$ & $56 *$ & 138 \\
& & $(3.0-3.5)$ & $(33-38)$ & $(316-503)$ & $(50-67)$ & $(105-200)$
\end{tabular}

CONT = control; $H C=$ hypercapnia $; H O=$ hypoxia $H C H O=$ hypercapnia and hypoxia; $M A P=$ mean arterial blood pressure; HR heart rate; ${ }^{*} p \leq 0.0 .5$ compared to control

and heart rate on the one hand and the embolization parameters (see below) on the other, in arterioles or in venules. These findings suggest that these whole animal parameters do not significantly influence the thromboembolic reaction following wall puncture in rabbit mesenteric microvessels.

The number of vessels punctured per group and the average values of the blood gas parameters and $\mathrm{pH}$ in the 4 groups at the moments of vessel puncture are shown in Table 6.3. During puncture of arterioles and venules the blood gas and $\mathrm{pH}$ values were comparable. The relation between $\mathrm{pH}$ and $\mathrm{pCO}_{2}$ was inconsistent, mainly due to varying base excess values. In the CONT-group the average base excess value was slightly negative ( $-4 \mathrm{mM}$ ), while it ranged from 0 to $3 \mathrm{mM}$ in the other groups. These varying base excess values are likely to be of less importance because no significant correlation could be detected between these values and any of the thromboembolic parameters (see below), in either arterioles or venules.

\section{Reactions in arterioles and venules}

In all punctured arterioles and venules diameter changes were minimal and bleeding times were short, with no significant differences between groups or between arterioles (group medians 1.7-3.9 s) and venules (group medians 2.3-4.8 s). The same holds for the estimated number of RBCs leaving the vessel, which did not correlate with the subsequent thromboembolic reaction, as quantitated by the number of emboli produced.

A platelet (white) thrombus started to grow within $0.1 \mathrm{~s}$ following wall puncture and reached its maximal size in most vessels within $2 \mathrm{~s}$. The maximal thrombus height remained relatively constant thereafter and did not differ between groups or between 


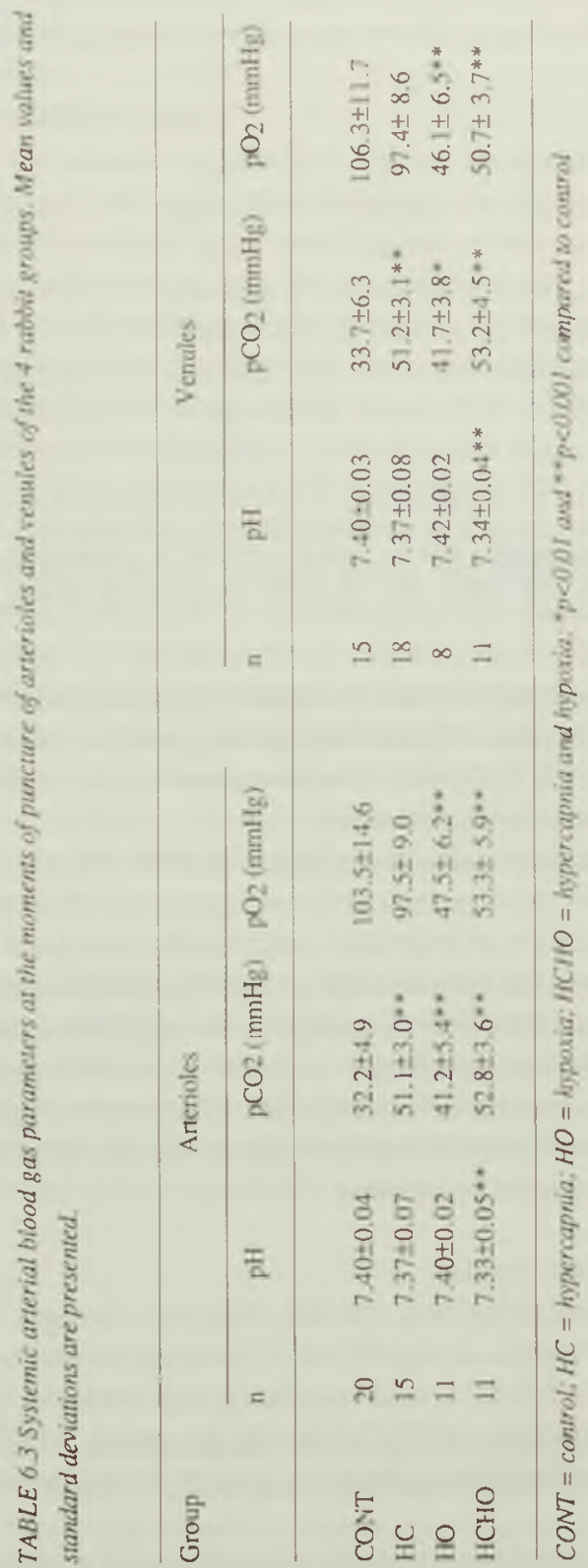




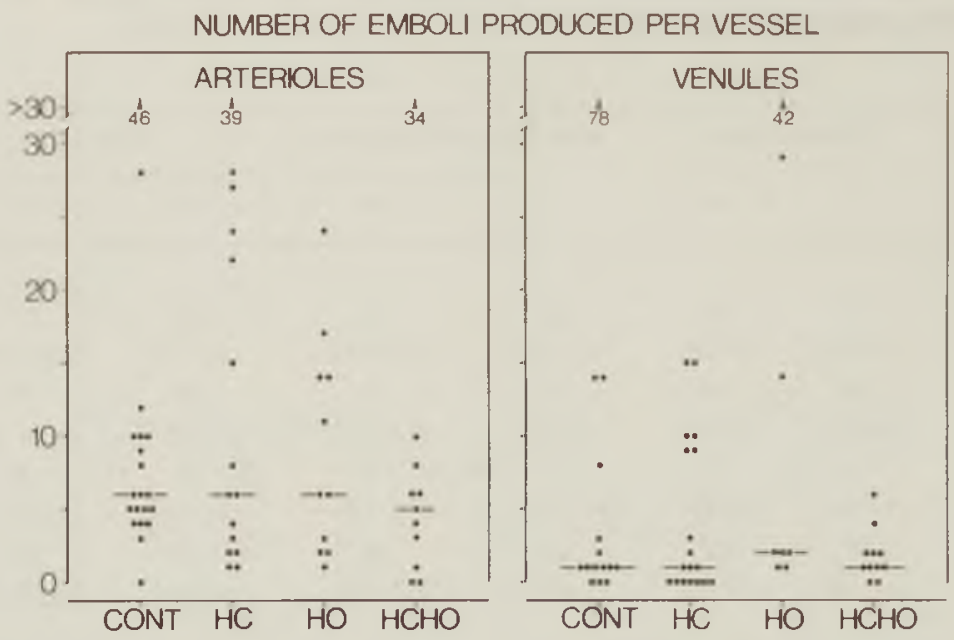

FIGURE 6.1 Number of emboli produced in the arterioles and yenules in the 4 rabbit groups. Horizontal bars indicate the median values per vessel group. Each arrow head represents one yessel, in which more than 30 emboli are produced, as is indicated by the concomitant numbers. $\mathrm{CONT}=$ control; $\mathrm{HC}=$ hypencapnia; $\mathrm{HO}=$ hypaxia; $\mathrm{HCHO}=$ hypercapnia + hypoxia .

arterioles (group medians 60-67\%) and venules (group medians 60-71\%).

In most vessels adhesion of circulating platelets to the downstream side of the thrombus and embolization of such downstream parts continued for a certain period of time. The size of the stationary part of the thrombus appeared to be rather constant. No differences in duration of the embolization period existed between arteriolar groups (group medians 75-179 s) or between venular groups (group medians 17-112s), although it tended to become slightly longer when blood gasses were changed from $\mathrm{CONT}$ to HCHO-values. The number of emboli produced in arterioles (group medians 5-6) and venules (group medians 1-2) during the embolization period were not affected by changes in blood gas values (Figure 6.1), notwithstanding a small decrease in the arteriolar reaction in the $\mathrm{HCHO}$-group.

The fact that changes in blood gas and $\mathrm{pH}$ values have only a marginal influence on the embolization duration and the number of emboli produced is also reflected in the absence of significant correlations between these parameters and the individual blood gas values, when all arteriolar or venular data were pooled.

The values of the fluid dynamic parameters in arterioles and venules of all groups are shown in Table 6.4. The diameters of the punctured arterioles and venules were not different. Mean RBC velocities and U-values were higher in arterioles than in venules, except for the HCHO-group. No differences were found in diameters, mean RBC velocities and $U$-values between the venules of the 4 groups. The same holds for the arterioles of the CONT, $\mathrm{HC}$ and HO-group. In the arterioles of the HCHO-group 
TABLE 6.4 Fluid dynamic parameters in the antrioles $(A)$ and venules (V) of the 4 rabbit groups. Median values and ranges are presented.

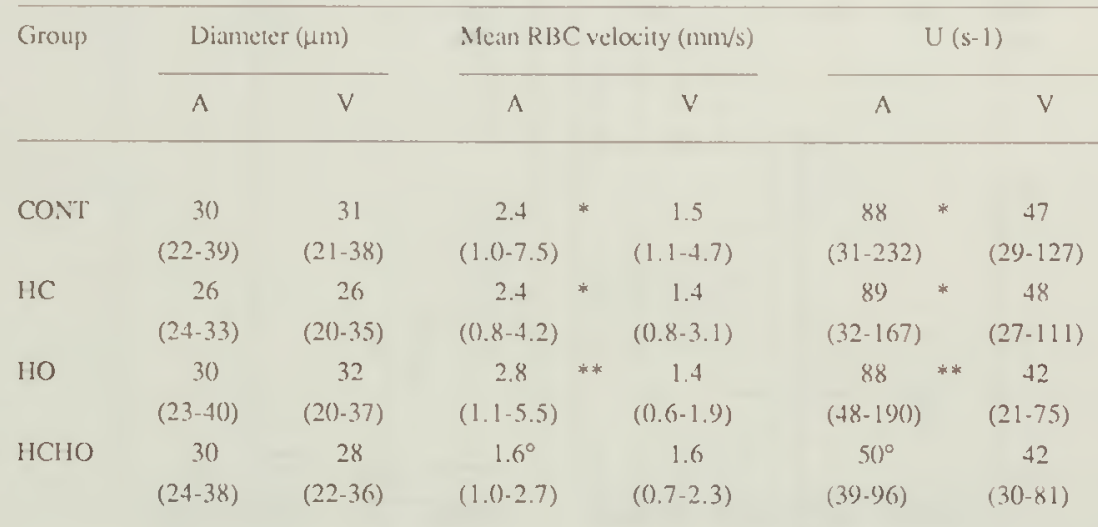

CONT = control; $H C=$ hypercapnia; $H O=$ hypaxia; $H C H O=$ hypercapnia and hypoxia; ${ }^{*} p \leq 0.05$ and ${ }^{* *} p \leq 0.01$ between arterioles and venules; ${ }^{\circ} p \leq 0.05$ compared to control

mean $\mathrm{RBC}$ velocities and U-values were significantly lower than in the CONT-arterioles. However, no significant correlation could be found between mean $\mathrm{RBC}$ velocities or $U$-values on the one hand and the embolization parameters on the other in any of the vessel groups.

\section{Embolus production time}

In contrast to the marginal influence of changes in blood gas and $\mathrm{pH}$ values on the total duration of embolization and the number of emboli produced, a change in blood gas and $\mathrm{pH}$ values did have a significant influence on the average time needed to produce a new embolus, as illustrated in Figure 6.2, in which the median embolus production time per vessel is shown. The median embolus production time per vessel was taken, instead of all individual time periods per embolus, to exclude the possibility that a vessel which produced for example 30 emboli would weigh 30 times more than a vessel which produced only one embolus. Consequently, vessels in which no embolus was produced following wall puncture (see Figure 6.1) are not included in the analysis and not shown in Figure 6.2. This procedure only slightly and similarly affected the number of vessels per group, except for the venules in the HC-group in which 7 of the 18 vessels were not included in the analysis. Beside from stochastic variation, this relatively high number of vessels without embolus production might have resulted from a specific influence of the high $\mathrm{pCO}_{2}$-values in these vessels. The time needed to produce a new embolus was significantly prolonged in the HCHO-group in arterioles as well as in venules (Figure 6.2), but not in the $\mathrm{HC}$ and HO-groups. Testing concomitant arteriolar and venular groups revealed no differences. No correlation was found be- 


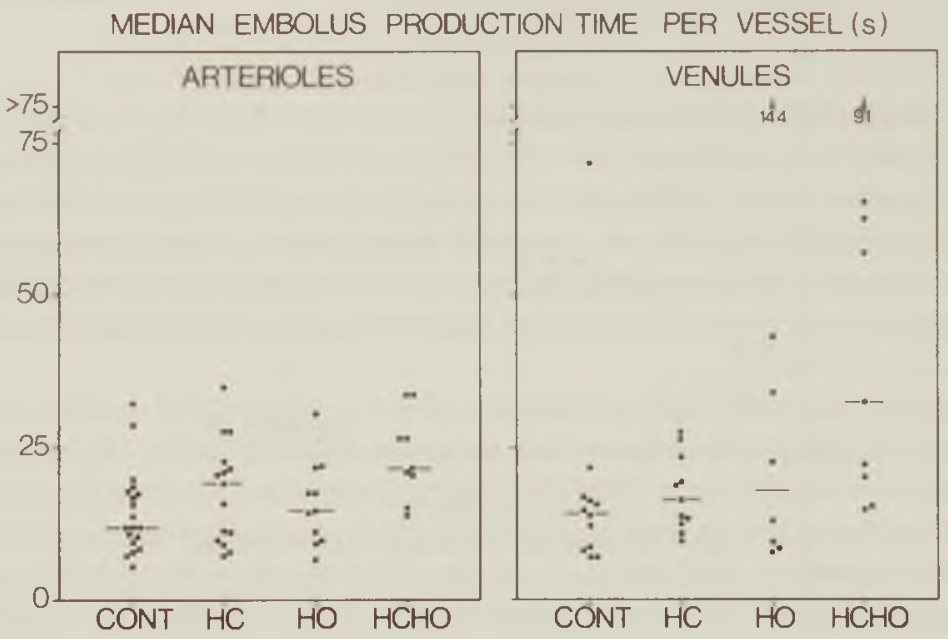

FIGURE 6.2 Median time period needed to produce a new embolus in the arterioles and venules of all rabbit groups. Horizontal bars indicate the median values per vessel group. Each arrow head represents one vessel, in which the median embolus production time was longer than $75 \mathrm{~s}$, as is indicated by the concomitant numbers. Vessels, in which no embolus was produced (see Figure 6.1), were deleted. CONT = control; $\mathrm{HC}=$ hypercapnia; $H O=$ hypaxia; $\mathrm{HCHO}=$ hypercapnia + hypoxia.

tween the time needed to produce a new embolus and $\mathrm{pH}$ or $\mathrm{pO}_{2}$. With $\mathrm{pCO}_{2}$, however, this correlation was significant, although the coefficients were low (arterioles: $r_{\mathrm{S}}=0.27$; venules: $\mathrm{r}_{\mathrm{S}}=0.37$ ).

\section{Thrombus growth pattern}

To investigate the cause of the prolongation in embolus production time in the vessels of the HCHO-group, the growth pattern of the thrombus was analyzed in arterioles and venules of the CONT ( 8 and 9 emboli-formations, respectively) and HCHO-groups (7 and 6 emboli-formations, respectively). Typical examples of the thrombus growth pattern in arterioles and venules in each group are shown in Figure 6.3. All surface area data were normalized to the surface area of the thrombus directly following embolization, because both first and subsequent emboli were taken into account. Part of each thrombus never embolized. Onto this "stationary" part new platelets adhered and from it platelet aggregates embolized. As is illustrated in Figure 6.3, the "stationary" part of the thrombus has a rather constant size during the entire period of embolization. The thrombus growth pattern was different in the vessels of the CONT-group and the vessels of the HCHO-group. In most arterioles and venules of the CONT-group thrombus growth continued till embolization, although not always at the same speed. In the HCHO-vessels, however, thrombus growth was less constant; it often stopped for certain periods of time. These "plateau-phases" in the growth pattern 

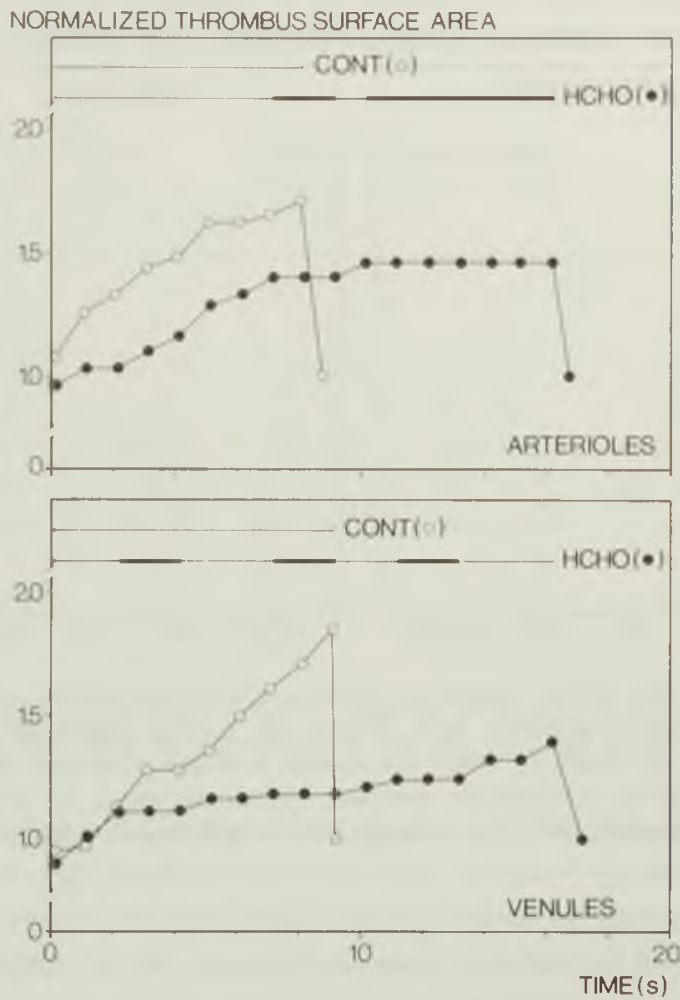

FIGURE 6.3 Typical examples of nomalized growth pattems of thrombi in arterioles and venules of the control (CONT) group and of the hypercapnic and hyporic (HCHO) group of rabbits. The bars added at the top of both figures show the time period needed for thrombus growth; the occurrence of "plateau-phases" is illustrated by thickenings in these bars.

of the thrombus, defined as a stop of growth for at least $2 \mathrm{~s}$, are also illustrated in Figure 6.3. "Plateau-phases" during thrombus growth occurred in the majority of the arterioles $(5 / 7)$ and venules (5/6) of the HCHO-group analyzed, up to a total fraction of the embolus production time per vessel ranging from 0.47 to 0.79 (mean 0.58 ) and from 0.28 to 0.59 (mean 0.39), respectively. In the CONT-vessels, however, "plateau-phases" occurred only in 3 of the 8 arterioles (fractions $0.16,0.26$ and 0.54 ) and in 2 of the 9 venules (fractions 0.09 and 0.20 ).

The final increase in normalized thrombus surface area tended to be higher in the CONT-vessels (medians arterioles: 1.8 and venules: 1.7) than in the HCHO-vessels (arterioles: 1.4 and venules: 1.4 ); only the arteriolar difference reached the level of statistical significance (Figure 6.3). 


\subsection{DISCUSSION}

In the present study changes in systemic blood gas and $\mathrm{pH}$ values did not influence the difference in thromboembolic reaction following vessel wall puncture between arterioles and venules, as indicated by the absence of an effect on the average number of emboli produced ( 6 and 1, respectively). However, in rabbits with hypercapnia and hypoxia the time needed to produce an embolus was significantly prolonged in both vessel types. This prolongation was largely caused by periods in which the thrombus did not grow.

The findings in the present study indicate that the difference in intravascular blood gas and $\mathrm{pH}$ values between arterioles and venules cannot explain the observed difference in thromboembolic reaction between both types of microvessels. Systemic arterial blood gas and $\mathrm{pH}$ values in the hypercapnic, hypoxic and combined hypercapnic/hypoxic rabbits were changed at least to values normally present in veins, which drain both the intestinal wall and the mesenteric tissue. The blood gas and $\mathrm{pH}$ values in these draining veins will reflect venular values, since only $1 \%$ or less of the intestinal blood flow passes through arteriovenous shunts (Lundgren, 1984). Because the intestine is metabolically more active than the mesentery, the values measured in the local veins represent "worst case" values with regard to the mesenteric venules. Therefore, the systemically induced changes in blood gas and $\mathrm{pH}$ values will have induced $\mathrm{pO}_{2}, \mathrm{pCO}_{2}$ and $\mathrm{pH}$ values in the mesenteric arterioles which are equal to or, more likely, even lower $\left(\mathrm{pO}_{2}\right.$ and $\left.\mathrm{pH}\right)$ or higher $\left(\mathrm{pCO}_{2}\right)$ than the values normally found in venules. The finding of Duling and Berne (1970) of transarteriolar oxygen loss, causing in arterioles of 20 to $40 \mu \mathrm{m} \mathrm{pO}$ values lower than systemic, further strengthens the supposition that the changes in systemic arterial $\mathrm{pO}_{2}$, as induced in the present study, have led to values in mesenteric arterioles comparable to, or lower than, those in venules in control situations. In addition, the finding that a change in systemic arterial $\mathrm{pO}_{2}$ was followed by a similar change in the $\mathrm{pO}_{2}$ of the draining veins, indicates that changes induced systemically were followed by similar changes along the whole vascular tree till at least the level of the draining veins.

Fluid dynamic conditions differed between the arterioles and the venules of all groups, with the exception of the group with combined hypercapnia and hypoxia. However, these differences between arterioles and venules are not responsible for the differences found in embolization behavior between both vessel types in any of the groups of the present study. When in these groups arterioles and venules, with the same mean RBC velocities and U-values, were compared, the number of emboli produced and the embolization duration were still different between both vessel types. The observation that differences in fluid dynamic factors cannot explain the differences in thromboembolic reaction between arterioles and venules, was under control conditions also found in previous studies (oude Egbrink et al, 1988; chapters 4 and 5). The finding that mean RBC velocities and $U$-values were lower in the arterioles of the rabbits with combined hypercapnia and hypoxia than in the arterioles of the control rabbits can also not ex- 
plain the difference in median embolus production time, as found between both vessel groups. In the control arterioles with mean $R B C$ velocities of $2.7 \mathrm{~mm} / \mathrm{s}$ or less $(n=12)$ vessel diameters, mean $\mathrm{RBC}$ velocities and $\mathrm{U}$-values did not differ from the values of these parameters in the arterioles of the rabbits with combined hypercapnia and hypoxia. When only these arterioles are considered the median embolus production time is still significantly shorter (10.2 s) than in the hypercapnic/hypoxic arterioles (21.5 s).

A possible explanation for the difference in thromboembolic reaction is a different thrombogenic or antithrombogenic activity of the vessel walls of arterioles and venules following injury. Because more and more differences are described between the endothelial properties of macro and microvessels and of the vessels in different organs (Gimbrone, 1981, 1986), it is conceivable that functional differences exist between arteriolar and venular endothelium within one organ. Also, the role of leukocytes cannot be excluded. In venules, but not in arterioles, leukocytes often roll along the wall, moving at a distinctly slower velocity than the other blood cells, and sometimes adhere to it. The release of such substances as prostacyclin (Mehta et al, 1985) from these leukocytes, if any, resulting in a relatively high concentration of this substance along the vessel wall, could influence platelet behavior, and, hence, diminish thromboembolic activity, in the venules. Prostacyclin, after all, is one of the most effective inhibitors of platelet aggregation (Moncada, 1982).

Variation in thrombogenic/antithrombogenic activity of the damaged vessel wall might explain the scatter as found in the data shown in Figure 6.1. The finding, that systemic platelet counts, systemic hematocrit, rheological parameters and blood gas and $\mathrm{pH}$ values do not correlate with the number of emboli produced per vessel, indicates that this scatter is not caused by these factors. The observation, that in the majority ( 9 out of 16) of the vessels which produced 15 emboli or more thrombus growth was so pronounced that the blood stream was hampered repeatedly, supports the above mentioned hypothesis.

The finding that the average time needed to produce a new embolus was significantly prolonged in arterioles and venules of rabbits with hypercapnia and hypoxia, mainly as a consequence of periods in which the thrombus did not grow, indicates that the adhesion and aggregation of new platelets to a thrombus is hampered in a hypoxic, hypercapnic and nore acid milieu. This may result from an effect on the platelets, the vessel wall or both. in vitro studies showed that platelet aggregation increases with a decreasing $\mathrm{pCO}_{2}$ and an increasing $\mathrm{pH}$ (Flatow and Freireich, 1966; Kikugawa et al, 1972; Rogers, 1972; Goldschmidt, 1973; Tang and Frojmovic, 1977; Kennedy et al, 1981 and Vermijlen et al, 1986). Although most of these in vitro studies have been performed in a different blood gas and $\mathrm{pH}$ range than the present investigation, the results are in agreement with our findings. The finding of Kennedy and coworkers (1981), however, that greater aggregates were formed by rat platelets with decreasing $\mathrm{pO}_{2}$, does not agree with our in vivo results.

Beside an effect on the platelets themselves, changes in blood gas values and $\mathrm{pH}$ could also cause functional changes in arteriolar and venular vessel walls. For example, from a macrocirculatory study of Busse and coworkers (1984) it is known that hypoxia 
can lead to an increase in the release of prostacyclin from arterial endothelial cells. Adenosine was also found to be produced in greater quantities in reaction to hypoxia, in coronary endothelial cells (Deussen $e t$ al, 1986). Like prostacyclin, adenosine is an inhibitor of platelet aggregation (Born and Cross, 1963). However, these data are the result of macrocirculatory investigations and it is not at all certain that these mechanisms are also involved in processes at the arteriolar and venular level. Nevertheless, they suggest that changes in $\mathrm{pO}_{2}$ might influence microvessel wall function.

In contrast to the effect of blood gas and $\mathrm{pH}$ values on the growth pattern of thrombi between two embolizations, there is no effect on the initial reaction following wall puncture. The number of RBCs leaving the punctured vessel, the duration of the bleeding period and also the initial thrombus formation are not affected. The initial thrombogenic stimulus, as created by puncture, is probably so strong that it cannot be easily influenced.

In conclusion, under the influence of hypoxia and hypercapnia adhesion and aggregation of blood platelets to a thrombus, leading to thrombus growth and embolization, appears to be hampered. These changes in blood gas and $\mathrm{pH}$ values do not change the number of emboli produced in arterioles or venules following wall puncture. Therefore, the observed difference in thromboembolic reaction between arterioles and venules cannot be explained by intravascular differences in blood gas and $\mathrm{pH}$ values between these microvessels.

\subsection{SUMMARY}

The influence of changes in systemic blood gas and $\mathrm{pH}$ values on the thromboembolic reaction following wall puncture was studied in rabbit mesenteric arterioles and venules (diameter 20-40 $\mu \mathrm{m}$ ), using intravital videomicroscopy. Under normal circumstances the number of emboli produced was higher in arterioles than in venules ( 6 and 1 , respectively). The initial thrombus growth, the number of emboli produced per vessel and the total duration of the embolization period were not significantly influenced by changes in blood gas and $\mathrm{pH}$ values in both arterioles and venules. Therefore, the observed difference in thromboembolic reaction between arterioles and venules cannot be explained by differences in blood gas and $\mathrm{pH}$ values in these microvessels. Since reduced velocity, as a measure of wall shear rate, did not correlate with the thromboembolic reaction in arterioles or venules, fluid dynamics can also not explain the difference, indicating that the thrombogenic or antithrombogenic activity of arteriolar and venular walls differs following injury. A combination of hypercapnia and hypoxia was found to result in a prolongation of the average time period needed to produce a new embolus in both vessel types. This prolongation in embolus production time was largely due to the occurrence of periods, in which the thrombus did not grow, reflecting hampering of the adhesion and aggregation of blood platelets to a growing thrombus under hypercapnic/hypoxic conditions. 


\section{INFLUENCE OF HYPERCAPNIA AND HYPOXIA ON RABBIT PLATELET AGGREGATION}

\subsection{INTRODUCTION}

In rabbit microvessels a combination of systemic hypercapnia and hypoxia hampers thrombus growth and embolization (oude Egbrink et al, 1989; chapter 6), as induced by vessel wall puncture with a micropipet (oude Egbrink et al, 1988; chapter 4). It is unknown whether this retardation is caused by an effect on the platelets, the vessel wall or both.

Knowledge of the effect of hypercapnia and, hence, acidosis, and hypoxia on the behavior of blood platelets following activation with substances, which play a role in thrombus formation following vessel wall damage in vivo, is scarce. Most of the studies presently available focus on the effects of changes in $\mathrm{pH}$ alone or on the effects of storage of platelet rich plasma (PRP) open to air, resulting in hypocapnic and, hence, alkalotic conditions (Flatow and Freireich, 1966; Skoza et al, 1967; Kikugawa et al, 1972; Rogers, 1972; Zucker, 1972; Han and Ardlie, 1974; Tang and Frojmovic, 1977; Watts et al, 1983; Vermijlen et al, 1986). The effects of changes in $\mathrm{pO}_{2}$ on platelet behavior have not been investigated in a systematic way. The only study concentrating on the combined effects of hypercapnia and hypoxia on platelet aggregation, albeit in rats and not in rabbits (Kennedy et al, 1981), revealed that the effects of changes in $\mathrm{pCO}_{2}$ and $\mathrm{pH}$ on platelet aggregation were subordinate to the aggregation stimulating effect of a decrease in $\mathrm{pO}_{2}$. An additional problem is that often only adenosine diphosphate (ADP) is used as aggregating agent, although in platelet reactions following vessel wall injury in vivo other substances, like collagen and thrombin, are likely to be involved as well.

The purpose of the present study was to investigate the effects of changes in $\mathrm{pCO}_{2}$, $\mathrm{pH}$ and $\mathrm{pO}_{2}$ on the aggregation of rabbit blood platelets in vitro, with emphasis on the changes induced by hypercapnia, acidosis and hypoxia. Aggregation tests were perfor- 
med in PRP, in which no hemoglobin is available to act as a buffer. Therefore, the relation between $\mathrm{pCO}_{2}$ and $\mathrm{pH}$, and the starting values of these parameters were not always the same as in the in vivo situation. Platelet aggregation was not only induced by ADP, but also by collagen, thrombin, serotonin and adrenaline, since all these agonists are likely to play a role in the platelet reaction to vessel wall injury in vivo. The aggregation data were analyzed in a quantitative way and included the influence of the time elapsed between collection of blood and performance of the aggregation test, because this time interval may influence platelet aggregation (Warlow et al, 1974).

\subsection{MATERIALS AND METHODS}

Blood was collected from central ear arteries of unanesthetized rabbits in $3.13 \%$ trisodium citrate $(0.1 \mathrm{vol} ; 110 \mathrm{mM})$, using $18 \mathrm{G}$ needles and allowing the blood to flow out freely. The first drops were discarded. To prepare PRP, the blood was centrifuged $(180 \mathrm{~g})$ at room temperature during 15 minutes. Electronic platelet counts were performed with a Coulter Counter (model ZF). The PRP was adjusted to a platelet count of $300.000 / 1$ with platelet poor plasma and was subsequently stored at room temperature in a closed volume with $95 \% \mathrm{~N}_{2}$ and $5 \% \mathrm{CO}_{2}$, to control gas tensions. The time interval between blood collection and start of the aggregation test ranged from 60 to 180 minutes.

Aggregation was measured photometrically (Born, 1962), using a Payton Dual Channel Aggregation Module $\left(37^{\circ} \mathrm{C}\right)$ connected to a strip chart recorder (BD40, Kipp en Zonen, or PM 8252, Philips). Beiore each aggregation test a sample of PRP (0.45 $\mathrm{ml}$ ) was preincubated with Tris-saline $(0.05 \mathrm{ml}, \mathrm{pH} 7.4 ; 0.1 \mathrm{vol} 100 \mathrm{mM}$ Tris, 0.9 vol 154 $\mathrm{mM} \mathrm{NaCl}$ ) at $37^{\circ} \mathrm{C}$ in a siliconized cuvette during 5 minutes. For calibration the level of light transmission through the preincubated PRP, continuously mixed with a magnetic stir bar (1100 RPM), was taken as $0 \%$ transmission and the level of light transmission through platelet free plasma as $100 \%$ transmission. Subsequently, aggregation was induced by adding $5 \mu \mathrm{l}$ of one of the following solutions (kept at $0^{\circ} \mathrm{C}$ ): ADP (Sigma, St. Louis, USA), dissolved in saline (154 $\mathrm{mM} \mathrm{NaCl}$ ), resulting in a final concentration in the PRP of 2-20 $\mu$ M; collagen (Horm, Hormon-Chemie, München, FRG), final concentration 4-6 $\mu \mathrm{g} / \mathrm{ml}$; bovine thrombin (kindly provided by Dr. E. Bevers, Dept. of Biochemistry), dissolved in Tris-saline containing human serum albumin (50 mM Tris, 175 $\mathrm{mM} \mathrm{NaCl}$ and $0.5 \mathrm{mg} / \mathrm{ml} \mathrm{HSA}$ ), final concentration 10-24 nM; serotonin (5-hydroxy tryptamine-creatinine sulfate; Serva, Heidelberg, FRG), dissolved in ice-cold Tris-saline $(0.1 \mathrm{vol} 100 \mathrm{mM}$ Tris, $0.9 \mathrm{vol} 154 \mathrm{mM} \mathrm{NaCl})$, final concentration $20 \mu \mathrm{M}$; and adrenaline (Sigma, St. Louis, USA), dissolved in saline, final concentration $200-600 \mu \mathrm{M}$. In each experiment the blood of one rabbit was used and 4 to 11 aggregation tests were performed at different gas tensions with only one agent, always at the same concentration. Because of the differences in platelet sensitivity between animals, at the beginning of each experiment the concentration of the agent, yielding a sub-maximal (70-90\%) 


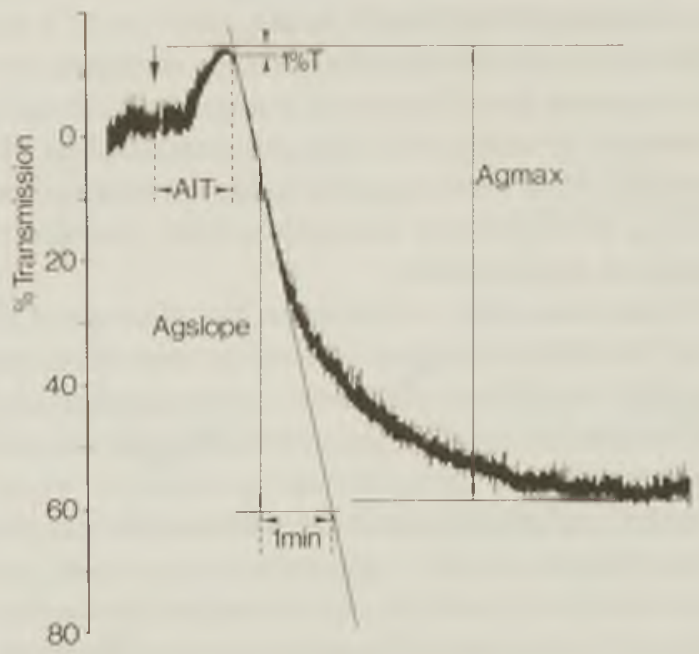

FIGURE 7.1 Tracing of collagen induced aggregation, showing the parameters ised for quantification. Agmax = maximal degree of aggregation; Agslope = maximal rate of aggregation; A.I.T. = aggregation induction time.

aggregation response at normal gas tensions, was determined. This was the concentration used in the experiment. In some experiments serotonin (final concentration of 20 $\mu \mathrm{M}$ ) was added to the PRP together with ADP or collagen, to investigate whether synergistic activation occurs and whether aggregation induced by two activators is influenced by changes in $\mathrm{pCO}_{2}, \mathrm{pH}$ and $\mathrm{pO}_{2}$.

An example of a tracing of collagen induced aggregation with the parameters used for quantification is shown in Figure 7.1. Following addition of an agent an initial decrease in light transmission, due to shape change of the activated platelets, occurs, followed by an increase in light transmission, representing the aggregation process, until a plateau is reached; desaggregation may follow. Quantification of these tracings was performed by measuring the maximal increase in light transmission from the peak of shape change to the highest transmission level (Agmax; $\Delta \% \mathrm{~T}$ ) and the maximal rate of aggregation, i.e. the steepest slope of the aggregation curve, expressed as the maximal increase in light transmission per minute (Agslope; $\Delta \% \mathrm{~T} / \mathrm{min}$ ). When aggregation was induced by collagen, we also measured the aggregation induction time (A.I.T.), being the time elapsing between collagen addition and the increase in transmission by $1 \%$ after the curve had passed through the shape change peak (see Figure 7.1).

To study the effect of different $\mathrm{pCO}_{2}, \mathrm{pH}$ and $\mathrm{pO}_{2}$ values, in each experiment samples of PRP were stored in a closed volume with gas mixtures of different composition during at least 15 minutes before the aggregation test. During the aggregation test itself the cuvettes were covered with rubber corks to prevent drifts in gas tensions. At the end of each test $\mathrm{pCO}_{2}, \mathrm{pH}$ and $\mathrm{pO}_{2}$ in the PRP sample were measured with an 
acid-base analyzer (ABL3, Radiometer) at $37^{\circ} \mathrm{C}$. Aggregation was tested over the following ranges in gas tensions: $\mathrm{pCO}_{2} 15$ to $75 \mathrm{mmHg}, \mathrm{pH} 7.6$ to 7.0 and $\mathrm{pO}_{2} 130$ to 50 $\mathrm{mmHg}$. $\mathrm{pCO}_{2}$ and $\mathrm{pH}$ values were found to be strongly correlated $(\mathrm{r}=-0.91 ; n=152)$.

In an attempt to separate the influences of changes in $\mathrm{pCO}_{2}$ and $\mathrm{pH}$, in some experiments $\mathrm{pH}$ was changed by adding $\mathrm{HCl}$ (final concentration in PRP: 0.5-5.0 mM) rather than by changing $\mathrm{pCO}_{2}$. However, again a strong correlation between $\mathrm{pCO}_{2}$ and $\mathrm{pH}$ was found $(\mathrm{r}=-0.71)$, so that also in this experimental situation the influences of $\mathrm{pCO}_{2}$ and $\mathrm{pH}$ could not be distinguished.

Analysis of covariance was used to determine the influence of changes in $\mathrm{pCO}_{2}$, $\mathrm{pH}$ and $\mathrm{pO}_{2}$ and of the duration of the time interval between blood collection and aggregation test (independent variables or covariates) on the aggregation parameters (dependent variables). Dependence on $\mathrm{pCO}_{2}$ and $\mathrm{pH}$ was always analyzed independently, because of their strong correlation. Data-sets were grouped per experiment. Because of the number of variables used in the analysis of covariance, the experiments were only analyzed, when per experiment at least 4 aggregation tests could be performed with different combinations of $\mathrm{pH}_{2} \mathrm{pCO}_{2}$ and $\mathrm{pO}_{2}$. In the analysis the regression coefficients, representing the effects of the independent variables on the dependent variables, of all experiments were tested for equality. When these coefficients were not significantly different from each other, the overall regression coefficients were determined (see Table 7.1).

\subsection{RESULTS}

Over the total ranges of gas tensions used, ADP, collagen and thrombin always induced monophasic aggregation responses, even at the highest doses used. Figure 7.2 shows typical examples of such aggregation tracings and illustrates the influence of changes in $\mathrm{pCO}_{2}, \mathrm{pH}$ and $\mathrm{pO}_{2}$. Figure 7.3 summarizes the effects of changes in $\mathrm{pH}$ and gas tension values on the aggregation parameters, depicted in Figure 7.1. Only effects that were found to be significant in the analysis of covariance are shown in Figure 7.3. All regression coefficients with their levels of significance are presented in Table 7.1. In contrast to ADP, collagen and thrombin, addition of adrenaline did not result in a measurable response, while serotonin only induced a decrease in light transmission, indicating shape change of the platelets.

$\mathrm{ADP}$ induced aggregation decreased with increasing $\mathrm{pCO}_{2}$ and decreasing $\mathrm{pH}$ values (Figures 7.2 and 7.3). This effect was found to be significant for the degree of aggregation (Agmax) as well as the rate of aggregation (Agslope). Changes in $\mathrm{pO}_{2}$ did not influence ADP induced aggregation (Table 7.1).

Aggregation induced by collagen also decreased in degree (Agmax) and rate (Agslope) with increasing $\mathrm{pCO}_{2}$ and concomitantly decreasing $\mathrm{pH}$ values (Figures 7.2 and 7.3). As illustrated by the steepness of the slopes in Figure 7.3 the effect of changes in $\mathrm{pCO}_{2}$ and $\mathrm{pH}$ is likely to be more pronounced with collagen than with ADP. The A.I.T. 
ADP INDUCED AGGREGATION
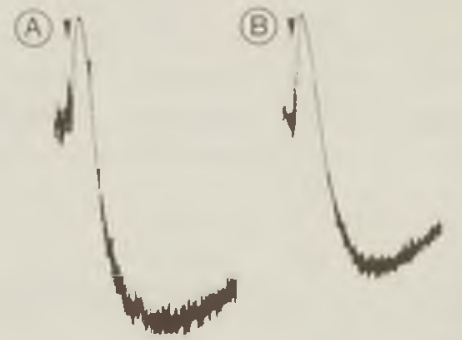

(A) Agmax : 58\%

Agslope $98 \% / \mathrm{min}$

$\mathrm{pH} \quad 7.59$

$\mathrm{pCO}_{2} \quad 18.9 \mathrm{mmHg}$

(B) Agmax : $51 \%$

Agslope: $88 \% / \mathrm{min}$

$\mathrm{pH}: 7.27$

$\mathrm{pCO}_{2} \quad 436 \mathrm{mmHg}$

\section{COLLAGEN INDUCED AGGREGATION}
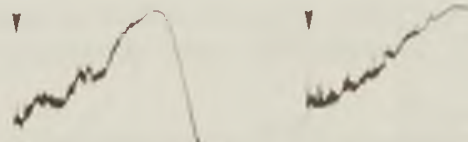

AIT

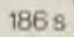

AIT

$207 \mathrm{~s}$

Agmax

$97 \%$

Agmax : $79 \%$

Agstope: $75 \% / m i n$

Agslope: $59 \% / \mathrm{min}$

$\mathrm{pH}: 7.43$

$\mathrm{pCO}_{2} \quad: 29.0 \mathrm{mmHg}$

$\mathrm{pH} \quad: \quad 7.15$

$\mathrm{pCO}_{2}: 61.0 \mathrm{mmHg}$

THROMBIN INDUCED AGGREGATION
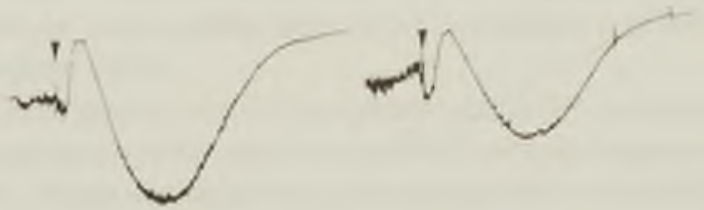

Agmax : $29 \%$

Agmax : $19 \%$

Agslope: $41 \% / \mathrm{min}$

Agshope: $23 \% / m i n$

$\begin{array}{l:c}\mathrm{pH} & 7.48 \\ \mathrm{pCO}_{2} & : 23.4 \mathrm{mmHg} \\ \mathrm{pO}_{2} & : 83.6 \mathrm{mmHg}\end{array}$

$\mathrm{pH}: 7.41$

$\mathrm{pCO}_{2} \quad: 28.3 \mathrm{mmHg}$

$\mathrm{pO}_{2}: 60.9 \mathrm{mmHg}$

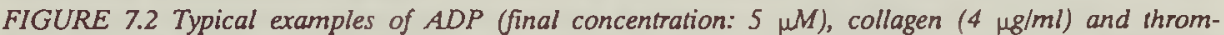
bin (10 nM) induced aggregation, respectively, at various $p H$ and gas tension values. $p \mathrm{CO}_{z} p H$ and $\mathrm{pO}_{2}$ values are given only when they had a significant influence (see Table 7.1). Arrowheads indicate the moments of addition of the agent to the PRP. 

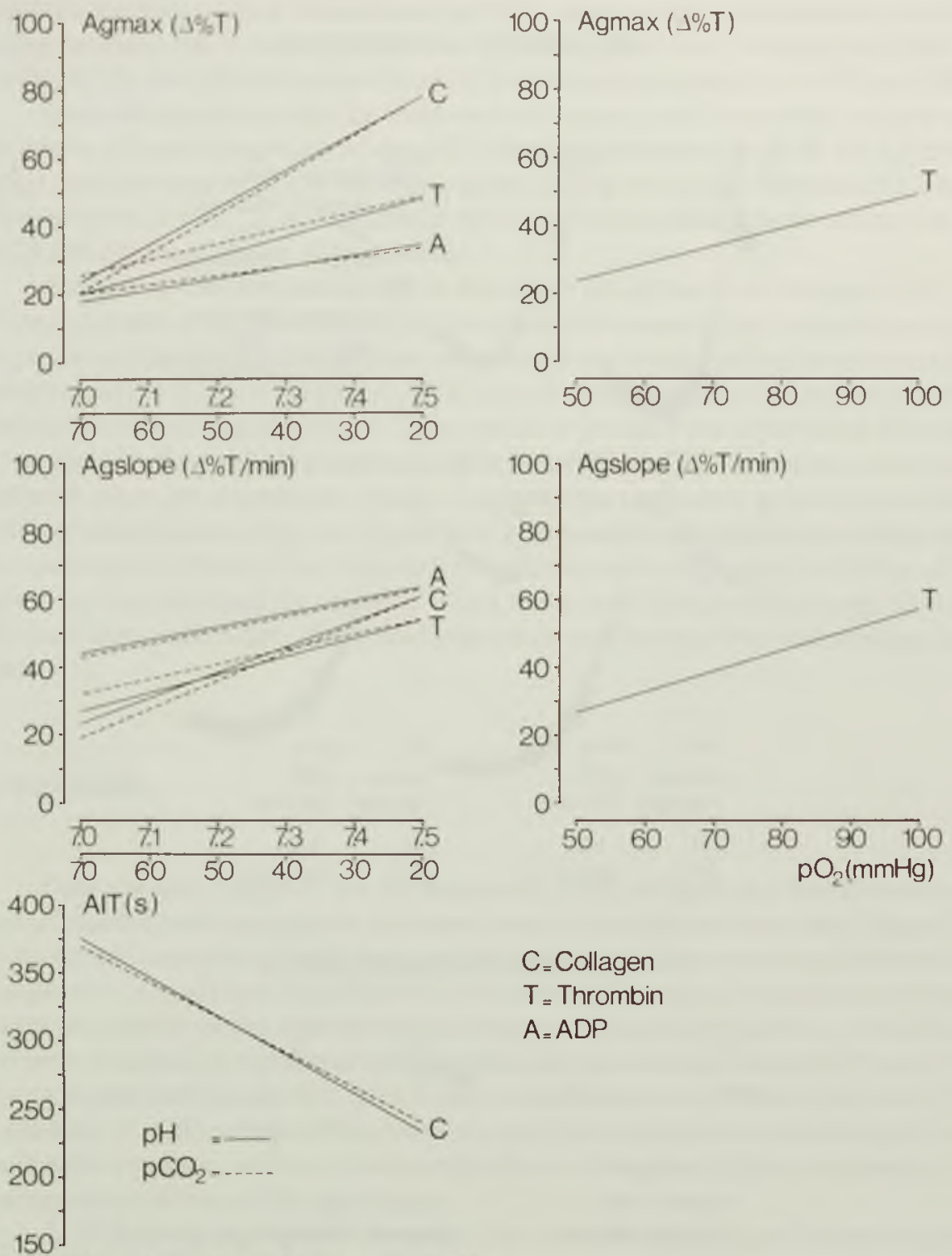

$\mathrm{C}=$ Collagen

$\mathrm{T}=$ Thrombin

$A=A D P$

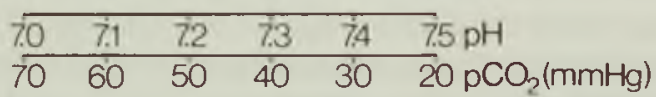

FIGURE 7.3 Relations between $\mathrm{pCO}_{2} \quad \mathrm{pH}$ and $\mathrm{pO}_{2}$ and the aggregation parameters (see Figure 7.1), as based on the results of the analysis of covariance. Only relations that were found to be significant are shown (see Table 7.1). Linear relations are drawn through the means of both $p \mathrm{CO}_{2} / \mathrm{pH}$ or $\mathrm{pO}_{2}$ and aggregation parameters. The effects of $\mathrm{pCO}_{2}$ (dashed lines) and $\mathrm{pH}$ (solid lines) are shown in the same graphs because of their strong correlation $(r=-0.91)$. 
TABLE 7.1 Regression coefficients of the linear relation between aggregation parameters (see Figure 7.1) and time, $\mathrm{pCO}_{3} \mathrm{pH}$ and $\mathrm{pO}_{3}$ respectively, as found with analysis of covariance.

\begin{tabular}{|c|c|c|c|c|c|c|c|}
\hline \multirow[b]{2}{*}{ Covariates } & \multicolumn{2}{|c|}{$\mathrm{ADP}(n=55)$} & \multicolumn{3}{|c|}{ Colligen $(n=46)$} & \multicolumn{2}{|c|}{ Thrombin $(n=3())$} \\
\hline & $\begin{array}{l}\text { Agmax } \\
\left(\Delta \%^{\prime}{ }^{\prime}\right)\end{array}$ & $\begin{array}{l}\text { Agslope } \\
\text { ( } \triangle \% \mathrm{~T} / \mathrm{min})\end{array}$ & $\begin{array}{l}\text { Agnา:เx } \\
(\triangle \% \mathrm{~T})\end{array}$ & $\begin{array}{l}\text { Agslope } \\
\text { ( } \triangle \% T / m i n)\end{array}$ & $\begin{array}{l}\text { A.I.T. } \\
\text { (s) }\end{array}$ & $\begin{array}{l}\text { Agmax } \\
(\Delta \% \mathrm{~T})\end{array}$ & $\begin{array}{l}\text { Agslope } \\
\text { ( } \triangle \% T / \text { min) }\end{array}$ \\
\hline Time (min) & $-0.13 * * *$ & $-0.20 * *$ & $-0.5 l^{* *}$ & $-0.44^{* *}$ & $1.13^{*}$ & $-0.4 .3 * *$ & -0.26 \\
\hline $\mathrm{pCO}_{2}(\mathrm{~mm} / \mathrm{gg})^{l}$ & - () $27 * * *$ & -(). $.34^{* *}$ & $-1.1 .5^{* *}$ & $-0.82 * *$ & $2.61^{*}$ & $-0.46 *$ & $-0.42^{*}$ \\
\hline$p l^{l}$ & $32.700^{* * *}$ & $39.56 * *$ & $107.90^{*}$ & $72.90^{*}$ & $-287.30 *$ & $56.90 *$ & $53.70^{*}$ \\
\hline $\mathrm{pO}_{2}(\mathrm{~mm} / \mathrm{lg})$ & 0.01 & 0.07 & -0.27 & -0.12 & 0.51 & $0.49 * *$ & $0.59 * *$ \\
\hline
\end{tabular}

${ }^{1}$ Because of their strong correlation $(r=-0.91), \mathrm{pCO}_{2}$ and $\mathrm{pH}$ values were separated during analysis; $n$ is number of data-sets; levels of significance: " $p \leq 0.05 ; " * p \leq 0.01 ;{ }^{* *} p \leq 0.001$

increased, when $\mathrm{pCO}_{2}$ increased and $\mathrm{pH}$ decreased. Again, $\mathrm{pO}_{2}$-changes had no effect (Table 7.1).

In contrast to ADP and collagen induced aggregation, aggregation induced by thrombin was influenced by changes in $\mathrm{pO}_{2}$, as is shown in Figures 7.2 and 7.3. Agmax as well as Agslope decreased with decreasing $\mathrm{pO}_{2}$. Increases in $\mathrm{pCO}_{2}$ with concomitant decreases in $\mathrm{pH}$ also significantly decreased the degree (Agmax) and rate ( $\mathrm{Ag}$ slope) of thrombin induced aggregation (Figures 7.2 and 7.3), the slopes in Figure 7.3 being intermediate between the slopes with collagen and ADP.

Both the degree of aggregation (Agmax) and the rate of aggregation (as reflected in Agslope and A.I.T.) decreased significantly with time, except for the rate of thrombin induced aggregation (Table 7.1). It should be noted, however, that by factoring the influence of time into the analysis of covariance, the relationships between the gas tensions or $\mathrm{pH}$ on the one hand and the aggregation parameters on the other hand are independent of this time effect.

Addition of serotonin to the PRP together with $\mathrm{ADP}$ or collagen always resulted in an increased aggregation response, as compared with the response induced by ADP or collagen alone. When serotonin was added together with ADP, both the degree (Agmax) and rate (Agslope) of aggregation increased by a factor of about 1.5, while the rate of desaggregation appeared to decrease, as is illustrated in Figure 7.4. Addition of serotonin together with collagen resulted in a considerable increase of in particular the velocity of aggregation (as reflected in Agslope and A.I.T.). The increased aggregation response, as induced by serotonin in combination with $\mathrm{ADP}$ or collagen, appeared to be equally sensitive to changes in $\mathrm{pCO}_{2}$ and $\mathrm{pH}$ values as the response induced by $\mathrm{ADP}$ or collagen alone, as is illustrated for ADP in Figure 7.4. No effect of changes in $\mathrm{pO}_{2}$ were noted. 

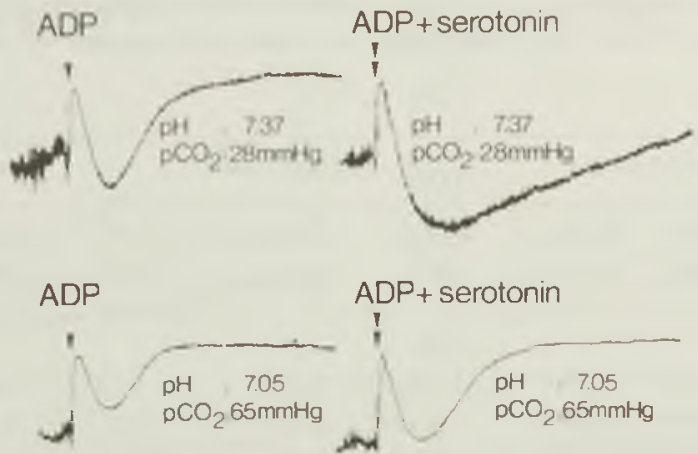

FIGURE 7.4 Effect of the addition of serotonin ( $20 \mu M$; right panels) on ADP induced aggregation (left panels). The differences between the upper and lower tracings illustrate the effects of differences in $\mathrm{pCO}_{2}$ and $\mathrm{pH}$.

\subsection{DISCUSSION}

The present study shows that hypercapnia and acidosis cause a reduction in rabbit platelet aggregation, as induced by collagen, thrombin and ADP, the influence being most pronounced with collagen and smallest with ADP. In contrast, hypoxia only influences thrombin induced aggregation. Serotonin and adrenaline do not induce aggregation of rabbit blood platelets, although serotonin potentiates aggregation induced by ADP and collagen. The amplification due to serotonin seems to be equally sensitive to $\mathrm{pCO}_{2}$ and $\mathrm{pH}$ changes as the response induced by the substances alone.

Collagen, thrombin and ADP were found to induce monophasic aggregation responses. In contrast to human platelets, rabbit platelets never show a biphasic aggregation reaction (Kinlough-Rathbone et al, 1977a; Dodds, 1978).

In the present study, the time interval between collection of blood and performance of the aggregation test was factored into the statistical analysis. Therefore, the relationships found between gas tensions or $\mathrm{pH}$ and aggregation parameters are independent of the influence of time. Although the influence of time on platelet aggregation has been known for quite a while (Warlow et al, 1974), most earlier studies did not take this complicating factor into consideration.

\section{$\mathrm{pO}_{2}$ effect}

Changes in $\mathrm{pO}_{2}$ towards hypoxic values were found to have a decreasing effect on thrombin induced aggregation, but not on ADP and collagen induced aggregation. To our best knowledge, this phenomenon has not been published in literature before and needs further investigation. Unstimulated platelets have a steady $\mathrm{O}_{2}$ consumption, which rapidly increases upon stimulation with high doses of thrombin (Akkerman, 
1986). This extra $\mathrm{O}_{2}$ uptake is mainly used for arachidonic acid metabolism (Akkerman, 1986), which may contribute to platelet aggregation by the production of thromboxane $\mathrm{A}_{2}$. Assuming that this mechanism also holds with the thrombin doses used in the present study, which are 20 to $40 \%$ of the dose used by Akkerman (1986), the low external $\mathrm{pO}_{2}$ values could have reduced the platelet reactions because of a suppression of the arachidonic acid pathway. However, the finding that hypoxic conditions did not influence collagen induced aggregation, which also involves the arachidonic acid pathway (Kinlough-Rathbone et al, 1977b), makes this explanation unlikely.

In the present study no effect of hypoxia on rabbit platelet aggregation, as induced by ADP and collagen, is found. In contrast, Watts and coworkers (1985) found a decrease in aggregation response of human platelets to collagen with decreasing $\mathrm{pO}_{2}$ values, although the release reaction was not influenced. Kennedy and his group (1981) found an increase in rat platelet aggregation induced by $\mathrm{ADP}$ with a decrease in $\mathrm{pO}_{2}$, by measuring mean size and total volume of platelet aggregates with an electronic particle counter. Differences in species may have been an important cause of the discrepancies between the latter two studies and the present study.

\section{$\mathrm{pH} / \mathrm{pCO} 2$ effect}

The effects of hypercapnia and acidosis on platelet aggregation induced by ADP, which is a relatively weak agonist (see also Holmsen, 1977), are small as compared to the effects on collagen and thrombin induced aggregation. Although collagen and thrombin probably play an important role in platelet-vessel wall interactions following vessel wall injury in vivo, the effects of changes in $\mathrm{pCO}_{2}$ and $\mathrm{pH}$ values on aggregation induced by these substances have not been studied in detail before. The finding in the present study that collagen induced aggregation of rabbit platelets decreased when $\mathrm{pH}$ decreased is in agreement with the finding of Watts and coworkers (1983) on collagen induced aggregation of human platelets. However, our finding that thrombin induced aggregation also decreased with $\mathrm{pH}$ differs from the observation of Han and Ardlie (1974). These investigators found human platelet aggregation, as induced by thrombin, to increase when $\mathrm{pH}$ decreased. Species differences might be the reason for this latter discrepancy.

The finding that $\mathrm{ADP}$ induced aggregation of rabbit platelets is inhibited only weakly by hypercapnia and acidosis is in disagreement with the finding of Kikugawa and colleagues (1972). These investigators found the ADP induced aggregation of rabbit platelets to decrease clearly with decreasing $\mathrm{pH}$ within the same $\mathrm{pH}$ range as in the present study. This discrepancy can likely be explained by the fact that Kikugawa and colleagues (1972) used higher citrate concentrations to anticoagulate the blood following collection. Higher citrate concentrations, after all, were found to amplify the effects of a decreasing pH on ADP induced platelet aggregation (Tang and Frojmovic, 1977). The results of the studies with human platelets are conflicting. In most of these studies on ADP induced aggregation a positive relation was found between $\mathrm{pH}$ values and aggregation in the $\mathrm{pH}$ range, as used in the present study (Flatow and Freireich, 1966; Skoza et al, 1967; Zucker, 1972; Watts et al, 1983). Others found aggregation to be in- 
sensitive to changes in $\mathrm{pH}$ (Rogers, 1972; Tang and Frojmovic, 1977) or even to increase with decreasing $\mathrm{pH}$ (Han and Ardlie, 1974). The cause of this discrepancy is unknown.

The mechanism by which platelet aggregation is influenced by changes in $\mathrm{pCO}_{2}$ and $\mathrm{pH}$ is not yet elucidated. Lamberth and coworkers (1974) proposed that $\mathrm{pH}$ is the important variable. Stimulation of human platelets by substances as thrombin induces a rapid alkalinization of the cytoplasm (Horne $e t$ al, 1981), which seems to be essential for further activation (Kitagawa et al, 1987). The cytoplasmic alkalinization seems to result from a stimulus provoked $\mathrm{Na}^{+} / \mathrm{H}^{+}$exchange (Sweatt et al, 1986). This $\mathrm{Na}^{+} / \mathrm{H}^{+}$ exchange has been proposed to regulate platelet aggregation and dense granule secretion by modulating arachidonic acid mobilization in response to agonists like ADP, adrenaline and low doses of thrombin (Sweatt et al, 1985). Inhibition of $\mathrm{Na}^{+} / \mathrm{H}^{+}$exchange and arachidonic acid release could be achieved by decreasing extraplatelet $\mathrm{pH}$. Therefore, the inhibiting effect of an hypercapnic and acid milieu on rabbit platelet aggregation induced by various agents, as found in the present study, might result from inhibition of the $\mathrm{Na}^{+} / \mathrm{H}^{+}$exchange.

\section{Synergisms}

In contrast to the situation in most in vitro studies, where often only one agonist is used to activate blood platelets, in vivo the platelets are likely to be simultaneously exposed to a combination of agonists in case of vessel wall injury. Synergism between substances, like for example serotonin on the one hand and ADP or collagen on the other, can increase the aggregation response. The present study confirms that synergism does occur in case of rabbit platelet aggregation (see also Kinlough-Rathbone $e t$ al, 1977a), as it does in other species (De Clerck and Herman, 1983). The present study suggests that this synergistic activation of rabbit blood platelets is influenced by hypercapnia and acidosis in the same way as activation by the individual agents.

\section{Relation to the in vivo situation}

The results of the present study indicate that the retardation in thrombus growth and embolization following vessel wall injury in rabbit mesenteric microvessels under hypercapnic/hypoxic conditions (oude Egbrink et al, 1989; chapter 6) can at least partially be explained by a direct negative effect on platelet aggregation itself. The in vivo study showed that hypercapnia alone did not hamper rabbit platelet activation and that it was only effective in combination with hypoxia. Combining this in vivo finding with the present in vitro observation, that $\mathrm{pO}_{2}$ changes only influence thrombin induced aggregation, it is tempting to speculate that thrombin is an important agonist in case of platelet-vessel wall interactions in rabbit mesenteric microvessels following vessel wall injury. However, it has been shown that hypoxia can also enhance the production of, for example, adenosine (Deussen et al, 1986) and prostacyclin (Edlund and Wennmalm, 1983; Busse et al, 1984) by the vessel wall. Through an increased production of these platelet inhibitors, in vivo hypoxia can also indirectly cause an inhibition of platelet reactivity. 
In conclusion, hypoxia reduces rabbit platelet aggregation induced by thrombin, but not by ADP and collagen. Hypercapnia and acidosis cause a reduction in rabbit platelet aggregation, as induced by collagen, thrombin and ADP, the effect being most pronounced with collagen and smallest with ADP. Synergistic activation of rabbit platelets seems to be equally sensitive to changes in $\mathrm{pCO}_{2}$ and $\mathrm{pH}$ as activation by the individual agents.

\subsection{SUMMARY}

The influence of changes in $\mathrm{pCO}_{2}, \mathrm{pH}$ and $\mathrm{pO}_{2}$ on the aggregation of rabbit blood platelets was studied in vitro, with emphasis on hypercapnia, acidocis and hypoxia. Hypercapnia combined with acidosis caused a reduction in rabbit platelet aggregation, as induced by collagen, thrombin and ADP; the effect being most pronounced with collagen and smallest with ADP. Hypoxia reduced thrombin induced platelet aggregation, but had no effect on ADP and collagen induced aggregation. Synergistic activation of rabbit platelets, as induced by the addition of serotonin to platelet rich plasma together with collagen or $\mathrm{ADP}$, seemed to be equally sensitive to changes in $\mathrm{pCO}_{2}$ and $\mathrm{pH}$ as activation by the individual agents, and insensitive to changes in $\mathrm{pO}_{2}$. 


\section{INTERACTION BETWEEN LEUKOCYTES AND PLATELETS IN VENULES}

\subsection{INTRODUCTION}

In rabbit mesentery the platelet reaction to vessel wall injury is more pronounced in arterioles than in venules (oude Egbrink et al, 1988; chapter 4). During the thromboembolic reaction following wall puncture, the number of emboli produced in arterioles is 6 times higher than that in venules, a difference which cannot be explained by fluid dynamic factors (oude Egbrink et al, 1988; chapters 4 and 5) or by differences in intravascular $\mathrm{pH}$ and blood gas values between these vessel types (oude Egbrink et al, 1989; chapter 6).

Another difference between both vessel types is the rolling and sticking of leukocytes in venules, but not in arterioles (Atherton and Born, 1972; Schmid-Schönbein et al, 1980; House and Lipowsky, 1987). Rolling of leukocytes, i.e. movement along the venular endothelium at a clearly lower velocity than the other blood cells, is a wellknown phenomenon in mesenteric tissue exposed for intravital microscopic observation. Leukocytes may also adhere, or stick, to the venular vessel wall. This phenomenon may be related to the observed difference in platelet reaction between arterioles and venules. In vitro studies have shown that leukocytes can produce substances, like thromboxane A2 (Higgs et al, 1976), prostacyclin (Orchard et al, 1983) and 13-HODE (Soberman et al, 1985). Such substances may be present in sufficiently high concentrations along the venular wall to influence platelet behavior. On the other hand, substances derived from activated platelets may alter leukocyte behavior, as has been shown by in vitro studies (Benveniste et al, 1982; Lucchesi et al, 1987; Marcus et al, 1985; Turner et al, 1975). Whether there is a functional interaction between leukocytes and platelets in vivo is unknown.

It was the aim of the present study to investigate the relation, if any, between the extent of rolling and sticking of the leukocytes on the one hand and the thromboembolic

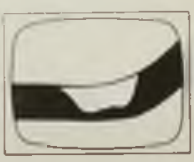


reaction following vessel wall puncture on the other. The experiments were performed in the rabbit mesentery with the use of intravital videomicroscopy. To be able to study the relation between leukocyte behavior and platelet reaction in as many vessels as possible, data were taken from several other studies described in this thesis and from some additional experiments. This includes experiments in which blood gas and $\mathrm{pH}$ values were normocapnic hypoxic or normoxic hypercapnic. In a previous study it was shown that the platelet reaction to vessel wall injury is not influenced by these changes in blood gas and pH values (oude Egbrink et al, 1989; chapter 6). It is not known, however, whether these changes in blood gas and $\mathrm{pH}$ values do influence leukocyte rolling and sticking. Therefore, the influence of normocapnic hypoxia and normoxic hypercapnia on leukocyte rolling and sticking was also investigated.

\subsection{MATERIALS AND METHODS}

\section{Animal preparation}

The data, described in this chapter, were taken from experiments with 43 rabbits, which were also used in the studies described in chapter 4, chapter 6 (control group, normocapnic hypoxic group and normoxic hypercapnic group) and in chapter 9 (control group). In addition, data were included from venules, which were discarded from the before mentioned studies, because of the high number of rolling or sticking leukocytes, as compared to the number in the other vessels under investigation. The rabbits were of various breeds and either sex and ranged in weight from 2.3 to $3.5 \mathrm{~kg}$. Anesthesia was induced by intramuscular injection of ketamine hydrochloride (Vetalar, Parke-Davis, or Nimatek, A.U.V.), $40 \mathrm{mg} / \mathrm{kg}$ body weight, and xylazine hydrochloride (Rompun, $2 \%$ solution, Bayer, or Sedamun, A.U.V.), $4 \mathrm{mg} / \mathrm{kg}$ body weight, and was maintained by a continuous intravenous infusion of ketamine $(40 \mathrm{mg} / \mathrm{kg} / \mathrm{hr}$ ) and xylazine $(5 \mathrm{mg} / \mathrm{kg} / \mathrm{hr})$. Electronic platelet counts and measurements of hematocrit, arterial blood pressure and heart rate were performed, as previously described (oude Egbrink et al, 1988; chapter 4). In all rabbits electronic platelet counts (range: $282-690 \times 10^{9} /$ ) and hematocrit values (range: 32.2-42.9\%) were within normal ranges (Kozma et al, 1974). Mean arterial blood pressure and heart rate, as measured at the moments of puncture, was $64 \pm 11 \mathrm{mmHg}$ and $126 \pm 31$ beats per minute (means \pm s.d.), respectively.

The rabbits were ventilated with a mixture of nitrogen, oxygen and carbon dioxide. They were divided in 3 groups according to their systemic arterial $\mathrm{pH}, \mathrm{pCO}_{2}$ and $\mathrm{pO}_{2}$ values: a control group (referred to as CONT) with normal blood gas and $\mathrm{pH}$ values, a normocapnic hypoxic group (HO) and a normoxic hypercapnic group (HC). The average blood gas and $\mathrm{pH}$ values in these groups at the moments of puncture of the venules are shown in Table 8.1.

Mesentery preparation and intravital videomicroscopy were performed, as described previously (oude Egbrink et al, 1988; chapter 4). Vessel diameter and mean red 
TABLE 8.1 Systemic arterial blood gas and $p H$ values at the moments of puncture of venules of the 3 rabbit groups. Mean values and standard deviations are presented.

\begin{tabular}{lrccc}
\hline Group & \multicolumn{1}{c}{$\pi$} & $\mathrm{pH}$ & $\mathrm{pCO}_{2}(\mathrm{mmHg})$ & $\mathrm{pO}_{2}(\mathrm{mmmHg})$ \\
\hline CONT & 40 & $7.42 \pm 0.03$ & $38.3 \pm 6.2$ & $98.5 \pm 12.7$ \\
HO & 9 & $7.42 \pm 0.02$ & $41.2 \pm 4.6$ & $44.7 \pm 7.2$ \\
HC & 19 & $7.37 \pm 0.08$ & $51.2 \pm 3.1$ & $97.4 \pm 8.6$
\end{tabular}

CONT = control; $H O=$ hypoxia $; H C=$ hypercapnia

blood cell ( $R B C)$ velocity were measured in all selected vessels at the sites of puncture, using the methods described by Intaglietta and Tompkins (1973) and Slaaf and coworkers $(1981 ; 1986)$, respectively. From these parameters the reduced velocity U ( $\mathrm{U}=$ mean $\mathrm{RBC}$ velocity/vessel diameter) was calculated.

\section{Vessel wall puncture}

Arterioles and venules were selected, ranging in diameter from 20 to $40 \mu \mathrm{m}$. To evoke a thromboembolic reaction, the walls of these vessels were punctured with glass micropipets having tip diameters of 6 to $8 \mu \mathrm{m}$, as previously described (oude Egbrink et al, 1988; chapter 4). Puncture was considered to be successful only, if RBCs left the vessel. The moment of puncture and the subsequent intravascular reactions were recorded on videotape up to $600 \mathrm{~s}$.

Immediately following puncture bleeding and thrombus formation started in all vessels. Adhesion of circulating platelets to the downstream side of the thrombus continued in most vessels and parts of these thrombi embolized during a certain period. Bleeding time, thrombus height relative to the local vessel diameter, the number of emboli produced, the duration of embolization and the median embolus production time, i.e. the median of the time periods needed for every new embolus to be produced in a vessel, were determined off-line. Emboli were only counted if their short axis, perpendicular to the vessel wall, was greater than $25 \%$ of the local vessel diameter. Aggregates of smaller dimensions could not always be distinguished from the background with sufficient accuracy.

\section{Rolling and sticking leukocytes in venules}

The numbers of rolling and sticking leukocytes were determined off-line near the site of puncture. Counting was performed in all venules within the last minute before puncture during a period of $26 \pm 13 \mathrm{~s}$ (mean \pm s.d.). In 36 vessels of the control rabbits rolling leukocytes were also counted following puncture, during and/or after embolization, both upstream and downstream of the thrombus. These counting periods lasted $60 \mathrm{~s}$ and started within the first minute following puncture, but always after bleeding had stopped. In each venule the numbers of rolling and sticking leukocytes were counted during the same period at least two times by two different observers. Leuko- 
cytes were considered as "rolling", if they were moving along the vessel wall at a visibly lower velocity than the RBC velocity. Rolling leukocytes moved either at a rather constant velocity or saltated, i.e. periods of contact with the wall were alternated with periods of travelling in the blood stream (see also: Atherton and Born, 1972; Schmid-Schönbein et al, 1987). To be sure that all rolling leukocytes were counted, including the saltating cells, counting was performed in a vessel segment with a length of 50 to $100 \mu \mathrm{m}$. Cells, present in the segment at the beginning of the period of counting, were not included. Rolling was expressed as the number of cells passing per minute through the cross-section at the beginning of the vessel segment. A leukocyte was counted as "sticking" or adhering to the wall, if it was stationary during the whole counting period. It was more difficult to assess the number of sticking leukocytes than the number of rollers, because of the lack of movement. In case of doubt due to low contrast of the leukocytes, data on sticking were discarded. The number of sticking leukocytes was expressed as number of cells per $100 \mu \mathrm{m}$ of vessel length.

In all experiments the mid-plane of a vessel, where the diameter was largest, was in focus. To be certain that all rolling and sticking leukocytes in the selected vessel segments could be distinguished, including those not in the plane of focus, in some vessels (diameters 30-40 $\mu \mathrm{m}$ ) the objective was focused up and down through the lumen after the experiment. In this way it could be affirmed that leukocytes rolling or sticking along the upper or lower wall were seen when focus was in the mid-plane of the vessel.

\section{Duration of experiment}

With increasing duration of an experiment, more substances produced by the mesenteric tissue, if any, may preferentially enter the venules, because of their relatively high permeability as compared to that of arterioles (Arfors et al, 1976a). Such substances could influence leukocyte behavior and the thromboembolic reaction following puncture of the venules. Therefore, it was investigated whether the duration of an experiment, i.e. the time period between the moment of mesentery preparation and puncture, was related to leukocyte rolling and sticking and/or to the embolization parameters in both arterioles and venules.

\section{Statistics}

Correlations were performed with the non-parametric Spearman rank correlation test (coefficient $=r_{s}$ ). Paired data-groups were compared with the Wilcoxon signed-rank test. In case of two independent data-groups the Mann-Whitney $U$ test was used. In all tests the level of significance was set at $5 \%$. 


\subsection{RESULTS}

Leukocytes were never seen rolling along or sticking to the arteriolar vessel wall in any of the groups, either before or after puncture, irrespective of vessel diameter (range: $21-40 \mu \mathrm{m}$ ), mean $\mathrm{RBC}$ velocity (range: $0.8-7.5 \mathrm{~mm} / \mathrm{s}$ ) and reduced velocity $\mathrm{U}$ (range: $31-232 \mathrm{~s}^{-1}$ ). Only occasionally, leukocytes could be seen rolling along the arteriolar thrombus or sticking to it for a short period of time, until being swept away into the blood stream.
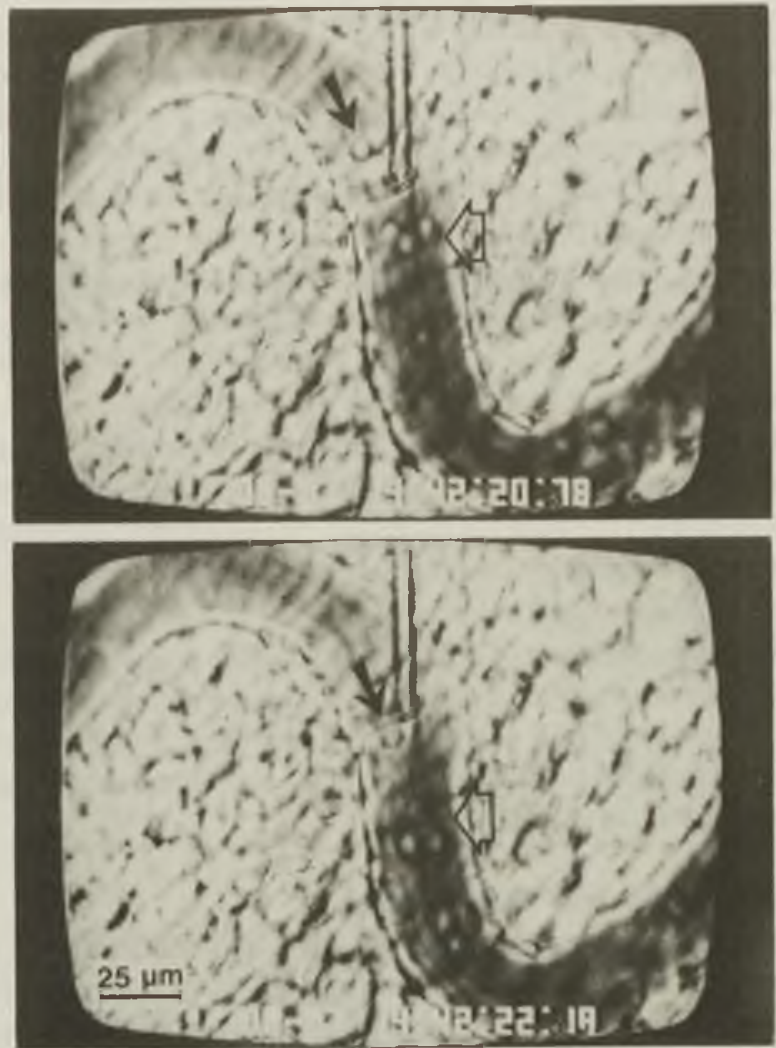

FIGURE 8.1 Leukocyne rolling in a venule (diameter: $34 \mu \mathrm{m}$ ), immediately before puncture; the micropipet is already positioned against the vessel wall. In the time period between both video frames $(1.4 \mathrm{~s})$ the rolling leukocytes, some of them indicated by the two different arrows, have travelled along the wall at different velocities. The direction of the blood stream is from left to right. 
In contrast to the arterioles $(n=64)$, in all venules $(n=68)$, exept one, rolling leukocytes were observed before puncture (Figure 8.1). In 46 of the 50 venules, with adequate contrast to count the number of sticking leukocytes, these cells were actually observed. One or two venules without sticking leukocytes were found in all rabbit groups.

The extent of leukocyte rolling and sticking in the venules was not related to the duration of the experiment, which ranged from 15 to 182 minutes. In the arterioles and venules of all groups of rabbits no significant relation was found between the duration of the experiment and the thromboembolic parameters.

\section{Blood gas parameters and leukocyte rolling and sticking}

The number of leukocytes rolling along the venular vessel wall was not different between the CONT-rabbits (median: $43 / \mathrm{min}$; range: $5-138 / \mathrm{min}$ ), the HO-rabbits (59/min; 0-128/min) and the HC-rabbits (34/min; 3-110/min). The same holds for the number of sticking leukocytes. Per $100 \mu \mathrm{m}$ of vessel length, the median number of sticking leukocytes was 4 in the venules of the CONT-group (range: 0-16), 2 in the HO-venules (0-7) and 3 in the $\mathrm{HC}$-venules (0-7). Therefore, all data were pooled for further analysis, irrespective of the $\mathrm{pH}$ and blood gas values of the rabbits, especially because the platelet reaction to vessel wall puncture was not influenced by these changes in blood gas and $\mathrm{pH}$ values either (oude Egbrink et al, 1989).

\section{Fluid dynamic parameters and leukocyte rolling and sticking}

The overall median number of rolling leukocytes was 44 per minute. Leukocyte rolling was only slightly related to the vessel diameter $\left(r_{s}=0.31 ; p \leq 0.05\right)$. Therefore, it was decided not to correct the data for diameter. No significant correlation was found between the number of rolling leukocytes on the one hand and mean $\mathrm{RBC}$ velocity (range: $0.6-4.7 \mathrm{~mm} / \mathrm{s})$ and reduced velocity $U\left(23-127 \mathrm{~s}^{-1}\right)$ on the other.

The overall median number of sticking leukocytes was 3 per $100 \mu \mathrm{m}$ of vessel length. The number of sticking leukocytes was weakly correlated to the number of rolling leukocytes $\left(r_{s}=0.36, p \leq 0.05\right)$. No significant correlation was found between the number of sticking leukocytes on the one hand and vessel diameter, mean $\mathrm{RBC}$ velocity and reduced velocity $U$ on the other.

\section{Leukocytes and the thromboembolic reaction}

In 16 vessels the number of rolling leukocytes, counted following puncture in a segment about 10 to $50 \mu \mathrm{m}$ upstream of the thrombus, was not different from the number counted in the same segment before puncture (median in both groups: 44 rolling leukocytes per minute; median difference between number before and after puncture was -2). Therefore, the thromboembolic parameters were related to the number of rolling leukocytes counted before puncture.

The relation between the number of emboli produced per venule and the number of rolling leukocytes is shown in Figure 8.2. It should be noted that in venules with 20 or less rolling leukocytes per minute the median number of emboli produced per 


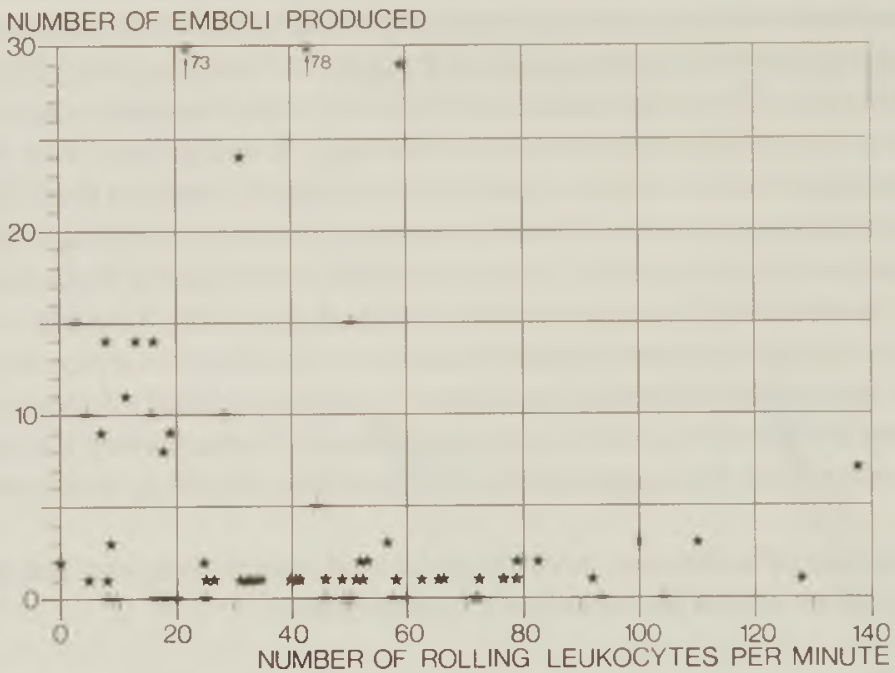

FIGURE 8.2 Scatter plot of the number of emboli produced per venule as a function of the number of rolling leukocytes passing per minute. In 2 venules more than 30 emboli were produced, as indicated by the numbers and the arrows.

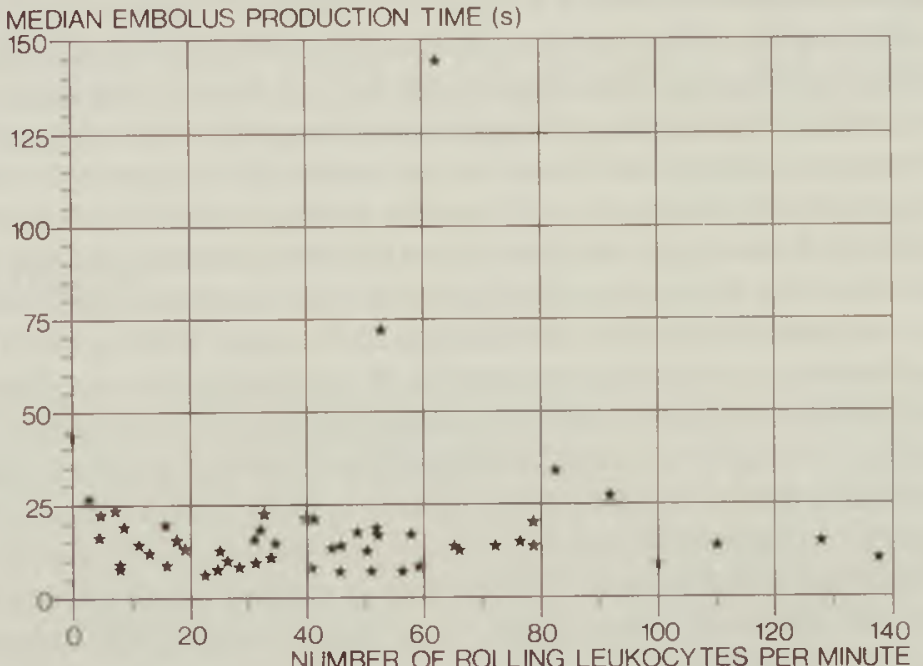

FIGURE 8.3 Scatter plot of the median embolus production time per venule as a function of the number of rolling leukocytes passing per minute. 
vessel was 8 , while in vessels with more than 20 rolling leukocytes the median number of emboli produced was one. As compared to the vessels with more than 60 rollers per minute, embolus production was significantly higher in the vessels with 20 or less rolling leukocytes ( $p \leq 0.05$ ). In the vessels with 20 to 60 rollers the median number of emboli produced was one, but variation was rather high. A comparison with the number of emboli produced in the arterioles (median number of 6) revealed that embolization was significantly more pronounced in arterioles than in venules with more than 20 rolling leukocytes per minute ( $p \leq 0.001)$, but that no difference existed between the arterioles and the venules with 20 or less rollers per minute $(p=0.25)$. The relation between the number of rolling leukocytes and the duration of embolization, a parameter strongly related to the number of emboli produced $\left(r_{s}=0.94 ; p \leq 0.001\right)$, followed the same trend as described for the number of emboli produced. Consequently, the median embolus production time was independent of the number of rolling leukocytes (Figure 8.3).

The number of leukocytes, sticking to the wall before puncture, was not related to bleeding time or any of the embolization parameters.

\section{Platelet reaction and leukocyte rolling}

In 6 of the 36 venules, in which leukocyte rolling upstream and downstream of the thrombus was studied, there was no embolization following wall puncture. As is illustrated in Figure 8.4A, the number of rolling leukocytes in these vessels was not different upstream and downstream of the thrombus.

In the other 30 venules emboli were produced following puncture. In 15 of these vessels, in which a median number of 2 emboli was produced (range: 1-73), the number of rolling leukocytes was counted during embolization. A significant difference in leukocyte rolling was found between the upstream and downstream vessel segments (a median decrease by $45 \%$; $p \leq 0.001$; Figure $8.4 B$ ). In 12 of these 15 vessels the number of rollers was counted again after embolization had stopped (on the average from the 3 rd to the 4 th minute after production of the last embolus). In Figure $8.4 \mathrm{C}$ these data are shown together with the data from 15 venules in which embolization had stopped before the period of counting in the first minute following puncture started. The data in this figure show that the number of rolling leukocytes decreased significantly from upstream to downstream also after embolization had stopped (50\%; $p \leq 0.01)$. No relation existed between the change in the number of rolling leukocytes and the duration of the period between the end of embolization and the moment of counting.

The change in number of rolling leukocytes from upstream to downstream of the thrombus normalized to the number rolling upstream, as calculated over all 36 vessels, was correlated to the number of emboli produced per vessel $\left(r_{s}=0.45 ; p \leq 0.01\right)$. However, no relation was found between this decrease in number of rolling leukocytes on the one hand and relative thrombus height, vessel diameter, mean RBC velocity or reduced velocity $U$ on the other. 


\section{NUMBER OF ROLLING LEUKOCYTES \\ NORMALIZED TO THE NUMBER ROLLING UPSTREAM}
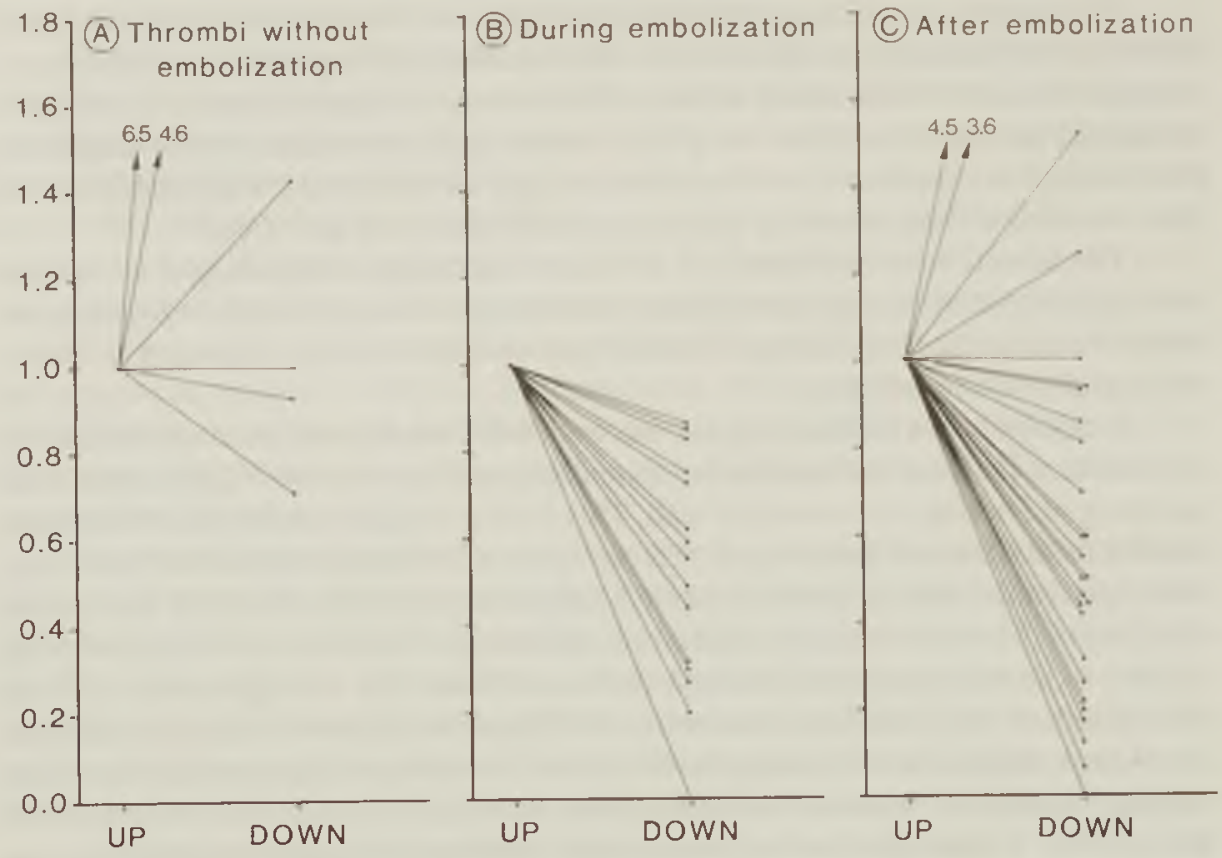

FIGURE 8.4 The number of leukocytes rolling per minute from the vessel segment upstream (UP) to the vessel segment downstream (DOWN) of a thrombus, normalized to the number of rolling leukocytes in the upstream vessel segment. Data are shown from venules in which no emboli were produced following puncture $(A ; n=6)$, from venules in which embolization was still going on during the period of leukocyte counting $(B ; n=15)$, and from venules in which embolization had stopped before the counting period started $(C ; n=27)$.

\subsection{DISCUSSION}

Rolling and sticking leukocytes can be found in almost all venules, but never in intact arterioles of the exposed rabbit mesentery. This difference in leukocyte behavior between both vessel types is not due to differences in fluid dynamic conditions. Leukocyte rolling and sticking is not influenced by changes in systemic arterial blood gas and $\mathrm{pH}$ values. The number of emboli produced during the thromboembolic reaction following puncture of the venular vessel wall is inversely related to the number of rolling leukocytes per minute: embolization activity decreases with an increasing number of rolling leukocytes. No relation is found between the number of sticking leukocytes and the thromboembolic reaction following puncture. Another finding in the

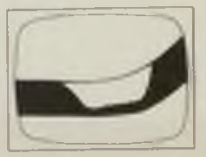


present study is that embolization activity is attended with a decrease in leukocyte rolling from upstream to downstream of a thrombus.

The number of rolling and sticking leukocytes nor the thromboembolic reaction following wall puncture are influenced by the duration of an experiment in both arterioles and venules. It is therefore unlikely that mesenteric tissue products, if any, have influenced leukocyte behavior and platelet-vessel wall interactions in the venules. In the course of an experiment, such substances might have entered preferentially the venules because of their relatively high permeability (Arfors et al, 1976a).

The present study indicates that in venules the rolling and sticking of leukocytes is not influenced by changes in blood gas parameters towards hypoxic or hypercapnic values. In addition, these changes in blood gas and $\mathrm{pH}$ values do not result in leukocyte margination in arterioles.

In addition, our findings suggest that both $R B C$ velocity and reduced velocity $U$, as a measure for local wall shear rate, do not influence the number of leukocytes rolling along or sticking to the venular wall. This finding is supported by the observation that the formation of a thrombus, which can cause a decrease in flow in the vessel segment upstream of this thrombus (chapter 5), does not result in a change in the number of rollers in this vessel segment. Therefore, the extent of leukocyte rolling and sticking appears to be independent of fluid dynamic conditions. This is in agreement with the observation of Mayrovitz and coworkers (1977) that the number of rolling leukocytes can change independent of changes in blood flow. It has been suggested that leukocyte rolling is caused by increased adhesion forces towards the vessel wall (Atherton and Born, 1972). In this light the observation that rolling and sticking leukocytes are not found in intact arterioles indicates that in arterioles such adhesion forces are absent. The occasional rolling of leukocytes along a thrombus in arterioles and, more frequently, in venules may be caused by 12-HETE production in the thrombus by the aggregated platelets. 12-HETE, after all, is a chemotactic factor for polymorphonuclear leukocytes (Turner et al, 1975).

When the number of rolling leukocytes rises above approximately 20 per minute, the number of emboli produced per venule decreases from a level equal to the arteriolar production to a level significantly different from the production in arterioles. AIthough the variation in data is still too high to draw definite conclusions, this finding suggests that the presence of rolling leukocytes in venules and not in arterioles is directly or indirectly related to the difference in thromboembolic reaction, normally found between both vessel types. In a previous study, in which this difference in thromboembolic reaction was reported (oude Egbrink et al, 1988; chapter 4), the median number of leukocytes rolling per minute along the venular wall was 41 (range: 9-65). The decrease in embolization activity, when leukocyte rolling increases, may reflect a direct effect of the rolling leukocytes on the platelets. Another possible explanation is an alteration in functioning of the venular endothelium, indirectly reflected by the rolling of the leukocytes. Such an alteration could be induced by inflammatory mediators, released from the tissue, and preferentially influencing venular endothelium. After all, the rolling of leukocytes along the venular wall may be the first indication of inflam- 
mation (Atherton and Born, 1972). The altered endothelial cell function might simultaneously induce an increase in the number of leukocytes rolling along the wall and a decrease in the platelet reaction to vessel wall injury.

Rolling leukocytes may inhibit platelet reaction directly through inactivation of platelet activating substances. As described by Harrison and colleagues (1966), leukocytes can inactivate adenosine diphosphate (ADP) and inhibit platelet aggregation, as induced by $\mathrm{ADP}$, serotonin and thrombin. Findings in another in vitro study (Oudinet et al, 1988) indicate that the availability for platelets of exogenous arachidonic acid, originating from damaged endothelial cells, can be diminished via utilization by polymorphonuclear leukocytes. This phenomenon could result in inhibition of the production of the aggregation promoting substance thromboxane $\mathrm{A}_{2}$ by the platelets. Besides, leukocytes can produce 13-HODE (Soberman et al, 1985), a substance that inhibits platelet adhesion to endothelial cells (Buchanan and Bastida, 1987), and prostacyclin (Orchard et al, 1983; Mehta et al, 1985), which is known to be a potent inhibitor of platelet aggregation (Moncada, 1982).

An alternative explanation for the effect of rolling leukocytes on the thromboembolic reaction may be that the normal distribution of platelets is disturbed. In arterioles, the highest concentration of platelets is found near the vessel wall (Tangelder $e t$ $a l, 1985$ ). The relatively high number of leukocytes rolling along the wall in venules may hinder the platelets in their reaction to an injury of the wall. However, the finding that not the rate of embolus production, but the duration of embolization is affected by a high concentration of rolling leukocytes is not in accordance with this possibility.

In the present study the number of leukocytes sticking to the venular wall was low and in the same order as the number found by House and Lipowsky $(1987,1988)$ in cat mesenteric venules in control conditions. The sticking leukocytes did not appear to exert a measurable influence on the thromboembolic parameters.

The findings of the present study suggest that thromboembolic activity induces a decrease in leukocyte rolling along the vessel wall. As is illustrated in Figure $8.4 \mathrm{~A}$, this effect is not the result of the presence of a partially occluding thrombus per se, since no decrease in rolling was found in venules in case of a thrombus without embolization. The high velocity in the stenosis does not detach the leukocytes from the wall, along which they roll, into the central blood stream. In addition, the data in Figure 8.4B and $\mathrm{C}$ show that the decrease in rolling of the leukocytes distal to the thrombus is not caused by attachment to and capture within emboli. The number of rolling leukocytes still decreases after embolization has stopped. Therefore, the effect must be caused by substances produced by either the aggregated platelets present in the stationary thrombus itself or the damaged vessel wall. The significant correlation between the amount of emboli produced and the decrease in leukocyte rolling indicates that such substances are produced in higher quantities when embolization activity increases. However, they are likely not involved in the activation of platelets themselves, because leukocyte rolling still decreases within the first few minutes after embolization has stopped. The nature of these substances needs further investigation. 
In conclusion, the rolling of leukocytes, a phenomenon found in venules and not in arterioles, appears to be related to the platelet reaction following vessel wall puncture. With an increasing number of rollers the number of emboli produced decreases below the arteriolar level of embolus production. This observation may lead to an explanation for the difference in thromboembolic reaction found between arterioles and venules. Sticking leukocytes, present in venules only in low numbers, do not have a detectable influence. The thromboembolic reaction itself appears to decrease leukocyte rolling. This phenomenon is not the result of the fluid dynamic effects of the thrombus, but more likely of the production of substances, which are able to inhibit leukocyte rolling, either by platelets in the stationary thrombus or by the damaged vessel wall.

\subsection{SUMMARY}

In microvessels of the exposed rabbit mesentery the extent of rolling and sticking of leukocytes was studied in relation to the thromboembolic reaction following vessel wall puncture as a measure of platelet activity, using intravital videomicroscopy. Rolling and sticking leukocytes can be found along the wall in most venules, but never in arterioles. This difference in leukocyte behavior between arterioles and venules is not due to differences in fluid dynamic conditions. Changes in blood gas parameters towards hypoxia or hypercapnia do not influence leukocyte rolling and sticking. The number of emboli produced during the thromboembolic reaction following puncture of the venular vessel wall appears to decrease with an increasing number of leukocytes rolling along the wall. Therefore, the presence of leukocyte rolling in venules, but not in arterioles, may lead to an explanation for the difference in thromboembolic reaction, as normally found between both vessel types. Sticking leukocytes, only present in low numbers, do not influence the thromboembolic reaction. In venules, in which emboli are produced following wall puncture, the number of rolling leukocytes decreases from upstream to downstream of the thrombus. This decrease is not the result of the fluid dynamic changes induced by the thrombus or of inclusion of the leukocytes in the emboli produced by the thrombus. Therefore, substances produced by aggregated platelets in the stationary thrombus or by the damaged vessel wall are probably responsible for the decrease in the number of rolling leukocytes per minute. 


\title{
EFFECTS OF ASPIRIN ON THE
}

\section{THROMBOEMBOLIC REACTION FOLLOWING}

\section{VESSEL WALL INJURY DIFFER IN ARTERIOLES}

\author{
AND VENULES
}

\subsection{INTRODUCTION}

Following vessel wall injury several substances are involved in the interaction between platelets and the damaged vessel wall (Mustard and Packham, 1970). It has been suggested that prostaglandins such as prostacyclin ( $\mathrm{PGI}_{2}$ ) and thromboxane $\mathrm{A}_{2}$ (TXA2) play an important role. $\mathrm{PGI}_{2}$ is produced and released by the vessel wall and is a potent inhibitor of platelet aggregation (Moncada et al, 1976; Gryglewski et al, 1976). On the other hand, TXA 2 is secreted by the platelets themselves and stimulates their aggregation (Hamberg et al, 1975). It has been proposed that these two prostaglandins form a balanced control mechanism, regulating the interaction between platelets and the vessel wall at the site of wall injury (Moncada and Vane, 1979).

The role of both prostaglandins in platelet-vessel wall interactions appears to be limited to the site of their production, since both $\mathrm{PGI}_{2}$ (Haslam and McClennaghan, 1981; Blair et al, 1982) and TXA2 (Fitzgerald et al, 1987) do not circulate in concentrations sufficiently high to exert a systemic effect. In vitro studies have shown that the production of $\mathrm{PGI}_{2}$ depends on the vascular origin of the vessel segments or endothelial cells under investigation. Cultured endothelial cells, originating from different organs (Revtyak et al, 1987) or even from various sized vessels (macro versus microvessels) in the same organ (Gerritsen and Cheli, 1983; Revtyak et al, 1987), appear to produce different amounts of $\mathrm{PGI}_{2}$. Sofar, it is not known whether the production and role of prostaglandins is different in arterioles and venules of the same tissue.

The aim of the present study was to investigate in vivo the involvement of pros- 


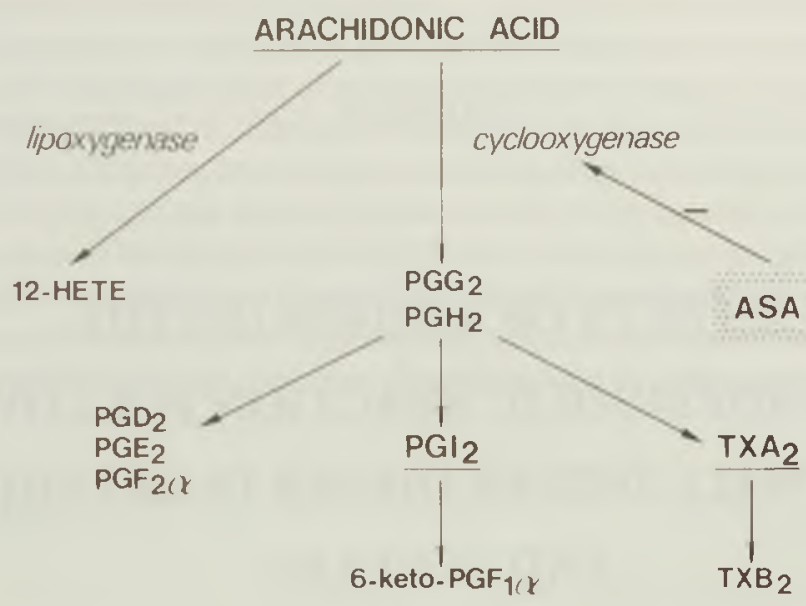

FIGURE 9.1 Formation of prostaglandins (PGs) from arachidonic acid via the cycloogenase pathway. Inhibition of the enzyme cyclooxygenase by aspirin (ASA) blocks the formation of all PGs and may induce overflow to the lipoxygenase pathway, resulting in an increased production of, for example, 12-HETE.

taglandins in the thromboembolic reaction in mesenteric arterioles and venules following puncture of the vessel wall. To this purpose rabbits were pretreated with aspirin, thereby irreversibly acetylating the active site of the enzyme cyclooxygenase (Figure 9.1; Roth et al, 1975). High doses of aspirin (100 and $200 \mathrm{mg} / \mathrm{kg}$ ) were used to ensure complete inhibition, not only of TXA2 but also of $\mathrm{PGI}_{2}$ production (Kelton et al, 1978; Ellis et al, 1980; Buchanan et al, 1981; Wu et al, 1981).

\subsection{MATERIALS AND METHODS}

\section{Experimental setup}

Experiments were performed on anesthetized New Zealand white rabbits of either sex. Surgery, exposure of the mesentery and intravital videomicroscopy were performed as described in detail before (oude Egbrink et al, 1988; chapter 4). In short, anesthesia was induced with $40 \mathrm{mg} / \mathrm{kg}$ body weight ketamine hydrochloride (Nimatek, A.U.V., Cuijk, The Netherlands) and $4 \mathrm{mg} / \mathrm{kg}$ body weight xylazine hydrochloride (Sedamun, A.U.V., Cuijk, The Netherlands), given by intramuscular injections. Anesthesia was maintained with a continuous intravenous infusion of ketamine $(40 \mathrm{mg} / \mathrm{kg} / \mathrm{hour})$ and xylazine $(5 \mathrm{mg} / \mathrm{kg} / \mathrm{hour})$, dissolved in a lactetrol solution ( $15 \mathrm{ml} /$ hour; Aesculaap, Boxtel, The Netherlands). Electronic platelet counts, hematocrit values, arterial blood pressures and heart rates were measured (oude Egbrink et al, 1988; chapter 4). 
The rabbits were ventilated with a mixture of nitrogen, oxygen and carbon dioxide to maintain systemic arterial $\mathrm{pH}, \mathrm{pCO}_{2}$ and $\mathrm{pO}_{2}$ at normal values. The average values were: $\mathrm{pH} 7.43 \pm 0.03, \mathrm{pCO}_{2} 41 \pm 3 \mathrm{mmHg}$ and $\mathrm{pO}_{2} 90 \pm 9 \mathrm{mmHg}$ (means \pm s.d.). No differences existed between groups (see below).

The mesenteric tissue was visualized with an intravital microscope, using a long working distance objective (LL25, numerical aperture 0.35 ). Images were recorded on videotape for off-line analysis. Vessel diameter and mean red blood cell (RBC) velocity were determined in all selected vessels (oude Egbrink et al, 1988; chapter 4). The reduced velocity $U$, as a measure of local shear rate, was calculated ( $U=$ mean $R B C$ velocity divided by vessel diameter).

\section{Vessel wall puncture}

Arterioles and venules were selected within the diameter range of 20 to $40 \mu \mathrm{m}$. Vessel wall puncture was performed by means of glass micropipets with tip diameters of 6 to $8 \mu \mathrm{m}$, as described before (oude Egbrink et al, 1988; chapter 4). To be certain that all layers of the wall were damaged, puncture was considered to be successful only if RBCs left the vessel. The moment of puncture and the subsequent thromboembolic reaction were recorded on videotape up to $600 \mathrm{~s}$.

Bleeding time, the maximal thrombus height, the number of emboli produced, the duration of embolization and the median embolus production time per vessel, i.e. the median period of time needed for the emboli of a vessel to be produced, were determined off-line. Emboli were only counted when their short axis, perpendicular to the vessel wall, was greater than $25 \%$ of the local vessel diameter. Aggregates of smaller dimensions could not always be distinguished from the background with enough accuracy. In case of rebleedings, the frequency and duration were determined.

The number of leukocytes rolling along the vessel wall immediately before puncture was counted, as previously described (chapter 8 ). The period of counting was 30 $\pm 14 \mathrm{~s}$ (mean \pm s.d.).

\section{Aspirin}

Aspirin (acetyl salicylic acid: ASA; Sigma, St. Louis, USA) was suspended in water at a concentration of 100 or $200 \mathrm{mg} / \mathrm{ml}$. Subsequently, sodium carbonate crystals were slowly added until the ASA crystals dissolved. The $\mathrm{pH}$ of the solution remained just below 7.0, so that hydrolysis of the ASA was minimal (Kelton et al, 1978). The ASA solution or the vehicle, with the same $\mathrm{pH}$, was administered intravenously through a polyethylene catheter in the marginal ear vein, in a volume of $1 \mathrm{ml} / \mathrm{kg}$ body weight. Administration was performed in about 1 to 2 minutes. Vessel wall puncture started about 15 minutes after administration of ASA or vehicle. Additional punctures were performed at various intervals within 3 hours from the moment of administration.

\section{Experimental groups}

The experiments were performed on 3 groups of rabbits. The first group of 11 rabbits (weight: $2.3-2.7 \mathrm{~kg}$ ) served as control group and received the vehicle only. In

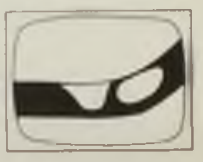


these rabbits 19 arterioles and 21 venules were punctured, and the subsequent reactions in these vessels were studied. The second group of 10 rabbits $(2.3-2.9 \mathrm{~kg})$ received $100 \mathrm{mg} / \mathrm{kg}$ body weight ASA (ASA-100 group). In this group the reaction following wall injury was studied in 18 arterioles and 16 venules. The third group of rabbits received $200 \mathrm{mg} / \mathrm{kg}$ body weight ASA (ASA-200 group) ( $\mathrm{n}=4 ; 2.3-2.6 \mathrm{~kg}$ ). This dose of 200 $\mathrm{mg} / \mathrm{kg}$ was administered in 2 equal parts, about 30 minutes apart, to prevent severe hypotension. In the latter group of rabbits the thromboembolic reaction was studied in 11 venules to investigate whether the change in the venular thromboembolic process, as induced by $100 \mathrm{mg} / \mathrm{kg} \mathrm{ASA}$, could be extended.

In the ASA-200 group only 2 arterioles were studied. The results obtained were similar to the results obtained in the ASA-100 arterioles and will not be discussed separately.

\section{Collagen induced platelet aggregation}

The influence of ASA and vehicle on ex vivo platelet aggregation, as induced with collagen, was determined in 3 of the control rabbits and in 5 rabbits, that received 100 $\mathrm{mg} / \mathrm{kg}$ ASA, to check the capacity of their platelets to produce TXA2. The formation of TXA 2 has been shown to play a major role in collagen induced aggregation (Kinlough-Rathbone et al, 1977b). Before and about 3 hours after administration of ASA or vehicle, $4.5 \mathrm{ml}$ blood was collected from a central ear artery in $0.5 \mathrm{ml} \mathrm{3.13 \%}$ trisodium citrate $(110 \mathrm{mM})$. The preparation of platelet rich plasma (PRP; 300.000 platelets/I) and the measurement of aggregation were performed as described in chapter 7. In all samples of PRP, aggregation was induced by three different quantities of collagen (Horm, Hormon-Chemie, München, FRG), the final concentrations in the PRP being 5, 10 and $20 \mu \mathrm{g} / \mathrm{ml}$. From the tracings the maximal degree of aggregation and the maximal rate of aggregation were measured, according to the method described in chapter 7. Drifts in gas tensions and $\mathrm{pH}$ in the PRP before and during the aggregation tests were prevented by keeping the PRP in closed volumes with $95 \% \mathrm{~N}_{2}$ and $5 \% \mathrm{CO}_{2}$.

\section{HPLC-assessments of TXA2 and 12-HETE production ex vivo}

High-performance liquid chromatography (HPLC) was employed to determine the amount of overflow, if any, from the inhibited cyclooxygenase pathway to the lipoxygenase pathway (Figure 9.1). In platelets of 2 rabbits of the ASA-100 group the capacity to produce ex vivo TXA 2 and 12-hydroxyeicosatetraenoic acid (12-HETE) was measured. Blood was collected (see above) before as well as 40 and 100 minutes after administration of ASA. PRP was prepared, the number of platelets counted and platelet aggregation induced by collagen (final concentration of $20 \mu \mathrm{g} / \mathrm{ml}$ ), as described before. 20 minutes after addition of collagen, the PRP was centrifuged at $5000 \mathrm{~g}$ for 5 minutes at $4{ }^{\circ} \mathrm{C}$ to remove the platelet aggregates. The remaining plasma was stored at $-20{ }^{\circ} \mathrm{C}$.

Plasma-concentrations of 12-hydroxyheptadecatrienoic acid (HHT), which was used as a measure of the concentration of TXA2 (Diczfalusy et al, 1977), and of 12HETE were measured with HPLC as previously described by Engels and coworkers 
(1987). The plasma samples were acidified with acetic acid to $\mathrm{pH} 4.0-4.5$, after addition of 15 hydroxy-20:2 as the internal standard, and were subsequently applied to C18 reverse-phase chromatography columns. After washing of these columns with methanol/water (15:85) and water, the HHT/HETE fraction was eluted with methanol and dried by a stream of nitrogen. The residue was applied to silica gel chromatography followed by stepwise elution with increasing polarity according to Claeys and coworkers (1985). The eluted HHT/HETE fraction was dried by a stream of nitrogen, resuspended in methanol and applied to reverse-phase HPLC with ultraviolet detection at $235 \mathrm{~nm}$.

\section{Data handling}

Because of their non-symmetrical distribution, most data are presented as medians. Box plots are used to display groups of data (Tukey, 1977). A box plot shows the median, the interquartile range (box) and the range, minus the stray values which are indicated separately. Differences between two groups were tested with the non-parametric Mann-Whitney U test, the level of significance being 0.05 . Hematocrits, electronic platelet counts, blood gas and $\mathrm{pH}$ values, arterial blood pressures and heart rates are presented as means with standard deviations.

\subsection{RESULTS}

The hematocrit values ranged from 32 to $42 \%$ and were not different in the control and ASA-rabbits (mean value: $37 \%$ in both groups). The same holds for the electronic platelet counts: means $422 \times 10^{9} / \mathrm{n}$ in the control and $404 \times 10^{9} /$ in the ASA-group (total range: 287 to $542 \times 10^{9} / \mathrm{n}$ ). These values are all within the normal ranges for rabbits (Kozma et al, 1974). Likewise, no differences were found between control and ASA-rabbits in mean arterial blood pressure ( $64 \pm 6$ and $67 \pm 6 \mathrm{mmHg}$, respectively) and mean heart rate $(119 \pm 22$ and $134 \pm 27$ beats per minute, respectively).

No differences existed between the rabbits receiving 100 or $200 \mathrm{mg} / \mathrm{kg}$ ASA, as far as these four parameters are concerned.

\section{Effect of ASA on platelet function ex vivo}

ASA, in a dose of $100 \mathrm{mg} / \mathrm{kg}$, completely inhibited platelet aggregation induced with 5 or $10 \mu \mathrm{g} / \mathrm{ml}$ collagen. With $20 \mu \mathrm{g} / \mathrm{ml}$ collagen, the inhibitory effect of ASA was still strong: the maximal degree and rate of aggregation were reduced to 11 and $3 \%$, respectively, of the reaction before ASA-administration. The vehicle did not influence the rate of aggregation, irrespective of the collagen concentration used, while the maximal degree of aggregation was still 90 to $95 \%$ of the reaction before administration of the vehicle.

Platelets, collected from two rabbits before administration of ASA, produced both HHT ( 51 and $62 \mathrm{ng} / 10^{6}$ platelets) and 12-HETE ( 31 and $44 \mathrm{ng} / 10^{6}$ platelets) upon activation with a high dose of collagen. Administration of $100 \mathrm{mg} / \mathrm{kg}$ ASA resulted in 
complete inhibition of the production of HHT and, hence, TXA2. The production of 12-HETE, however, increased. When measured 40 and 100 minutes after administration of ASA, the amount produced increased on the average to 1.32 and 1.43 times the control value, respectively. No effects of ASA were observed on the limited production of other hydroxy acids by the platelets.

\section{Effect of ASA on the thromboembolic reaction in vivo}

In both the ASA and control group, bleeding as well as thrombus formation started immediately following puncture of the wall of arterioles and venules. In all vessels a thrombus started to grow within $0.1 \mathrm{~s}$ following puncture and reached its maximal size within 1 to $2 \mathrm{~s}$. In most vessels adhesion of circulating platelets to the downstream side of the thrombus continued for some time. Parts of these thrombi embolized, leaving the shape of the thrombus virtually unaffected. The formation of the thrombus itself was not influenced by ASA in both arterioles and venules.

Arterioles. The median period of bleeding in the arterioles of the control rabbits was $2.3 \mathrm{~s}$ and $0.5 \mathrm{~s}$ following ASA, a non-significant difference $(p=0.13)$. The height of the thrombus, relative to the local vessel diameter, was similar in both groups (median

\section{EMBOLIZATION IN ARTERIOLES}
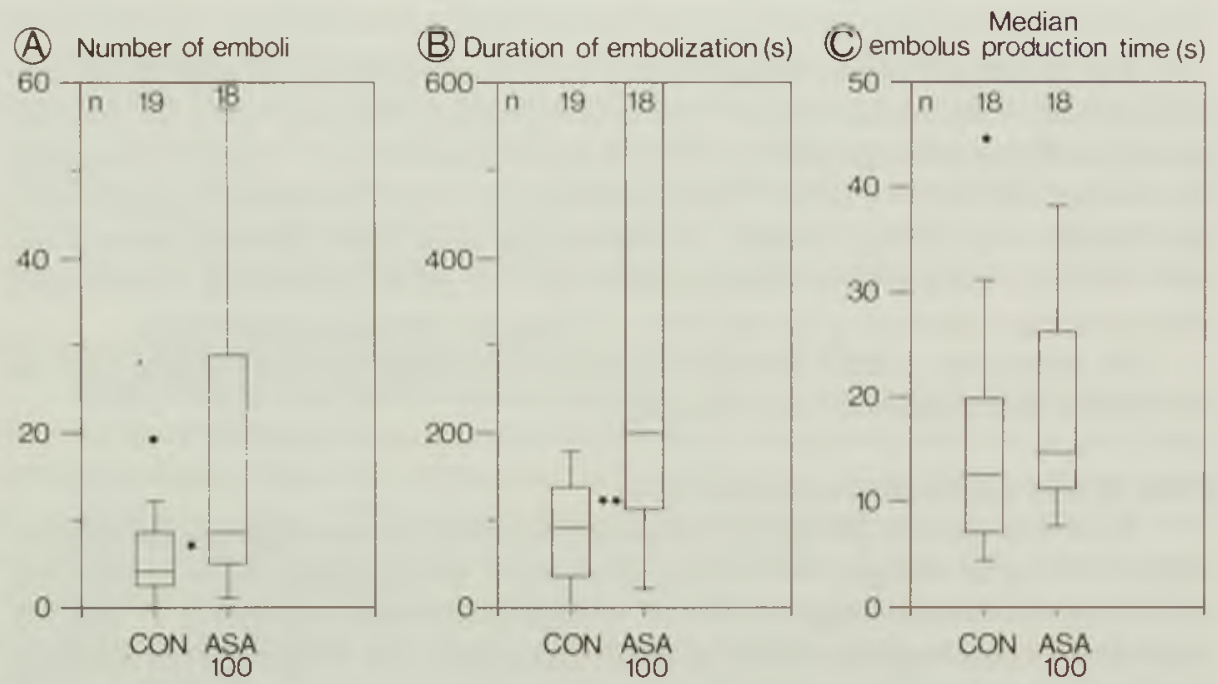

FIGURE 9.2 Embolization parameters in arterioles of control rabbits (CON) and rabbits that received $100 \mathrm{mg} / \mathrm{kg}$ aspirin (ASA-100). The number of emboli produced (A), the duration of embolization $(B)$ and the median embolus production time per vessel $(C)$ are shown by baxplots (see methods-section). Circles represent stray values. The median embolus production time could only be assessed in vessels in which emboli were produced * $p \leq 0.05$ and ** $p \leq 0.005$ as compared to control. 
heights: $68 \%$ and $72 \%$, respectively). The production of emboli started in the control arterioles on the average $21 \mathrm{~s}$ and in the ASA- 100 vessels $22 \mathrm{~s}$ after wall puncture. The embolization process in the arterioles of both groups of rabbits is illustrated in Figure 9.2. The number of emboli produced per vessel (Figure 9.2A) increased significantly $(p \leq 0.05)$ after ASA administration, the median value being 4 in the control group and 8.5 in the ASA-100 group. Concomitantly, the duration of embolization (Figure 9.2B) was significantly longer ( $p \leq 0.005$ ) in the ASA-100 arterioles (median: $200 \mathrm{~s}$ ) than in the control vessels $(91 \mathrm{~s})$. In arterioles the median embolus production time (Figure 9.2C) was in arterioles not influenced by ASA (control: $13 \mathrm{~s}$; ASA-100: $15 \mathrm{~s}$ ). Rebleeding through the thrombus during the observation period occurred in 2 of the 19 control arterioles ( 1 and 6 times, respectively) and in 2 of the 18 ASA-100 arterioles ( 1 and 3 times, respectively). The duration of the rebleeding periods ranged from 0.4 to $14.9 \mathrm{~s}$.

Thus, as is schematically illustrated in Figure 9.4, the essential effect of ASA on the thromboembolic reaction in arterioles was an increase in the number of emboli produced. However, in arterioles the rate of embolus production, as represented by the slope, was not influenced by ASA. The end of the embolization process, as represented by the point where the curve becomes horizontal, was delayed.

\section{EMBOLIZATION IN VENULES}

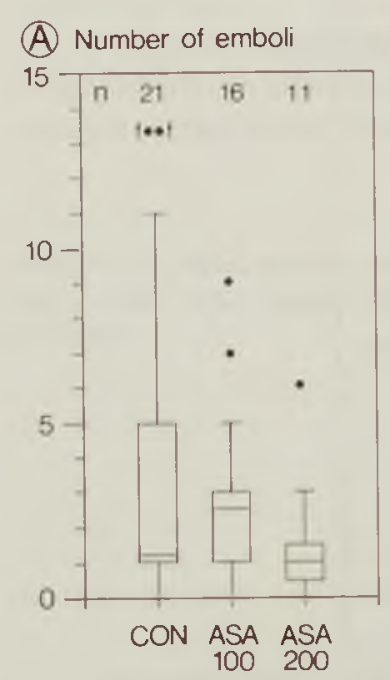

(B) Duration of embolization (s)

Median
(C) embolus production time (s)
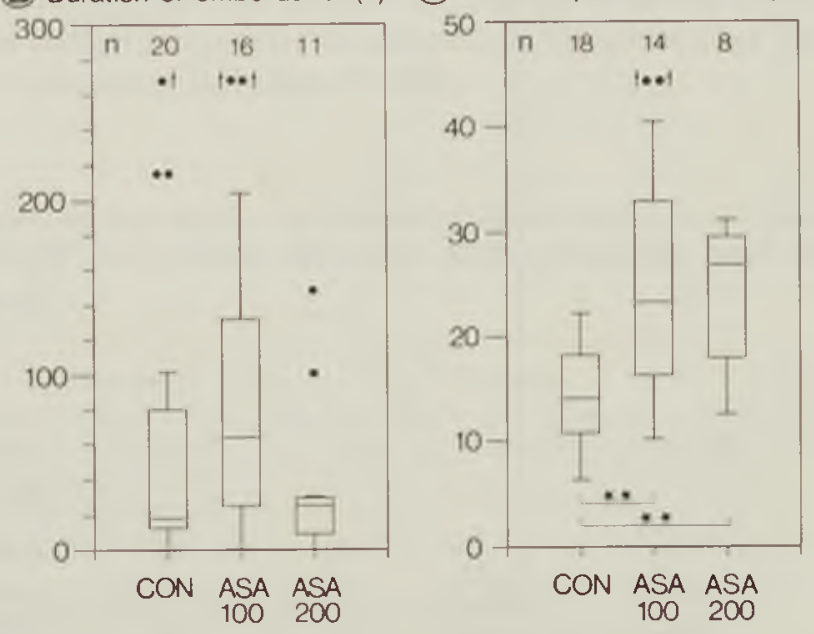

FIGURE 9.3 Embolization parameters in venules of control rabbits (CON) and of rabbits that received 100 or $200 \mathrm{mg} / \mathrm{kg}$ aspirin (ASA-100 and ASA-200). The number of emboli produced (A), the duration of embolization (B) and the median embolus production time per vessel (C) are shown by baxplots (see methods-section). Circles represent stray values. Some of the stray values fall outside the range presented in the figures and are indicated by the arrows. The median embolus production time could only be assessed in vessels in which emboli were produced. ** $p \leq 0.005$ as compared to control. 
Venules. The periods of bleeding following puncture were short in venules and not influenced by ASA (median duration in the control group: $2.1 \mathrm{~s}$; ASA-100: $3.8 \mathrm{~s}$; ASA-200: $1.8 \mathrm{~s})$. The relative height of the thrombus was similar in all groups $(65 \%$, $68 \%$ and $63 \%$, respectively). The venular embolization process is presented in Figure 9.3. The number of emboli produced per venule (Figure 9.3A) was not influenced by ASA (medians in control: 1, ASA-100: 2.5 and ASA-200: 1). The duration of the embolization period per vessel (Figure 9.3B), with a median of $18 \mathrm{~s}$ in the control venules, was not significantly influenced by the administration of ASA (ASA-100: $64 \mathrm{~s}$ and ASA200: $25 \mathrm{~s}$ ), although the p-value was near the level of significance in the ASA-100 group $(p=0.09)$. The median embolus production time per vessel (Figure 9.3C) was significantly longer ( $p \leq 0.005$ ) after ASA treatment (medians: control $14 \mathrm{~s}$, ASA-100: $23 \mathrm{~s}$ ). Increasing the dose of aspirin to $200 \mathrm{mg} / \mathrm{kg}$ did not induce further prolongation of the embolus production time (median: $27 \mathrm{~s}$ ). The prolongation in overall embolus production time in the ASA-vessels is reflected in the production time of the first embolus in a vessel (median values: control 16 s; ASA-100 25 s; ASA-200 27 s), the differences be-

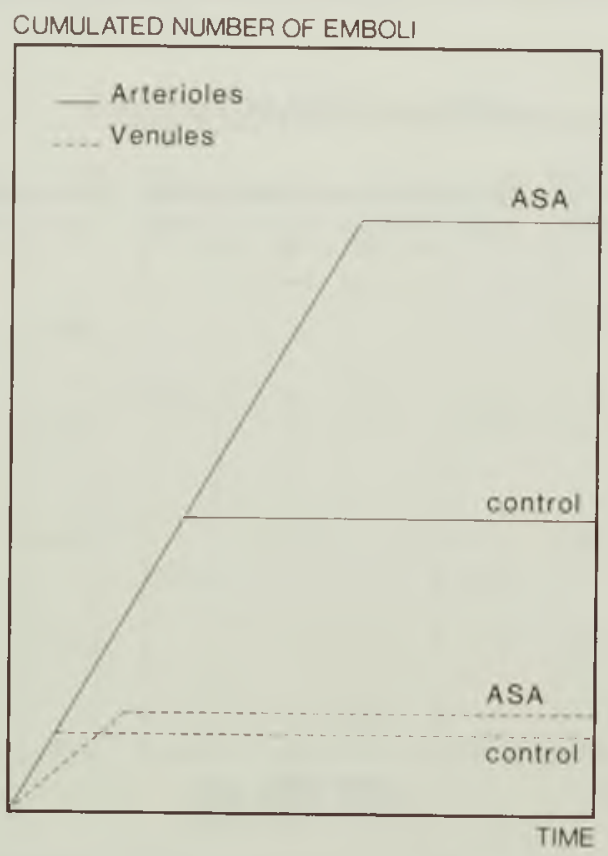

FIGURE 9.4 Schematical representation of the average effects of aspirin (ASA) on the process of embolus production in antrioles and venules. The effects of 100 and $200 \mathrm{mg} / \mathrm{kg}$ aspirin are pooled. The rate of embolus production is represented by the slope of the curve. When the curve becomes horizontal, embolus production stopped. 
tween the control group and both ASA-groups being significant ( $p \leq 0.005$ ). Periods of rebleeding occurred in venules of all groups. In 4 of the 21 control venules 1 to 4 periods of rebleeding were observed with a median duration of $4.7 \mathrm{~s}$ per vessel. Following $100 \mathrm{mg} / \mathrm{kg}$ ASA rebleeding occurred in 4 of the 16 venules ( 1 to 10 times; median duration per vessel $1.2 \mathrm{~s}$ ) and after $200 \mathrm{mg} / \mathrm{kg}$ ASA it was seen in 2 of the 11 vessels ( 1 and 2 times; duration 0.6 , and 0.8 and $2.5 \mathrm{~s}$ ).

The median number of leukocytes rolling along the venular vessel wall was not different between the control and the ASA-100 group (control: 32/min; ASA-100: $43 / \mathrm{min}$ ), but it was significantly lower in the ASA-200 group ( $8 / \mathrm{min} ; \mathrm{p} \leq 0.005)$.

Thus, as is illustrated in Figure 9.4, the overall effect of ASA (both 100 and 200 $\mathrm{mg} / \mathrm{kg}$ ) on the thromboembolic reaction in venules was a decrease in the rate of embolus production, while the duration of embolization and the number of emboli produced were only slightly and not significantly increased.

\section{Fluid dynamic conditions in different vessel groups}

The median values of the fluid dynamic parameters in the different groups of vessels are presented in Table 9.1. No differences existed in any of these parameters between the arteriolar groups. In the 3 venular groups, diameters were also similar. RBC velocity and reduced velocity U, however, were significantly lower in the ASA-200 venules than in the control and in the ASA-100 venules. RBC velocities and reduced velocities were significantly lower in the latter two groups of venules than in the arterioles of these groups.

Changes in diameter following puncture of the vessel wall were minimal in the arterioles and venules of the control group and the ASA-groups. On the average the changes ranged from $0 \%$ to a reduction in diameter by $3 \%$.

TABLE 9.1 Fluid dynamic parameters in anterioles and venules of rabbits of the control group and of both ASA groups (ASA-100 and ASA-200, respectively). Median values and ranges are presented.

\begin{tabular}{|c|c|c|c|c|c|}
\hline & \multicolumn{2}{|c|}{ Ancrioles } & \multicolumn{3}{|c|}{ Venules } \\
\hline & Control & $\triangle S A-100$ & Control & ASA-100 & ASA-200 \\
\hline \multirow{2}{*}{ Diameter $(\mu \mathrm{m})$} & 28 & 27 & 29 & 29 & 27 \\
\hline & $(21-39)$ & $(22-35)$ & $(21-39)$ & (23-37) & $(23-39)$ \\
\hline \multirow[t]{2}{*}{ RBC velocity (mm/s) } & 2.5 & 2.0 & 1.4 & 1.4 & $0.9 *$ \\
\hline & $(1.5-4.7)$ & $(0.5-4.7)$ & $(0.7-3.4)$ & $(0.5-2.1)$ & $(0.6-1.1)$ \\
\hline \multirow[t]{2}{*}{$\mathrm{U}\left(\mathrm{s}^{-1}\right)$} & 96 & 78 & 41 & 48 & $31 *$ \\
\hline & $(42-181)$ & $(17-141)$ & $(31-121)$ & $(18-72)$ & $(18-43)$ \\
\hline
\end{tabular}

- $p \leq 0.01$ as compared to control 
In 2 arterioles of the rabbits that received $200 \mathrm{mg} / \mathrm{kg}$ ASA vasomotion was observed, with a peak-to-valley amplitude, relative to the mean vessel diameter, of 0.11 and 0.13 and a frequency of 12 and 15 vasomotion cycles per minute, respectively. These arterioles, that were not punctured, contracted strongly when they were touched with a micropipet. No vasomotion was observed in any of the other vessel groups.

\subsection{DISCUSSION}

Inhibition of the enzyme cyclooxygenase by aspirin does result in a prolongation of the period of embolization in arterioles, but not in venules of the rabbit mesentery following wall puncture. In the venules, however, aspirin induces a decrease in the rate of embolus production, while this rate is not influenced in the arterioles.

The doses of aspirin, as used in the present study, completely inhibited the capacity of aggregating platelets to produce TXA2. No techniques were available to determine directly whether the production of $\mathrm{PGI}_{2}$ by the wall of microvessels was also inhibited. However, the finding that the arteriolar thromboembolic reaction is prolonged after treatment with $100 \mathrm{mg} / \mathrm{kg}$ aspirin indirectly indicates that the formation of one or more aggregation inhibiting prostaglandins, for example PGI 2 , must have been partly or totally blocked. In addition, data derived from studies on larger vessels in rabbits indicate that with the doses, as used in the present study, the production of $\mathrm{PGI}_{2}$ must have been blocked almost completely for the duration of our experiments (Kelton et al, 1978; Ellis et al, 1980; Buchanan et al, 1981; Wu et al, 1981). Some other studies suggest that even lower doses of aspirin induce an almost total inhibition of PGI2 production in larger vessels of rabbits (Buchanan and Hirsh, 1984; Frazer and Ritter, 1987). Doses of 100 and $200 \mathrm{mg} / \mathrm{kg}$ aspirin are not toxic for rabbits, although the higher dose has to be administered with caution. A dose of $500 \mathrm{mg} / \mathrm{kg}$, however, causes severe hypotension, which can lead to the death of the rabbit (unpublished observation).

The finding that in arterioles aspirin treatment prolongs the period of embolization, while the production rate is not affected (Figure 9.4), indicates that normally in these vessels the role of one or more platelet inhibiting prostaglandins is more important than the role of platelet stimulating prostaglandins. $\mathrm{PGI}_{2}$ could be such an inhibitor, since in vitro studies have shown that microvascular endothelium can synthesize $\mathrm{PGI}_{2}$, as well as other prostaglandins (Gerritsen and Cheli, 1983; Charo et al, 1984). $\mathrm{PGI}_{2}$ seems to be the most effective platelet inhibiting prostaglandin in platelet-vessel wall interactions in vivo (Ubatuba et al, 1979). The suggestion of Rosenblum and coworkers (1980), who investigated the effect of aspirin on platelet reactions in arterioles, but not in venules of the mouse mesentery, that $\mathrm{PGI}_{2}$ produced in the mesothelium might influence arteriolar platelet-vessel wall interactions, is not supported by the results of the present study. The finding that aspirin treatment prolongs the embolus production period in arterioles but not in the more permeable venules, indicates that 
the role of mesothelial $\mathrm{PGI}_{2}$, if any, has to be of secondary importance, as compared with the role of $\mathrm{PGI}_{2}$ produced by the vessel wall.

$\mathrm{TXA}_{2}$, the production of which was totally inhibited by aspirin, does not seem to be a very important platelet activator in mesenteric arterioles in case of vessel wall injury. Agents capable of activating platelets via cyclooxygenase independent pathways (see: Kinlough-Rathbone et al, 1977a; 1980) may be more important.

In contrast to arterioles, in venules the role of platelet stimulating prostaglandins, like TXA2, is at least equally important as that of platelet inhibiting prostaglandins, like $\mathrm{PGI}_{2}$, since aspirin induces a decrease in the rate of embolus production, without significant change in the duration of the reaction (Figure 9.4). These venular data seem contradictory to the findings of Arfors and colleaques (1972), who found that a high dose of aspirin $(200 \mathrm{mg} / \mathrm{kg}$ ) resulted in a shortening of the bleeding time in transected rabbit mesenteric venules but not in arterioles. However, their findings appeared to result from the inhibition of prostaglandins, formed within the tissue as a result of the relatively high amount of tissue trauma caused by the transectioning (Arfors $e t$ al, 1976a). It was proposed that these prostaglandins preferentially entered the more permeable venules. It is likely that the limited tissue trauma as induced by puncture explains the difference between their results and ours.

It is unlikely that the observed effects of a dose of $100 \mathrm{mg} / \mathrm{kg}$ aspirin are caused by differences in fluid dynamic conditions, as is apparent from the data shown in Table 9.1. Leukocyte rolling is probably not responsible for the effects either, since the number of rollers is similar after the administration of $100 \mathrm{mg} / \mathrm{kg}$ aspirin and in the control situation. In the venules of rabbits which received $200 \mathrm{mg} / \mathrm{kg}$ aspirin, on the other hand, the values of the fluid dynamic parameters as well as the number of leukocytes rolling along the wall differed from those in the control group and the group that received 100 $\mathrm{mg} / \mathrm{kg}$ aspirin. Despite these differences the thromboembolic reaction in venules of this group did not differ from that in the venules of rabbits which received a dose of $100 \mathrm{mg} / \mathrm{kg}$.

The findings of the present study indicate that the relative contribution to a thromboembolic reaction of platelet activating and platelet inhibiting prostaglandins is different in mesenteric arterioles and venules. A functional difference between arteriolar and venular endothelium could be the origin of this observation. The contribution of platelet stimulating factors, i.e. prostaglandins and other factors, produced in the arteriolar vessel wall might be higher than the contribution of such factors in venules, resulting in a relatively less important role for TXA2 produced by the platelets. On the other hand, arteriolar endothelial cells might produce more inhibiting prostaglandins, like $\mathrm{PGI}_{2}$, than venular ones. To our knowledge, it has not been investigated whether such differences do indeed exist between arteriolar and venular endothelium within the same tissue. In animals as well as in humans differences in PGI2 production are observed between arteries and veins, the difference probably being dependent on the origin of the vessels (Moncada et al, 1977b; Villa and de Gaetano, 1977; Johnson, 1980; Hanley and Bevan, 1985).

Some caution must be exercised before attributing all the observed effects of as- 
pirin only to the inhibition of prostaglandin formation. The HPLC measurements show that the inhibition of TXA 2 synthesis by the aggregating platelets is associated with an increase in the formation of 12-HETE of 30 to $40 \%$. The formation of 12-HETE is the result of an overflow from the inhibited cyclooxygenase pathway to the lipoxygenase pathway (see Figure 9.1). The physiological significance of 12-HETE is still subject to debate (Brash, 1985), although a variety of activities of this eicosanoid has been described. Dutilh and colleaques (1980) showed that in vitro 12-HETE can make platelet aggregation irreversible, despite the fact that it does not influence aggregation itself. 12-HETE facilitates platelet adhesion to collagen in vitro (Buchanan et al, 1986). Hadjiagapiou and Spector (1986) showed that 12-HETE reduces the formation of prostaglandins, including $\mathrm{PGI}_{2}$, in cultured endothelial cells. The significance of the increased production of 12-HETE in the platelet-vessel wall interactions in the present study is unclear and needs further investigation.

In contrast to other tissues, like skeletal muscle where vasomotion is a well known phenomenon (Tangelder et al, 1984; Oude Vrielink, 1988), we have never observed vasomotion in rabbit mesenteric arterioles (e.g. Tangelder, 1982; Tangelder et al, 1988). Therefore, it is interesting to note that vasomotion was observed in a few arterioles of the high dose $(200 \mathrm{mg} / \mathrm{kg})$ aspirin group. This finding is in agreement with that of Faber and colleaques (1982), who showed that inhibition of prostaglandin synthesis could induce vasomotion in cremaster muscle arterioles, which lacked spontaneous vasomotion. These observations indicate that, locally, prostaglandins play a role in the control of arteriolar vasomotion.

In conclusion, a high dose of aspirin induces changes in the thromboembolic reaction following wall puncture in rabbit mesenteric arterioles and venules. In arterioles, where the embolization period is prolonged following aspirin, the role of platelet inhibiting prostaglandins, like $\mathrm{PGI}_{2}$, appears to be more important than that of platelet stimulating prostaglandins, like TXAz. In venules, where the rate of embolization is decreased, the relative contribution of the stimulating prostaglandins appears to be most important. Functional differences between arteriolar and venular endothelium might be the origin of these findings.

\subsection{SUMMARY}

The involvement of prostaglandins in the thromboembolic reaction following vessel wall puncture was investigated in arterioles and venules of the rabbit mesentery, using intravital videomicroscopy. Pretreatment of the rabbits with high doses of aspirin (100 and $200 \mathrm{mg} / \mathrm{kg}$ ), which completely inhibited $\mathrm{TXA}_{2}$ formation by aggregating platelets and probably also the formation of inhibiting prostaglandins by the vessel walls, had different effects in arterioles and venules. In arterioles, the period of embolization was significantly prolonged by treatment with $100 \mathrm{mg} / \mathrm{kg}$ aspirin (from $91 \mathrm{~s}$ to $200 \mathrm{~s}$ ), while the rate of embolus production was not influenced. In venules, however, 100 
$\mathrm{mg} / \mathrm{kg}$ aspirin did not significantly influence the duration of embolization, but a decrease in the rate of embolus production was induced (from $14 \mathrm{~s}$ per embolus to $23 \mathrm{~s}$ per embolus). Increasing the dose of aspirin to $200 \mathrm{mg} / \mathrm{kg}$ had no further influence. The effects induced by aspirin cannot be explained by fluid dynamic factors or, in the venules, by changes in the degree of leukocyte rolling. Therefore, the findings of the present study suggest that the involvement of platelet activating and platelet inhibiting prostaglandins in the thromboembolic reaction following vessel wall injury differs in mesenteric arterioles and venules. 


\section{GENERAL DISCUSSION}

In the present study the thromboembolic reaction following a mechanically induced vessel wall injury was investigated in rabbit mesenteric microvessels, using intravital videomicroscopy. The reaction differs in arterioles and venules, the period of embolization being longer in arterioles than in venules. This difference cannot be explained by fluid dynamic factors or by the different blood gas and $\mathrm{pH}$ values in these vessel types. The presence of rolling leukocytes in venules, but not in arterioles may offer an explanation, either through a direct interaction between leukocytes and platelets or indirectly through involvement of vascular cells. The results of this thesis suggest that functional differences in vessel wall properties, other than prostaglandin production, exist between arterioles and venules, which may be responsible for the difference in thromboembolic reaction between both vessel types.

The preparation used in the present study, the rabbit mesentery, is a tissue which seems well suited to investigate platelet-vessel wall interactions. It can be exposed without extensive chirurgical interventions and it is thin and transparent, allowing the use of transillumination which yields clear microscopic pictures. An additional advantage of the mesentery with regard to the present study is the low vasoactivity of its microvessels. No vasoconstriction occurs following puncture; therefore, bleeding has to be stopped by platelet-vessel wall interactions alone. In addition, because mesenteric microvessels do not react with diameter variations to changes in intra or extravascular oxygen tension (Lang and Johnson, 1988; Sicking et al, 1988; own observation), the influence of changes in $\mathrm{pO}_{2}$ on the thromboembolic reaction (chapter 6) can be studied without interference by fluid dynamic changes.

A method was developed (chapter 4) to inflict in a standardized way a small mechanical trauma to a microvessel by puncture with a glass micropipet. The occasional toughness of the mesenteric connective tissue is the only inconvenience as far as this technique of inflicting a mechanical vessel wall injury is concerned. Consequently, puncture of a microvessel was not always successful. However, only vessels in which puncture resulted in actual bleeding and, hence, in a damage of all layers of the wall have been included in the studies. Puncture induces the formation of an intravascular 
thrombus, which is often attended with the subsequent formation of emboli. In contrast to transectioning of vessels, which induces the formation of a hemostatic plug, micropuncture produces only a small amount of tissue trauma.

The intravascular platelet-vessel wall interactions, as evoked by vessel wall puncture, stop bleeding within a few seconds. Thrombus formation starts within one tenth of a second after puncture and the maximal thrombus height is reached within one to two seconds (chapter 4). The so formed thrombus is stationary, its form being virtually unaffected during the process of embolization (chapter 6). Electron microscopic observation of a stationary thrombus (Figure 10.1) indicates that it consists of tightly packed platelets, which have lost their discoid shape and most of their contents. These platelets must have been activated within tens of milliseconds after infliction of the injury, which is some orders of magnitude faster than expected on the basis of aggregation tests performed in vitro (chapter 7; Born, 1970). Upon activation, the platelets adhere to the damaged vessel wall and enter the hole produced by puncture, covering the exposed collagen containing layers of the vessel wall (Figure 10.1). Subsequently, or maybe even simultaneously, they stick to each other to form a thrombus and release the contents of their secretory vesicles.

As is shown in Figure 10.1, puncture of a vessel may be associated with the production of a dent in the wall, protruding into the lumen. Therefore, the contribution of the platelet thrombus to the actual size and height of the stenosis, as measured with the use of intravital microscopic images, may be overrated due to the presence of a dent, which is covered by the aggregated platelets. Although the effective size of the stenosis was rather constant in arterioles and venules, it is not known to which extent, and possibly varying degree, the dent has contributed to the occluding mass, creating the stenosis. It should be pointed out, however, that with regard to the influence of a stenosis on flow the actual composition of the stenosis, i.e. platelets and/or dent, is not important. On the other hand, variability in the size of the dent may cause variations in the diffusion distances between vessel wall and surface of the platelet thrombus; this kind of variability may have contributed to the rather great variation in the results, as found in the present study. The chance that a dent is produced seems to be similar for arterioles and venules because of the similar vessel wall thickness in both vessel types (Rhodin, 1967, 1968; own observation).

Following the formation of the stationary thrombus, which plugs the hole and covers the exposed subendothelial layers, circulating platelets are still activated in most vessels. They adhere to the thrombus, often without loosing their shape and without a pronounced release reaction, and form a loosely packed platelet mass at the downstream side of the thrombus (Figure 10.1). From time to time such a downstream part breaks loose and is swept away in the bloodstream, leaving the stationary and tightly packed part of the thrombus intact. This process of embolization continues for a certain period of time, during which additional platelets are activated. The activation of platelets has to be the consequence of the dominance of stimulating over inhibiting factors at the site of injury, while the inhibiting factors must prevail from the moment that the thromboembolic reaction stops. 
A consistent finding in the present study is the difference in thromboembolic reaction between arterioles and venules. In arterioles the reaction continues during a longer period of time than in venules, resulting in an embolus production which is on the average 4 to 6 times higher in arterioles than in venules. The rate of embolus production, i.e. the median time period per embolus to be produced, and the size of the emboli (chapter 6) are similar in both vessel types. These latter findings indicate that the number of platelets that is activated per unit of time is similar in arterioles and venules, but that this activation continues during a longer period of time in arterioles. Therefore, in arterioles the balance between pro and antithrombotic factors seems to be in favor of the prothrombotic factors for a longer period of time than in venules. During the period of embolization the net quantitative difference between pro and antithrombotic contributions may be equal in arterioles and venules.

Fluid dynamic parameters cannot explain the difference in reaction between arterioles and venules. Neither the initial fluid dynamic conditions nor the fluid dynamic conditions induced following thrombus formation are responsible for the difference in thromboembolic reaction between both vessel types (chapters 4 and 5). No direct relation was found between the fluid dynamic factors and thromboembolic parameters in any of the studies. Therefore, the response of blood platelets to vessel wall damage in a mesenteric microvessel does not significantly depend on fluid dynamic conditions, at least not within the ranges studied in the present thesis. In the same preparation Arfors and Bergqvist (1974) also did not find a relation between platelet behavior and fluid dynamics during hemostatic plug formation. The finding that embolization stops in the presence of a stenosing thrombus indicates that relatively high levels of shear, up to at least $5500 \mathrm{~s}^{-1}$, can exist in vivo without direct activation of blood platelets.

Changing systemic blood gas and $\mathrm{pH}$ values towards hypercapnic and hypoxic conditions, similar to those found in venules under normal circumstances, induced a decrease in the rate of embolus production in arterioles and venules. However, this intervention did not influence the number of emboli produced in both vessel types. Therefore, the difference in blood gas and $\mathrm{pH}$ values in arterioles and venules cannot explain the difference in thromboembolic reaction between both vessel types (chapter 6). The decrease in rate of embolus production in combined hypercapnic/hypoxic conditions may be a direct consequence of the effect of hypercapnic and hypoxic blood gas and $\mathrm{pH}$ values on the aggregation of rabbit blood platelets (chapter 7), although an effect on vessel wall function cannot be excluded.

A striking phenomenon in the exposed rabbit mesentery is the presence of rolling and, to a lesser extent, sticking leukocytes along the wall in venules, but not in arterioles. When the number of rolling leukocytes rises above approximately 20 per minute, the number of emboli produced per venule appears to decrease below the arteriolar level of embolus production. Therefore, the presence of rolling leukocytes in venules may offer an explanation for the difference in thromboembolic reaction between arterioles and venules (chapter 8). The data suggest that in vivo functional and mutual interactions exist between leukocytes and platelets, while vascular cells may also be involved. Several in vitro studies have provided information on the possible 


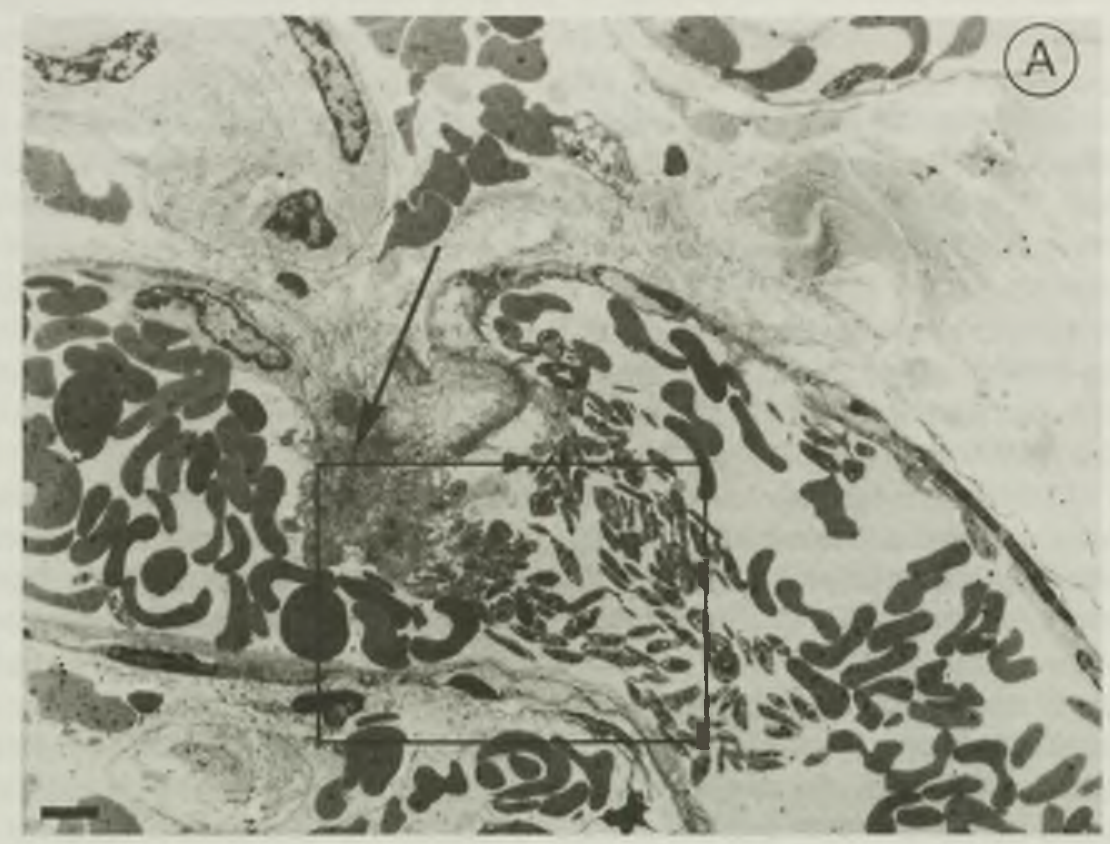

FIGURE 10.1 Electronmicrographs ( $A$ and $B$ ) and schematic textfigure (C) of a thromboembolic reaction in a punctured arteriole.

Figure $A$ presents an overview of the vessel and the dent, which is produced by puncture. The arrow is located in the dent and points towards the site of vessel wall injury. Blood flow is from left to right. The square indicates the part of this figure which is shown at a higher magnification in figure $B$ and matching textigure $C$. As illustrated in these figures, puncture resulted in bleeding (extravascular red blood cells). At the downstream side of the stationary thrombus, consisting of tightly packed platelets, new platelets have adhered and are aggregated without changing their shape; such a downstream part embolizes after a certain time. In contrast to the platelets in the thrombus, the platelets adhering downstream still contain most of their secretory vesicles. $R B C=$ red blood cell. $P L=$ platelet.

$B$ ar in each figure indicates $4 \mu \mathrm{m}$.

The mesenteric tissue was fuxated by superfusion during 10 minutes with $2.5 \%$ glutaraldehyde and $4 \%$ paraformaldehyde in $0.1 \mathrm{M}$ phosphate buffer ( $p H$ 7.3). After excision, the piece of mesentery with the injured vessel was postfixated in the same solution at $4^{\circ} \mathrm{C}$ for up to one week. After postfixation in $1 \% \mathrm{OsO}_{4}(60 \mathrm{~min}, 4 \mathrm{C})$, the tissue was dehydrated through graded alcohol and embedded in Epon. Ultrathin sections were stained with lead citrate and uranyl acelate, and examined with a Philips EM 400 electron microscope. 

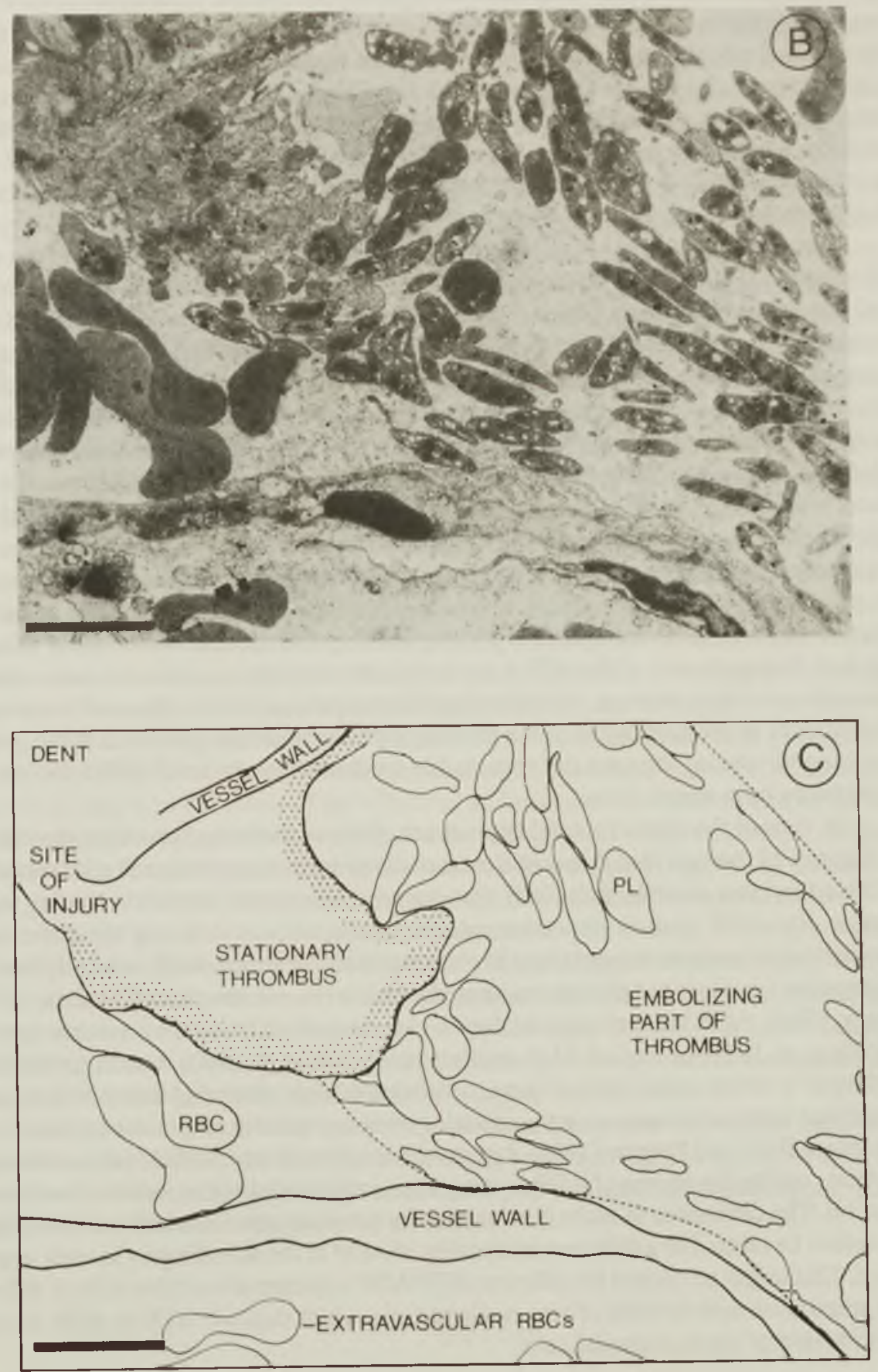
pathways of interactions between these three cell-types. Beside production or elimination of substances by one cell-type that can influence the behavior of another cell-type directly, it is possible that transcellular exchange of, for example, eicosanoid precursors or intermediates is involved in cell-cell interactions (Marcus, 1986). For example, leukocyte derived prostaglandin endoperoxides may be utilized by endothelial cells to produce the platelet inhibiting substance $\mathrm{PGI}_{2}$, while platelet derived 12-HETE can be utilized by either activated or resting leukocytes to produce substances, the function of which is not yet elucidated (Wong et al, 1984; Marcus et al, 1985).

The finding that neither differences in fluid dynamic factors nor in blood gas and $\mathrm{pH}$ values can explain the difference in thromboembolic reaction between arterioles and venules suggests that, beside the possible influence of rolling leukocytes on the venular reaction, differences in vessel wall functions are responsible for the different reactions in both vessel types. The presence of rolling and sticking leukocytes in mesenteric venules, but not in arterioles, is by itself an obvious indication of a functional difference between venular and arteriolar endothelial cells. The endothelial factor(s) related to leukocyte rolling may contribute to the less pronounced platelet reaction to vessel wall injury in venules as compared to arterioles. In addition to leukocyte related differences, arteriolar and venular vascular cells may also differ in pro and anti thrombotic properties. The results of the study described in chapter 9 suggest that the vascular production of platelet inhibiting prostaglandins, like $\mathrm{PGI}_{2}$, is not the same in arterioles and venules. Inhibition of prostaglandin production, however, does not result in a disappearance of the difference in thromboembolic reaction between arterioles and venules; in contrast, the difference is even enhanced. Therefore, although the involvement of prostaglandins in the thromboembolic reaction appears to differ in arterioles and venules, they are not responsible for the difference in embolization activity between both vessel types.

In view of the ultrastructural appearance of the embolizing part of the thrombus in Figure 10.1, being a loosely packed mass of discoid platelets which still contain most of their secretory vesicles, it is likely that one or more 'weak' platelet activating substances, like ADP, play an important role in platelet activation during the embolization period. In contrast to substances like thrombin and collagen, ADP induced platelet aggregation in vitro is not directly associated with the release reaction (Holmsen, 1977; Lages, 1986). ADP induced aggregation in vivo, as evoked by either laser irradiation (Hovig et al, 1974) or topical ADP application (Katori et al, 1987), results in the formation of a rather loose platelet mass, consisting of disk-shaped platelets with a well preserved internal structure; such a platelet mass completely embolizes in time. According to Born and Kratzer (1984), damaged vascular cells and probably also activated platelets can be the source of ADP in quantities, sufficiently high to induce platelet activation. The difference in embolization activity between arterioles and venules might therefore be related to a different availability of $A D P$ at the site of injury in both vessel types. This might be caused by different ATP/ADP contents of vascular cells or different amounts or activity rates of ecto-nucleotidases, which degrade ATP or ADP, on the luminal side of the endothelial cells. 
In both arterioles and venules collagen as well as thrombin may be involved in the initial phase of the thromboembolic reaction, during which period the stationary part of the thrombus is formed. Both collagen and thrombin are known as 'strong' platelet activating substances, inducing the total scale of platelet responses when present in sufficiently high concentrations (Holmsen, 1977; Lages, 1986). It is uncertain, however, whether these substances are important during the embolization phase. The collagen fibers, which are exposed by puncture, are quickly covered by activated platelets during the initial phase of thrombus formation. Therefore, it seems unlikely that collagen plays a role during the embolization phase. Thrombin may be formed at the site of injury as a result of vessel wall induced coagulation, although its actual availability also depends on local anti and procoagulant properties of the vascular cells. It cannot be excluded that low concentrations of thrombin are involved in platelet activation during the period of embolization. The role of $\mathrm{TXA}_{2}$, as produced and released by activated platelets, seems to be of subordinate importance in platelet-vessel wall interactions following vessel wall injury in arterioles (chapter 9); in venules the relative importance of $\mathrm{TXA}_{2}$ may be somewhat higher, possibly because of a lower availability of other platelet activating substances, like ADP.

A difference in thromboembolic reaction between arterioles and venules has not been reported before. It would be interesting to know whether platelet-vessel wall interactions, as induced by vessel wall injury, are more extensive in arterioles than in venules of other tissues as well. It is possible that exposure of the mesentery induces an inflammatory reaction, as might be inferred from the presence of rolling and sticking leukocytes. Recently, it has been reported that in the intact ear of the mouse leukocyte rolling is not observed, but that it can be induced by irritation of the skin (Tangelder and Arfors, 1988). The difference in thromboembolic reaction, as found in the exposed mesentery, might be the result of the effects of an inflammatory reaction and could be absent under non-inflammatory conditions. In venules with a low number of rolling leukocytes the reaction was similar to the reaction in arterioles (chapter 8). Subcutaneous vessels, which are interesting from a (patho)physiological viewpoint because of their relatively high risk for mechanical injury, and/or pial vessels, which are easily accessible when exposed, may be suited to study this phenomenon in the future. If the difference in thromboembolic reaction between arterioles and venules is substantiated in these tissues, the present findings could be applied more generally. A functional interpretation of such a finding could be that it offers a general protective mechanism in arterioles, in which generally blood pressure is higher than in venules.

In conclusion, the present study indicates that functional differences exist between arteriolar and venular vascular cells, which may contribute to the difference in thromboembolic reaction following vessel wall injury between both vessel types. The nature of this difference remains to be elucidated. 


\section{REFERENCES}

Akkerman JWN. Regulation of carbohydrate metabolism in platelets. A review. Thromb Haemost 39: 712 $724,1978$.

Akkerman JWN. Interactions of platelet activating pathways: studies with the platelet function analyzer. In: Platelet responses and metabolism, vol 1: Responses, edited by H Holmsen. CRC Press, Boca Raton, 1986, pp 251-265.

Apitz K. Die Bedeutung der Gerinnung und Thrombose fur die Blutstillung. Virchows Arch [A] 308: 540-614, 1942.

Arfors K-E, DP Dhall, J Engeset, H Hint, NA Matheson and O Tangen. Biolaser endothelial trauma as a means of quantifying platelet activity in vivo. Nature 218: 887-888, 1968.

Arfors K-E, D Bergqvist, S Bygdeman, FN McKenzie and E Svensjo. The effect of inhibition of the platelet release reaction on platelet behaviour in vitro and in vivo. Scand J Haemat 9: 322-332, 1972.

Arfors K-E and D Bergqvist. Influence of blood flow velocity on experimental haemostatic plug formation. Thromb Res 4: 447-461, 1974.

Arfors K-E and D Bergqvist. Platelet aggregability and vessel contraction in microvascular haemostasis. Microvasc Res 9: 22-28, 1975.

Arfors K-E, G Arturson, D Bergqvist and E Svensjō. The effect of inhibition of prostaglandin synthesis on microvascular haemostasis and macromolecular leakage. Thromb Res 8: 393-402, 1976a.

Arfors K-E, JS Cockburn and JF Gross. Measurement of growth rate of laser induced intravascular platelet aggregation and the influence of blood flow velocity. Microvasc Res 11: 79-87, 1976b.

Astrup T. Tissue activators of plasminogen. Fed Proc 25: 42-51, 1966.

Atherton A and GVR Born. Quantitative investigations of the adhesiveness of circulating polymorphonuclear leucocytes to blood vessel walls. J Physiol 222: 447-474, 1972.

Badimon L, JJ Badimon, VT Turitto and V Fuster. Thrombosis: studies under flow conditions. Ann NY Acad Sci 516: 527-540, 1987.

Barnes MJ. Blood vessel wall matrix components involved in vessel wall thrombogenicity. In: Biology and pathology of platelet-vessel wall interactions, edited by G Jolles, YJ Legrand and A Nurden. Academic Press, London, 1986, pp 21-37.

Begent N and GVR Born. Growth rate in vivo of platelet thrombi, produced by iontophoresis of ADP, as a function of mean blood flow velocity. Nature 227: 926-930, 1970.

Bennett JS. The platelet-fibrinogen interaction. In: Platelet membrane glycoproteins, edited by JN George, AT Nurden and DR Phillips. Plenum Press, New York, 1985, pp 193-214.

Benveniste J, R Roubin, M Chignard, E Jouvin Marche and JP Le Couedic. Release of platelet activating factor (PAF-acether) and 2-lyso Paf-acether from three cell types. Agents Actions 12: 711-713, 1982.

Bergqvist D and K-E Arfors. Influence of platelet count on haemostatic plug formation and stability. An experimental study in rabbits with graded thrombocytopenia. Thromb Diathes Haemorrh 30: 586-596, 1973 a. 
Bergqvist D and K-E Arfors. The growth rate of haemostatic plug in the rabbit mesentery. Bibl anat 12:186$192,1973 b$.

Bergqvist D. Hacmostatic plug formation in the rabbit mesentery. A methodological study. Ups J Med Sci 79 . 28-38, 1974.

Bergqvist $\mathrm{D}$ and K-E Arfors. Influence of fibrinolysis and coagulation on hacmostatic plug formation. An experimental study in rabbits. Thromb Res 4: 345-360, 1974.

Bergqvist D an K-E Arfors. Microvascular hacmostasis and the effect of local stimulation and inhibition of platelet function. An experimental study in rabbits. Thromb Haemost 36: 133-139, 1976.

Bergqvist D, S Arvidsson, CO Esquivel, B Lindblad an U Haglund. The effect of serotonin inhibition on initial microvessel hemostasis and platelet aggregation in vivo. Thromb Haemost 49: 173-175, 1983.

Bizzozero J. Ueber einen neuen Formbestandtheil des Blutes und dessen Rolle bei der Thrombose und der Blutgerinnung. Virchows Arch Pathol Anat Physiol Klin Mcd 90: 261-332, 1882.

Blair LA, SE Barrow, KA Waddell, PJ Lewis and CT Dollery. Prostacyclin is not a circulating hormone in man. Prostaglandins 23: 579-589, 1982.

Bocrgen KP, R Birngruber and F Hillenkamp. Laser-induced endovascular thrombosis as a possibility of selective vessel closure. Ophthalmic Res 13: 139-150, 1981.

Born GVR. Quantitative investigations into the aggregation of blood platelets. J Physiol 162: 67P-68P, 1962.

Born GVR and MJ Cross. The aggregation of blood platelets. J Physiol 168: 178-195, 1963.

Born GVR. Observations on the change in shape of blood platelets brought about by adenosine diphosphate. J Physiol 209: 487-511, 1970.

Born GVR, D Bergqvist and K-E Arfors. Evidence for inhibition of platelet activation in blood by a drug effect on erythrocytes. Nature 259, 233-235, 1976.

Born GVR and MAA Kratzer. Source and concentration of extracellular adenosine triphosphate during haemostasis in rats, rabbits and man. J Physiol 354: 419-429, 1984.

Born GVR. Adenosine diphosphate as a mediator of platelet aggregation in vivo: an editorial view. Circulation 72: 741-746, 1985.

Bourgain RH, H Vermariên, R Andries, F Vereecke, J Jacqueloot, J Rennies, E Blockeel and F Six. A standardized 'in vivo' model for the study of experimental arterial thrombosis: description of a method. Adv Exp Med Biol (Oxygen transport to tissue VI) 635-649, 1984.

Brash AR. A review of possible roles of the platelet 12-lipoxygenase. Circulation 72: 702-707, 1985.

Brown CH, LB Leverett, CW Lewis, CP Alfrey and JD Hellums. Morphological, biochemical, and functional changes in human platelets subjected to shear stress. J Lab Clin Med 86: 462-471, 1975.

Buchanan MR, E Dejana and M Gent. Enhanced platelet accumulation onto injured carotid arteries in rabbits after aspirin treatment. J Clin Invest 67: 503-508, 1981.

Buchanan MR and J Hirsh. Effect of aspirin and salicylate on platelet-vessel wall interactions in rabbits. Arteriosclerosis 4: 403-406, 1984.

Buchanan MR, RW Butt, J Hirsh, BA Markham and DJ Nazir. Role of lipoxygenase metabolism in platelet function: effect of aspirin and salicylate. Prostaglandins Leukotrienes Med 21: 157-168, 1986.

Buchanan MR and E Bastida. The role of 13-HODE and HETE's in vessel wall/circulating blood cell interactions. Agents Actions 22: 337-339, 1987.

Buchanan MR, M Richardson, TA Haas, J Hirsh and JA Madri. The basement membrane underlying the vascular endothelium is not thrombogenic: in vivo and in vitro studies with rabbit and human tissue. Thromb Haemost 58: 698-704, 1987.

Buchanan MR. Mechanisms of pathogenesis of arterial thrombosis: potential sites of inhibition by therapeutic compounds. Sem Thromb Haemost 14: 33-40, 1988.

Burns KF and CW de Lannoy. Compendium of normal blood values of laboratory animals with indication of variations. I. Random-sexed populations of small animals. Toxicol Appl Pharmacol 8: 429-437, 1966.

Busse R, U Forstermann, H Matsuda and U Pohl. The role of prostaglandins in the endothelium-mediated vasodilatory response to hypoxia. Eur J Physiol (Pflügers Arch) 401: 77-83, 1984.

Butler KD and AM White. Basic problems in the search for anti-thrombotic therapy. In: Thromboembolism. A new approach to therapy, edited by JRA Mithcell and JG Domenet. Academic Press, New York, 1977, pp 29-39. 
Chambers R and BW Zwcifach. Topography and function of the mesenteric capillary circulation. Am J Anat 75: 173-198, 1944.

Chap H, M-F Simon, G Mauco, M Plantavid, J Fauvel, L Rossignol, P Dajeans and L Douste-Blazy. Platelet phospholipids and their metabolites in the regulation of platelet responses. In: Biology and pathology of platelet-vessel wall interactions, edited by G Jolles, YJ Legrand and A Nurden. Academic Press, London, 1986, pp 267-287.

Chap H, M Plantavid, BP Perret, EM Bevers, L Douste-Blazy and RFA Zwaal. Phospholipids: structural and metabolic asymmetry of phospholipids. In: Platelet responses and metabolism, vol 3: Response-metabolism relationships, edited by H Holmsen. CRC Press, Boca Raton, 1987, pp 175-186.

Charo IF, S Shak, MA Karasek, PM Davison and IM Goldstein. Prostaglandin $\mathrm{I}_{2}$ is not a major metabolite of arachidonic acid in cultured endothelial cells from human for eskin microvessels. J Clin Invest 74: 914-919, 1984.

Chen TI and C Tsai. The mechanism of hacmostasis in peripheral vessels. J Physiol 107: 280-288, 1948.

Chernukh AM, VS Shinkarenko, LS Ivanov, OV Alekseev and VS Sinyakov. Simulation of microcirculatory disorders by the use of an ultraviolet laser. Bull Exp Biol Med 81: 19-22, 1976.

Chesterman $\mathrm{CN}$ and $\mathrm{MC}$ Berndt. Platelet and vessel wall interaction and the genesis of atherosclerosis. Clin Haematol 15: 323-353, 1986.

Claeys M, GAA Kivits, E Christ-Hazelhof and DH Nugteren. Metabolic profile of linoleic acid in porcine leukocytes through the lipoxygenase pathway. Biochim Biophys Acta 837: 35-51, 1985.

Coccheri S and T Astrup. Thromboplastic and fibrinolytic activities of large human vessels. Proc Soc Exp Biol Med 108: 369-372, 1961.

Coller BS. Platelet-von Willebrand factor interactions. In: Platelet membrane glycoproteins, edited by JN George, AT Nurden and DR Phillips. Plenum Press, New York, 1985, pp 215-244.

Crawford N and MC Scrutton. Biochemistry of the blood platelet. In: Haemostasis and thrombosis, edited by AL Bloom and DP Thomas. Churchill Livingstone, Edinburgh, 1987, pp 47-77.

De Clerck FF and AG Herman. 5-Hydroxytryptamine and platelet aggregation. Fed Proc 42: 228-232, 1983.

De Gaetano G and S Garattini (eds). Platelets: a multidisciplinary approach. Raven Press, New York, 1978.

Deussen A, G Môser and J Schrader. Contribution of coronary endothelial cells to cardiac adenosine production. Eur J Physiol (Pflügers Arch) 406: 608-614, 1986.

Diczfalusy U, P Falardeau and S Hammarstrồm. Conversion of prostaglandin endoperoxides to $\mathrm{C}_{1} \tau$ hydroxy acids catalyzed by human platelet thromboxane synthase. FEBS lett 84: 271-274, 1977.

Didisheim P. Animal models useful in the study of thrombosis and antithrombotic agents. In: Progress in hemostasis and thrombosis, edited by TH Spaet. Grune and Stratton, New York, 1972, pp 165-197.

Dixon WJ. BMDP statistical software. University of California Press, Berkeley, 1983.

Dodds WJ. Platelet function in animals: species specificities. In: Platelets: a multidisciplinary approach, edited by G de Gaetano and S Garattini. Raven Press, New York, 1978, pp 45-59.

Duling BR and RM Berne. Longitudinal gradients in periarteriolar oxygen tension. Circ Res 27:669-678, 1970.

Dutilh CE, E Haddeman and F ten Hoor. Role of arachidonate lipoxygenase pathway in blood platelet aggregation. In: Advances in prostaglandin and thromboxane research, vol 6, edited by B Samuelsson, PW Ramwell and R Paoletti. Raven Press, New York, 1980, pp 101-105.

Duval DL, P Didisheim, JL Titus, JA Spittell and CA Owen. Experimental arterial thrombosis: description of a method. Mayo Clin Proc 45: 388-395, 1970.

Edlund $\mathrm{A}$ and $\AA$ Wennmalm. Hypoxia elicits liberation of anti-aggregatory substances form isolated rabbit hearts. Clin Physiol 3: 399-409, 1983.

Ellis EF, KF Wright, PS Jones, DW Richardson and CK Ellis. Effect of oral aspirin dose on platelet aggregation and vascular prostacyclin ( $\mathrm{PGI}_{2}$ ) synthesis in humans anci rabbits. J Cardiovasc Pharmacol 2: 387 $397,1980$.

Engels W, J Endert, M Kamps, G van der Vusse, M van Bilsen and RS Reneman. Extraction and determination of eicosanoids in biological samples by reverse-phase high-performance liquid chromatography. Prog appl Microcirc 12: 316-321, 1987.

Erickson LA, RR Schleef, T Ny and DJ Loskutoff. The fibrinolytic system of the vascular wall. Clin Haematol 14: 513-530, 1985 . 
Esmon CT. Regulation of protein C activation by components of the endothelial cell surface. In: Vascular endothelium in hemostasis and thrombosis, edited by MA Gimbrone. Churchill Livingstone, Edinburgh, 1986, pp 99-119.

Faber JE, PD Harris and IG Joshua. Microvascular response to blockade of prostaglandin synthesis in rat skeletal muscle. Am J Physiol 243: H51-H60, 1982.

Fitzgerald GA, F Catella and JA Oates. Eicosanoid biosynthesis in human cardiovascular disease. Hum Pathol 18: 248-252, 1987.

Flatow FA and EJ Freireich. The increased effectiveness of platelet concentrates prepared in acidified plasma. Blood 27: 449-459, 1966.

Frasher WG and $\mathrm{H}$ Wayland. A repeating modular organization of the microcirculation of cat mesentery. Microvasc Res 4: 62-76, 1972.

Frazer CE and JM Ritter. Recovery of prostacyclin synthesis by rabbit aortic endothelium and other tissues after inhibition by aspirin. Br J Pharmacol 91: 251-256, 1987.

Frojmovic MM and JG Milton. Human platelet size, shape, and related functions in bealth and disease. Physiol Rev 62: 185-261, 1982.

Gaehtgens P. Pathways and interactions of white cells in the microcirculation. Prog appl Microcirc 12: 51-66, 1987.

George JN, AT Nurden and DR Philips (eds). Platelet membrane glycoproteins. Plenum Press, New York, 1985.

Gerlach E, BF Becker and S Nces. Formation of adenosine by vascular endothelium: a homeostatic and antithrombogenic mechanism? In: Topics and perspectives in adenosine research, edited by E Gerlach and BF Becker. Springer Verlag, Berlin, 1987, pp 309-320.

Gerritsen ME and C Cheli. Arachidonic acid and prostaglandin endoperoxide metabolism in isolated rabbit and coronary microvessels and isolated and cultivated coronary microvessel endothelial cells. J Clin Invest 72: 1658-1671, 1983.

Gimbrone MA, RH Aster, RS Cotran, J Corkery, JH Jandl and J Folkman. Preservation of vascular integrity in organs perfused in vitro with a platelet-rich medium. Nature 222: 33-36, 1969.

Gimbrone MA. Vascular endothelium and atherosclerosis. In: Vascular injury and atherosclerosis, edited by S Moore. Marcel Dekker, New York, 1981, pp 25-52.

Gimbrone MA. Vascular endotbelium: nature's hlood container. In: Vascular endothelium in hemostasis and thrombosis, edited by MA Gimbrone. Churchill Livingstone, Edinburgh, 1986, pp 1-13.

Goldschmidt B. Effect of lactic acid on the aggregation of human platelets induced by ADP, adrenaline and collagen. Experientia 29: 1399-1401, 1973.

Goldsmith HL, SSK Yu and J Marlow. Fluid mechanical stress and the platelet. Thromb Diathes Haemorrh 34: $32-41,1975$.

Goldsmith HL and VT Turitto. Rheological aspects of thrombosis and haemostasis: basic principles and applications. Thromb Haemost 55: 415-435, 1986.

Gordon JL, RJ Evans and GA Gresham. Experimental thrombus formation in mesenteric microvessels: evaluation of a method. Microvasc Res 6: 108-115, 1973.

Gordon JL and JD Pearson. Biology of the vascular endothelium. In: Haemostasis and thrombosis, edited by AL Bloom and DP Thomas. Churchill Livingstone, Edinburgh, 1987, pp 303-311.

Grant L and FF Becker. Mechanisms of inflammation. I. Laser-induced thrombosis, a morphologic analysis. Proc Soc Exp Biol Med 119: 1123-1129, 1965.

Griffith TM, DH Edwards, RL Davies and AH Henderson. The role of EDRF in flow distribution: a microangiographic study of the rabbit isolated ear. Microvasc Res 37: 162-177, 1989.

Gryglewski RJ, S Bunting, S Moncada, RJ Flower and JR Vane. Arterial walls are protected against deposition of platelet thrombi by a substance (prostaglandin $\mathrm{X}$ ) which they make from prostaglandin endoperoxides. Prostaglandins 12: 685-713, 1976.

Hadjiagapiou C and AA Spector. 12-hydroxyeicosatetraenoic acid reduces prostacyclin production by endothelial cells. Prostaglandins 31: 1135-1144, 1986.

Hamberg M, J Svensson and B Samuelsson. Thromboxanes: a new group of biologically active compounds derived from prostaglandin endoperoxides. Proc Natl Acad Sci USA 72: 2994-2998, 1975. 
Han $\mathrm{P}$ and NG Ardlie. The influence of $\mathrm{pH}$, temperature, and calcium on platelet aggregation: maintenance of environmental $\mathrm{pH}$ and platelet function for in vitro studies in plasma stored at $37^{\circ} \mathrm{C}$. $\mathrm{Br} \mathrm{J}$ Haematol 26: 373-389, 1974

Hanley SP and J Bevan. Inhibition by aspirin of human arterial and venous prostacyclin synthesis. Prostaglandins Leukotrienes Med 20: 141-149, 1985.

Hardisty RM and JP Caen. Disorders of platelet function. In: Haemostasis and Thrombosis, edited by AL Bloom and DP Thomas. Churchill Livingstone, Edinburgh, 1987, pp 365-392.

Harrison MJG, PR Emmons and JRA Mitchell. The effect of white cells on platelet aggregation. Thromb Diathes Haemorrh 16: 105-121, 1966.

Haslam RJ and MD McClenaghan. Measurement of circulating prostacyclin. Nature 292: 364-366, 1981.

Haslam RJ. Signal transduction in platelet activation. In: Thrombosis and haemostasis 1987, edited by M Verstraete, J Vermylen, R Lijnen and J Arnout. Leuven University Press, Leuven, 1987, pp 147-174.

Hatanaka K, M Minamiyama, S Takaichi, K Tanaka, H Ishibasbi-Ueda, M Imakita and A Yamamoto. Thrombus formation by the application of thrombin to the outer surface of mouse mesenteric vein: comparison with the application of ADP. Thromb Res 40: 731-743, 1985.

Herrmann KS. Platelet aggregation induced in the hamster cheek pouch by a photochemical process with excited fluorescein isothiocyanate-dextran. Microvasc Res 26: 238-249, 1983.

Herrmann KS and W-H Voigt. Ultrastructural observations of an electron dense amorphous layer on selectively damaged endothelial cells, a possible trigger of thrombogenesis in vivo, and its inhibition by nafazatrom. Thromb Res 36: 205-215, 1984.

Herrmann RG, JD Frank and DL Marlett. An in vivo technique for assessing the formation of a hemostatic platelet plug. Proc Soc Exp Biol Med 128: 960-964, 1968.

Higgs GA, S Bunting, S Moncada and JR Vane. Polymorphonuclear leukocytes produce thromboxane $A_{2}$ like activity during phagocytosis. Prostaglandins 12, 749-757, 1976.

Holmsen H. Prostaglandin endoperoxide-thromboxane synthesis and dense granule secretion as positive feedback loops in the propagation of platelet responses during "the basic platelet reaction". Thromb Haemost 38: 1030-1041, 1977.

Holmsen H. Platelet metabolism and activation. Semin Hematol 22: 219-240, 1985.

Holmsen H (ed). Platelet responses and metabolism, vol 2: Receptors and metabolism, chapters 1A-1G: Agonists and receptors. CRC Press, Boca Raton, 1987a, pp 3-103.

Holmsen H. Cyclic AMP-dependent protein kinases and protein kinase C. In: Platelet responses and metabolism, vol 3: Response-metabolism relationships, edited by H Holmsen. CRC Press, Boca Raton, 1987b, pp 51-68.

Holmsen $\mathrm{H}$ and $\mathrm{M}$ Farstad. Energy metabolism. In: Platelet responses and metabolism, vol 2: Receptors and metabolism, edited by H Holmsen. CRC Press, Boca Raton, 1987, pp 245-254.

Honour AJ and RW Ross. Experimental platelet embolism. Br J Exp Pathol 43, 350-362, 1962.

Honour AJ and JRA Mitchell. Platelet clumping in injured vessels. Br J Exp Pathol 45: 75-87, 1964.

Horne WC, NE Norman, DB Schwartz and ER Simons. Changes in cytoplasmic pH and in membrane potential in thrombin-stimulated human plalets. Eur J Biochem 120: 295-302, 1981.

Hornstra G. Dietary fats and arterial thrombosis. Thesis, Universtiy of Limburg, Maastricht, The Netherlands, 1980.

House SD and HH Lipowsky. Leukocyte-endothelium adhesion: microhemodynamics in mesentery of the cat. Microvasc Res 34: 363-379, 1987.

House SD and HH Lipowsky. In vivo determination of the force of leukocyte-endothelium adhesion in the mesenteric microvasculature of the cat. Circ Res 63, 658-668, 1988.

Hovig T, FN McKenzie and K-E Arfors. Measurement of the platelet response to laser-induced microvascular injury. Ultrastructural studies. Thromb Diathes Haemorrh 32: 695-703, 1974.

Hugues J. Contribution à l'étude des facteurs vasculaires et sanguins dans l'hémostase spontante. Arch Int Physiol 61: 565-711, 1953.

Intaglietta $M$ and WR Tompkins. Microvascular measurements by video image shearing and splitting. Microvasc $\operatorname{Res}$ 5: 309-312, 1973. 
Johnson AR. Human pulmonary enothelial cells in culture. Activities of cells from arteries and cells from veins $\mathrm{J}$ Clin Invest 65: 841-850, 1980.

Johnson SA, RS Balboa, BH Dessel, RW Monto, KA Siegesmund and TJ Greenwalt. The mechanism of the endothelial supporting function of intact platelets. Exp Mol Pathol 3: 115-127, 1964.

Junqueira LC, J Carneiro and JA Long. Basic histology. Lange Medical Publications, Los Altos, 1986.

Katori M, K Sasaki, K Nagai and R Hirose. Roles of arachidonate metabolites in thrombus formation and leukocyte migration: analyses at microcirculatory level. Jpn Circ J 51: 445-450, 1987.

Kelton JG, J Hirsh, CJ Carter and MR Buchanan. Thrombogenic effect of high-dose aspirin in rabbits. Relationship to inhibition of vessel wall synthesis of prostaglandin $\mathrm{I}_{2}$-like activity. J Clin Invest 62: 892-895, 1978.

Kennedy PS, JA Ware, JK Horak and RT Solis. The effect of acute changes in arterial blood $\mathrm{pH}$ and $\mathrm{pO}_{2}$ on platelet aggregation. Microvasc Res 22: 324-330, 1981.

Kikugawa K, K Iizuka and M Ichino. Effect of plasma pH on stability and capacity of aggregation of platelets. Chem Pharm Bull 20: 1569-1571, 1972.

Kinlough-Rathbone RL, MA Packham and JF Mustard. Synergism between platelet aggregating agents: the role of the arachidonate pathway. Thromb Res 11: 567-580, 1977a.

Kinlough-Rathbone RL, MA Packham, H-J Reimers, J-P Cazenave and JF Mustard. Mechanisms of platelet shape change, aggregation, and release induced by collagen, thrombin, or A23,187. J Lab Clin Med 90 : $707-719,1977 b$.

Kinlough-Rathbone RL, J-P Cazenave, MA Packham and JF Mustard. Effect of inhibitors of the arachidonate pathway on the release of granule contents from rabbit platelets adherent to collagen. Lab Invest 42 : 28-34, 1980.

Kitagawa S, M Awai and F Kametani. Relationship of the effects of nigericin on the aggregation and cytoplasmic $\mathrm{pH}$ of bovine platelets in the presence of different cations. Biochim Biophys Acta 930: 48-54, 1987

Kjaerheim $\AA$ and T Hovig. The ultrastructure of haemostatic blood platelet plugs in rabbit mesenterium. Thromb Diathes Haemorrh 7: 1-15, 1962.

Kochen JA and S Baez. Vascular and intravascular effects of a pulsed laser micro-beam. Bibl Anat 7: 46-49, 1965.

Kotzé HF, P Wessels and H Pieters. Kinetics, redistribution, and sites of sequestration of normal platelets. In: Platelet kinetics and imaging, vol 1: Techniques and normal platelet kinetics, edited by A du Heyns, PN Badenhorst and MG Lôtter. CRC Press, Boca Raton, 1985, pp 107-123.

Kovacs IB, A Tigyi-Sebes, K Trombitas and P Gōrōg. Evans blue: an ideal energy-absorbing material to produce intravascular microinjury by HE-NE gas laser. Microvasc Res 10: 107-124, 1975.

Kozma C, W Macklin, LM Cummins and R Mauer. The anatomy, physiology, and the biochemistry of the rabbit. In: The biology of the laboratory rabbit, edited by SE Weisbroth, RE Flatt and AL Kraus AL. Academic Press, New York, 1974, pp 50-72.

Lages B. In vitro platelet responses: dense granule secretion. In: Platelet responses and metabolism, vol 1: Responses, edited by H Holmsen. CRC Press, Boca Raton, 1986, pp 115-143.

Lamberth EL, RA Warriner and ED Batchelor. Effect of metabolic acidosis and alkalosis on human platelet aggregation induced by epinephrine and ADP. Proc Soc Exp Biol Med 145: 743-746, 1974.

Lang DJ and PC Johnson. Elevated ambient oxygen does not affect autoregulation in cat mesentery. Am J Physiol 255: H131-H137, 1988.

Leung LLK. Role of thrombospondin in platelet aggregation. J Clin Invest 74, 1764-1772, 1984.

Loskutoff DJ. The fibrinolytic system of cultured endothelial cells: insights into the role of endothelium in thrombolysis. In: Vascular endothelium in hemostasis and thrombosis, edited by MA Gimbrone. Churchill Livingstone, Edinburgh, 1986, pp 120-141.

Lucchesi BR, JK Mickelson, JW Homeister and CV Jackson. Interaction of the formed elements of blood with the coronary vasculature in vivo. Fed Proc 46: 63-72, 1987.

Lundgren O. Microcirculation of the gastrointestinal tract and pancreas. In: Handbook of Physiology, section 2: The cardiovascular system, vol 4: Microcirculation, edited by EM Renkin and CC Michel. American Physiological Society, Bethesda, 1984, pp 799-863. 
Marcum JA, JS Rosenterg, KA Bauer and RS Rosenberg. The heparin-antithrombin mechanism and vessel wall function. In: Vascular endothelium in hemostasis and thrombosis, edited by MA Gimbrone. Churchill Livingstone, Edinburgh, 1986, pp 70-98.

Marcus AJ, LB Safier, HL Ullman, MJ Broekman, N Islam, TD Oglesby, RR Gorman and JW Ward. Inhibition of platelet function in thrombosis. Circulation 72: 698-701, 1985.

Marcus AJ. Transcellular metabolism of eicosanoids. Prog Hemost Thromb 8: 127-142, 1986.

Mayrovitz HN, MP Wiedeman and RF Tuma. Factors influencing leukocyte adherence in microvessels. Thromb Haemost 38, 823-830, 1977.

McIntyre LV, JA Frangos, BG Rhee, SG Eskin and ER Hall. The effect of fluid mechanical stress on cellular arachidonic acid metabolism. Ann NY Acad Sci 516: 513-524, 1987.

McKenzie FN, K-E Arfors an NA Matheson. Measurement of the platelet response to laser-induced microvascular injury. Assessment of determinants of platelet aggregation in vivo. Thromb Diathes Haemorrh 32: 704-713, 1974.

Mehta J and A Roberts. Human vascular tissues produce thromboxane as well as prostacyclin. Am J Physiol 244: R839-R844, 1983.

Mehta J, P Mehta, DL Lawson, N Ostrowski and L Brigmon. Influence of selective thromboxane synthetase blocker CGS-13080 on thromboxane and prostacyclin biosynthesis in whole blood: Evidence for synthesis of prostacyclin by leukocytes from platelet-derived endoperoxides. J Lab Clin Med 106: 246-252, 1985.

Mills DCB and DP Thomas. Blood platelet nucleotides in man and other species. Nature 222: 991-992, 1969.

Moncada S, R Gryglewski, S Bunting and JR Vane. An enzyme isolated from arteries transforms prostaglandin endoperoxides to an unstable substance that inhibits platelet aggregation. Nature 263: 663-665, 1976.

Moncada S, AG Herman, EA Higgs and JR Vane. Differential formation of prostacyclin (PGX or $\mathbf{P G I}_{2}$ ) by layers of the arterial wall. An explanation for the anti-thrombotic properties of vascular endothelium. Thromb Res 11: 323-344, 1977a.

Moncada S, EA Higgs and JR Vane. Human arterial and venous tissues generate prostacyclin (prostaglandin $\mathrm{X})$, a potent inhibitor of platelet aggregation. Lancet i: 18-20, $1977 \mathrm{~b}$.

Moncada S and JR Vane. Arachidonic acid metabolites and the interactions between platelets and bloodvessel walls. N Engl J Med 300: 1142-1147, 1979.

Moncada S. Biological importance of prostacyclin. Br J Pharmacol 76: 3-31, 1982.

Moncada S, RMJ Palmer and EA Higgs. Prostacyclin and endothelium-derived relaxing factor: biological interactions and significance. In: Thrombosis and Haemostasis 1987, edited by M Verstraete, J Vermylen, R Lijnen and J Arnout. Leuven University Press, Leuven, 1987, pp 597-618.

Mustard JF and MA Packham. Factors influencing platelet function: adhesion, release, and aggregation. Pharmacol Rev 22: 97-187, 1970.

Mustard JF and MA Packham. Normal and abnormal haemostasis. Br Med Bull 33: 187-192, 1977.

Myers PR, R Guerra and DG Harrison. Release of NO and EDRF from cultured bovine aortic endothelial cells. Am J Physiol 256: H1030-H1037, 1989.

Nachman RL, RL Silverstein and AS Asch. Thrombospondin: cell biology of an adhesive glycoprotein. In: Thrombosis and haemostasis 1987, edited by M Verstraete, J Vermylen, $\mathrm{R}$ Lijnen and J Arnout. Leuven University Press, Leuven, 1987, pp 81-91.

Nawroth PP and DM Stern. Endothelial cells as active participants in procoagulant reactions. In: Vascular endothelium in hemostasis and thrombosis, edited by MA Gimbrone. Churchill Livingstone, Edinburgh, 1986, pp 14-39.

Nieuwenhuis HK, JWN Akkerman, WPM Houdijk and JJ Sixma. Human blood platelets showing no response to collagen fail to express surface glycoprotein Ia. Nature 318: 470-472, 1985.

Nieuwenhuis HK, KS Sakariassen, WPM Houdijk, PFEM Nievelstein and JJ Sixma. Deficiency of platelet membrane glycoprotein Ia associated with a decreased platelet adhesion to subendothelium: a defect in platelet spreading. Blood 68: 692-695, 1986.

Nievelstein PFEM and PG de Groot. Interaction of blood platelets with the vessel wall. Haemostasis 18: 342$359,1988$.

Niewiarowski S. Secreted platelet proteins. In: Haemostasis and thrombosis, edited by AL Bloom and DP Thomas. Churchill Livingstone, Edinburgh, 1987, pp 90-100. 
Noordhoek Hegt V. Relations between activation and inhibition of fibrinolysis in the walls of human arteries and veins. Thromb Haemost 38: 407-419, 1977.

Nurden AT. Platelet membrane glycoproteins and their clinical aspects. In: Thrombosis and haemostasis 1987, edited by M Verstraete, J Vermylen, R Lijnen and J Arnout. Leuven University Press, Leuven, 1987, pp 93-125.

Orchard MA, IA Blair, CT Dollery and PJ Lewis. Blood can synthesise prostacyclin. Lancet 2: 565, 1983.

oude Egbrink MGA, GJ Tangelder, DW Slaaf and RS Reneman. Thromboembolic reaction following wall puncture in arterioles and venules of the rabbit mesentery. Thromb Haemost 59: 23-28, 1988.

oude Egbrink MGA, GJ Tangelder, DW Slaaf and RS Reneman. Effect of blood gases and pH on thromboembolic reactions in rabbit mesenteric microvessels. Eur J Physiol (Pflügers Arch) 414: 324-330, 1989.

Oude Vrielink HHE. Vasomotion and skeletal muscle perfusion. Thesis, University of Limburg, Maastricht, The Netherlands, 1988.

Oudinet J-P, J Sracr, M Bens and R Ardaillou. Influence of polymorphonuclear leukocytes on the metabolism of arachidonate in human platelets. Thromb Haemost 60, 59-62, 1988.

Palmer RMJ, AG Ferrige and S Moncada. Nitric oxide release accounts for the biological activity of endothelium-derived relaxing factor. Nature 327: 524-526, 1987.

Pearson JD, JS Carleton and JL Gordon. Metabolism of adenine nucleotides by ectocnzymes of vascular endothelial and smooth-muscle cells in culture. Biochem J 190: 421-429, 1980.

Penington DG. Thrombopoiesis. In: Haemostasis and thrombosis, edited by AL Bloom and DP Thomas. Churchill Livingstone, Edinburgh, 1987, pp 1-19.

Perret B, HJ Chap and L Douste-Blazy. Assymetric distribution of arachidonic acid in the plasma membrane of human platelets. A determination using purified phospholipases and a rapid method for membrane isolation. Biochim Biophys Acta 556: 434-446, 1979.

Phillips DR. Receptors for platelet agonists. In: Platelet membrane glycoproteins, edited by JN George, AT Nurden and DR Phillips. Plenum Press, New York, 1985, pp 145-169.

Phillips DR, IF Charo, LV Parise and LA Fitzgerald. The platelet membrane glycoprotein IIb-IIIa complex Blood 71: 831-843, 1988.

Poole JCF and JE French. Thrombosis. J Atheroscler Res 1: 251-282, 1961.

Radomski MW, RMJ Palmer and S Moncada. Comparative pharmacology of endothelium-derived relaxing factor, nitric oxide and prostacyclin in platelets. Br J Pharmac 92: 181-187, 1987.

Reber K. A device for the production of well-defined lesions of mesenteric blood vessels with resulting platelet thrombi. Thromb Diathes Haemorrh 15: 471-475, 1965.

Revtyak GE, AR Johnson and WB Campbell. Prostaglandin synthesis in bovine coronary endothelial cells: comparison with other commonly studied endothelial cells. Thromb Res 48: 671-683, 1987.

Rhodin JAG. The ultrastructure of mammalian arterioles and precapillary sphincters. J Ultrastruct Res 18 : 181-223, 1967.

Rhodin JAG. Ultrastructure of mammalian venous capillaries, venules, and small collecting veins. J Ultrastruct Res 25: 452-500, 1968.

Rink TJ and TJ Hallam. What turns platelets on? Trends Biochem Sci 9: 215-219, 1984.

Rodgers GM. Hemostatic properties of normal and perturbed vascular cells. FASEB J 2: 116-123, 1988.

Rogers AB. The effect of $\mathrm{pH}$ on human platelet aggregation induced by epinephrine and ADP. Proc Soc Exp Biol Med 139: 1100-1103, 1972.

Rosenblum WI and F El-Sabban. Platelet aggregation in the cerebral microcirculation. Effect of aspirin and other agents. Circ Res 40, 320-328, 1977.

Rosenblum WI, F El-Sabban and EF Ellis. Aspirin and indomethacin enhance platelet aggregation in mouse mesenteric arterioles. Am J Physiol 239: H220-H226, 1980.

Roth GJ, N Stanford and PW Majerus. Acetylation of prostaglandin synthase by aspirin. Proc Natl Acad Sci USA 72: 3073-3076, 1975.

Rubanyi GM, JC Romero and PM Vanhoutte. Flow-induced release of endothelium-derived relaxing factor. Am J Physiol 250: H1145-H1149, 1986.

Saniabadi AR, GDO Lowe, JC Barbenel and CD Forbes. Further studies on the role of red blood cells in spontaneous platelet aggregation. Thromb Res 38: 225-232, 1985. 
Sato $\mathrm{M}$ and N Oshima. Platelet thrombus induced in vivo by filtered light and fluorescent dye in mesenteric microvessels of the rat. Thromb Res 35: 319-334, 1984.

Schmid-Schonbein GW, S Usami, R Skalak and S Chicn. The interaction of leukocytes and erythrocytes in capillary and postcapillary vessels. Microvasc Res 19: 45-70, 1980.

Schmid-Schonbein GW, R Skalak, SI Simon and RL Engler. The interaction between leukocytes and endothelium in vivo. Ann NY Acad Sci 516: 348-361, 1987.

Schmid-Schōnbein H, H Rieger and T Fischer. Fluid-dynamic boundary conditions for thrombotic processes in high shear environments in vivo. In: Blood vessels: problems arising at the border of natural and artificial blood vessels, edited by S Effert and JD Meyer-Erkelenz. Springer, Berlin, 1976, pp 57-63.

Seiffge D and E Kremer. Influence of ADP, blood flow velocity, and vessel diameter on the laser-induced thrombus formation. Thromb Res 42: 331-341, 1986.

Shepro D and PA d'Amore. Physiology and biochemistry of the vascular wall endothelium. In: Handbook of Physiology, section 2: The cardiovascular system, vol 4: Microcirculation, edited by EM Renkin and CC Michel. American Physiological Society, Bethesda, 1984, pp 103-164.

Shishido $\mathrm{M}$ and $\mathrm{M}$ Katori. A quantitative method using continuous recording of platelet thrombus size in hamster cheek pouch. Microvasc Res 22: 199-209, 1981.

Sicking AHJM, N Hoogerwerf, GC van den Bos, N Westerhof and P Sipkema. Oxygen sensitivity of arteriolar and venular diameter in rat mesentery and skeletal muscle. Int J Microcirc Clin Exp 7: S109, 1988.

Siegel S. Nonparametric statistics for the behavioral sciences. McGraw-Hill Kogakusha, LTD, Tokyo, 1956.

Siegenbeek van Heukelom J, K Dijkstra and $\mathrm{H}$ van Ingen. A versatile and reproducibly operating microelectrode puller. Med Biol Eng 3: 644-652, 1976.

Siess W. Molecular mechanisms of platelet activation. Physiol Rev 69: 58-178, 1989.

Sixma JJ and J Wester. The hemostatic plug. Semin Haematol 14: 265-299, 1977.

Sixma JJ. Morphology. In: Platelet responses and metabolism, vol 1: Responses, edited by H Holmsen. CRC Press, Boca Raton, 1986, pp 33-61.

Sixma JJ. Platelet adhesion in bealth and disease. In: Thrombosis and haemostasis 1987, edited by M Verstreate, J Vermylen, R Lijnen and J Arnout. Leuven University Press, Leuven, 1987, pp 127-146.

Skoza L, MB Zucker, Z Jerushalmy and R Grant. Kinetic studies of platelet aggregation induced by adenosine diphosphate and its inhibition by chelating agents, guanidino compounds, and adenosine. Thromb Diathes Haemorrh 18: 713-725, 1967.

Slaaf DW, JPSM Rood, GJ Tangelder, TJM Jeurens, R Alewijnse, RS Reneman and T Arts. A bidirectional optical (BDO) three-stage prism grating system for on-line measurement of red blood cell velocity in microvessels. Microvasc Res 22: 110-122, 1981.

Slaaf DW, R Alewijnse and $\mathrm{H}$ Wayland. Use of telescopic imaging in intravital microscopy: a simple solution for conventional microscopes. Int J Microcirc Clin Exp 1: 121-134, 1982.

Slaaf DW, GJ Tangelder, RS Reneman and T Arts. Dual sensor model calculations applied to blood cell velocity profiles obtained by direct observation in vivo. Int J Microcirc Clin Exp 5: 242, 1986.

Soberman RJ, TW Harper, D Betteridge, RA Lewis and KF Austen. Characterization and separation of the arachidonic acid 5-lipoxygenase and linoleic acid $\omega-6$ lipoxygenase (arachidonic acid 15-lipoxygenase) of human polymorphonuclear leukocytes. J Biol Chem 260, 4508-4515, 1985.

Stormorken H. Platelets in hemostasis and thrombosis. In: Platelet responses and metabolism, vol 1: Responses, edited by H Holmsen. CRC Press, Boca Raton, 1986, pp 3-32.

Sweatt JD, SL Johnson, EJ Cragoe and LE Limbird. Inhibitors of $\mathrm{Na}^{+} / \mathrm{H}^{+}$exchange block stimulus-provoked arachidonic acid release in human platelets. J Biol Chem 260: 12910-12919, 1985.

Sweatt JD, TM Connolly, CJ Cragoe and LE Limbird. Evidence that $\mathrm{Na}^{+} / \mathrm{H}^{+}$exchange regulates receptormediated phospholipase $A_{2}$ activation in human platelets. J Biol Chem 261: 8667-8673, 1986.

Takano $S$ and $T$ Suzuki. A study on the in vivo production of thrombosis in rat mesenteric arterioles and action of prostaglandin (PG) $I_{2}$ on the thrombosis. Jpn J Pharmacol 32: 439-444, 1982.

Tang SS and MM Frojmovic. The effects of $\mathrm{pCO}_{2}$ and $\mathrm{pH}$ on platelet shape change and aggregation for human and rabbit platelet-rich plasma. Thromb Res 10: 135-145, 1977.

Tangelder GJ. Distribution and orientation of blood platelets flowing in small arterioles. Thesis, University of Limburg, Maastricht, The Netherlands, 1982. 
Tangelder GJ, DW Slaaf and RS Reneman. Fluorescent labeling of blood platelets in vivo. Thromb Res 28 : 803-820, 1982a.

Tangelder GJ, DW Slaaf, HC Teirlinck, R Alewijnse and RS Reneman. Localization within a thin optical section of fluorescent blood platelets flowing in a microvessel. Microvasc Res 23: 214-230, 1982b.

Tangelder GJ, DW Slaaf and RS Reneman. Skeletal muscle microcirculation and changes in transmural and perfusion pressure. Prog appl Microcirc 5: 93-108, 1984.

Tangelder GJ, HC Teirlinck, DW Slaaf and RS Reneman. Distribution of blood platelets flowing in arterioles. Am J Physiol 248: H318-H323, 1985.

Tangelder GJ, DW Slaaf, AMM Muijtjens, T Arts, MGA oude Egbrink and RS Reneman. Velocity profiles of blood platelets and red blood cells flowing in arterioles of the rabbit mesentery. Circ Res 59: 505-514, 1986.

Tangelder GJ and K-E Arfors. Monoclonal antibody MEL-14 cannot abolish leukocyte rolling in mouse venules. Int J Microcirc Clin Exp 7: S68, 1988.

Tangelder GJ, DW Slaaf, $T$ Arts and RS Reneman. Wall shear rate in arterioles in vivo: least estimates from platelet velocity profiles. Am J Physiol 254: H1059-H1064, 1988.

Tangelder GJ, MGA oude Egbrink, DW Slaaf and RS Reneman. Blood platelets: an overview. J Reconstr Microsurg 5: 167-171, 1989.

Tocantins LM. Historical notes on blood platelets. Blood 3: 1073-1082, 1948.

Tukey JW. Exploratory data analysis. Addison-Wesley Publishing Company, Reading Massachusetts, 1977.

Turitto VT and HR Baumgartner. Platelet interaction with subendothelium in a perfusion system: physical role of red blood cells. Microvasc Res 9: 335-344, 1975.

Turitto VT and HR Baumgartner. Platelet interaction with subendothelium in flowing rabbit blood: effect of blood shear rate. Microvasc Res 17, 38-54, 1979.

Turitto VT and HJ Weiss. Red blood cells: their dual role in thrombus formation. Science 207: 541-543, 1980.

Turner SR, JA Tainer and WS Lynn. Biogenesis of chemotactic molecules by the arachidonate lipoxygenase system of platelets. Nature 257, 680-681, 1975.

Ubatuba FB, S Moncada and JR Vane. The effect of prostacyclin $\left(\mathrm{PGI}_{2}\right)$ on platelet behaviour. Thrombus formation in vivo and bleeding time. Thromb Haemost 41: 425-435, 1979.

Vermijlen J, J Arnout, H Deckmijn, B Xhonneux and F de Clerck. Continuous inhibition of the platelet S2serotonergic receptors during the long term administration of ketanserin. Thromb Res 42: 721-723, 1986.

Villa $S$ and $G$ de Gaetano. Prostacyclin-like activity in rat vascular tissues. Fast, long-lasting inhibition by treatment with lysine acetylsalicylate. Prostaglandins 14: 1117-1124, 1977.

Warlow C, A Corina, D Ogston and AS Douglas. The relationship between platelet aggregation and time interval after venepuncture. Thromb Diathes Haemorrh 31: 133-141, 1974.

Watts SE, LJ Tunbridge and JV Lloyd. Storage of platelets for tests of platelet function: effects of $\mathrm{pH}$ on platelet aggregation and liberation of $\beta$-thromboglobulin. Thromb Res 29: 343-353, 1983.

Watts SE, LJ Tunbridge, EM Duncan and JV Lloyd. Storage of platelets for tests of platelet function: comparison of two methods of pH control. Thromb Res 37: 73-83, 1985.

Weichert W, V Pauliks and HK Breddin. Laser-induced thrombi in rat mesenteric vessels and antithrombotic drugs. Haemostasis 13: 61-71, 1983.

Wharton Jones T. On the state of the blood and the blood-vessels in inflammation, ascertained by experiments, injections, and observations by the microscope. Guy's Hosp Rep $2^{\text {nd Ser 7: 1-78, } 1851 .}$

White JG. Platelet ultrastructure. In: Haemostasis and thrombosis, edited by AL Bloom and DP Thomas. Churchill Livingstone, Edinburgh, 1987a, pp 20-46.

White JG. Platelet structural physiology: the ultrastructure of adhesion, secretion and aggregation in arterial thrombosis. Cardiovasc Clin 18: 13-33, $1987 \mathrm{~b}$.

Wiedeman MP. Vascular reactions to laser in vivo. Microvasc Res 8: 132-138, 1974.

Wong PY-K, P Westlund, M Hamberg, E Granstrōm, PH-W Chao and B Samuelsson. $\omega$-Hydroxylation of 12 . L-hydroxy-5,8,10,14-eicosatetraenoic acid in human polymorphonuclear leukocytes. J Biol Chem 259: 2683-2686, 1984.

Wu KK, Y-C Chen, E Fordham, C-H Ts'ao, G Rayudu and D Matayoshi. Differential effects of two doses of aspirin on platelet-vessel wall interaction in vivo. J Clin Invest 68: 382-387, 1981. 
Yu SK and HL Goldsmith. Some rheological aspects of platelet thrombosis. In: Platelets, drugs and thrombosis, edited by J Hirsch, JF Cade, AS Gallus and E Schonbaum. Karger, Basel, pp 78-93, 1975.

Zahn FW. Untersuchungen über Thrombose. Centralbl Med Wiss 10: 129-130, 1872.

Zimmerman GA, TM McIntyre and SM Prescott. Production of platelet-activating factor by human vascular endothelial cells: evidence for a requirement for specific agonists and modulation by prostacyclin. Circulation 72: 718-727, 1985.

Zucker MB. Platelet agglutination and vasoconstriction as factors in spontaneous hemostasis in normal, thrombocytopenic, heparinized and hypoprothrombinemic rats. Am J Physiol 148: 275-288, 1947.

Zucker MB. Proteolytic inhibitors, contact and other variables in the release reaction of human platelets. Thromb Diathes Haemorrh 28: 393-407, 1972.

Zwaal RFA, EM Bevers and J Rosing. Structural aspects of the platelet membrane with emphasis on procoagulant phospholipids. In: Biology and pathology of platelet-vessel wall interactions, edited by G Jolles, YJ Legrand and A Nurden. Academic Press, London, 1986, pp 247-265.

Zweifach BW. Quantitative studies of microcirculatory structure and function. II: Direct measurement of capillary pressure in splanchnic mesenteric vessels. Circ Res 34: 858-866, 1974. 


\section{SUMMARY}

Vessel wall injury leads to an interaction between blood platelets and the damaged vessel wall. This process is influenced simultaneously by a variety of factors. It was the aim of the present study to investigate platelet-vessel wall interactions following vessel wall injury in vivo and to obtain more insight into the role of some physiological variables in this interaction. Intravital microscopy was used to investigate in arterioles and venules of the rabbit mesentery the thromboembolic reaction, i.e. the formation of a thrombus and the subsequent process of embolization, evoked by vessel wall injury.

A method was developed to inflict to the microvessels (diameter 20 to $40 \mu \mathrm{m}$ ) a small, standardized mechanical trauma by puncture with a glass micropipet (tip diameter 6 to $8 \mu \mathrm{m}$; chapter 4 ). Following induction of the injury thrombus formation started immediately. Bleeding times were short, on the average less than $2 \mathrm{~s}$, and did not differ in arterioles and venules. Within $2 \mathrm{~s}$ following puncture the thrombus grew to its maximal height of about $65 \%$ of the vessel diameter in both vessel types. In most vessels platelets continued to adhere to the downstream side of the thrombi. Parts of such thrombi embolized, leaving the height of the stationary thrombus virtually unaffected. This process of embolization was significantly different in arterioles and venules; the duration of embolization was about 6 times longer, and 6 times more emboli were produced, in arterioles than in venules.

Initial mean red blood cell velocity and reduced velocity, which is a measure of wall shear rate, were on the average slightly higher in arterioles than in venules. The difference in thromboembolic reaction, however, still existed when groups of vessels with similar fluid dynamic conditions were compared (chapter 4). Therefore, the initial fluid dynamic conditions were not responsible for the difference in thromboembolic reaction between arterioles and venules. This also holds for the fluid dynamic changes as a consequence of the formation of the thrombus itself. The effective size of the thrombus and, hence, the degree of stenosis induced by the thrombus was similar in arterioles and venules. Thrombus formation also induced similar changes in blood flow and reduced velocity in both vessel types (chapter 5). In addition, no direct relation was 
found between fluid dynamic factors and the thromboembolic reaction, indicating that platelet-vessel wall interactions in these mesenteric microvessels were not dependent on fluid dynamic conditions, at least within the range studied.

An alternative explanation for the observed difference in reaction could be the different intravascular blood gas and $\mathrm{pH}$ values in arterioles and venules, because in vitro studies have shown that changes in $\mathrm{pCO}_{2}$ and $\mathrm{pH}$ can influence platelet aggregation. Changing the systemic blood gas and $\mathrm{pH}$ values towards hypercapnic and hypoxic conditions, similar to those normally present in venules (chapter 6 ), did indeed induce a decrease in the rate of embolus production in both arterioles and venules. However, this intervention did not influence the number of emboli produced, indicating that the different blood gas and $\mathrm{pH}$ values in arterioles and venules are not responsible for the difference in thromboembolic reaction between both vessel types. The decrease in rate of embolus production in hypercapnic/hypoxic conditions might have been due to a direct effect on the platelets, the vessel wall or both. The aggregation of rabbit platelets, as induced in vitro by several platelet stimulating agonists alone or in combination (chapter 7), appeared to be reduced in hypercapnic conditions. Hypoxia only reduced thrombin induced platelet aggregation. It cannot be excluded that vessel wall functions are also influenced by changes in blood gas and $\mathrm{pH}$ values.

A striking phenomenon in the exposed rabbit mesentery is the presence of rolling and, to a lesser extent, sticking or adhering leukocytes in venules, but not in arterioles. The presence of rolling leukocytes, i.e. leukocytes that travel along the wall at a clearly lower velocity than the red blood cells, may offer an explanation for the difference in thromboembolic reaction between arterioles and venules (chapter 8 ). When the number of rolling leukocytes was higher than about 20 per minute the number of emboli produced per venule appeared to decrease below the arteriolar level of embolus production. This finding could be explained by a direct effect of leukocytes on platelets, or might reflect a change in endothelial functioning, which influences the behavior of both leukocytes and platelets. Sticking leukocytes, which were only present in low numbers, did not appear to influence the thromboembolic reaction. On the other hand, leukocyte rolling itself was influenced by the thromboembolic reaction. The number of rolling leukocytes was lower downstream than upstream of a thrombus. This difference could not be explained by fluid dynamic changes, as induced by the thrombus, or inclusion of leukocytes in the emboli produced by the thrombus. Substances produced by aggregated platelets in the thrombus or by the damaged vessel wall might be responsible for the "disappearance" of rolling leukocytes. The results described in chapter 8 suggest that in vivo mutual functional interactions exist between leukocytes and platelets, while vascular cells may also be involved.

Pretreatment of the rabbits with high doses of aspirin, which inhibits the formation of prostaglandins that may play a role during the thromboembolic reaction, had different effects in arterioles and venules, but did not result in a disappearance of the difference in thromboembolic reaction between both vessel types (chapter 9). In arterioles, but not in venules, the period of embolization was significantly prolonged by aspirin treatment. In venules, however, a decrease in the rate of embolus production 
was induced, while this rate was not influenced in arterioles. The effects of aspirin could not be explained by fluid dynamic factors or, in the venules, by changes in leukocyte rolling. Therefore, the involvement of platelet activating prostaglandins, like thromboxane $\mathrm{A}_{2}$, and platelet inhibiting prostaglandins, like prostacyclin, in the thromboembolic reaction appears to differ in arterioles and venules.

The findings of the present study suggest that, beside a possible direct effect of rolling leukocytes on the venular reaction, the difference in thromboembolic reaction between arterioles and venules has to be the result of differences in vessel wall functions between both vessel types, other than prostaglandin production. In view of the ultrastructural appearance of the embolizing part of a thrombus, being a loosely packed mass of discoid platelets still containing most of their secretory vesicles (chapter 10), one or more 'weak' platelet activating substances like ADP may play an important role in platelet activation during the embolization period, although other activators like thrombin may also be involved. Differences in local availability of such substances in arterioles and venules during the embolization phase may be the origin of the difference in thromboembolic reaction. 


\section{SAMENVATTING}

\section{THROMBO-EMBOLISCHE REACTIE NA BESCHADIGING VAN DE VAATWAND IN ARTERIOLEN EN VENULEN}

Wanneer bij een verwonding bloedvaten beschadigd raken, dan resulteert dit in een bloeding. Om het verlies van bloed zoveel mogelijk te beperken worden er in het lichaam mechanismen in werking gesteld die ervoor zorgen dat de bloeding stopt. Deze mechanismen worden aangeduid met hemostase of thrombose. Wanneer een vat is doorgesneden wordt de bloeding gestopt door de vorming van een (zogeheten) hemostatische plug die het vat afsluit (hemostase). Wanneer er sprake is van een klein gat in de wand, dan wordt dit gedicht door een prop (thrombus) die zich binnen in het vat vormt (thrombose).

In de onderzoeken, die beschreven staan in dit proefschrift, is met behulp van een speciale lichtmicroscoop de reactie bestudeerd die volgt op een vaatwandbeschadiging in hele kleine bloedvaten van levende, verdoofde konijnen (in vivo). Deze reactie bestaat uit de vorming van een thrombus binnen in het vat, gevolgd door het afbreken (embolisatie) van stukken van deze thrombus. Dit proces wordt daarom thrombo-embolische reactie genoemd. In deze samenvatting zal eerst ter inleiding een korte beschrijving gegeven worden van het bloed en de bloedsomloop. Daarna volgt een beschrijving van het doel van het onderzoek en de gehanteerde onderzoeksmethode. Vervolgens worden de thrombo-embolische reactie en de meest belangrijke resultaten van het onderzoek besproken.

\section{Inleiding}

Het bloed. Om ervoor te zorgen dat alle cellen in het lichaam goed kunnen functioneren is het noodzakelijk dat zij continu worden voorzien van voldoende zuurstof en voedingsstoffen, terwijl koolzuur en afvalstoffen moeten worden afgevoerd. Het bloed is verantwoordelijk voor dit transport. Bloed is een vloeistof waarin zich naast onder andere eiwitten, zouten en de hierboven genoemde voedings- en afvalstoffen 
drie verschillende typen bloedcellen bevinden. De rode bloedcellen, die ongeveer $40 \%$ van het volume van het bloed innemen, dragen zorg voor het transport van zuurstof en koolzuur. Witte bloedcellen, de minst voorkomende bloedcellen, vervullen een belangrijke functie bij de afweer tegen lichaamsvreemde organismen, zoals bacteriën en virussen. Het bloedplaatje is het derde en tevens kleinste type bloedcel. Bloedplaatjes zijn onmisbaar bij het stoppen van een bloeding na beschadiging van een bloedvat. Bij de processen beschreven in dit proefschrift is dan ook vooral het gedrag van de bloedplaatjes van belang.

Hoewel bloedplaatjes in een intact bloedvat regelmatig in contact komen met de vaatwand, worden ze hierdoor niet geactiveerd. Na een beschadiging van de vaatwand treedt echter activatie van bloedplaatjes op, waardoor ze zich gaan hechten aan de beschadigde wand (adhesie) en aan elkaar (aggregatie) (hoofdstuk 2). Op deze wijze groeit op de plek van de beschadiging een plaatjesprop (thrombus genoemd), die het gat in de wand afsluit en zo de bloeding stopt. De plaatjesprop wordt vervolgens verstevigd door een netwerk van draden (fibrine). Deze draden vormen het eindproduct van de stolling, een keten van reacties tussen verschillende eiwitten die zich in het bloed bevinden. Dit proces wordt ook in gang gezet door de vaatwandbeschadiging.

De bloedsomloop. Om alle lichaarnscellen te bereiken wordt het bloed door het hart rond gepompt via een netwerk van bloedvaten, dat zich tot alle delen van het lichaam uitstrekt. Vanuit het hart wordt het bloed gepompt in grote vaten met een stevige, elastische wand, de slagaders of arteriën. Deze vaten vertakken zich steeds verder in kleinere vaten (arteriolen) tot ze uiteindelijk uitmonden in de kleinste bloedvaatjes, de haarvaten of capillairen. In de haarvaten vindt de uitwisseling plaats van stoffen tussen bloed en lichaamscellen. Het bloed wordt vanuit de haarvaten afgevoerd via kleine vaten (venulen), die samenvloeien tot steeds grotere vaten, de aders of venen, welke het bloed terugvoeren naar het hart.

De wanden van de bloedvaten bestaan uit verschillende lagen cellen. De binnenste laag wordt in alle bloedvaten gevormd door een aaneengesloten laag platte cellen, de endotheelcellen. Deze cellaag wordt omgeven door een aantal lagen spiercellen, met daaromheen bindweefsel. Zowel het aantal lagen spiercellen als de dikte van de bindweefsellaag varieert en hangt af van het type bloedvat. In de haarvaten zijn deze twee buitenste lagen zelfs geheel afwezig.

Het onderzoek. In het onderzoek beschreven in dit proefschrift is de reactie van de bloedplaatjes op een vaatwandbeschadiging onderzocht in het kleinste formaat slagaders en aders, de arteriolen en venulen. De diameter van deze vaatjes varieerde van é́n-vijftigste tot éen-vijfentwintigste millimeter $(20$ tot $40 \mu \mathrm{m})$. De wand van zowel arteriolen als venulen bestaat uit de endotheelcellaag, éen laag spiercellen en een hele dunne laag bindweefsel.

Uit onderzoek aan geïsoleerde endotheelcellen en spiercellen is gebleken dat onder normale omstandigheden deze cellen ertoe bijdragen dat bloedplaatjes zich niet aan de vaatwand en aan elkaar hechten. Wanneer daarentegen de endotheelcellen en 
spiercellen beschadigd worden treedt een verandering op in hun functioneren en blijken zij de vorming van een plaatjesprop of thrombus te kunnen stimuleren (hoofdstuk 2). Deze gegevens suggereren dat bij de reacties die in een bloedvat optreden na beschadiging van de wand niet alleen de bloedplaatjes maar ook de cellen in de vaatwand een belangrijke rol spelen. Het is echter de vraag of vaatwandcellen en bloedplaatjes in een levend organisme (in vivo) net zo functioneren als cellen, die uit het lichaam zijn geisoleerd (in vitro). In een levend organisme is er bovendien sprake van een groot aantal andere factoren, zoals het stromingsgedrag en de zuurgraad van het bloed, die de interactie tussen bloedplaatjes en de vaatwand zouden kunnen beinvloeden. Ook is het mogelijk dat cellen in de wand van verschillende typen bloedvaten op verschillende wijze functioneren, zowel onder normale omstandigheden als na een beschadiging.

Het doel van dit proefschrift was om in vivo de interacties tussen bloedplaatjes en de vaatwand na een vaatwandbeschadiging te bestuderen in twee verschillende typen bloedvaten (arteriolen en venulen). Daarnaast werd de invloed van verschillende omgevingsfactoren op deze interacties onderzocht.

\section{Methoden}

Door gebruik te maken van een microscoop die geschikt is om levende preparaten te bekijken (intravitaal microscoop) was het mogelijk de reacties na een vaatwandbeschadiging te bestuderen in arteriolen en venulen van een levend organisme (in vivo). Gewerkt werd met arteriolen en venulen in het darmvlies van het levende, verdoofde konijn. Het darmvlies kan gemakkelijk worden blootgelegd en is vanwege zijn geringe dikte en goede doorzichtbaarheid een zeer geschikt weefsel om reacties, die zich afspelen binnen in bloedvaten, microscopisch te bestuderen.

Een vaatwandbeschadiging werd aangebracht door de wand van een arteriole of venule onder microscopische controle aan te prikken met een glazen naaldje (micropipet). Een micropipet werd gemaakt van een glazen buisje, waaraan onder verhitting een hele fijne punt werd getrokken; deze punt werd naderhand afgebroken tot een diameter van 6 tot $8 \mu \mathrm{m}$. Ten gevolge van het aanprikken van een vaatwand ontstond een gat in die wand, groot genoeg voor rode bloedcellen om uit het bloedvat te ontsnappen: er ontstond een bloeding. In zowel arteriolen als venulen stopte deze bloeding gemiddeld binnen enkele seconden.

Van elk vat, waarvan de wand werd aangeprikt, werden zowel vór als na het prikken de microscopische beelden gedurende 10 minuten via een TV-camera vastgelegd op videoband. Na afloop van de experimenten werden deze videobeelden geanalyseerd.

\section{De thrombo-embolische reactie}

Onmiddellijk na het beschadigen van de vaatwand begon in elk bloedvat de thrombo-embolische reactie (hoofdstuk 4). Door de hechting van geactiveerde bloedplaatjes aan de beschadigde vaatwand en aan elkaar werd binnen enkele seconden een 

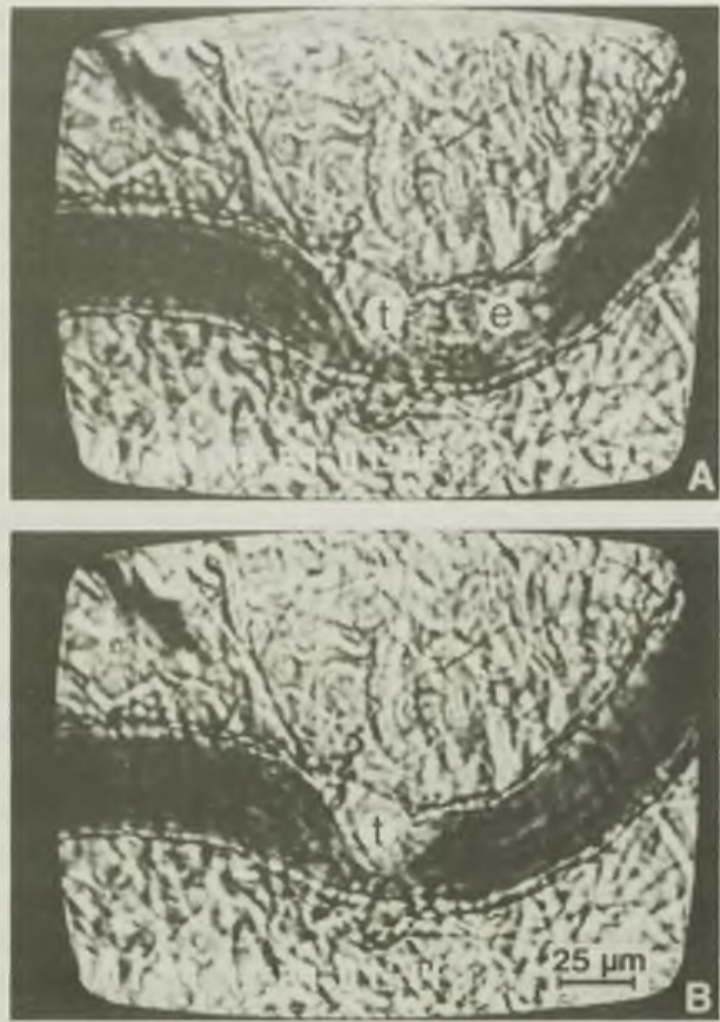

FIGUUR 1 De thrombo-embolische reactie na het aanprikken van de wand in een arteriole (stromingsrichting van links naar rechts). Er heeft zich een thrombus (t) gevormd, die aan de stroomafwaartse zijde verder uitgroeit (A), totdat dit nieuw gevormde stuk (embolus; e) afbreekt en wordt weggevoerd met het bloed (embolisatie). De thrombus zelf blijf daarbij vrijwel onveranderd op zijn plaats (B). Het tijdsverschil tussen beide opnames is $0.12 \mathrm{~s}$.

thrombus gevormd, die meestal doorgroeide tot een hoogte van 60 tot $70 \%$ van de diameter van het vat (Figuur 1). In de meeste vaten ging het activatie proces van de bloedplaatjes gedurende een langere periode door, hetgeen resulteerde in het verder uitgroeien van de thrombus aan stroomafwaartse zijde. Van tijd tot tijd brak zo'n nieuw gevormd stuk van de thrombus af (embolus) om te worden weggevoerd met het bloed (Figuur 1). Dit proces van embolisatie stopte na verloop van tijd, terwijl de thrombus zelf op zijn plaats bleef. 
Voor elk vat, waarvan de wand werd aangeprikt, werd de duur van de bloeding gemeten, de hoogte van de thrombus, het aantal emboli dat gevormd werd evenals de duur en snelheid van het proces van embolisatie.

\section{Reactie in arteriolen en venulen}

Het meest opvallende resultaat, dat in alle experimenten terugkeerde, was dat onder normale omstandigheden het proces van embolisatie 4 tot 6 keer langer doorging in de arteriolen dan in de venulen (hoofdstukken 4, 6 en 9). Omdat de snelheid van embolisatie in beide typen bloedvaten ongeveer gelijk was, werden ook 4 tot 6 keer zoveel emboli gevormd in arteriolen dan in venulen. Zowel de duur van de bloeding als de hoogte van de thrombus bleek niet te verschillen in beide typen bloedvaten, terwijl ook de grootte van de emboli overeenkomstig bleek te zijn (hoofdstuk 6).

\section{Invloed van omgevingsfactoren}

Stromingsgedrag van het bloed. In de meeste weefsels van het lichaam stroomt het bloed met een hogere snelheid door de arteriolen dan door de venulen. Omdat in vitro onderzoek heeft uitgewezen dat bloedplaatjes sneller worden geactiveerd bij een toenemende stromingssnelheid, is in alle vaten die werden aangeprikt naast de diameter ook de stromingssnelheid van het bloed gemeten. In het darmvlies bleek de stromingssnelheid ook hoger te zijn in de arteriolen dan in de venulen, alhoewel het verschil klein en de overlap groot was. Dit (kleine) verschil in stromingssnelheid bleek echter niet verantwoordelijk te zijn voor het verschil in thrombo-embolische reactie tussen arteriolen en venulen: ook wanneer alleen de reacties in vaten met vergelijkbare diameters en stromingssnelheden werden vergeleken bleek de thrombo-embolische reactie te verschillen tussen arteriolen en venulen (hoofdstuk 4).

Zowel de mate van vaatvernauwing, ten gevolge van de aanwezigheid van de thrombus, als het effect van een gelijksoortige vaatvernauwing op de doorstroming bleken niet te verschillen in arteriolen en venulen. Het verschil in embolisatie tussen deze vaten kan daarom ook niet verklaard worden uit verschillen in veranderingen in het stromingsgedrag van het bloed ten gevolge van de thrombusvorming (hoofdstuk 5).

Bloedgassen en zuurgraad. Ten gevolge van de uitwisseling van zuurstof en koolzuur in de haarvaten is de zuurst of concentratie lager en de koolzuurconcentratie hoger in de venulen dan in de arteriolen. De hogere koolzuurconcentratie in de venulen heeft ook een hogere zuurgraad (ofwel een lagere $\mathrm{pH}$ ) tot gevolg. Experimenten met geïsoleerde bloedplaatjes, meestal van menselijke herkomst, hebben aangetoond dat dergelijke bloedplaatjes sneller konden worden gestimuleerd bij een lage zuurgraad en een lage koolzuurconcentratie dan bij meer normale omstandigheden. Daarom werd onderzocht of in vivo de verschillen in zuurgraad, koolzuur- en zuurstofconcentratie tussen venulen en arteriolen verantwoordelijk waren voor het verschil in thrombo-embolische activiteit tussen beide typen bloedvaten (hoofdstuk 6). Voor dit doel werden konijnen beademd met een zodanig mengsel van gassen dat in de arteriolen de koolzuurconcentratie en de zuurgraad omhoog gingen (hypercapnia) en de zuurstofcon- 
centratie zakte (hypoxia) tot nivo's die onder normale omstandigheden aanwezig zijn in venulen. Deze behandeling resulteerde in een beperkte daling in de snelheid van embolisatie, zowel in arteriolen als venulen. Het verschil in het aantal geproduceerde emboli en de duur van de embolisatie bleef echter bestaan. Dit betekent dat de verschillen in zuurgraad, en koolzuur- en zuurstofconcentratie tussen arteriolen en venulen niet verantwoordelijk zijn voor het verschil in thrombo-embolische reactie tussen deze bloedvaten.

De daling in snelheid van embolisatie, die gevonden werd in zowel arteriolen als venulen na de veranderingen in zuurgraad, en koolzuur- en zuurstofconcentratie, kan het gevolg zijn van een direct effect van deze veranderingen op het gedrag van de bloedplaatjes zelf, op het functioneren van cellen in de vaatwand of op beide. Om te onderzoeken of de aggregatie van bloedplaatjes beïnvloed wordt door dergelijke veranderingen werden in vitro met bloedplaatjes uit konijnebloed aggregatie-testen uitgevoerd (hoofdstuk 7). De aggregatie van deze bloedplaatjes, opgewekt met stoffen waarvan bekend is dat ze in het lichaam bloedplaatjes kunnen stimuleren, bleek af te nemen in omstandigheden met een relatief hoge koolzuurconcentratie en zuurgraad (hypercapnia). Een lage zuurstofconcentratie (hypoxia) had minder effect; alleen de aggregatie opgewekt met thrombine bleek te dalen. Het is niet uitgesloten dat behalve het gedrag van bloedplaatjes ook het functioneren van vaatwandcellen beïnvloed wordt door veranderingen in zuurgraad, en koolzuur- en zuurstofconcentraties.

Witte bloedcellen. Een opvallend fenomeen in het blootgelegde darmvlies is de aanwezigheid van witte bloedcellen (leukocyten) die zich met een opvallend lage snelheid al rollend langs de wand van venulen voortbewegen. Dit verschijnsel wordt nooit waargenomen in arteriolen. Het is mogelijk dat deze witte bloedcellen, die zich gedurende relatief lange tijd in een venule bevinden, stoffen produceren die de interactie tussen bloedplaatjes en de vaatwand bij een vaatwandbeschadiging kunnen beïnvloeden. Inventarisatie van het aantal rollende witte bloedcellen vlak voor het aanprikken van de wand en het optreden van de thrombo-embolische reactie na het aanprikken wees uit dat in venulen met weinig rollende witte bloedcellen het aantal geproduceerde emboli niet verschilde van het aantal emboli in arteriolen. Wanneer er echter meer dan ongeveer 20 witte bloedcellen per minuut langs de wand van het aangeprikte vatsegment rolden was de productie duidelijk lager dan in de arteriolen (hoofdstuk 8). Dit resultaat kan betekenen dat er inderdaad een rechtstreekse invloed is van de rollende witte bloedcellen op de reactie van de bloedplaatjes. Het zou ook zo kunnen zijn, dat zowel het toegenomen aantal rollende witte bloedcellen als de daarmee gepaarde gaande verminderde reactie van de bloedplaatjes een afspiegeling zijn van een veranderd functioneren van de endotheelcellen.

Een tweede interessante bevinding in hoofdstuk 8 was dat het aantal rollende witte bloedcellen zelf ook beïnvloed werd door de thrombo-embolische reactie. Het aantal rollers, geteld ná aanprikken, bleek af te nemen bij het passeren van de thrombus. Dit effect trad echter alleen op wanneer de thrombus emboli produceerde of geproduceerd had. De daling in het aantal rollende witte bloedcellen was niet het gevolg 
van veranderd stromingsgedrag van het bloed rondom de thrombus of van het wegvoeren van witte bloedcellen in wegschietende emboli. Deze bevindingen suggereren dat er door de geaggregeerde bloedplaatjes in een "emboliserende" thrombus of door cellen in de beschadigde vaatwand stoffen worden geproduceerd die maken dat rollende witte bloedcellen de wand loslaten.

De resultaten in hoofdstuk 8 geven aan dat er in vivo sprake is van een wederzijdse functionele beïnvloeding tussen bloedplaatjes en witte bloedcellen, waarbij ook de vaatwandcellen betrokken zouden kunnen zijn.

Prostaglandine-productie. Zowel de cellen in de vaatwand als de bloedplaatjes produceren stoffen uit meervoudig onverzadigde vetzuren die in staat zijn de interactie tussen bloedplaatjes en de vaatwand positief of negatief te beinvloeden. Deze stoffen worden prostaglandines genoemd. De rol van prostaglandines tijdens de thrombo-embolische reactie in arteriolen en venulen werd onderzocht door hun productie te remmen (hoofdstuk 9). Daartoe werden de konijnen behandeld met aspirine. Mits gegeven in voldoende hoge dosering, remt aspirine de productie van prostaglandines door zowel de vaatwand als de bloedplaatjes. Deze behandeling bleek de thrombo-embolische reactie in arteriolen en venulen op verschillende wijze te beïnvloeden, maar resulteerde niet in het verdwijnen van het onderlinge verschil in reactie. In de arteriolen had de behandeling met aspirine een duidelijke verlenging van de embolisatie periode tot gevolg, terwijl dit in de venulen niet het geval was. In de venulen daarentegen werd een daling in de snelheid van embolisatie gevonden, terwijl deze snelheid in de arteriolen niet veranderde. Het effect van de aspirine was niet het gevolg van een verandering van het stromingsgedrag van het bloed of, in de venulen, van een verandering in het rollen van de witte bloedcellen. Het lijkt er daarom op dat de betrokkenheid van prostaglandines, die de interacties tussen bloedplaatjes en vaatwand hetzij positief hetzij negatief kunnen beïnvloeden, verschillend is in arteriolen en venulen. Een dergelijk verschil is echter niet verantwoordelijk voor het verschil in thrombo-embolische reactie tussen arteriolen en venulen.

\section{Eindbeschouwing}

De bevindingen zoals beschreven in dit proefschrift wijzen erop dat het verschil in thrombo-embolische reactie na een vaatwandbeschadiging tussen arteriolen en venulen niet het gevolg is van verschillen in omgevingsfactoren, zoals het stromingsgedrag of de zuurgraad van het bloed. Blijkbaar spelen naast de bloedplaatjes de cellen in de vaatwand van beide typen bloedvaten een zodanig belangrijke rol in de thrombo-embolische reactie, dat de duur van deze reactie mede afhankelijk is van hun functioneren. Functionele verschillen tussen vaatwandcellen in arteriolen en venulen van én weefsel zijn niet eerder beschreven. Een direct effect van rollende witte bloedcellen op de reactie van de bloedplaatjes in de venulen kan niet worden uitgesloten. De relatie, zoals gevonden tussen het rollen van de witte bloedcellen en de thrombo-embolische reactie, kan echter ook een afspiegeling zijn van een gelijktijdige beïnvloeding van bloedplaatjes en witte bloedcellen door cellen in de vaatwand. 


\section{LIST OF ABBREVIATIONS}

$\begin{array}{ll}\text { ADP } & \text { adenosine diphosphate } \\ \text { AIT } & \text { aggregation induction time } \\ \text { (c)AMP } & \text { (cyclic) adenosine monophosphate } \\ \text { ATP } & \text { adenosine triphosphate } \\ \text { ASA } & \text { aspirin (acetyl salicylic acid) } \\ \text { EDRF } & \text { endothelium-derived relaxing factor } \\ \text { HC } & \text { hypercapnia } \\ \text { HCHO } & \text { hypercapnia and hypoxia } \\ \text { 12-HETE } & \text { 12-hydroxyeicosatetraenoic acid } \\ \text { HHT } & \text { 12-hydroxyheptadecatrienoic acid } \\ \text { HO } & \text { hypoxia } \\ \text { 13-HODE } & \text { 13-hydroxyoctadecadienoic acid } \\ \text { 12-HPETE } & \text { 12-hydroperoxyeicosatetraenoic acid } \\ \text { HPLC } & \text { high-performance liquid chromatography } \\ \text { PGI } & \text { prostacyclin } \\ \text { PRP } & \text { platelet rich plasma } \\ \text { RBC } & \text { red blood cell } \\ \text { TXA2 } & \text { thromboxane A2 } \\ \text { vWF } & \text { von Willebrand factor }\end{array}$




\section{CURRICULUM VITAE}

Mirjam oude Egbrink

5-4-1960 geboren te Oldenzaal

1960-1978 opgegroeid te Denekamp

1972-1978 gymnasium $\beta$ aan het Twents Carmellyceum te Oldenzaal

1978-1985 studie Biologie aan de Rijksuniverstiteit Groningen

-hoofdvak Endocrinologie

-bijvakken Voortplantingsfysiologie

Anatomie en morfologie van hogere planten

-eerste graads onderwijsbevoegdheid Biologie

1985-1988 wetenschappelijk assistent bij de vakgroep Fysiologie van de Rijksuniversiteit Limburg te Maastricht

1987 prijs voor Jonge Fysiologen van de Nederlandse Vereniging voor Fysiologie

1989- toegevoegd onderzoeker bij de vakgroep Fysiologie van de Rijksuniversiteit Limburg te Maastricht 


\section{PUBLICATIONS}

\section{Papers}

Tangelder GJ, DW Slaaf, AAM Muijtjens, T Arts, MGA oude Egbrink and RS Reneman. Velocity profiles of blood platelets and red blood cells flowing in arterioles of the rabbit mesentery. Circ Res 59: 505-514, 1986.

oude Egbrink MGA, GJ Tangelder, DW Slaaf and RS Reneman. Thromboembolic reaction following wall puncture in arterioles and venules of the rabbit mesentery. Thromb Haemost 59: 23-28, 1988.

Tangelder GJ, MGA oude Egbrink, DW Slaaf and RS Reneman. Blood platelets: an overview. J Reconstr Microsurg 5: 167-171, 1989.

oude Egbrink MGA, GJ Tangelder, DW Slaaf and RS Reneman. Effect of blood gases and pH on thromboembolic reactions in rabbit mesenteric microvessels. Eur J Physiol (Pflügers Arch) 414: 324-330, 1989. oude Egbrink MGA, GJ Tangelder, DW Slaaf, S Weymer-van Velzen and RS Reneman. Influences of hypercapnia and hypoxia on rabbit platelet aggregation. Submitted.

\section{Proceedings/Abstracts}

oude Egbrink MGA, GJ Tangelder, DW Slaaf and RS Reneman. Thromboembolic reaction in rabbit mesenteric arterioles and venules following wall puncture. Int J Microcirc Clin Exp 5: 252, 1986.

oude Egbrink MGA, GJ Tangelder, DW Slaaf and RS Reneman. Thromboembolic reactions in microvessels in vivo following wall puncture. Experientia 42: 1306, 1986.

oude Egbrink MGA, GJ Tangelder, DW Slaaf and RS Reneman. The influence of changes in $\mathrm{pCO}_{2}$ and $\mathrm{pO}_{2}$ on thromboembolic reactions in microvessels in vivo following wall puncture. In: Manuskriptsammlung 10. Jahrestagung der Geselschaft fur Mikrozirkulation e.V., edited by K Messmer and M Steinhausen. Heidelberg, 1986, pp 104-107.

oude Egbrink MGA, GJ Tangelder, DW Slaaf and RS Reneman. The influence of changes in $\mathrm{pCO}_{2}$ and $\mathrm{pO}_{2}$ on thromboembolic reactions in microvessels in vivo following wall puncture. Int J Microcirc Clin Exp 6: 81, 1987.

oude Egbrink MGA, GJ Tangelder, DW Slaaf and RS Reneman. The role of $\mathrm{pCO}_{2}$ and $\mathrm{pO}_{2}$ in thromboembolic reactions in microvessels in vivo following wall injury. Fed Proc 46: 1527, 1987.

oude Egbrink MGA, GJ Tangelder, DW Slaaf and RS Reneman. In vivo changes in systemic $\mathrm{pCO}_{2}$ and $\mathrm{pO}_{2}$ influence the thromboembolic reaction following wall puncture in venules but not in arterioles. Thromb Haemost 58: 108, 1987.

oude Egbrink MGA, GJ Tangelder, DW Slaaf and RS Reneman. The role of blood gases in thromboembolic reactions in arterioles and venules in vivo following wall puncture. Eur J Physiol (Pflügers Arch) 410: S29, 1987.

Slaaf DW, GJ Tangelder, MGA oude Egbrink and RS Reneman. Rheological behavior of platelets and the thromboembolic reaction to vessel wall injury. In: New perspectives in pharmacological sciences, edited by F Drago and JM van Ree. The Italian Pharmacological Society, Florence, 1987, pp 73-75.

oude Egbrink MGA, GJ Tangelder, DW Slaaf and RS Reneman. Effect of $\mathrm{pH}, \mathrm{pCO}_{2}$, and $\mathrm{pO}_{2}$ on rabbit platelet aggregation induced by ADP and thrombin. FASEB J 2: A1163, 1988.

oude Egbrink MGA, GJ Tangelder, DW Slaaf and RS Reneman. Influence of $\mathrm{pH}, \mathrm{pCO}_{2}$ and $\mathrm{pO}_{2}$ on rabbit platelet aggregation. Eur J Physiol (Pflügers Arch) 412: S4, 1988.

oude Egbrink MGA, GJ Tangelder, DW Slaaf and RS Reneman. Blood gasses and thromboembolic reaction in rabbit mesenteric microvessels. Int J Microcirc Clin Exp 7: 293, 1988. 
oude Egbrink MGA, GJ Tángelder, DW Slaaf and RS Reneman. Blood gasses and thromboembolic reaction in arterioles and venules. Int J Microcirc Clin Exp 7: S66, 1988.

oude Egbrink MGA, GJ Tangelder, DW Slaaf and RS Reneman. Prostaglandins and thromboembolic reactions following wall puncture in microvessels. In: Manuskriptsammlung 12. Jahrestagung der Gesellschaft für Mikrozirkulation e.V., edited by F Mahler. Bern, 1988, pp 103-106.

oude Egbrink MGA, GJ Tangelder, DW Slaaf and RS Reneman. Prostaglandins and thromboembolic reactions following wall puncture in microvessels. Int J Micocirc Clin Exp 8: 97, 1989.

oude Egbrink MGA, GJ Tangelder, DW Slaaf and RS Reneman. Role of prostaglandins in the thromboembolic reaction following wall puncture in rabbit mesenteric microvessels. FASEB J 3: A1384, 1989.

Tangelder GJ, RS Reneman, DW Slaaf and MGA oude Egbrink. Interaction of platelets with the wall of microvessels. Proc IUPS XVII: 136, 1989.

oude Egbrink MGA, GJ Tangelder, DW Slaaf and RS Reneman. Interaction between leukocytes and platelets following vessel wall injury in venules of the exposed rabbit mesentery. J Physiol in press, 1989. 
TER AFSLUITING...

Ter afsluiting van dit proefschrift wil ik iedereen die op wat voor manier dan ook heeft bijgedragen aan het onderzoek en het tot stand komen van dit werkstuk bedanken.

In de eerste plaats mijn directe begeleiders in de afgelopen jaren; vooral in de eindfase had ik vaak het gevoel dat het werk voornamelijk bestond uit een continu gesprek met drie heren: Dr. G.J. Tangelder, Dr. D.W. Slaaf en Prof.Dr. R.S. Reneman. Geert-Jan Tangelder was van dit drietal de meest belangrijke. Beste Geert-Jan, je enthousiasme en je onophoudelijke stroom van ideeen hebben me niet alleen meerdere keren een koude maaltijd opgeleverd (zelfs toen je in Amerika was), maar ze hebben me vooral gestimuleerd om steeds vol vertrouwen door te gaan. Dick Slaaf hanteerde een geheel andere benadering van 'het doen van onderzoek'. Beste Dick, je mathematische aanpak van ideeen en je kritische kijk op resultaten hebben zeker positief bijgedragen aan het onderzoek. Bewondering heb ik voor de uiterst snelle verwerking van steeds weer nieuwe versies van de verschillende hoofdstukken. Rob Reneman was vooral de man van de afronding. Beste Rob, alhoewel ik het betreur dat je het zo druk hebt dat er weinig tijd overblijft voor meer overleg, hebben we toch op belangrijke momenten zeer verhelderende gesprekken gehad. Vaak weet je de vinger precies op de zere plek te leggen. Je grote kennis en inzicht zijn voor mij zeer waardevol geweest.

Naast de begeleiders zijn het vooral de mensen op het laboratorium voor Microcirculatie die hebben bijgedragen aan het onderzoek. De hulp van Sabrina Weijmervan Velzen tijdens de experimenten en bij allerlei andere bezigheden, variērend van het maken van posters tot het opsporen van weer eens zoek geraakte sleutels, was onmisbaar. Rinus Alewijnse verzorgde de electronische kant van de zaak en bleek te beschikken over een soort van 'magic touch', die makte dat apparaten op cruciale momenten alsnog gingen functioneren. Jan Corsel verleende deskundige hulp bij 'het tekenen' op de VAX. De samenwerking met de overige 'labgebruikers' was heel prettig. Twee van hen wil ik speciaal noemen: mijn paranimfen Huub Oude Vrielink en Frank Peeze Binkhorst. Beiden hebben ook bijgedragen aan de inhoud van dit boekje, de één figuurlijk en de ander electronenmicroscopisch.

Ook buiten ons eigen lab hebben velen een bijdrage geleverd. Lucienne van Haarlem, Karin van Brussel, Jos Heemskerk, Emmy van Roosmalen en Rosy Hanssen hebben in de eerste fase van het onderzoek artikelen ingevoerd op de tekstverwerker, een luxe die later niet echt haalbaar bleek. Ook daarnaast zijn zij op allerlei manieren behulpzaam geweest. Puck Muller en Paul Devilée leenden ons een aggregometer en bijbehorend materiaal voor het in vitro deel van het onderzoek. Wim Engels en Paul Lemmens hebben bepalingen gedaan op de HPLC. Henk Jas verzorgde de cosmetica van het proefschrift (over je stropdas zal ik hier niets zeggen). De mensen van de CPV en de spoelkeuken, tenslotte, zorgden dat konijnen en schoon glaswerk beschikbaar waren. 
Tenslotte wil ik nog de leden van de beoordelingscommissie, Prof.Dr. H.A.J. Struyker Boudier, Prof.Dr. J.A. Flendrig, Prof.Dr. H.C. Hemker, Prof.Dr. F. ten Hoor en Prof.Dr. J.J. Sixma bedanken voor het kritisch doorlezen van de niet onaanzienlijke stapel papier, die het manuscript was.

Een nadeel van een persoonlijk nawoord in een proefschrift is dat er altijd mensen vergeten worden. Bovendien is het aandeel van sommigen niet simpel onder woorden te brengen. Voor al deze mensen: bedankt! 


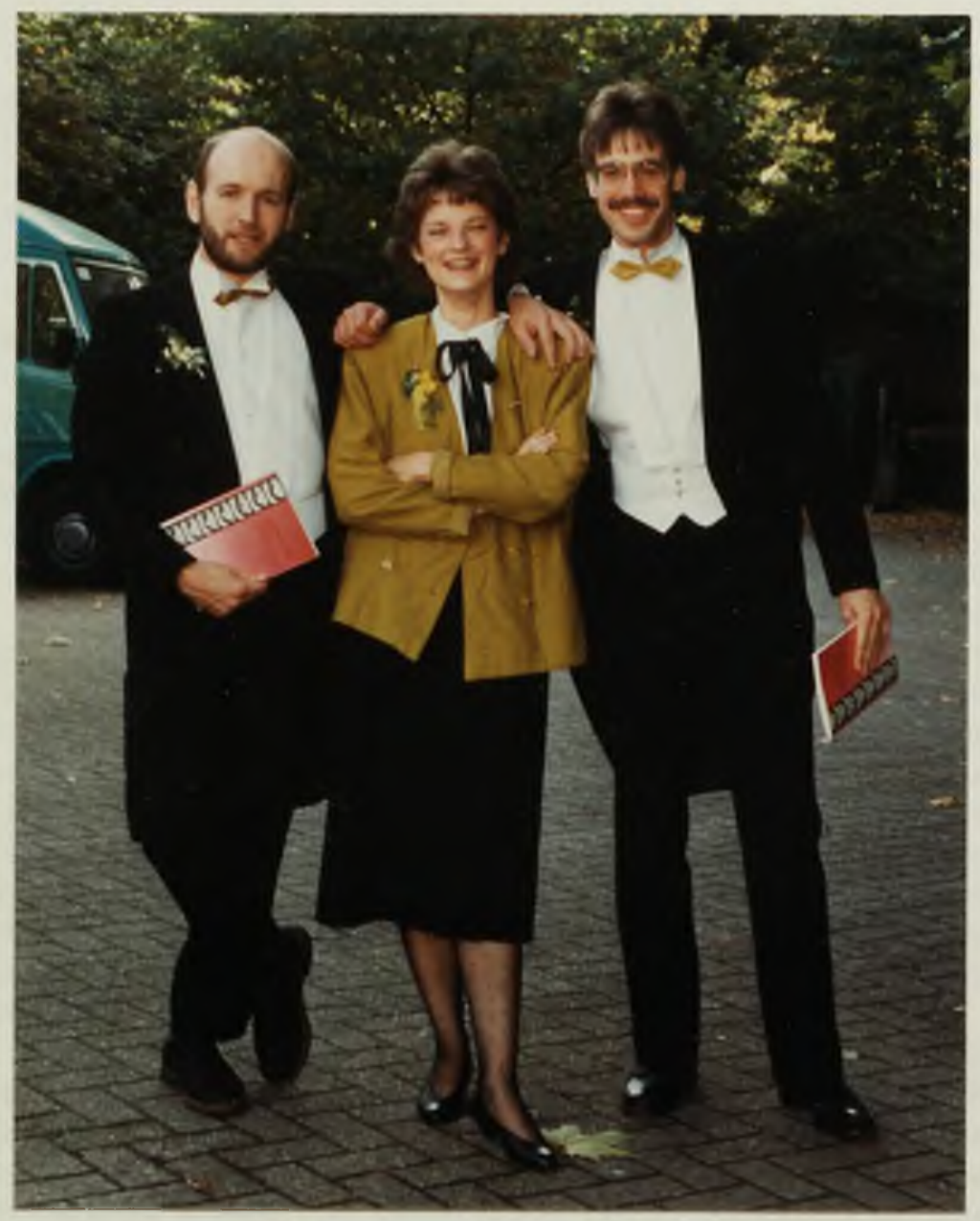


